\title{
UAB
}

Universitat Autònoma de Barcelona

\section{Iterative Synthetic Strategy for Azaphenalene Alkaloids. Total Synthesis of (-)-9a-epi-hippocasine}

\author{
Sílvia Alujas Burgos
}

ADVERTIMENT. L'accés als continguts d'aquesta tesi queda condicionat a l'acceptació de les condicions d'ús establertes per la següent llicència Creative Commons:

(c) (i) (\$) $\mathrm{http}: / /$ cat.creativecommons.org/?page_id=184

ADVERTENCIA. El acceso a los contenidos de esta tesis queda condicionado a la aceptación de las condiciones de uso establecidas por la siguiente licencia Creative Commons: (c) (i) @) http://es.creativecommons.org/blog/licencias/

WARNING. The access to the contents of this doctoral thesis it is limited to the acceptance of the use conditions set by the following Creative Commons license: (c) (i) $\Theta($ ) $\mathrm{https}$ ://creativecommons.org/licenses/?lang=en 


\title{
UAB
}

Universitat Autònoma de Barcelona

Facultat de Ciències

Departament de Química

\section{Iterative Synthetic Strategy for Azaphenalene Alkaloids.}

\section{Total Synthesis of (-)-9a-epi-hippocasine}

\author{
Ph.D. THESIS \\ Ph.D. in Chemistry
}

Sílvia Alujas Burgos

2017

Supervisors:

Dr. Pau Bayón Rueda

Prof. Marta Figueredo Galimany 

Memòria presentada per aspirar al Grau de Doctor per Sílvia Alujas Burgos

Sílvia Alujas Burgos

Vist i plau,

Dr. Pau Bayón Rueda

Prof. Marta Figueredo Galimany

Bellaterra, 28 de setembre de 2017 

"No deixis de caminar encara que et fallin les forces"

Txarango 



\section{Table of contents}

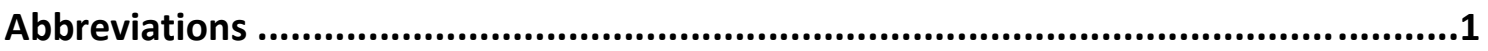

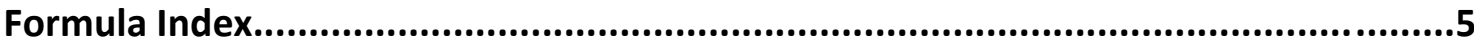

I. General Introduction .....................................................................13

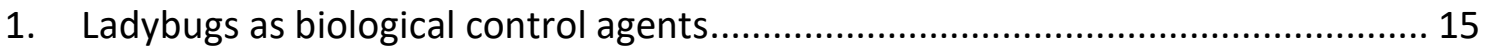

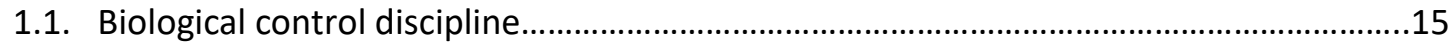

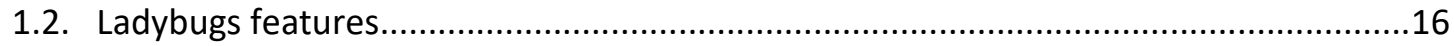

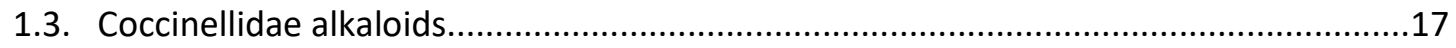

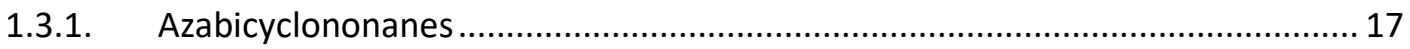

1.3.2. Piperidines, pyrrolidines, aromatic amines and acyclic amines.......................... 17

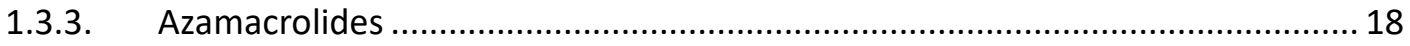

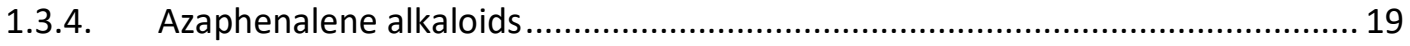

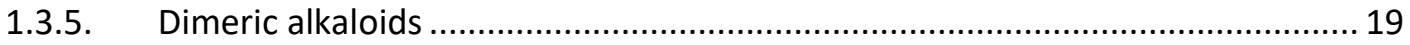

2. Azaphenalene alkaloids: uses, isolation and synthesis ....................................... 21

2.1. Structure, isolation and identification of azaphenalene alkaloids ...............................21

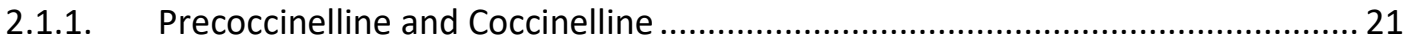

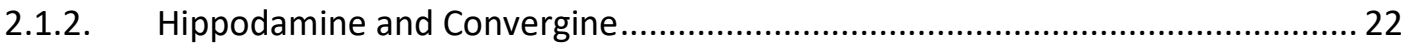

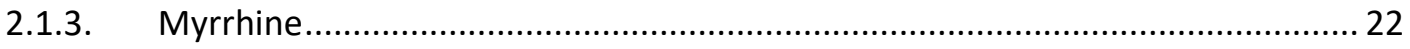

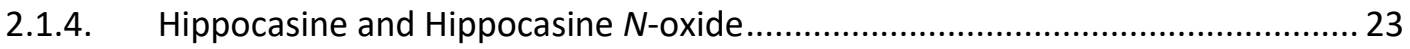

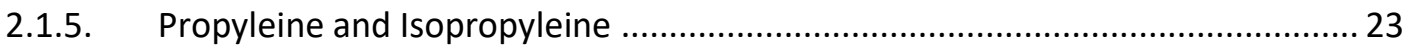

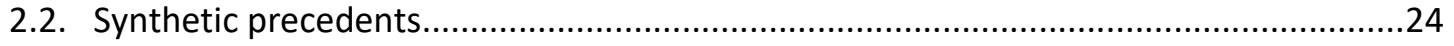

2.2.1. Synthesis of achiral azaphenalene alkaloids and synthesis of racemic chiral

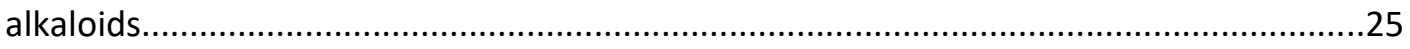

2.2.2. Enantioselective synthesis of chiral azaphenalene alkaloids .............................. 38

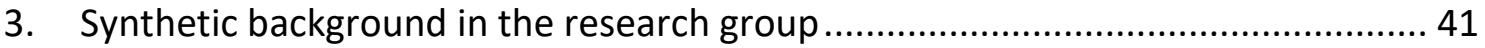

II. Objectives and synthetic plan...........................................................43

\section{Results and discussion. Chapter 1: Synthesis of (-)-9a-epi-}

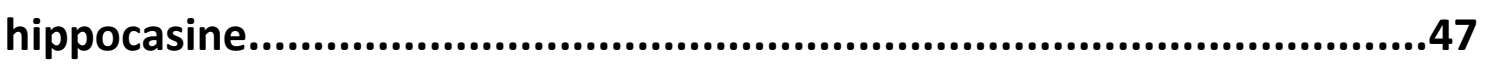

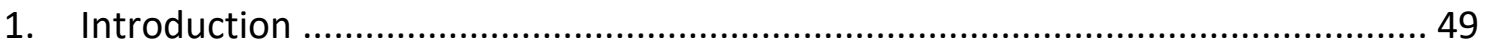

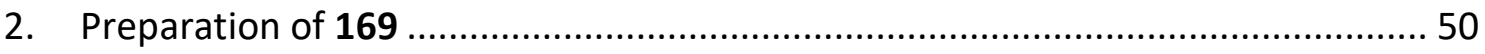

2.1. Asymmetric Allylic Alkylation (AAA). Synthesis of compound 167 ...................................50 
2.2. Reduction and first nucleophilic allylation. Synthesis of $\mathbf{1 5 9 .}$ . .52

2.3. First Ring-closing metathesis. Synthesis of bicycle 168 ...........................................54

2.4. Oxidation of alcohol 168 and Wittig alkenylation. Synthesis of intermediate 169.........56

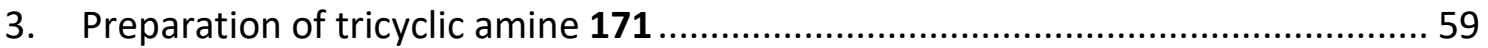

3.1. Reduction and second nucleophilic allylation. Synthesis of 170.................................59

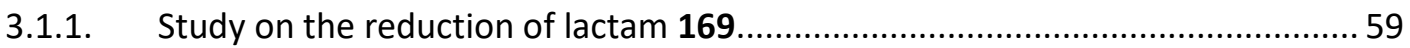

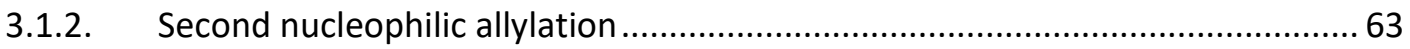

3.2. Second Ring-Closing Metathesis. Formation of the tricyclic skeleton............................67

4. Hydrogenation. Synthesis of the final azaphenalene alkaloid ............................. 69

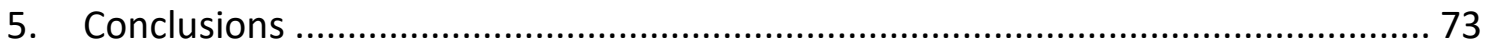

\section{Results and discussion. Chapter 2: Towards other azaphenalene}

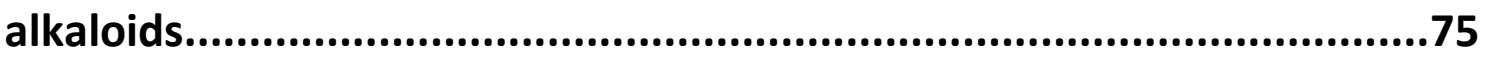

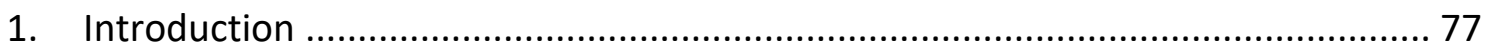

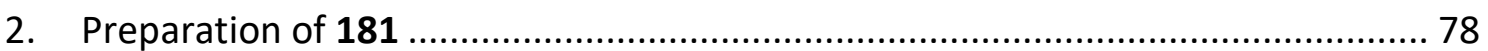

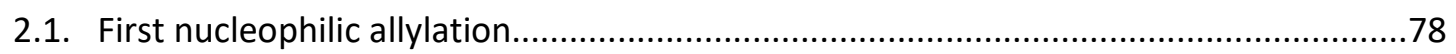

2.2. First ring-closing metathesis and synthesis of alcohol 181........................................80

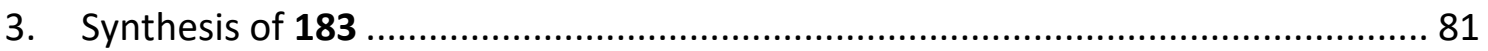

3.1. Oxidation of alcohol $\mathbf{1 8 1}$ and Wittig alkenylation. Synthesis of intermediate $182 \ldots \ldots . . .81$

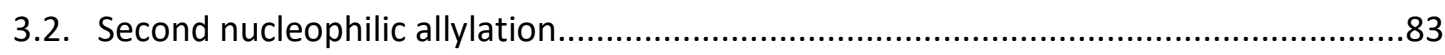

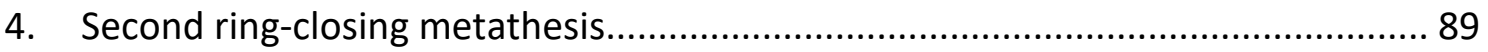

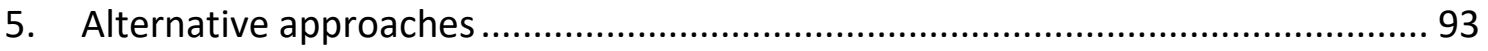

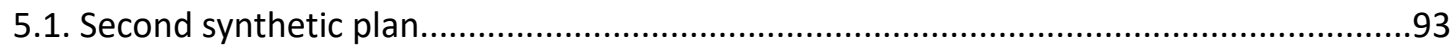

5.1.1. Dess-Martin oxidation and Tebbe alkenylation ................................................. 94

5.1.2. Reduction and second nucleophilic allylation .................................................... 95

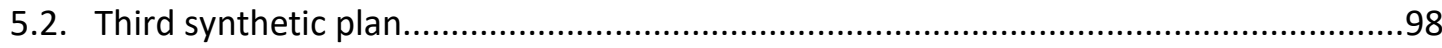

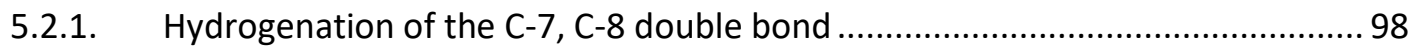

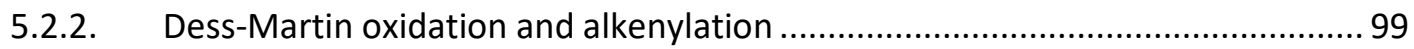

5.3. Forth synthetic plan. The Relay Ring-Closing Metathesis approach.

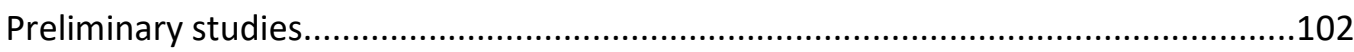

5.3.1. Definition of Relay Ring-Closing Metathesis (RRCM) ..................................... 102

5.3.2. Possible relay-arms and aldehydes to be tested ............................................ 103

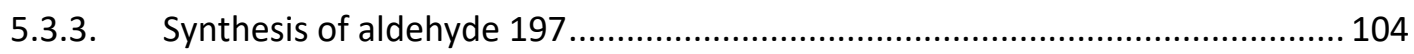

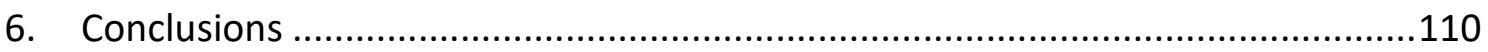




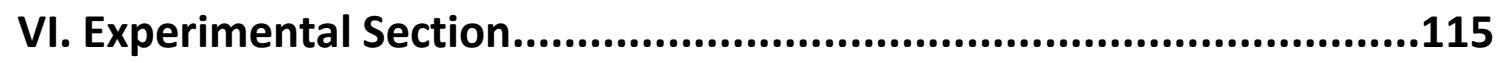

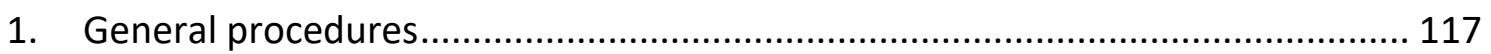

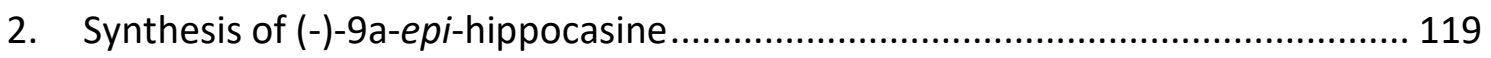

3. Towards other azaphenalene alkaloids .......................................................... 130

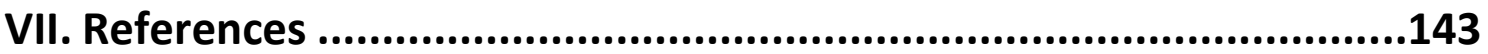

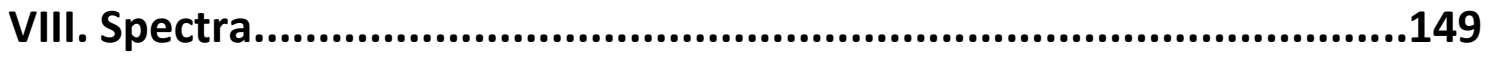



Abbreviations 



\begin{tabular}{|c|c|c|c|}
\hline 9-BBN & 9-borabicyclo[3.3.1]nonane & $m-\mathrm{CPBA}$ & $m$-chloroperbenzoic acid \\
\hline AAA & $\begin{array}{l}\text { Asymmetric allylic } \\
\text { alkylation }\end{array}$ & NMR & $\begin{array}{l}\text { Nuclear Magnetic } \\
\text { Ressonance }\end{array}$ \\
\hline AIBN & azobis(isobutyronitrile) & nOe & Nuclear Overhauser Effect \\
\hline Boc & tert-butyloxycarbonyl & PCC & Pyridinium chlorochromate \\
\hline CHPLC & $\begin{array}{l}\text { Chiral high-performance } \\
\text { liquid chromatography }\end{array}$ & $\begin{array}{l}\text { PTSA } \\
\text { RCM }\end{array}$ & $\begin{array}{l}p \text {-toluensulfonic acid } \\
\text { Ring-closing metathesis }\end{array}$ \\
\hline CINHODNP & $\begin{array}{l}N \text {-chloro-O- }(2,4- \\
\text { dinitrophenyl)hydroxylami } \\
\text { ne }\end{array}$ & Red-Al & $\begin{array}{l}\text { sodium bis(2- } \\
\text { methoxyethoxy)aluminum } \\
\text { hydride }\end{array}$ \\
\hline $\begin{array}{l}\text { COSY } \\
\text { CSA }\end{array}$ & $\begin{array}{l}\text { Correlation spectroscopy } \\
\text { Camphorsulfonic acid }\end{array}$ & RRCM & $\begin{array}{l}\text { Relay ring-closing } \\
\text { metathesis }\end{array}$ \\
\hline DBU & $\begin{array}{l}\text { 1,8-Diazabicyclo } \\
\text { [5.4.0]undec-7-ene }\end{array}$ & ria & $\begin{array}{l}\text { room temperature } \\
\text { siamyl (1,2-dimethylpropyl) }\end{array}$ \\
\hline DIAD & $\begin{array}{l}\text { Diisopropyl } \\
\text { azodicarboxylate }\end{array}$ & sm & starting material \\
\hline DIBAL-H & $\begin{array}{l}\text { Diisobutylaluminium } \\
\text { hydride }\end{array}$ & TBAF & $\begin{array}{l}\text { tetrabutylammonium } \\
\text { fluoride }\end{array}$ \\
\hline Dil. & Diluted & & tert-butyldimethylsilyl \\
\hline DIPEA & N,N-Diisopropylethylamine & TBDMSOTf & $\begin{array}{l}\text { tert-butyldimethylsilyl } \\
\text { trifluoromethanesulfonate }\end{array}$ \\
\hline DMAP & 4-dimethylaminopyridine & TBDMSCl & tert-butyldimethylsilyl \\
\hline DMF & $N, N$-Dimethylformamide & & chloride \\
\hline DMPI & Dess-Martin Periodinane & TBDPS & tert-butyldiphenylsilyl \\
\hline DMSO & $\begin{array}{l}\text { dimethylsulfoxide } \\
\text { Ethylenediaminetetraacetic }\end{array}$ & TBDPSCl & $\begin{array}{l}\text { tert-butyldiphenylsilyl } \\
\text { chloride }\end{array}$ \\
\hline & acid & THF & Tetrahydrofuran \\
\hline HRMS & $\begin{array}{l}\text { High-Resolution Mass } \\
\text { Spectra }\end{array}$ & $\begin{array}{l}\text { TFA } \\
\text { TFAA }\end{array}$ & $\begin{array}{l}\text { Trifluoroacetic acid } \\
\text { Trifluoroacetic anhydride }\end{array}$ \\
\hline IBX & o-iodoxybenzoic acid & TLC & Thin Layer \\
\hline IR & Infrared spectroscopy & & Chromatography \\
\hline KHMDS & potassium & TMS & trimethylsilyl \\
\hline LDA & $\begin{array}{l}\text { hexamethyldisilazide } \\
\text { lithium diisopropylamide }\end{array}$ & TMSOTf & $\begin{array}{l}\text { trimethylsilyl } \\
\text { trifluoromethanesulfonate }\end{array}$ \\
\hline
\end{tabular}



Formula Index 



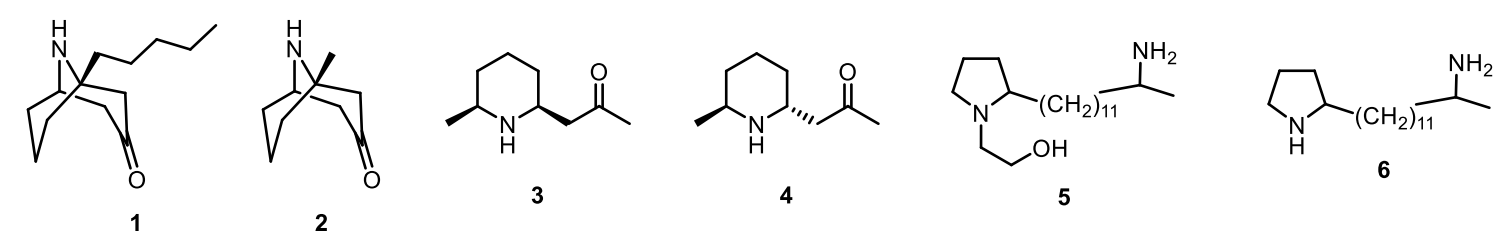

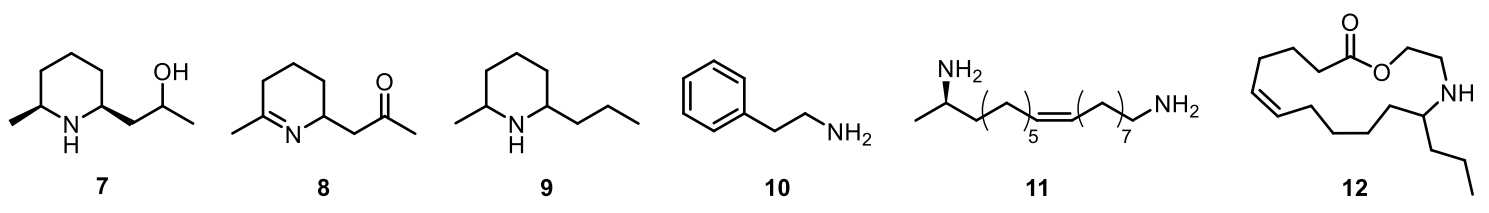<smiles>CCCC(C/C=C\C/C=C\CCCC(=O)OCCNC(CC)CCCC/C=C\CCCC(=O)OCCNC(CC)CC)NC</smiles><smiles>CCCC1CCCCC/C=C\CCCC(=O)OCCN1</smiles>

15

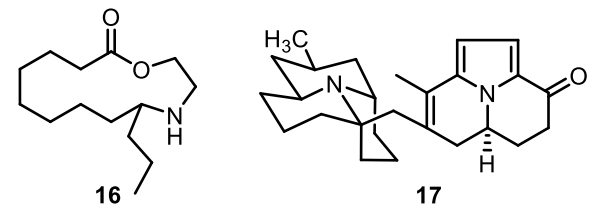

(c)

18

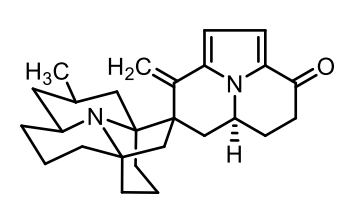

19

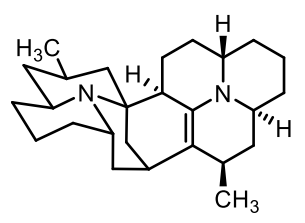

20

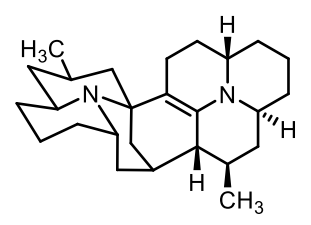

21

型

22

23

24

25

26

$\underbrace{+O}_{\equiv}$

27<smiles>CC1C[C@@H]2CCC[C@H]3CC(=O)C[C@H](C1)N32</smiles>

28

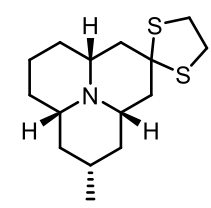

29<smiles>Cc1cccc(C)n1</smiles>

30
$\mathrm{OCH}_{3}^{\mathrm{H}_{3} \mathrm{CO}}$

31

(n) 32

33

34

35

36

$\underbrace{\mathrm{O}_{37}}_{\mathrm{CO}_{2} \mathrm{Me}}$

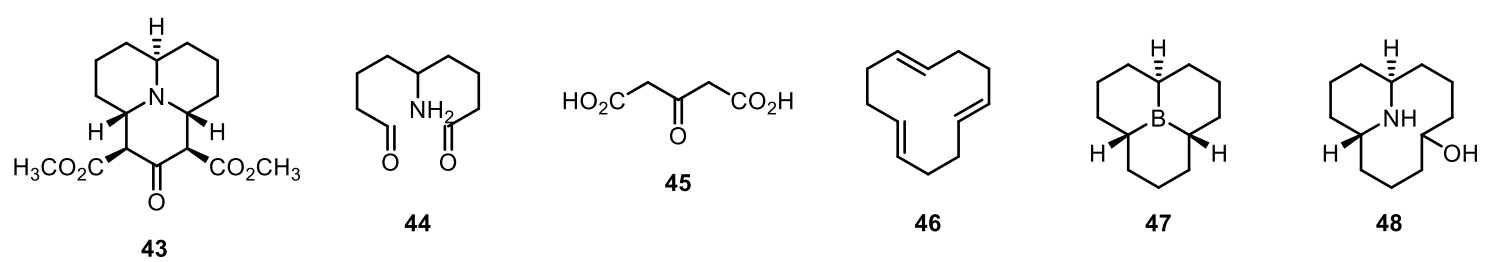


(1)

49

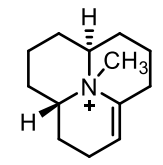

50

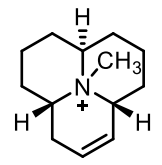

51

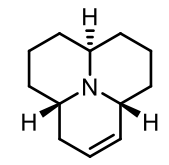

52

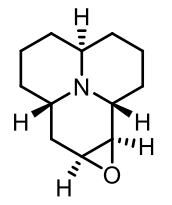

53<smiles>OC1C[C@@H]2CCC[C@H]3CCC[C@H](C1)N32</smiles>

54<smiles>C=C1C[C@H]2CCCC3CCC[C@H](C1)N32</smiles>

55<smiles>CC1=C[C@H]2CCC[C@@H]3CCC[C@H](C1)N32</smiles>

56<smiles>O[C@@H]1CC[C@H]2CCC[C@@H]3CCC[C@@H]1N32</smiles>

57<smiles>O[C@H]1CC[C@H]2CCC[C@@H]3CCC[C@@H]1N32</smiles>

58<smiles>O=C1CC[C@H]2CCC[C@@H]3CCC[C@H]1N32</smiles>

59<smiles>O=C1CC[C@@H]2CCC[C@@H]3CCC[C@@H]1N23</smiles>

60

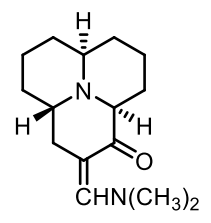

61

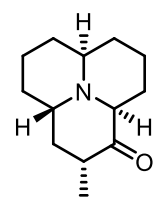

62<smiles>CO[C@H]1C[C@H]2C[C@H](C)C[C@H]2N2CCCC1CCC2</smiles>

63<smiles>C1C[C@H]2CCC[C@H]3CCC[C@H](C1)N23</smiles>

64<smiles>C1=C2CCC[C@H]3CCC[C@H](CC1)N23</smiles>

65<smiles>O=C1CC[C@H]2CCC[C@@H]3CCC[C@@H]1N32</smiles>

66

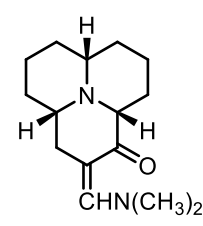

67

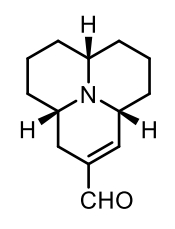

68

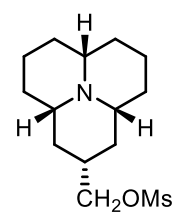

69<smiles>CCC/C=C\OCC</smiles>

70<smiles>CCOC(=O)CC1CCCCN1[O-]</smiles>

71<smiles>C=CCCOCCOCCCOCC</smiles>

76<smiles>C[C@@H]1C[C@H]2CCC[C@@H]3CC(O)C[C@@H](C1)N32</smiles>

77<smiles>CCOC(=O)C[C@H](O)[C@H]1CCCC(COC(=O)OCC)N1</smiles><smiles>CCOC(=O)C1CC2CCCC3CC(OC(C)C)CC(C1)N32</smiles>

75<smiles>COC1CC2[CH]CC[C@@H]3CC(=O)C[C@@H](C1)N23</smiles><smiles>C=C(CC1CCC[C@@]2(CCCC3OCCO3)OC[C@H](c3ccccc3)N12)OC</smiles>

82<smiles>C=C(CC1CCCC(CCCC2OCCO2)N1[C@@H](CO)c1ccccc1)OC</smiles>

83<smiles>CSC(=S)O[C@@H]1C[C@H]2CCC[C@H]3C[C@H](C)C[C@H](C1)N32</smiles>

78

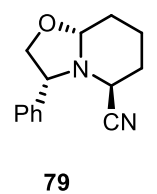

79

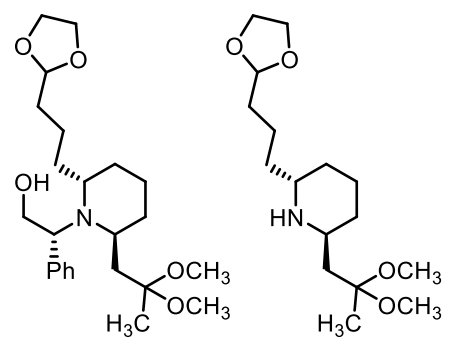

84

85<smiles>C=CCC(O)CCC[C@@H](O)CC=C</smiles>

88<smiles>C=CC[C@@H]1CCCC2C[C@@H](CI)OC(=O)N21</smiles>

89

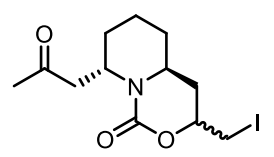

90<smiles>C=CCCCC(CCCC=C)C1C(=O)c2ccccc2C(=O)N1C(=O)c1ccccc1</smiles> 


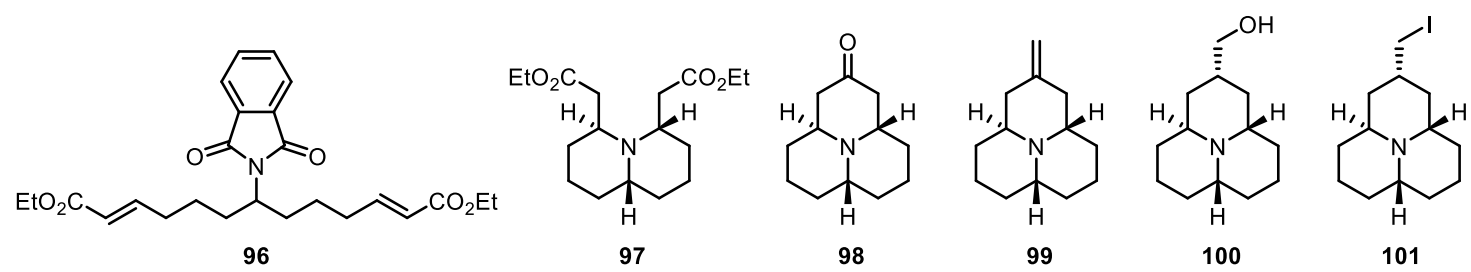

$\overbrace{102}^{O} \underbrace{\mathrm{EtO}_{2} \mathrm{C}}_{103} \underbrace{\mathrm{CO}_{2} \mathrm{Et}}_{104} \underbrace{\mathrm{TBDPSO}}_{105}=$<smiles>COC(=O)/C=C1/CC(C)CC(CCC/C=C\C=O)N/C1=C\C(=O)OC</smiles><smiles>CC(=O)C1=C2C[C@@H](C)C[C@H]3CCC[C@H](CC1)N23</smiles>

111<smiles>CC(=O)C1CC[C@H]2CCC[C@@H]3CC(C)CC1N23</smiles>

112<smiles>COC(=O)[C@H]1CC[C@H]2CCC[C@@H]3CC(C)C[C@]123</smiles>

113<smiles>CC1C[C@@H]2CCC[C@@H]3CC[C@@H](C(=O)O)[C@H](C1)N23</smiles>

114<smiles>CC(=O)C1CC[C@H]2CCC[C@@H]3CC(C)C[C@]123</smiles>

115<smiles>CC1C[C@H]2[C@@H](C(=O)O)CC[C@H]3CCC[C@H](C1)N23</smiles>

116<smiles>CC(=O)C1CC[C@@H]2CCC[C@@H]3CC(C)C[C@@H]1N23</smiles>

117<smiles>CCOC(=O)C=CCCCC(CCCC=CC(=O)OCC)NC(=O)c1ccccc1</smiles>

118<smiles>CCOC(CCC[AlH2])OCC</smiles>

119<smiles>C=CC[C@H]1CC(C)=C[C@H](CCCC(OCC)OCC)N1</smiles><smiles></smiles>

122<smiles>C=CC[C@@H]1CC(C)=CC(CCCC(C=C)OC(C)=O)N1</smiles>

123<smiles>C=CC[C@]1(C=C)CC(C)=C[C@H]2CCC[C@H](C=C)N21</smiles>

124<smiles>CC1=CC2CCCC3C=CCC(C1)N32</smiles><smiles>CC(C)c1cccc2c1-c1c(C(C)C)cccc1[C@H](O)C2</smiles><smiles>CCOC(=O)C(=CCC=O)OCC</smiles>

126 127<smiles>[R]C=CC(=CC=NC(C(C)C)C(C)C)C(=O)OCC</smiles>

128<smiles>CCOC(=O)C1=C[C@@H](CCCC2OCCO2)N2C3OCc4cccc(c43)C[C@H]2C1</smiles>

130

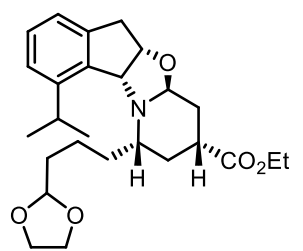

131<smiles></smiles>

132<smiles>C=CC1C[C@H](C)C[C@H](CCCC2OCCO2)N1C[C@H]1c2c(cccc2C(C)C)C[C@H]1O</smiles>

133<smiles>C=CC1C[C@@H](C)C[C@H](CCCC2OCCO2)N1C(=O)c1ccccc1</smiles>

134<smiles>CC(=O)CC1C[C@@H](C)C[C@@H](CCCC2OCCO2)N1[14CH3]</smiles>

135<smiles>CC(=O)CC1C[C@@H](C)C[C@H](CCCC2OCCO2)N1</smiles>

136<smiles>C[C@H]1C[C@@H]2CCCOC3(C1)C[C@@H]2C[C@@H](C)C1OCCN13</smiles>

137

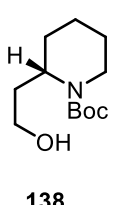

138 
OTBDMS 139

140

141

142

143

144

(145

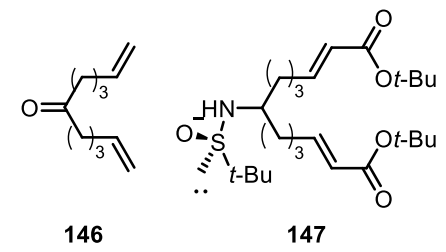

146

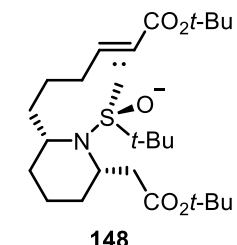<smiles>CCOC(=O)CN1CCCCC1COC(=O)OCc1ccccc1</smiles>

149

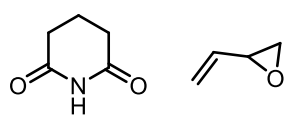

$150 \quad 151$<smiles>C=CC(COC(=O)c1ccccc1)[N+]1=CCCCC1=O</smiles>
152<smiles>C=CC(CO[Pb])C(=O)N1C=CCCC1=O</smiles>

157
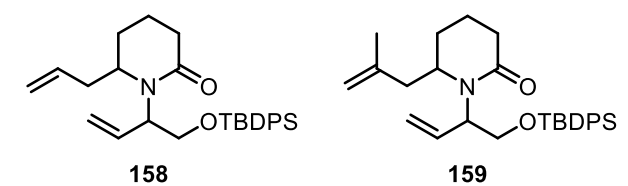

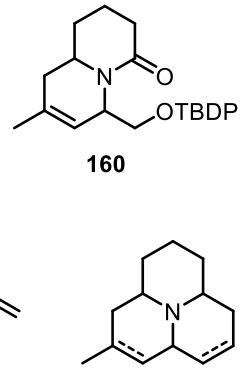

166<smiles>CC1=CC(CO[PbH2])C(C[18OH])N2CC1CCCC2=O</smiles><smiles>O=CC1C=CCC2CCCC(=O)N12</smiles>

162<smiles>CC1=CC(CO)N2C(=O)CCCC2C1</smiles>

168<smiles>CC1=CC(C=O)N2C(=O)CCCC2C1</smiles>

174<smiles>CC1=CC(C=O)N2C(=O)CCCC2C1</smiles>

163<smiles>C=C(C)CC1CCCC2CC=CC(/C=C/C)N21</smiles>

164<smiles>C=CCC1CCCC2CC(C)=CC(/C=C/C)N12</smiles>

165<smiles>C=CCC1CCCC2CC(C)=CC(/C=C/C)N12</smiles>

170<smiles>CC1=CC2C=CCC3CCCC(C1)N23</smiles>

171<smiles>O=C(O)c1c(P)ccc2ccccc12</smiles>

172<smiles>C=CC(CO[18O]Cc1ccccc1)N1C(=O)CCCC1=O</smiles>

167<smiles>C=CCC1(CC=C)CCCC2CC(C)=CC(C=CC)N21</smiles>

180<smiles>C=CC1C=C(C)CC2CCCC(=O)N12</smiles>

175<smiles>CC1=CC(/C=C/c2ccccc2)N2C(=O)CCCC2C1</smiles>

176<smiles>C/C=C/C1C=C(C)CC2CCCC(O)N12</smiles>

177<smiles>C/C=C/C1C=C(C)CC2CCCCN12</smiles>

178<smiles>C=C(C)CC1CCCC2CC=CC(/C=C/C)N21</smiles>

183<smiles>O=CC1C=CCC2CCCC(=O)N12</smiles><smiles>N[C@@H]1CCCC[C@H]1N</smiles>

173<smiles>CC=CC1C=CCC2CCCC(=O)N12</smiles><smiles>C/C=C/C1C=CCC2CCCC(O)N12</smiles>

185<smiles>C/C=C/C1C=CCC2CCC=CN12</smiles>

186<smiles>C=CC1C=CCC2CCCC(=O)N12</smiles>

187<smiles>C=CC1C=CCC2CCCC(CC(=C)C)N12</smiles>

188<smiles>C=CC1C=CCC2CCC=CN12</smiles>

189<smiles>O=C1CCCC2CCCC(CO)N12</smiles>

190<smiles>C=CC1CCCC2CCCC(=O)N12</smiles>

191<smiles>CC=CC1C=C(C)CC2CCC=CN12</smiles>

179 
$\widehat{C}_{n}$

193<smiles>C1=CC2COC3CCCC(C1)N23</smiles>

198

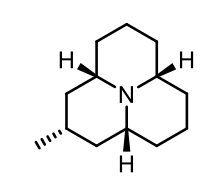

Myrrhine<smiles>C=CCCCC/C=C/C1C=CCC2CCCC(CC(=C)C)N12</smiles>

194<smiles>C=CCOC/C=C\C1C=CCC2CCCC(CC(=C)C)N12</smiles>

195<smiles>C=CCOC(=O)/C=C/C1C=CCC2CCCC(CC(=C)C)N12</smiles>

196<smiles>C=C(C)CC1CCCC2CC=CC(C=O)N21</smiles>

197<smiles>C=C(C)CC1CCCC2CC=CC(CO)N21</smiles>

199<smiles>C[C@H]1C[C@@H]2CCC[C@H]3CCC[C@H](C1)N32</smiles>

Precoccinelline

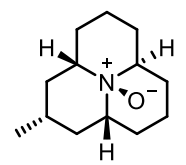

Coccinelline

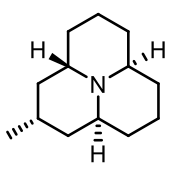

Hippodamine

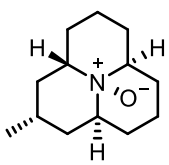

Convergine

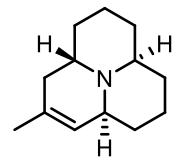

Hippocasine

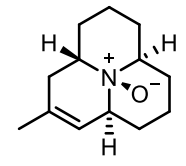

Hippocasine $\mathrm{N}$-oxide

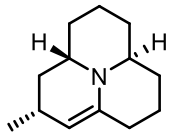

Propyleine

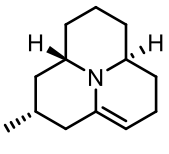

Isopropyleine

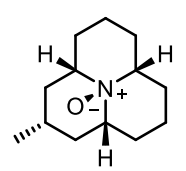

Myrrhine

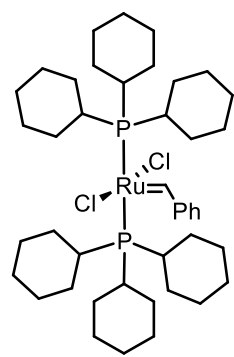

First Generation Grubbs catalyst (Grubbs I)

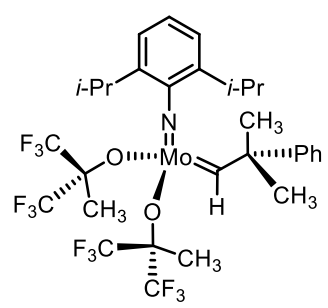

Schrock catalyst

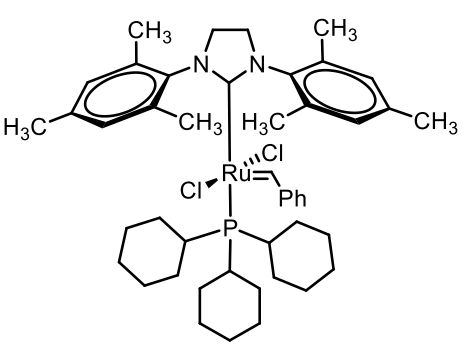

Second Generation Grubbs catalyst (Grubbs II)

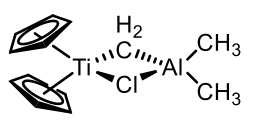

Tebbe reagent

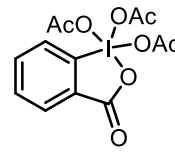

Dess-Martin periodinane (DMPI)

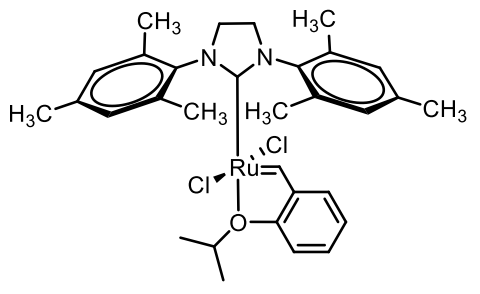

Second Generation Hoveyda-Grubbs catalyst (Hoveyda-Grubbs II) 



\section{General Introduction}





\section{Ladybugs as biological control agents}

Ladybugs belong to the Coccinellidae's family which is formed by 5200 species worldwide. ${ }^{1}$ This family of beetles is highly diverse, both in the biological habits and in food preferences. Most of these species are carnivorous and others are phytophagous or mycophagous. Carnivorous ladybugs eat aphids, mites and coccids among others (Figure 1a), which are damaging for the harvests. Because of this fact, ladybugs are widely studied, having an important role in the biological control of agricultural pests.

Few examples of coccinellids used in the biological control of agricultural pests are Rodalia cardinalis, which controls Icerya purchasi (a pest on citrus), and Cycloneda sanguinea or Hippodamia convergens, which control aphids in different crops. ${ }^{2}$

\subsection{Biological control discipline}

Biological control area was already known prior to Christ by the Chinese farmers who used some ant species for the regulation of caterpillar pest on citrus. ${ }^{2}$ During the industrial Era, some biological control agents such as microorganisms were discovered.

One of the most remarkable example of biological control of agricultural pests took place in 1887, when the citrus crops in California were devastated by Icerya purchasi, an insect from Australia. ${ }^{3}$ At that time, the citrus industry in California was just beginning, but it was being a great promise as a powerful upward market. On 1888, Albert Koebele travelled to Australia to find natural enemies of Icerya purchasi and brought them to California. He sent to California around 40.000 specimens of coccinellids of 40 species. Only four of these species became established and only one, vedalia (Rodalia cardinalis), was a successful controlling agent. The voracity of the ladybugs was visible and impressively productive, thus beneficial results were immediately noticeable. At the end of 1989 the pest of $I$. purchasi was completely regulated and the citrus industry in California was saved.

As a result of the success in California, vedalia bettles were exported to new plagues in other areas and the results were also excellent. For this reason, the interest for biological control of agricultural pests extremely increased and the use of coccinellids was extended worldwide.

\footnotetext{
${ }^{1}$ a) Daloze, D.; Braekman, J. C.; Pasteels, J. M. Chemoecology 1994/1995, 5/6, 173-183. b) King, A. G.; Meinwald, J. Chem. Rev. 1996, 96, 1105-1122.

${ }^{2}$ Badii, M. H.; Abreu, J. L. Int. J. Good Cons. 2006, 1, 82-89.

${ }^{3}$ Caltagirone, L. E.; Doutt, R. L. Ann. Rev. Entomol. 1989, 34, 1-16.
} 
Some years later, the synthetic chemical pesticides were discovered and heavily used, causing a decrease in the biological control discipline. Nevertheless, the problems associated with environmental contamination, residue in all kinds of food chains and the resistance of pests to pesticides produced an increase of the employment of biological controls.

\subsection{Ladybugs features}

Most ladybug species are known to have beautiful red-orange colors which are deterrent to their predators, especially when they form aggregations (Figure 1b). Furthermore, coccinellids are rarely exploited as a food source by other organisms due to their aposematic odors, bad taste and, in some cases, because they are poisonous. Both, the bright coloration and the strong smell are warning to the possible predators (such as birds and ants) that these beetles possess chemical defenses. The aposematism of coccinellids correlates with the presence of alkaloids in these beetles. ${ }^{1}$

The most known defense mechanism of coccinellids is "reflex bleeding". It consists in the secretion of an orange fluid (hemolymph, analogous to the blood in vertebrates) from the tibiofemoral joints in their legs when these insects feel attacked (Figure 1c). ${ }^{4}$ This fluid has bitter taste and it is toxic to their predators. In addition, it is well-known that this fluid contains a mixture of defensive alkaloids. ${ }^{5}$

a)

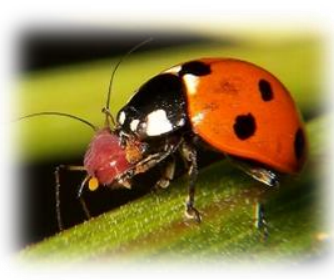

b)

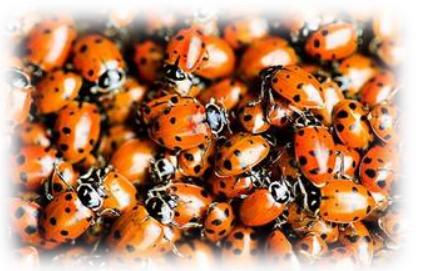

c)

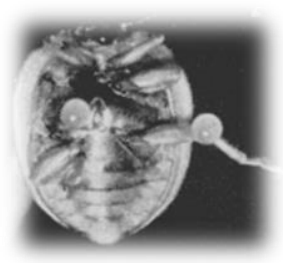

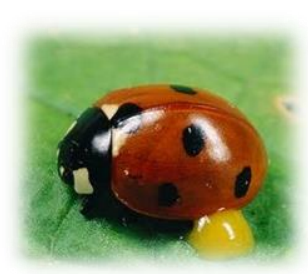

Figure 1. a) Ladybug eating an aphid. b) Aggregation of ladybugs. c) Reflex bleeding mechanism. ${ }^{4}$

Alkaloids in ladybugs were not only found in adults, they were also found in the other stages of the life cycle including eggs, larvae and pupae. ${ }^{1}$

\footnotetext{
${ }^{4}$ Happ, G. M.; Eisner, T. Science 1961, 134, 329-331.

${ }^{5}$ Gerasyuto, A. I.; Hsung, R. P. Org. Lett. 2006, 8, 4899-4902.
} 


\subsection{Coccinellidae alkaloids}

To date, around 50 alkaloids have been isolated and characterized from ladybugs, including azabicyclononanes, acyclic amines, pyrrolidines, piperidines, aromatic amines, azamacrolides, dimeric structures and perhydroazaphenalenes. ${ }^{1}$

\subsubsection{Azabicyclononanes}

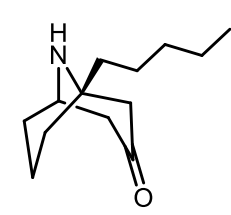

1

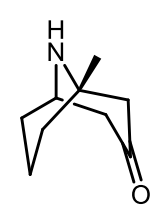

2

Figure 2. Examples of azabicyclononanes: Adaline, $\mathbf{1}$ and Euphococcinine, $\mathbf{2}$.

Adaline, 1, is an alkaloid synthesized by a 2-spot ladybug Adalia bipunctata which protects these ladybugs against bird predators giving them the bad taste. ${ }^{6}$ It was also isolated from other species, such as Adalia quadrimaculata Scopoli and Adalia pantherina L. ${ }^{7}$

Euphococcinine, 2, was first isolated from plants (Euphorbia atoto) ${ }^{8}$ and later was found in the Mexican beetle Epilachna varivestis. ${ }^{9}$ Euphococcinine is the alkaloid responsible of the protection against spiders and ants due to its presence in the reflex bleeding fluid.

\subsubsection{Piperidines, pyrrolidines, aromatic amines and acyclic amines}

Some piperidine alkaloids were isolated from Cryptolaemus montrouzieri. The molecular formula obtained from the high-resolution mass spectrum of these alkaloids, $\mathrm{C}_{9} \mathrm{H}_{17} \mathrm{NO}$, did not reveal the exact structure of the principal alkaloids presents in this beetle. Nevertheless, some tests indicated that the alkaloids synthesized by this ladybug were $\mathbf{3}$ and $\mathbf{4}$ (Figure 3 ). ${ }^{10}$

\footnotetext{
${ }^{6}$ de Jong, P. W.; Holloway, G. J.; Brakefield, P. M.; de Vos, H. Chemoecology 1991, 2, 15-19.

7 Tursch, B.; Braekman, J. C.; Daloze, D.; Hootele, C.; Losman, D.; Karlsson, R.; Pasteels, J. M. Tetrahedron Lett. 1973, 14, 201-202.

${ }^{8}$ Hart, N. K.; Johns, S. R.; Lamberton, J. A. Aust. J. Chem. 1967, 20, 561-563.

${ }^{9}$ Eisner, T.; Goetz, M.; Aneshansley, D.; Ferstandig-Arnold, G.; Meinwald, J. Experientia 1986, 42, 204-207.

${ }^{10}$ Brown, W. V.; Moore, B. P. Aust. J. Chem. 1982, 35, 1255-1261.
} 


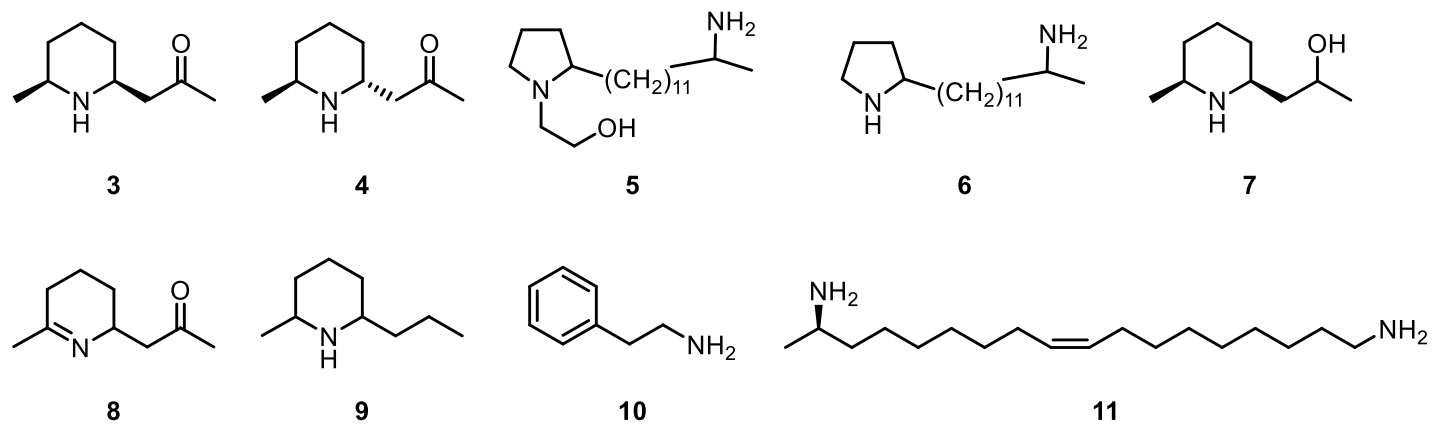

Figure 3. Alkaloids identified in Cryptolaemus montrouzieri, E. varivestis and Harmonia leis conformis.

The extract of the Mexican bean beetle, Epilachna varivestis, was shown to contain a mixture of alkaloids presents in eggs, larvae and adult beetles. While the alkaloid $\mathbf{5}$ was the most abundant in all three stages, alkaloids 3, 7-10 and also 2 were found only in adults. It is noticeable that euphococcinine, 2, and the two pyrrolidine alkaloids $\mathbf{5}$ and $\mathbf{6}$ comprised over $90 \%$ of the defensive alkaloid mixture in adults. ${ }^{11}$

Harmonine, $\mathbf{1 1}$, is an acyclic amine isolated from Harmonia leis conformis. ${ }^{12}$

\subsubsection{Azamacrolides}

A microscopic examination of the surface of Epilachna varivestis pupae revealed the presence of a dense layer of glandular hairs, each with a small drop at its tip (Figure 4a). ${ }^{13}$ These droplets contain a group of alkaloids called azamacrolides. The major constituent of this secretion is epilachnene, $\mathbf{1 2}$, (90\%) but it also contains eplachnadiene, 13, and trace amounts of three related alkaloids, 14-16 (Figure $4 \mathrm{~b}$ ).

a)

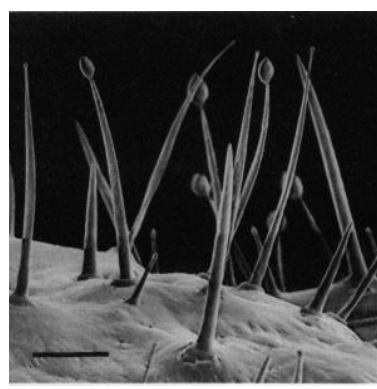

b)<smiles>CCCCC/C=C\CCCCCNC(CCC)OC(=O)OCC</smiles>

12<smiles>CCCC(C/C=C\C=C/CCCC(=O)OCC)NCC</smiles>

13<smiles>CCNC(CC)CCCC/C=C\CCCC(=O)OCCN</smiles>

14

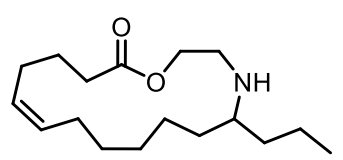

15<smiles>CCCCCCCCCCCCCC1CCCCCCCC(=O)OCCN1</smiles>

Figure 4. a) Glandular hairs of Epilachna varivestis. ${ }^{13}$ b) isolated azamacrolides from Epilachna varivestis.

\footnotetext{
${ }^{11}$ Attygalle, A.; Xu, S.-C; McCormick, K. D.; Meinwald, J.; Blankespoor, C.; Eisner, T. Tetrahedron 1993, 49, 9333-9342.

12 Braconier, M. F.; Braekman, J. C; Daloze, D.; Pasteels, J. M. Experientia 1985, 41, 519-520.

${ }^{13}$ Attygalle, A.; McCormick, K. D.; Blankespoor, C. L.; Eisner, T.; Meinwald, J. Proc. Natl. Acad. Sci. U.S.A. 1993, 90, 5204-5208.
} 


\subsubsection{Azaphenalene alkaloids}

Azaphenalene alkaloids are tricyclic amines (Figure 5) and amine oxides which impart a bitter taste to many coccinellids. These alkaloids are the most characteristic in ladybugs. ${ }^{1}$<smiles>C1CC2CCCC3CCCC(C1)N23</smiles>

Figure 5. General structure of perhydro-9b-azaphenalene alkaloids.

Until now, nine azaphenalene alkaloids have been isolated from many ladybugs (Figure 6). Coccinellid beetles are the major natural source of alkaloids with azaphenalene skeleton, but they are also found in Chauliognathus pulchellus, which is the Australian soldier beetle belonging to Cantharidae, another family of beetles. These beetles use precoccinelline, hippodamine and propyleine as defensive agents. ${ }^{14}$

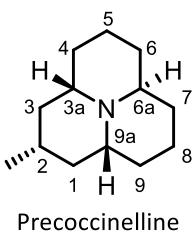<smiles>C[C@H]1C[C@H]2CCC[C@@H]3CCC[C@H](C1)N32</smiles>

Myrrhine
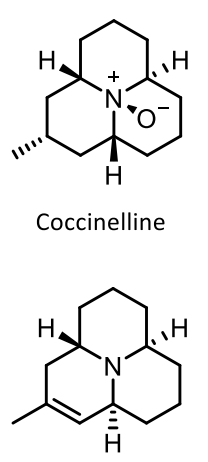

Hippocasine<smiles>C[C@H]1C[C@H]2CCC[C@H]3CCC[C@H](C1)N32</smiles>

Hippodamine

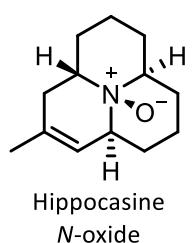

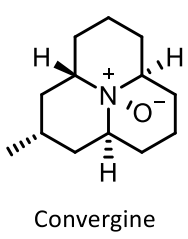

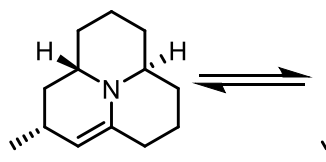

Propyleine

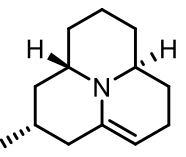

Isopropyleine

Figure 6. Azaphenalene alkaloids isolated from Coccinellids.

\subsubsection{Dimeric alkaloids}

Another class of alkaloids were isolated from different coccinellid beetles and were also characterized in order to establish the exact structure.

Exochomine, 17, is the first example of a dimeric ladybug alkaloid. It was obtained from the European ladybug Exochomus quadripustulatus as the major alkaloid (Figure 7). ${ }^{15}$ The configuration of all the stereogenic centers is the same to that in hippodamine and convergine.

\footnotetext{
${ }^{14}$ Moore, B. P.; Brown, W. V. Insect Biochem. 1978, 8, 393-395.

15 Timmermans, M.; Braekman, J. C.; Daloze, D.; Pasteels, J.; Merlin, J.; Declercq, J.P. Tetrahedron Lett. 1992, 33, 1281-1284.
} 
Moreover, Chilocorine A, 18, and Chilocorine B, 19, were extracted from the reflexbleeding droplets of Chilorcorus cacti. ${ }^{16}$ These three dimeric alkaloids are formed by a 2methylperhydro-9b-azaphenalene unit coupled to an azanaphthylene moiety.

Furthermore, Psylloborine A, 20, was indentified from the hemolymph of 22-pointed ladybug beetle Psyllobora 22-punctata ${ }^{17}$ and is formed by two azaphenalene monomers: precoccinelline and propyleine. Isopsylloborine $A, \mathbf{2 1}$, is an isomer of psylloborine $A$ and it was isolated from the European ladybugs Halyzia 16-guttata and Vibidia 12-guttata. ${ }^{18}$

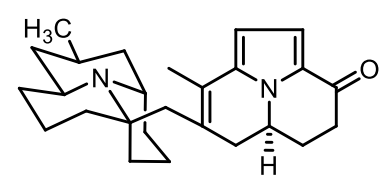

17

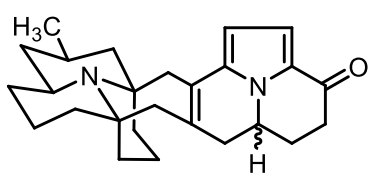

18

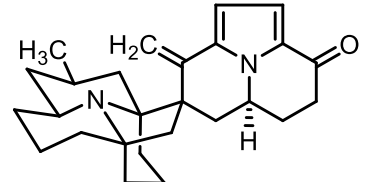

19

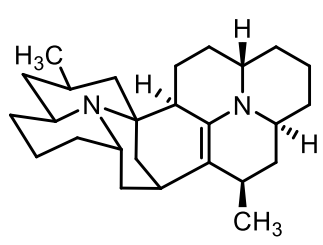

20

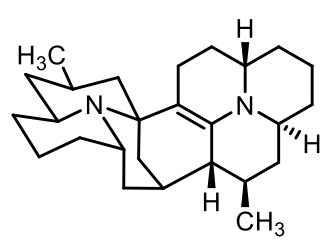

21

Figure 7. Discovered dimeric azaphenalene alkaloids.

\footnotetext{
${ }^{16}$ a) McCormick, K.; Attygalle, A.; Xu, S.-C.; Svatos, A.; Meinwald, J.; Houck, M.; Blankespoor, C.; Eisner, T. Tetrahedron 1994, 50, 2365-2372. b) Shi, X.; Attygalle, A.; Meinwald, J.; Houck, M.; Eisner, T. Tetrahedron 1995, 51, 8711-8718.

${ }^{17}$ Schröder, F. C.; Tolasch, T. Tetrahedron 1998, 54, 12243-12248.

${ }^{18}$ Lebrun, B.; Braekman, J. C., Daloze, D. Tetrahedron Lett. 1999, 40, 8115-8116.
} 


\section{Azaphenalene alkaloids: uses, isolation and synthesis}

Having all this information in mind, our research group has been focusing in azaphenalene alkaloids. Although they are useful in order to mimic the effect of ladybugs in crops, they also can interfere with the nervous system of higher animals. It is known that some coccinellid alkaloids are potent receptor antagonists of the neurotransmitter serotonin ${ }^{19}$ and are also noncompetitive antagonists for nicotinic acetylcholine receptor. ${ }^{20}$ Therefore, these molecules are attractive for the treatment of a number of brain disorders such as Alzheimer. In addition, recent studies revealed that these alkaloids can cause a decrease of the effect in some addictive drug withdrawal, for example nicotine. ${ }^{20}$

\subsection{Structure, isolation and identification of azaphenalene alkaloids}

As it is shown in Figure 6, precoccinelline, coccinelline and myrrhine are achiral compounds due to the presence of a symmetry plane which passes through three of the carbon atoms (C-2, C-6a and the methyl group). All the other azaphenalene alkaloids are chiral, either by the presence of a endocyclic double bond (hippocasine, its $\mathrm{N}$-oxide, propyleine and isopropyleine) or because of the trans position of protons $\mathrm{H}-3 \mathrm{a}$ and $\mathrm{H}-9 \mathrm{a}$ (hippodamine and convergine).

All these compounds were isolated and characterized during the 1970 s by different research groups (see beyond).

\subsubsection{Precoccinelline and Coccinelline}

Coccinelline and precoccinelline were the first azaphenalene alkaloids to be characterized. They were isolated from the European ladybug Coccinella septempunctata, with a ratio of $1: 13$, respectively, through extractions with methanol and $n$-pentane, followed by diverse recrystallizations. ${ }^{21}$ The characterization of these compounds was done by mass spectrometry, UV, IR and NMR techniques.

Coccinelline is a crystalline compound whereas precoccinelline is amorphous. Therefore, the structure of coccinelline could be stablished by a single-crystal $X$-ray diffraction experiment ${ }^{22}$

\footnotetext{
${ }^{19}$ a) Langlois, L.; Soulier, J. L.; Yang, D.; Bremont, B.; Florac, C.; Rampillon, V.; Giudice, A. Eur. J. Med. Chem. 1993, 28, 869-880. b) Rejzek, M.; Stockman, R. A.; Hughes, D. L. Org. Biomol. Chem. 2005, 3, 73-83.

${ }^{20}$ Leong, R. L.; Xing, H.; Braekman, J. C.; Kem, W. R. Neurochem. Res. 2014, 40, 2078-2086.

${ }^{21}$ Tursch, B.; Daloze, D.; Dupont, M.; Pasteels, J. M.; Tricot, M.C. Experientia 1971, 27, 1380-1381.

22 Karlsson, R.; Losman, D. J. Chem. Soc., Chem. Commun. 1972, 626-627.
} 
and the structure of precoccinelline was confirmed by reduction of the $\mathrm{N}$-oxide with ferrous sulfate. On the other hand, precoccinelline could be oxidized with monoperphtalic acid to obtain coccinelline which could be back-reduced to precoccinelline using also catalytic hydrogenation over $\mathrm{PtO}_{2}$.

The effectiveness as repellent to potential predators of ladybugs was tested using coccinelline and precoccinelline with ants. Coccinelline provides its bitter taste to $C$. septempunctata but not its peculiar smell.

\subsubsection{Hippodamine and Convergine}

These two azaphenalene alkaloids were isolated from the American ladybug Hippodamia convergens. The fractionation of the methanolic extract by solvent partitions and some purifications by column chromatography allowed to obtain convergine and hippodamine in a ratio of $2: 1 .^{23}$

Both alkaloids were characterized using the same techniques as precoccinelline and coccinelline. The fragmentation pattern of the mass spectrum of hippodamine was almost the same to that of precoccinelline, which suggested that these compounds are stereoisomers. In addition, the absolute configuration of these alkaloids was established by $\mathrm{X}$-ray analyses. ${ }^{24}$

It was known that convergine is the $\mathrm{N}$-oxide of hippodamine because the former was converted to hippodamine by a reduction with lithium aluminum hydride.

\subsubsection{Myrrhine}

Myrrhine was isolated from Myrrha octodecimguttata. ${ }^{25}$ It showed the same molecular formula as the previous alkaloids $\left(\mathrm{C}_{13} \mathrm{H}_{23} \mathrm{~N}\right)$ and the mass spectrum pattern was almost identical to those of precoccinelline and hippodamine.

Considering that precoccinelline showed cis, trans, cis ring fusion (describing the relationship between the nitrogen lone pair and the ring junction hydrogens) and hippodamine presented cis, cis, trans fusion, it could be predicted that the third alkaloid with the same molecular formula will be another stereoisomer exhibiting trans, trans, trans ring fusion. It was confirmed because of the presence of "Bohlmann bands" in its infrared spectrum (2700-2800

\footnotetext{
${ }^{23}$ Tursch, B.; Daloze, D.; Pasteels, J. M.; Cravador, A.; Braekman, J. C.; Hootele, C.; Zimmermann, D. Bull. Soc. Chim. Belg. 1972, 81, 649-650.

${ }^{24}$ Tursch, B.; Daloze, D.; Braekman, J. C.; Hootele, C.; Cravador, A.; Losman, D.; Karlsson, R. Tetrahedron Lett. 1974, 15, 409-412.

${ }^{25}$ Tursch, B.; Daloze, D.; Braekman, J. C.; Hootele, C.; Pasteels, J. M. Tetrahedron 1975, 31, 1541-1543. 
$\mathrm{cm}^{-1}$ ), which are characteristic of amines with $\mathrm{C}-\mathrm{H}$ bonds antiperiplanar to the nitrogen's lone pair. ${ }^{26}$

Of all perhydro-9b-azaphenalene alkaloids mentioned up to this point, myrrhine has the thermodynamically most stable tricyclic skeleton because all hydrogen atoms in the ring junctions are in cis configuration between them and trans to the preferred orientation of the nitrogen lone pair (Figure 8). ${ }^{27}$ In all cases, the nitrogen inversion would force one of the rings to be in boat conformation.
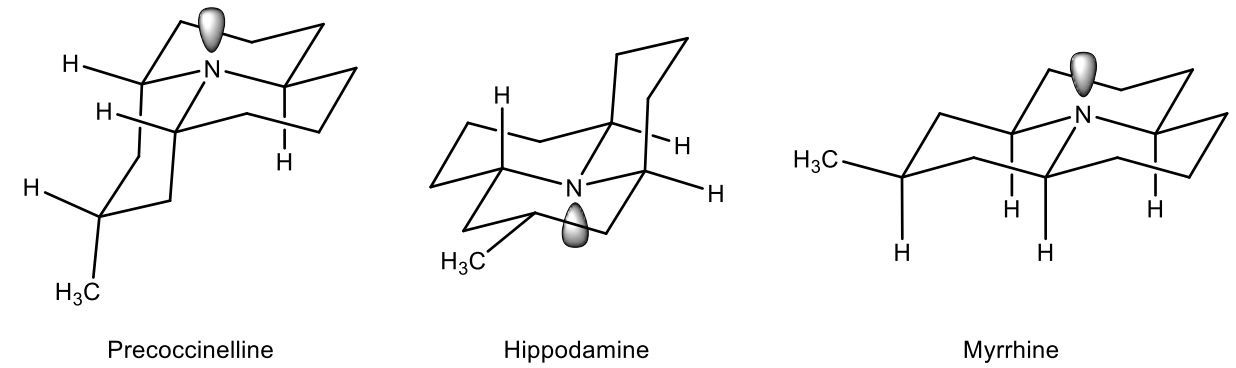

Figure 8. Conformers of the azaphenalene alkaloids precoccinelline, hippodamine and myrrhine.

\subsubsection{Hippocasine and Hippocasine $\mathbf{N}$-oxide}

The extraction with methanol of ladybugs from Canada, Hippodamia caseyi, and its fractionation followed by chromatographic separation, afforded four alkaloids. Two of them had been previously characterized (hippodamine and convergine) and the other two were identified as hippocasine and hippocasine $\mathrm{N}$-oxide, thanks to infrared and ${ }^{1} \mathrm{H}$ NMR spectroscopy and also $\mathrm{X}$-ray analyses. ${ }^{28}$ The structure of hippocasine $\mathrm{N}$-oxide was established because it could be furnished by the treatment of hippocasine with hydrogen peroxide.

\subsubsection{Propyleine and Isopropyleine}

The extraction from Propylaea quatuordecimpunctata gave an alkaloid called propyleine. ${ }^{29}$ The molecular formula obtained by high-resolution mass spectrum was $\mathrm{C}_{13} \mathrm{H}_{21} \mathrm{~N}$ and the fragmentation pattern was similar to that of the precoccinelline.

Since propyleine could be hydrogenated to give precoccinelline and also because of the high-resolution mass spectrum it was known that propyleine contains a double bond. The ${ }^{1} \mathrm{H}$

\footnotetext{
${ }^{26}$ Garraffo, H. M.; Simon, L. D.; Daly, J. W.; Spande, T. F.; Jones, T. H. Tetrahedron 1994, 50, 11329-11338.

27 Mueller, R. H.; Thompson, M. E.; DiPardo, R. M. J. Org. Chem. 1984, 49, 2217-2231.

${ }^{28}$ Ayer, W. A.; Bennett, M. J.; Browne, L. M.; Purdham, J. T. Can. J. Chem. 1976, 54, 1807-1813.

${ }^{29}$ Tursch, B.; Daloze, D.; Hootele, C. Chimia 1972, 26, 74-75.
} 
NMR spectrum shows a signal for only one alkene proton, indicating the presence of an enamine system.

In the acidic conditions of isolation, the iminium salt $\mathbf{2 2}$ was obtained, which rapidly isomerizes giving a mixture of propyleine and isopropyleine with a ratio of 1:3 (Figure 9).

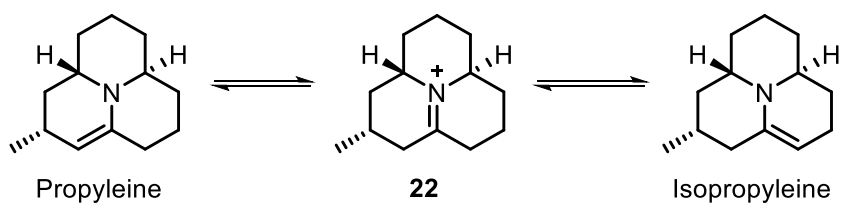

Figure 9. Propyleine, Isopropyleine and intermediate iminium salt 22.

Since these alkaloids were interconverted in the acidic isolation conditions, neither the real ratio between them in the ladybugs nor the absolute configuration were established.

\subsection{Synthetic precedents}

Due to the high interest towards azaphenalene alkaloids as biological control agents and also as antagonist receptors, many syntheses have been reported since 1976 to now.

In the plot displayed in Figure 10, it is shown that the syntheses reported from 1976 to 2010 were only of the achiral azaphenalene alkaloids or racemic mixtures of the chiral alkaloids. During the course of this thesis, three articles were published describing the synthesis of all chiral azaphenalene alkaloids in enantiopure form. Hippodamine was synthesized by three research groups from 2013 to $2015,30,31,32$ the synthesis of the non-natural alkaloid epihippodamine was reported in $2015^{32}$ and, finally, the synthesis of convergine, hippocasine, its $\mathrm{N}$-oxide and the isomeric mixture propyleine-isopropyleine were published in 2014 by the same group. ${ }^{31}$

\footnotetext{
${ }^{30}$ Fujita, S.; Sakaguchi, T.; Kobayashi, T.; Tsuchikawa, H.; Katsumura, S. Org. Lett. 2013, 15, 2758-2761.

${ }^{31}$ Sherwood, T. C.; Trotta, A. H.; Snyder, S. A. J. Am. Chem. Soc. 2014, 136, 9743-9753.

32 Guerola, M.; Sánchez-Rosselló, M.; Mulet, C.; del Pozo, C.; Fustero, S. Org. Lett. 2015, 17, 960-963.
} 


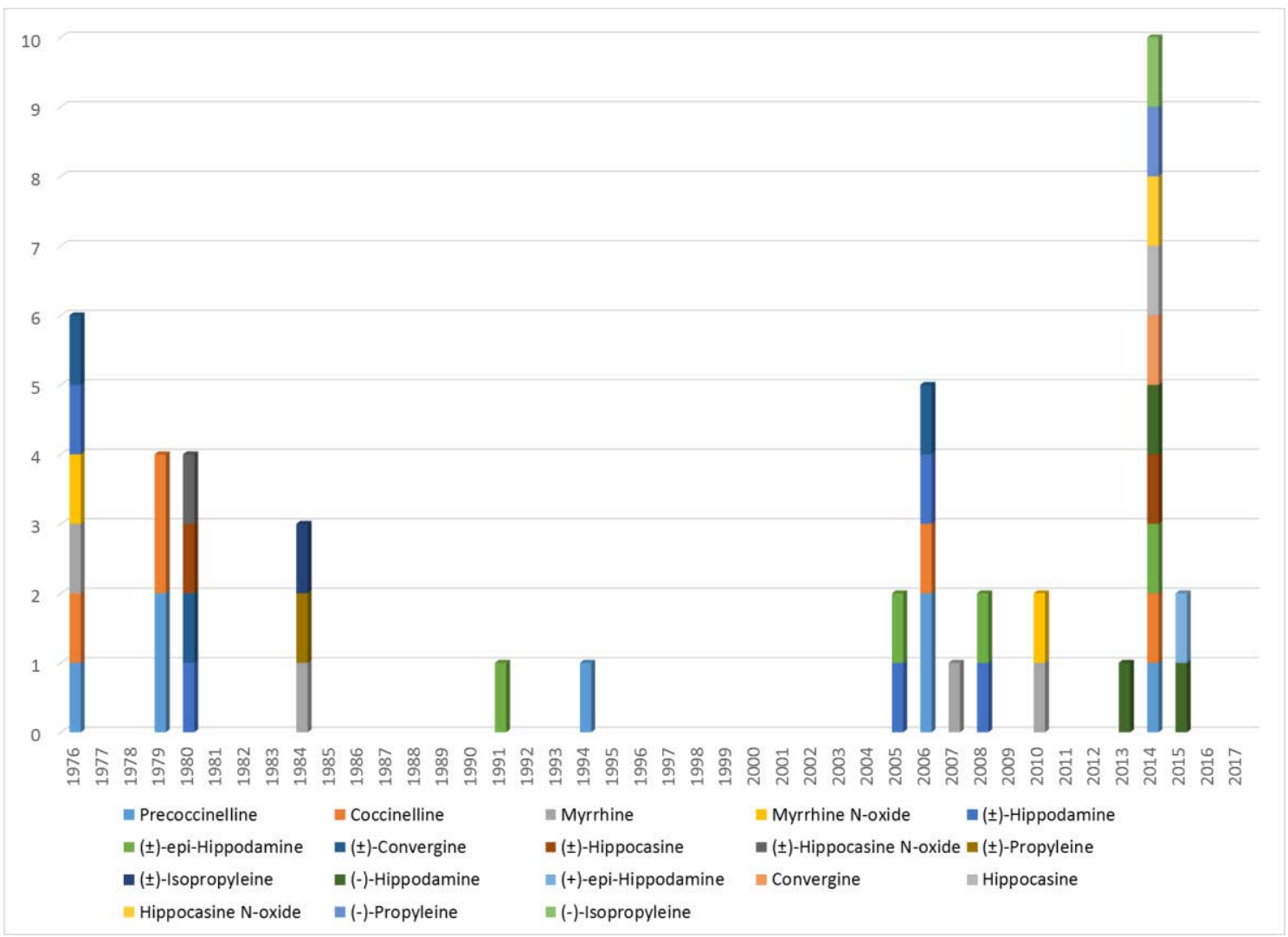

Figure 10. Azaphenalene alkaloids synthesized between 1976 and 2017.

\subsubsection{Synthesis of achiral azaphenalene alkaloids and synthesis of racemic chiral alkaloids}

The first synthesis of some perhydro-9b-azaphenalene alkaloids were reported in 1976 by Ayer et $a l^{33}$ They published the total synthesis of myrrhine, its non-natural $\mathrm{N}$-oxide, racemic convergine and hippodamine from a common intermediate (Scheme 1).

The synthesis begun with the formation of the monolithium derivative of 2,4,6-collidine, $\mathbf{2 3}$, followed by the alkylation with 3-bromopropionaldehyde dimethyl acetal to afford $\mathbf{2 4}$. The addition of phenyllithium originated an anion which reacted with acetonitrile to give the corresponding ketone which subsequently reacted with ethyleneglycol to furnish the acetal 25. Its reduction gave the amine $\mathbf{2 6}$, which was treated with $\mathrm{HCl}$ in order to remove all protecting groups, affording the racemic tricyclic amine $\mathbf{2 7}$. On one hand, this amine was treated with $p$ toluenesulfonic acid to give $\mathbf{2 8}$ with the same relative configuration of the stereogenic centers as myrrhine. This compound was immediately treated with $p$-toluenesulfonic acid, triethylamine and ethanedithiol to obtain thioacetal 29 that was reduced with Raney Ni yielding myrrhine.

\footnotetext{
${ }^{33}$ Ayer, W. A.; Dawe, R.; Eisner, R. A.; Furuichi, K. Can. J. Chem. 1976, 54, 473-481.
} 
Myrrhine $N$-oxide was obtained by the treatment of myrrhine with $m$-CPBA. On the other hand, the intermediate $\mathbf{2 7}$ reacted with pyrrolidine and acetic acid to form two stereomeric ketones. These ketones were also transformed to the corresponding thioacetals and reduced with Raney Ni to afford a mixture of myrrhine and hippodamine. The latter could be oxidized with $m$-CPBA to give its $N$-oxide, convergine.

Myrrhine was obtained in $2.4 \%$ overall yield whereas hippodamine was obtained in $1.7 \%$ overall yield.
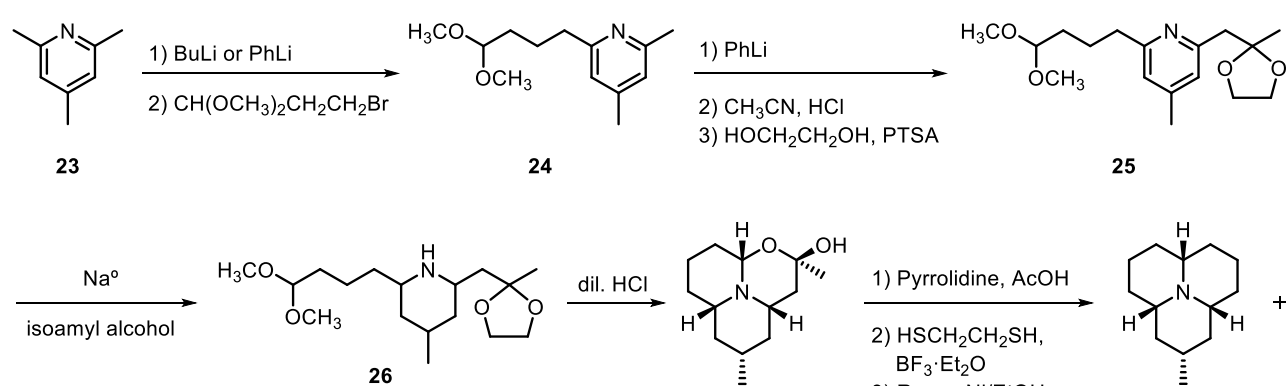

26

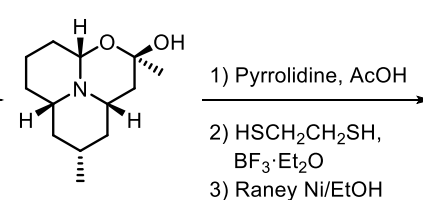

(士)-27

3) Raney Ni/EtOH

$\downarrow$ PTSA<smiles>C[C@@H]1C[C@H]2CCC[C@H]3CC(=O)C[C@@H](C1)N32</smiles>

28

PTSA, Et ${ }_{3} \mathrm{~N}$ $\mathrm{HSCH}_{2} \mathrm{CH}_{2} \mathrm{SH}$

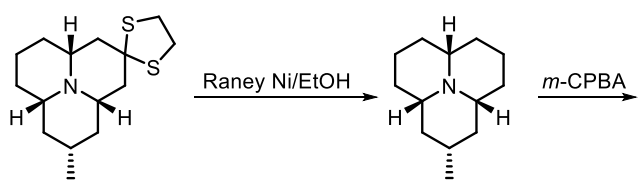

29

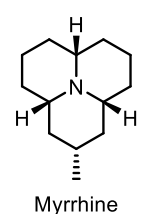

Myrrhine

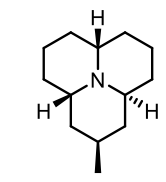

Hippodamine

$\mid m$-СРBA
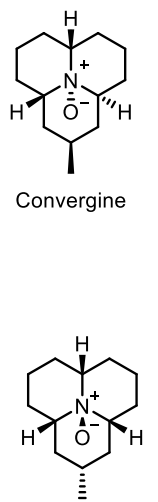

Myrrhine $\mathrm{N}$-oxide

Scheme 1. First total synthesis of myrrhine, myrrhine $N$-oxide, hippodamine and convergine. ${ }^{33}$

Few months later, the same research group published another article describing the first synthesis of coccinelline and precoccinelline through a similar approach (Scheme 2). ${ }^{34}$

Starting from 2,6-lutidine, 30, hemiketal $\mathbf{3 4}$ was prepared and it was treated with pyrrolidine and acetic acid to get the last ring, delivering a mixture of tricyclic ketones $\mathbf{3 5}$ and 36, which could be separated. These stereomeric ketones were independently treated with methyl lithium and thionyl chloride and then dechlorinated through hydrogenation to furnish myrrhine from 35 and precoccinelline from 36 . The latter was oxidized with $m$-CPBA affording coccinelline.

\footnotetext{
${ }^{34}$ Ayer, W. A.; Furuichi, K. Can. J. Chem. 1976, 54, 1494-1495.
} 


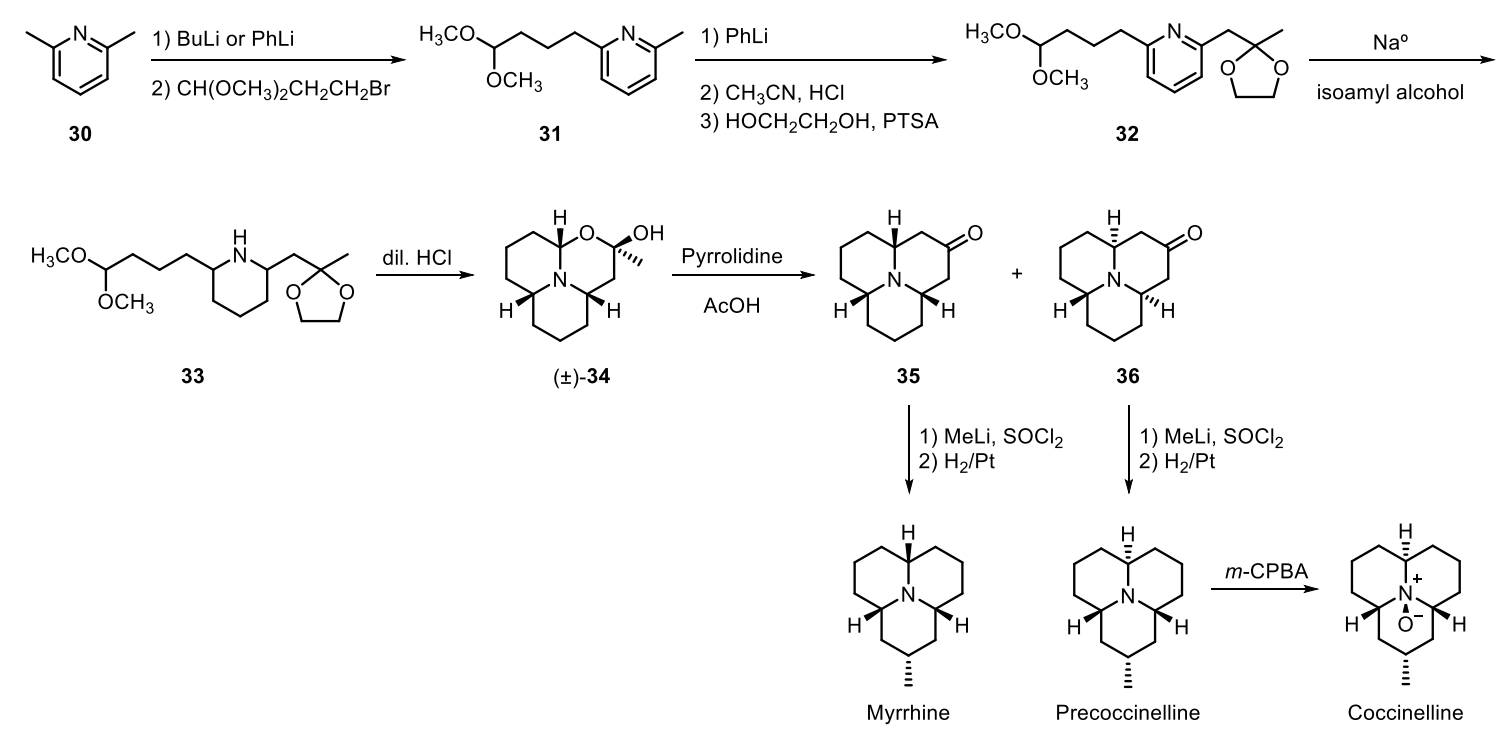

Scheme 2. First synthesis of Precoccinelline and Coccinelline. ${ }^{34}$

Three years later, Stevens and Lee reported a new synthesis of precoccinelline and coccinelline using the Robinson-Schöpf methodology ${ }^{35}$ to build the perhydro-9b-azaphenalene skeleton (Scheme 3). ${ }^{36}$

In order to obtain the key intermediate $\mathbf{4 2}$, malonic ester $\mathbf{3 7}$ was treated with acrolein, 38, giving aldehyde 39, which was protected as its dimethylacetal, followed by a decarboxymethylation which allowed to obtain 40 . Then, a self-Claisen condensation afforded the ketoester 41. Finally, a decarboxymethylation step and a reductive amination yielded $\mathbf{4 2}$.

The condensation of bisacetal $\mathbf{4 2}$ with dimethyl acetonedicarboxylate was the key step of the synthesis and furnished ketone $\mathbf{4 3}$, which already contains the perhydro-9b-azaphenalene skeleton. Then, $\mathbf{4 3}$ was heated in DMF with the presence of $\mathrm{NaCl}$ to gain ketone $\mathbf{3 6}$. The structure and stereochemistry of this ketone were determined from its IR spectrum and by NMR studies as well as from other data. A Wittig olefination was then performed, followed by a catalytic hydrogenation, affording precoccinelline which was oxidized with $m$-CPBA to obtain coccinelline.

\footnotetext{
35 a) Robinson, R. J. Chem. Soc. 1917, 111, 762-768. b) Schöpf, C. Angew. Chem. 1937, 50, 779-787.

${ }^{36}$ Stevens, R. V.; Lee, A. W. M. J. Am. Chem. Soc. 1979, 101, 7032-7035.
} 


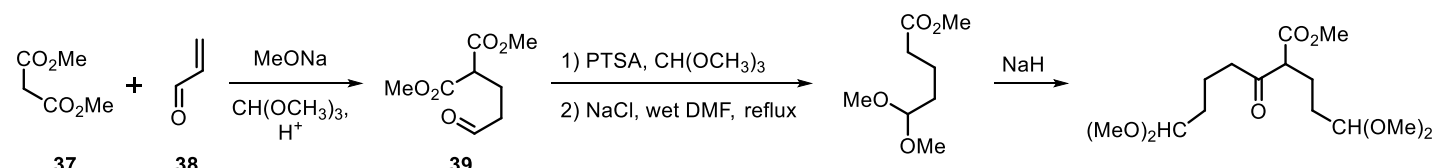

40

41
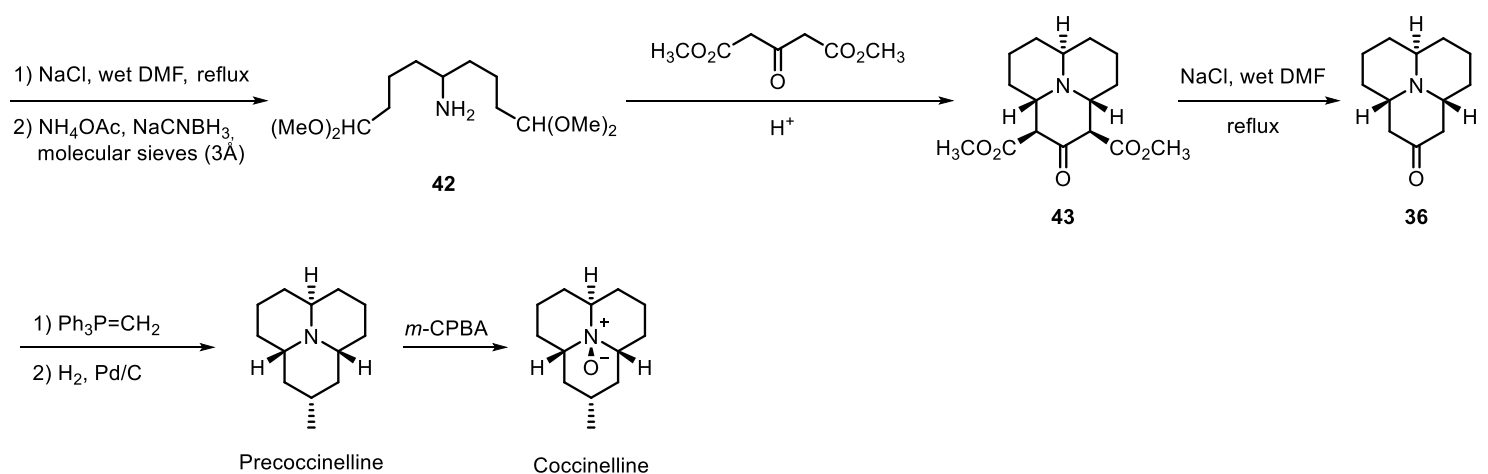

Scheme 3. Synthesis of Precoccinelline and Coccinelline using the Robinson-Schöpf methodology. ${ }^{36}$

A variation of the previous synthesis was established by Langlois et al. who described the synthesis of ketone $\mathbf{3 6}$ from the condensation of dialdehyde $\mathbf{4 4}$ with acetone dicarboxylic acid, 45, using also the Robinson-Schöpf cyclization methodology. ${ }^{35}$ The difference between this strategy and that of Stevens and Lee is that the decarboxymethylation step and the reaction of 43 to obtain 36 were not needed, increasing the overall yield (Scheme 4). ${ }^{37}$

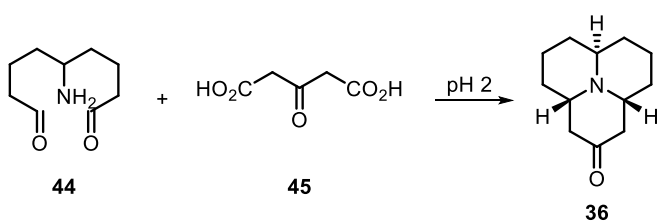

Scheme 4. Synthesis of $\mathbf{3 6}$ described by Langlois et al. ${ }^{37}$

Between 1979 and 1984, Mueller and Thompson described new methodologies to obtain precoccinelline, coccinelline and myrrhine. Moreover, they designed the first synthetic route to obtain hippocasine, convergine, propyleine and isopropyleine. ${ }^{27,38,39}$

Their synthesis starts with perhydro-9b-boraphenalene, $\mathbf{4 7}$, which has the three rings necessary to build the azaphenalene alkaloids but it requires changing boron to nitrogen (Scheme 5). Compound $\mathbf{4 7}$ was obtained by hydroboration of 1,5,9-cyclododecatriene, 46.

\footnotetext{
${ }^{37}$ Langlois, M.; Yang, D.; Soulier, J. L.; Florac, C. Synth. Commun. 1992, 22, 3115-3127.

38 Mueller, R. H.; Thompson, M. E. Tetrahedron Lett. 1979, 20, 1991-1994.

${ }^{39}$ Mueller, R. H.; Thompson, M. E. Tetrahedron Lett. 1980, 21, 1093-1096.
} 


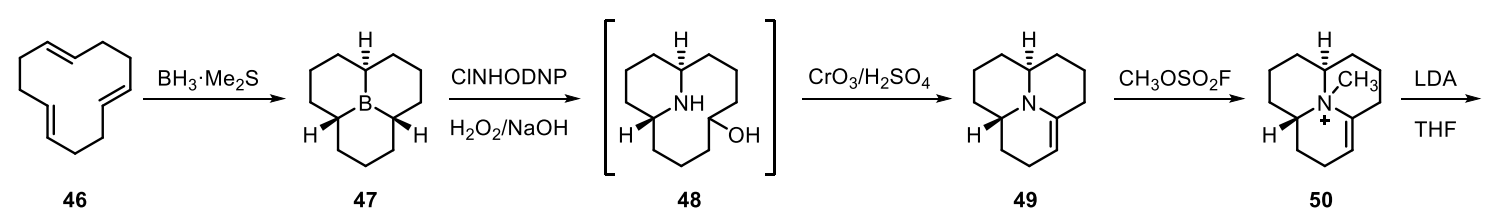

46

47

48

49

50

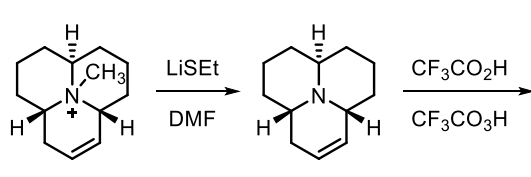

52

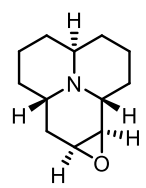

53

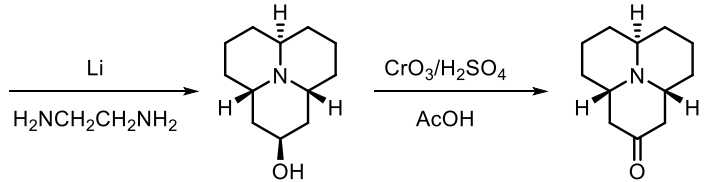

54

36

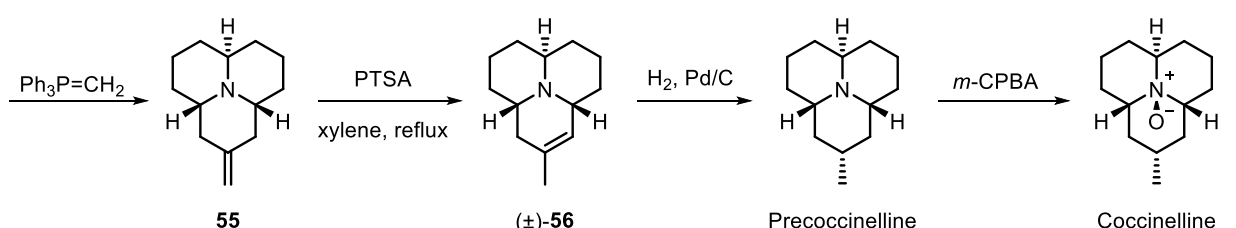

Scheme 5. Synthesis of precoccinelline and coccinelline by Mueller and Thompson. ${ }^{27,38}$

In the synthesis of precoccinelline and coccinelline, 47 reacted with $\mathrm{N}$-chloro-O-(2,4dinitrophenyl)hydroxylamine (CINHODNP) and hydrogen peroxide to furnish the alcohol 48, which was further oxidized to the tricyclic enamine 49. The addition of methyl fluorosulfonate gave the enamonium salt $\mathbf{5 0}$, which was treated with LDA in order to isomerize the double bond affording 51. Demethylation of $\mathbf{5 1}$ to the tricyclic amine $\mathbf{5 2}$ was performed using lithium ethyl mercaptide in DMF. Then, a stereoselective epoxidation of $\mathbf{5 2}$ led to 53, which was reduced to the axial alcohol 54. This alcohol was oxidized to form ketone 36 (intermediate of Ayer's synthesis of coccinelline and precoccinelline) which through a Wittig olefination gave olefin $\mathbf{5 5}$. Isomerization to the endocyclic alkene gave a racemic epimer of hippocasine, $( \pm)-56$, which after a hydrogenation afforded precoccinelline.

The synthesis of hippodamine, hippocasine and their $\mathrm{N}$-oxides (Scheme 6) started from the enamine 49 of the previous synthetic route. Through a hydroboration-oxidation step, alcohols $\mathbf{5 7}$ and $\mathbf{5 8}$ were obtained in a ratio of 1:3. This mixture was converted to ketone $\mathbf{6 0}$, precursor of the vinylogous amide $\mathbf{6 1}$, which was reduced to 62 .

On one hand, the amino ketone $\mathbf{6 2}$ was treated with ethanedithiol followed by lithium in ethylenediamine to remove the carbonyl group affording ( \pm )-hippodamine which was oxidized to ( \pm )-convergine. On the other hand, $\mathbf{6 2}$ was treated with hydrazine followed by $\mathrm{TsCl}$ and lithium tert-butyl amide giving ( \pm )-hippocasine which was oxidized to its $N$-oxide. ${ }^{27,39}$ 


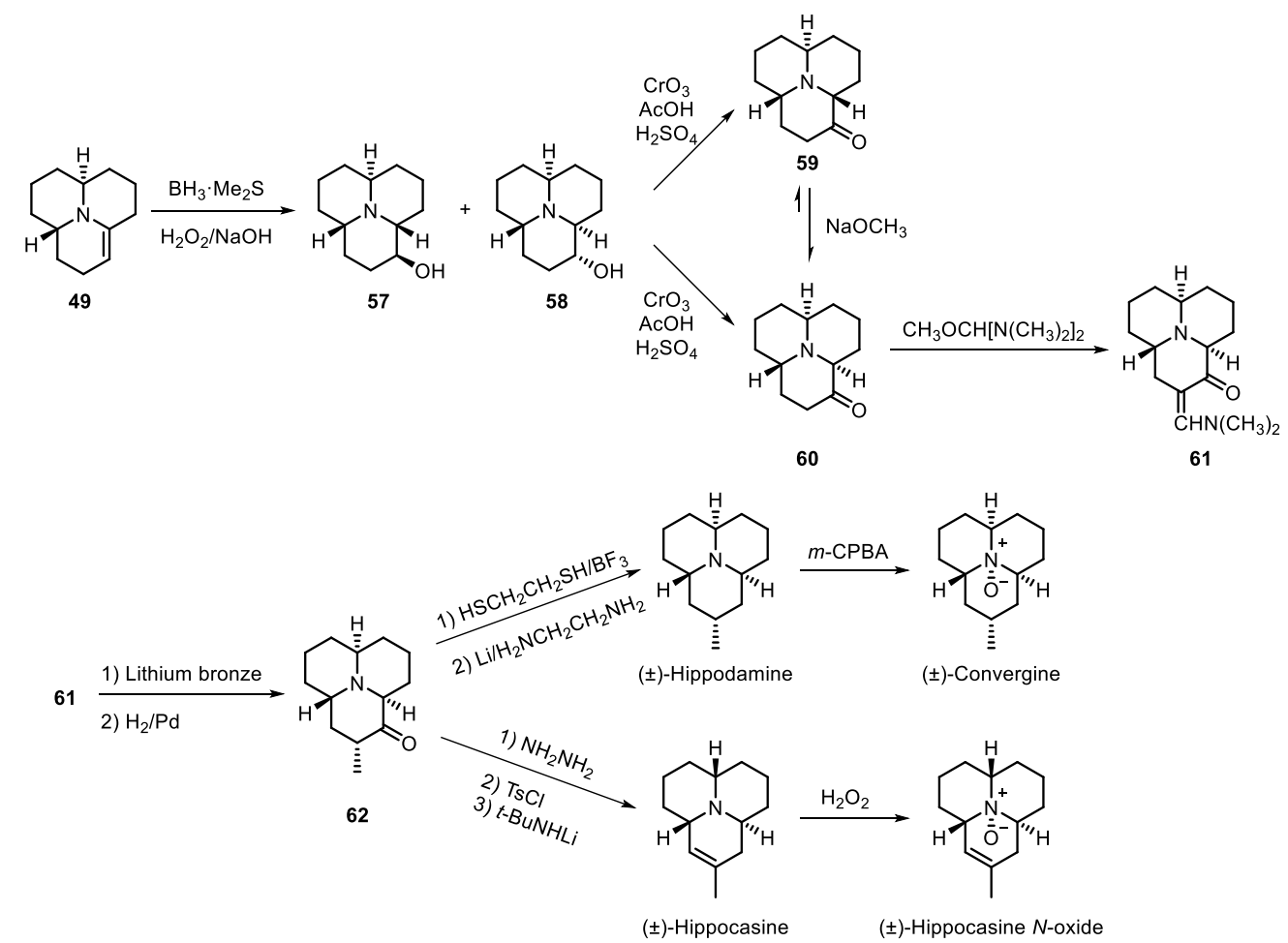

Scheme 6. First synthesis of $( \pm)$-hippodamine, ( \pm )-hippocasine and its $N$-oxides by Mueller and Thompson. ${ }^{27,39}$

Propyleine and isopropyleine were also synthesized from amino ketone 62 (Scheme 7), by reduction to the corresponding alcohol followed by mesylation and then treatment with potassium carbonate in dimethylsulfoxide. The resulting iminium salt $\mathbf{2 2}$ rapidly evolved to a mixture of $( \pm)$-propyleine and $( \pm)$-isopropyleine in a 1:3 ratio..$^{27,40}$

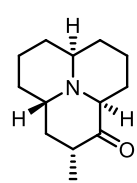

62

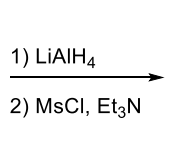

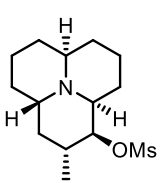

63

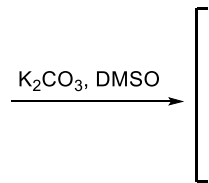

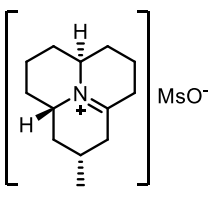

22

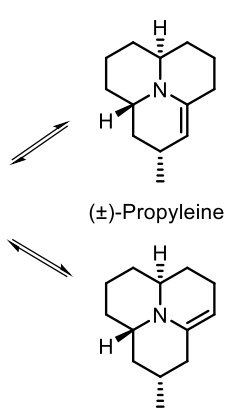

$( \pm)$-Isopropyleine

Scheme 7. First synthesis of propyleine and isopropyleine by Mueller and Thompson. ${ }^{27,40}$

The synthesis of myrrhine developed by Mueller and Thompson (Scheme 8) starts with the amino alcohol 48, intermediate of the synthesis of precoccinelline and coccinelline. This amino alcohol was converted in the tertiary amine 64 by treatment with $p$-toluenesulfonic acid. The amine was oxidized to its $\mathrm{N}$-oxide and then, treatment with trifluoroacetic acid and

\footnotetext{
${ }^{40}$ Mueller, R. H.; Thompson, M. E. Tetrahedron Lett. 1980, 21, 1097-1100.
} 
triethylamine delivered the enamine 65 with the two ring junction hydrogens in cis configuration. Hydroboration-oxidation step followed by another oxidation afforded ketone 66 . A Mannich type reaction converted 66 to the enaminone 67, which was transformed into the insaturated aldehyde 68. This aldehyde was reduced to the corresponding alcohol and activated with methanesulfonyl chloride affording 69 , which was reduced to finally obtain myrrhine. ${ }^{27}$
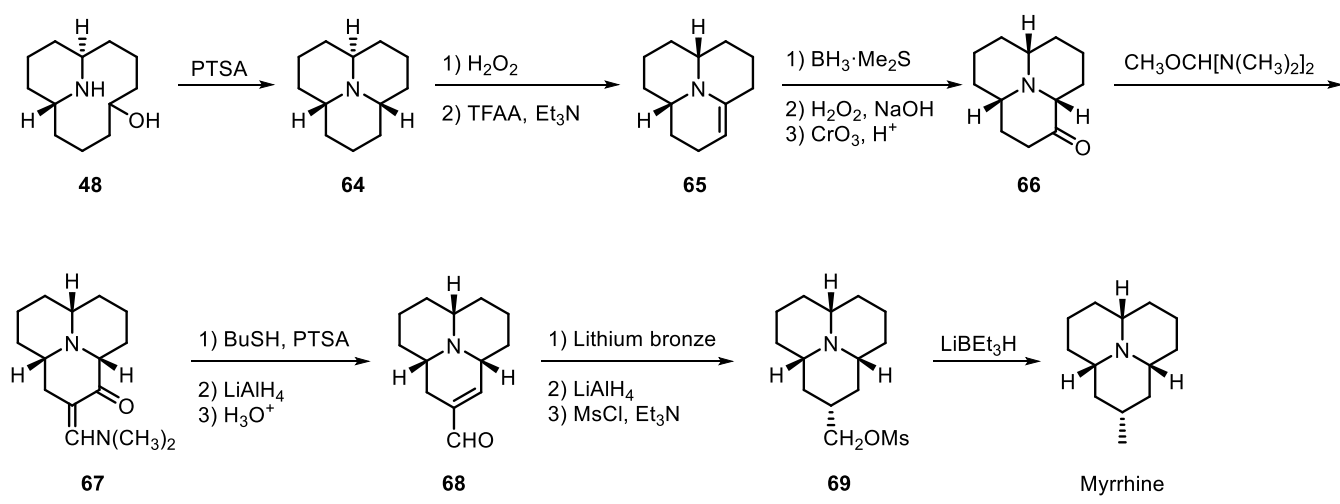

Scheme 8. Synthesis of myrrhine by Mueller and Thompson. ${ }^{27}$

Some years later, Adams and co-workers prepared ( \pm )-epi-hippodamine (Scheme 9), which is not a known natural azaphenalene alkaloid. ${ }^{41}$ It was synthesized starting from nitrone 71, generated in situ by treatment of aldehyde $\mathbf{7 0}$ with hydroxylamine. This nitrone reacted with ethyl hexa-3,5-dienoate to form a diastereomeric mixture of isoxazoline $\mathbf{7 2}$ (the structure represented in Scheme 9 corresponds to the major isomer). The following $\mathrm{N}-\mathrm{O}$ bond reduction and base-promoted isomerization yielded $\mathbf{7 3}$ which was rapidly involved in an intramolecular conjugated addition followed by silylation, affording the bicycle $\mathbf{7 4}$ that has two rings of the target. The unisolated tricycle $\mathbf{7 5}$ was obtained through a Dieckmann ring-closure and immediately treated with lithium chloride giving 76 . Then, a Wittig reaction, followed by hydrogenation and subsequent deprotection, gave the amino alcohol $\mathbf{7 7}$. Deoxygenation of 77 proceeded through xanthate $\mathbf{7 8}$ to finally furnish ( \pm )-epi-hippodamine.

\footnotetext{
${ }^{41}$ Adams, D. R.; Carruthers, W.; Crowley, P. J. J. Chem. Soc., Chem. Commun. 1991, 1261-1263.
} 


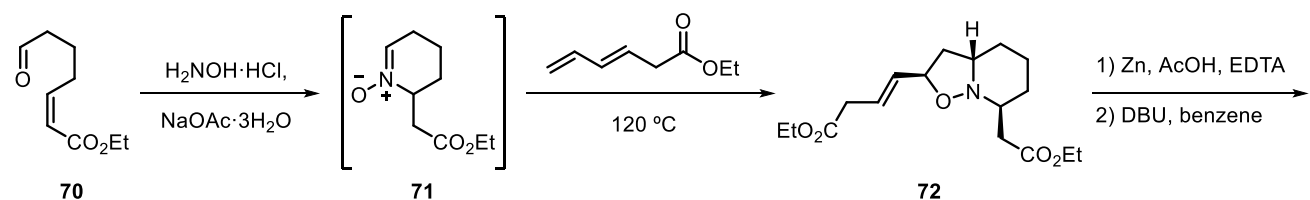

70

71

72

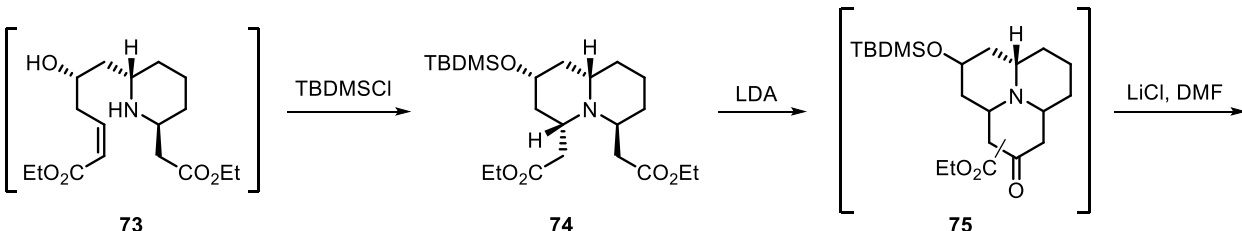

73

74

75

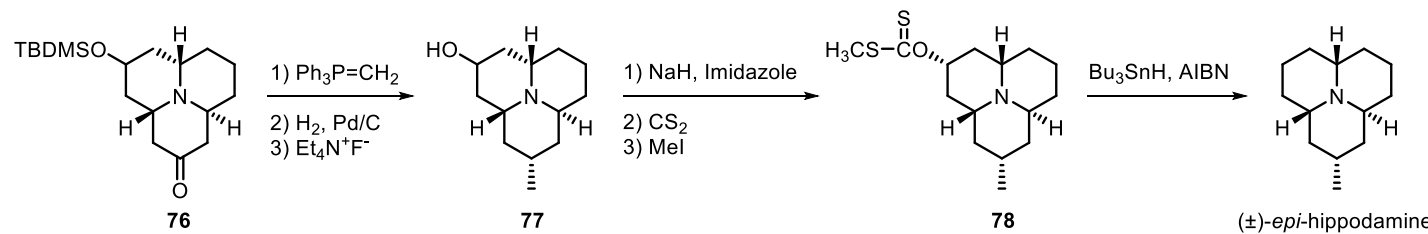

Scheme 9. Synthesis of ( \pm )-epi-hippodamine by Adams et al. ${ }^{41}$

In 1994, Royer and co-workers described a new synthesis of ketone $\mathbf{3 6}$, which is a precursor of the achiral alkaloid precoccinelline (see Scheme 2), starting from the chiral compound 79 (Scheme 10). ${ }^{42}$ The diastereoselective alkylation of 79 with 3-bromo-2methoxypropane yielded $\mathbf{8 0}$. Its treatment with TBDMSOTf and $\mathbf{8 1}$ gave oxazolidinone $\mathbf{8 2}$ via tandem alkylation/aza-Cope rearrangement. The reductive ring cleavage followed by the "onepot" methanolysis-debenzylation afforded the ketoacetal 85. Removal of all protecting groups and intramolecular Mannich reaction furnished ketone 36.
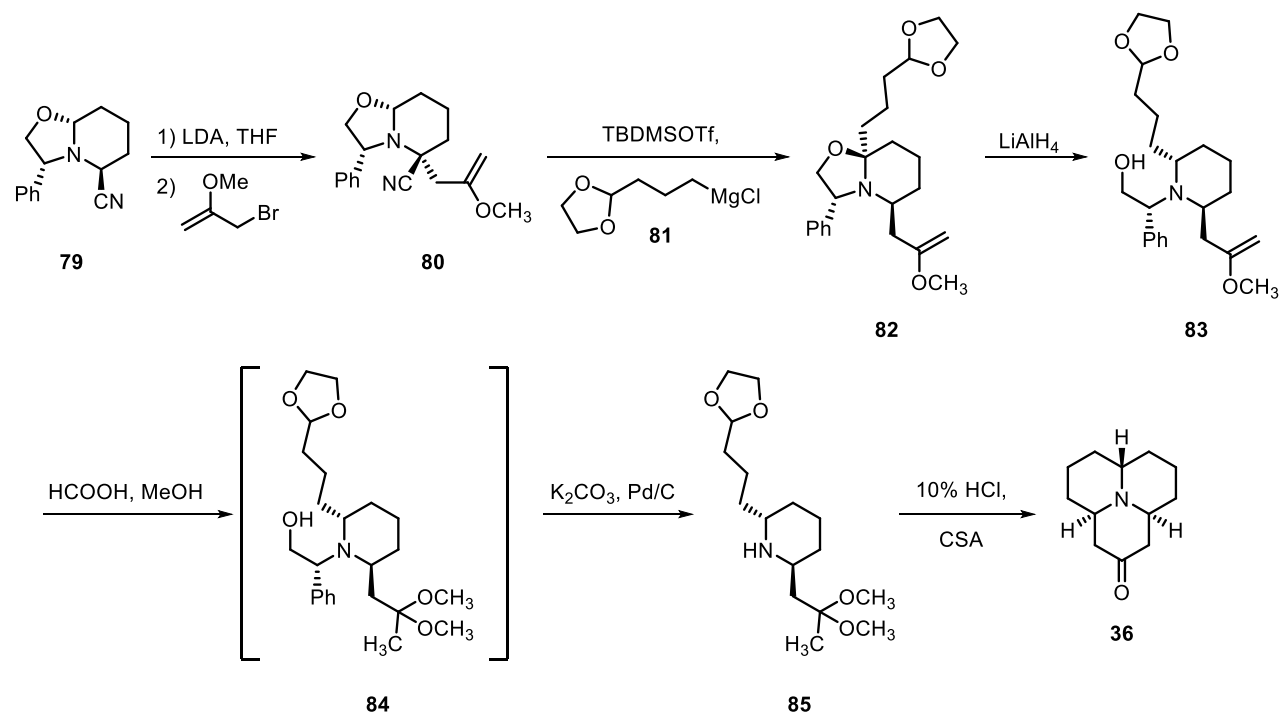

Scheme 10. Synthesis of intermediate 36 by Royer et al. ${ }^{42}$

\footnotetext{
${ }^{42}$ Yue, C.; Nicolay, J.-F.; Royer, J.; Husson, H.-P. Tetrahedron 1994, 50, 3139-3148.
} 
In 2002, Takahata and collaborators designed a new methodology to prepare ketone $\mathbf{3 6}$ (Scheme 11). ${ }^{43}$ The synthesis begun with the treatment of dialdehyde 86 with DIP-chloride and allylmagnesium bromide, followed by oxidation with hydrogen peroxide to obtain diol 87 . A cyclic amination of the corresponding ditosylate with benzylamine followed by $N$-protecting group change furnished the carbamate $\mathbf{8 8}$. An iodocarbamation of $\mathbf{8 8}$ gave the oxazinone $\mathbf{8 9}$ which was oxidized under Wacker conditions to ketone $\mathbf{9 0}$. This ketone was transformed in the alkene 91 and it was treated with $\mathrm{OsO}_{4}$ and $\mathrm{NaIO}_{4}$ followed by a Wittig olefination furnishing the aldehyde 92. Subsequently, a hydrogenation of the C-C bond was performed gaining the ketoaldehyde 93, which was treated with TFA in order to liberate the amine and submit it to an intramolecular Mannich-type cyclization, obtaining, at the end, the expected ketone 36.
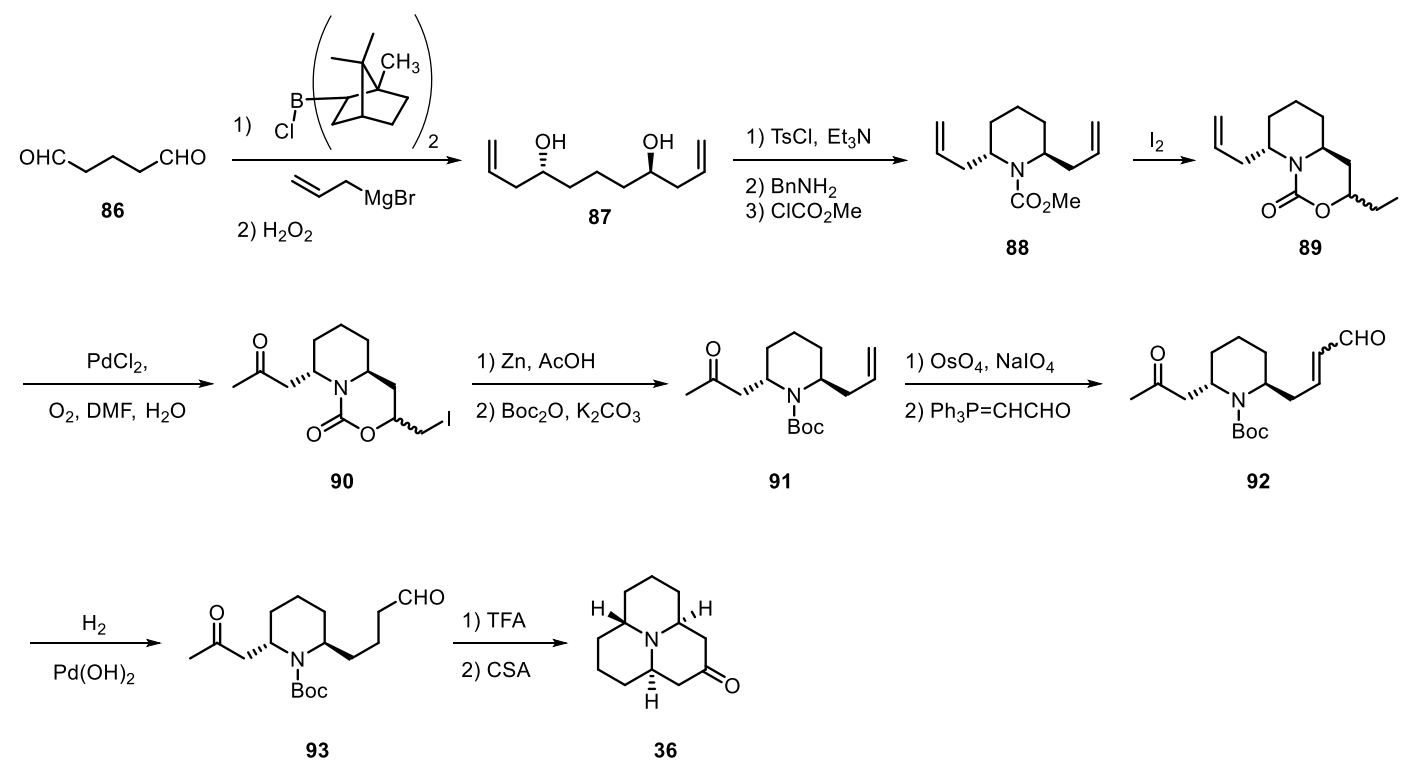

Scheme 11. New synthetic pathway to obtain 36 by Takahata et al. ${ }^{43}$

Some years later, a new synthetic strategy for ( \pm )-hippodamine and ( \pm )-epi-hippodamine was developed by Stockman et al. (Scheme 12). ${ }^{19 b}$ The synthesis started with the known symmetric alcohol $94 .{ }^{44}$ The alcohol was substituted by phtalamide through Mitsunobu methodology gaining diene $\mathbf{9 5}$. An oxidative cleavage of $\mathbf{9 5}$ followed by a double HornerWadsworth-Emmons olefination gave diester 96 which was treated with $\mathrm{NaBH}_{4}$ to remove the phtaloyl group. Two intramolecular conjugated additions afforded the bicycle 97. Dieckmann

\footnotetext{
43 a) Takahata, H.; Ouchi, H.; Ichinose, M.; Nemoto, H. Org. Lett. 2002, 4, 3459-3462. b) Takahata, H.; Saito, Y.; Ichinose, M. Org. Biomol. Chem. 2006, 4, 1587-1595.

${ }^{44}$ Kitching, W.; Lewis, J. A.; Perkins, M. V.; Drew, R.; Moore, C. J.; Schurig, V.; König, W. A.; Francke, W. J. Org. Chem. 1989, 54, 3893-3902.
} 
condensation followed by deethoxycarbonylation yielded ketone $\mathbf{9 8}$, which was olefinated to 99.
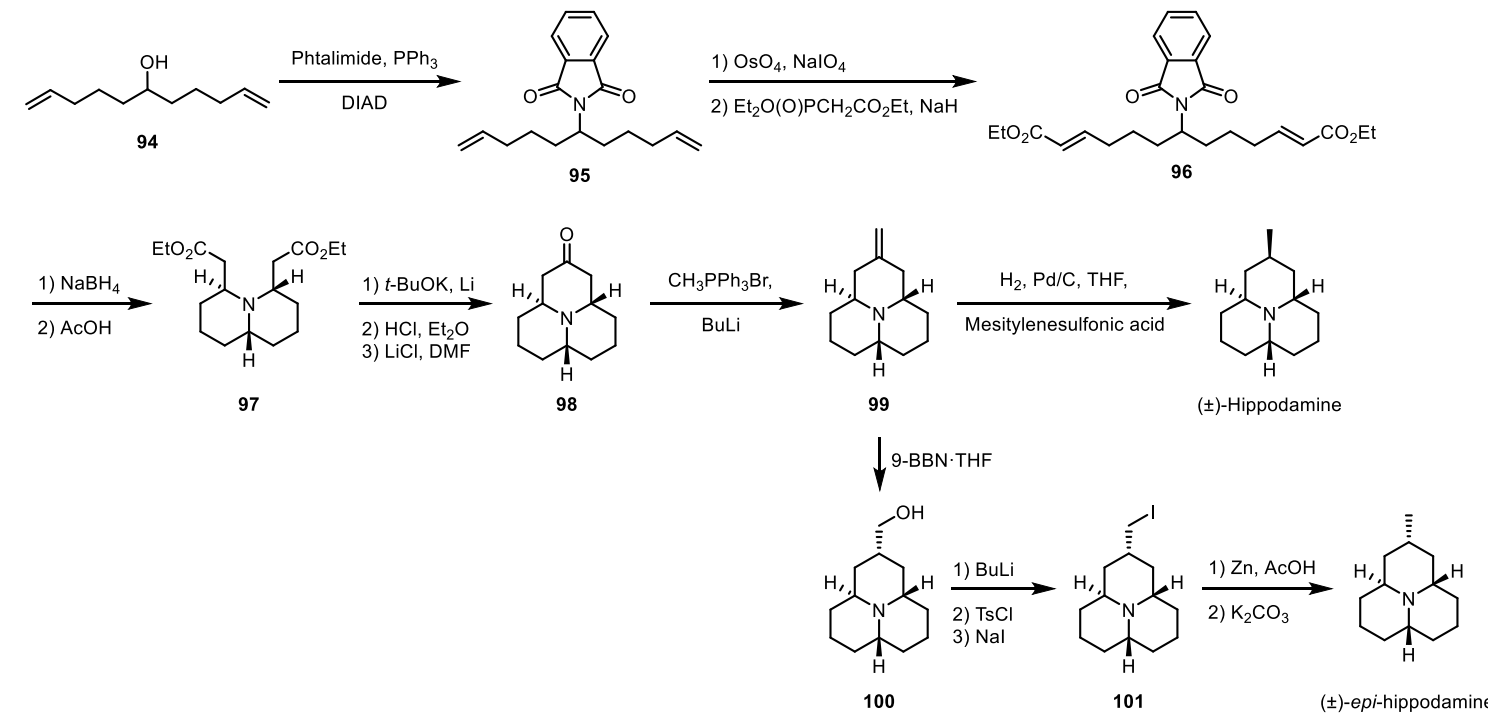

Scheme 12. New methodology to obtain ( \pm )-hippodamine and ( \pm )-epi-hippodamine by Stockman et al..$^{43}$

On one hand, olefin 99 was stereoselectively hydrogenated using mesitylenesulfonic acid as additive yielding $( \pm)$-hippodamine in $8 \%$ overall yield.

On the other hand, stereoselective hydroboration of 99 with 9-BBN furnished alcohol 100, which was converted to the iodide $\mathbf{1 0 1}$. This last intermediate was reduced with zinc delivering ( \pm )-epi-hippodamine in $13 \%$ overall yield.

Some years later, the authors introduced some changes to improve this synthesis. ${ }^{45}$ Due to the instability of the dialdehyde obtained after the oxidative cleavage, they had to make the Horner-Wadsworth-Emmons reaction directly after the isolation of the dialdehyde. Moreover, the oxidative cleavage produced large amounts of toxic osmium waste. Therefore, they established an alternative to these reactions: a double cross-metathesis with ethyl acrylate using Hoveyda-Grubbs second generation catalyst (Scheme 13). With these changes, the synthesis of $( \pm)$-hippodamine consisted in eight steps and the overall yield was increased from 8 to $10 \%$, while ( \pm )-epi-hippodamine was obtained in eleven steps and $16 \%$ overall yield.

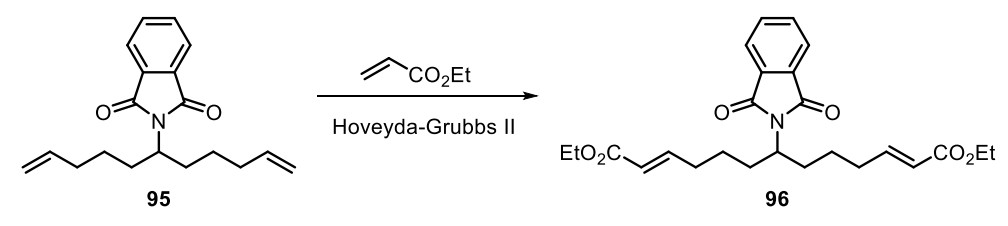

Scheme 13. Improved synthesis of intermediate 96 by Stockman et al. ${ }^{45}$

\footnotetext{
${ }^{45}$ Newton, A. F.; Rejzek, M.; Alcaraz, M. L.; Stockman, R. A. Beilstein J. Org. Chem. 2008, 4.
} 
Furthermore, they developed a new tandem reductive amination/double intramolecular Michael addition in order to obtain intermediate $\mathbf{9 7}$ without using phtalimide as a protecting group (Scheme 14)..$^{45}$

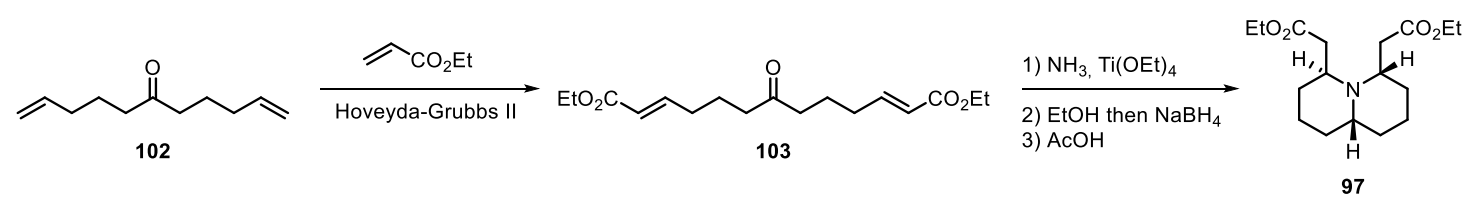

Scheme 14. Tandem reductive amination/double intramolecular conjugated addition. ${ }^{45}$

In 2006, Hsung and Gerasyuto described a new synthesis of precoccinelline, hippodamine and their $\mathrm{N}$-oxides using an aza-[3+3] annulation as a key step (Scheme 15$).{ }^{5}$ The synthetic route started with the alkylation of alkyne 104 with 1,3-dibromopropane followed by hydrogenation obtaining alkene 105. Then, a reductive alkylation of 4-methyl glutarimide, with the magnesium reagent derived from 105, furnished lactam 106 as a 1,3-cis isomer. Such lactam 106 was treated with Lawesson's reagent ${ }^{46}$ and then alkylated with $\alpha$-bromo methyl acetate giving the ester 107 . Eschenmoser sulphide contraction led to the insaturated ester which alcohol was deprotected by treatment with TBAF. The allylic alcohol 108 was oxidized to the aldehyde 109, which was subjected to the aza-[3+3]annulation with piperidinium trifluoro acetate, followed by a hydrogenation step to gain the stable tricyclic compound 111. After a second hydrogenation, two isomers were obtained, $\mathbf{1 1 2}$ (with the framework of precoccinelline) and $\mathbf{1 1 3}$ (with the skeleton of hippodamine). The former was treated with potassium hydroxide to hydrolyze the ester yielding 114 which was decarboxylated using Barton's methodology. ${ }^{47}$ Alternatively, isomer 113 was treated with KHMDS in order to obtain the equatorial ester 115, amenable of a Barton's decarboxylation.

\footnotetext{
${ }^{46}$ Jesberger, M.; Davis, T. P.; Barner, L. Synthesis 2003, 13, 1929-1958.

${ }^{47}$ Barton, D. H. R.; Bridon, D.; Fernandez-Picot, I.; Zard, S. Z. Tetrahedron 1987, 43, 2733-2740.
} 


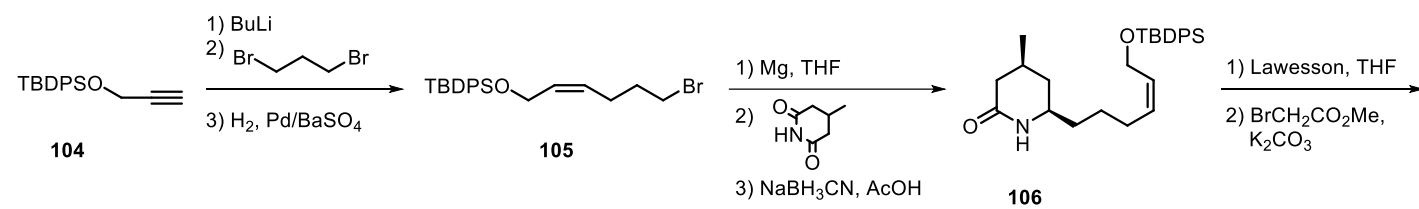

2) $\frac{\text { TBAF }}{\text { 1) } \mathrm{PPh}_{3}, \text { DIPEA }}$

107<smiles>CC(=O)C1=C2C[C@H](C)C[C@H]3CCC[C@H](C=C1)N23</smiles>

110<smiles>COC(=O)/C=C1/CC(C)CC(CCC/C=C\CO)N1</smiles>

108
DIPEA, $\mathrm{CH}_{2} \mathrm{Cl}_{2}$

109

09

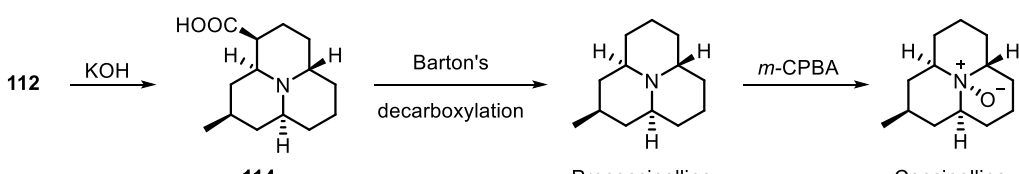<smiles>CC(=O)C[C@H]1CC[C@H]2CCC[C@@H]3C[C@@H](C)C[C@]213</smiles>

113<smiles>COC(=O)C1CCC2CCC[C@@H]3CC(C)CC1N23</smiles>

112<smiles>COC(=O)/C=C1/CC(C)CC(CCCCCC=O)N1</smiles>

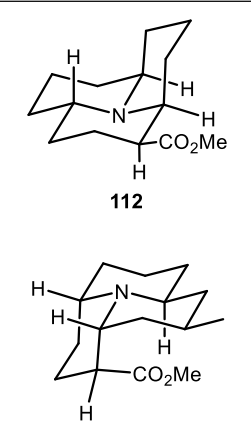

113

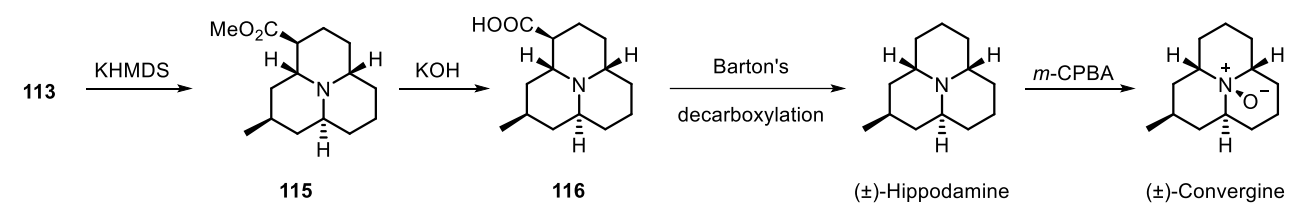

Scheme 15. Synthesis of precoccinelline, coccinelline, hippodamine and convergine by Hsung and Gerasyuto. ${ }^{5}$

In 2007, the same research group published an article describing the synthesis of myrrhine starting from the previous intermediate $\mathbf{1 1 0}$ (Scheme 16). ${ }^{48}$ After the aza-[3+3]annulation, an aromatization-reduction step was performed with DDQ followed by hydrogenation yielding $\mathbf{1 1 7}$ with the relative configuration of the stereogenic centers as those of myrrhine. Then, the ester group in $\mathbf{1 1 7}$ was hydrolyzed and decarboxylation under Barton's methodology yielded myrrhine.

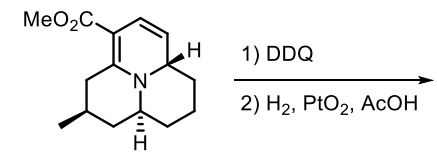

110

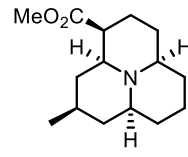

117

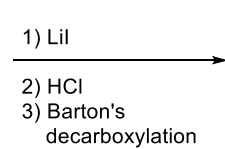

decarboxylation

(decarboxylation

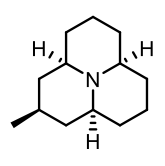

Myrrhine

Scheme 16. Synthesis of myrrhine by Hsung and Gerasyuto. ${ }^{48}$

\footnotetext{
${ }^{48}$ Gerasyuto, A. I.; Hsung, R. P. J. Org. Chem. 2007, 72, 2476-2484.
} 
In 2010, Spring and co-workers developed a new synthesis of myrrhine $\mathrm{N}$-oxide (Scheme 17). ${ }^{49}$ Starting from the alcohol 94 , a Mitsunobu reaction followed by a deprotection and a double cross-metathesis were carried out affording aminodienediester 118. Two conjugated additions and then a Dieckmann condensation gave tricycle 119 which was decarboxylated. Then, a Wittig olefination and subsequent hydrogenation were performed yielding myrrhine, which was treated with $m$-CPBA affording the non-natural alkaloid myrrhine $\mathrm{N}$-oxide.

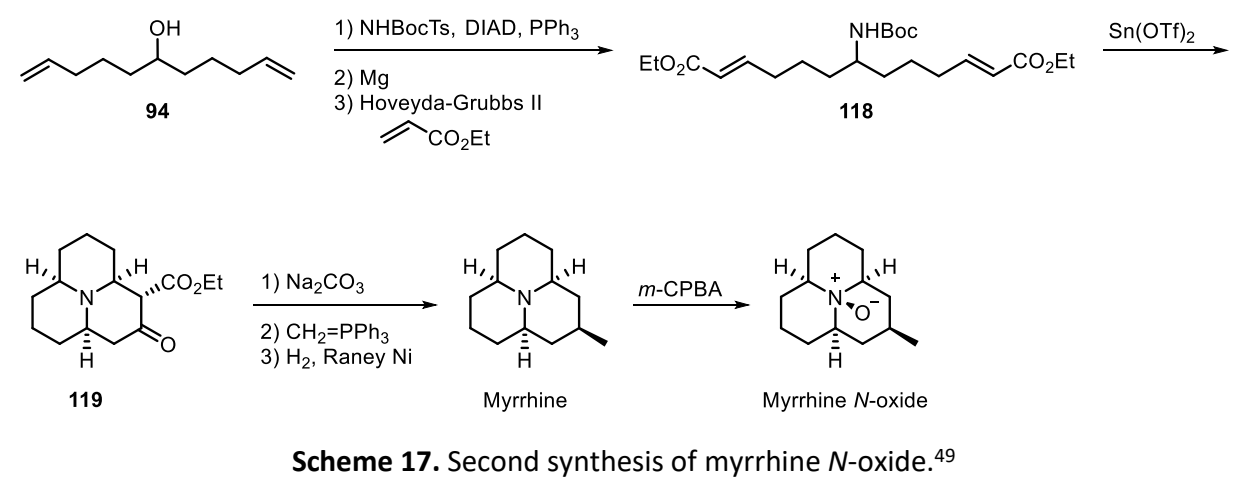

Four years later, Kuznetsov and collaborators described a new synthetic way for $( \pm)$ hippocasine and ( \pm )-epi-hippodamine (Scheme 18$) \cdot{ }^{50}$ The synthesis started from 4-picoline and had as key steps an allylboration reaction, a palladium- and iridium-catalyzed intramolecular allylic amination and a ring-closing metathesis reaction.

The first step was the 1,2-organolithiation of 4-picoline with the lithium derivative $\mathbf{1 2 0}$ followed by a trans-allylation with triallylborane, affording amine 121 which was then protected. The acetal was hydrolyzed to the corresponding aldehyde, which reacted with vinylmagnesium bromide yielding the allylic alcohol 122. Acylation of the alcohol and deprotection of the amine group gave amine 123. After a "Pd" or "Ir" catalyzed cyclization, the bicyclic compound $\mathbf{1 2 4}$ was obtained. Subsequently, it was treated with Grubbs second generation catalyst to furnish the tricyclic amine 125. Then, partial hydrogenation of the less substituted double bond yielded ( \pm )hippocasine while exhaustive hydrogenation furnished ( \pm )-epi-hippodamine.

\footnotetext{
49 Díaz-Gavilán, M.; Galloway, W. R. J. D.; O’Connell, K. M. G.; Hodkingson, J. T.; Spring, D. R. Chem. Commun. 2010, 46, 776-778.

${ }^{50}$ Kuznetsov, N. Y.; Lyubimov, S. E.; Godovikov, I. A.; Bubnov, Y. N. Russ. Chem. Bull., Int. Ed. 2014, 63, 529537.
} 


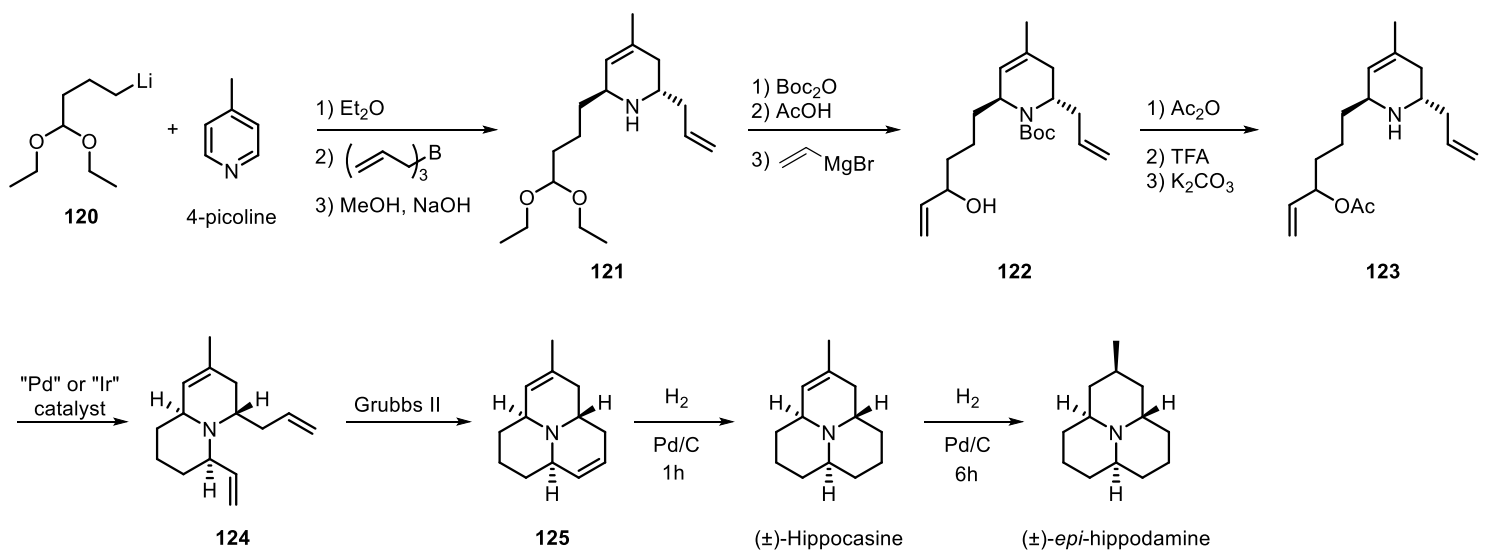

Scheme 18. Synthesis of ( \pm )-hippocasine and ( \pm )-epi-hippodamine by Kuznetsov et al. ${ }^{50}$

\subsubsection{Enantioselective synthesis of chiral azaphenalene alkaloids}

The first enantioselective synthesis of hippodamine was developed by Katsumura and coworkers in 2013 (Scheme 19). ${ }^{30}$ This synthesis had as key step a one-pot asymmetric azaelectrocyclization reaction which led to amine $\mathbf{1 3 0}$ in $\mathbf{8 1 \%}$ yield having all the stereogenic centers of the azaphenalene alkaloid established in a stereocontrolled manner. The synthesis of such amine was previously reported by the same research group ${ }^{51}$ as they were the starting materials 126 and $\mathbf{1 2 7} .^{52}$

Amine 130 was hydrogenated to amine 131 and, then, a chemoselective reduction of the ethyl ester to alcohol, followed by deoxygenation afforded compound $\mathbf{1 3 2}$. The indanol moiety was removed and the amine was converted into the carbamate $\mathbf{1 3 4}$. A sequence of reactions, including hydroboration-oxidation, nucleophilic methylation and a second oxidation gave methylketone 135. The Cbz protection was removed and an intramolecular Mannich reaction furnished the tricyclic compound $\mathbf{1 3 7}$ as a single isomer. Finally, ketal $\mathbf{1 3 7}$ was deoxygenated using the same method as Ayer et al. ${ }^{33}$ and a subsequent hydrogenation gave (-)-hippodamine in $12 \%$ overall yield.

\footnotetext{
${ }^{51}$ Kobayashi, T.; Nakashima, M.; Hakogi, T.; Tanaka, K.; Katsumura, S. Org. Lett. 2006, 8, 3809-3812.

52 a) Kobayashi, T.; Tanaka, K.; Miwa, J.; Katsumura, S. Tetrahedron: Asymmetry 2004, 15, 185-188. b) Tanaka, K.; Mori, H.; Yamamoto, M.; Katsumura, S. J. Org. Chem. 2001, 66, 3099-3110.
} 


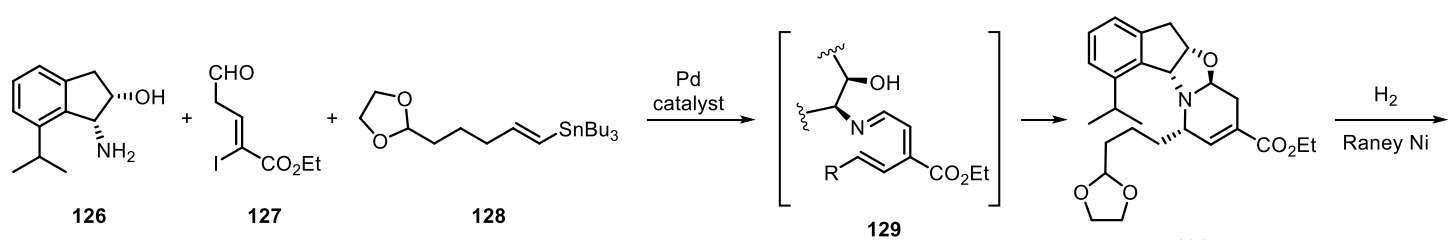

126

127

128

129

130

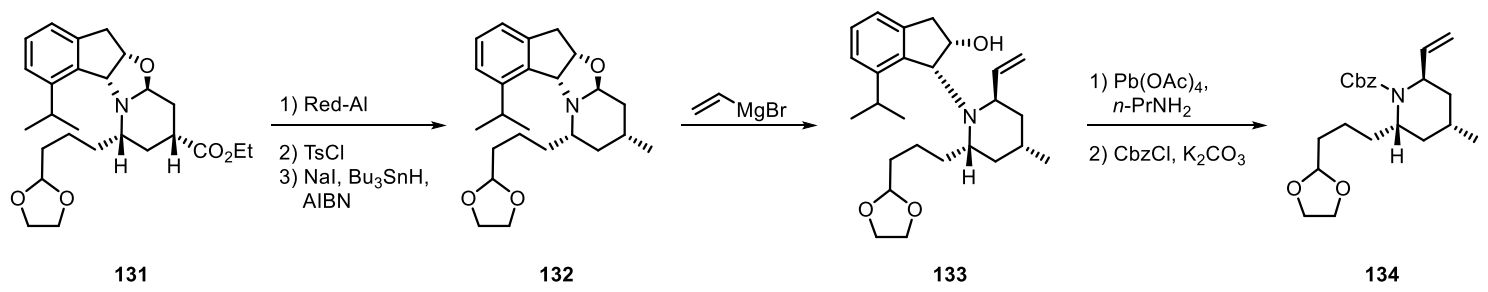<smiles>CC(=O)C[C@H]1C[C@@H](C)C[C@H](CCCC2OCCO2)N1</smiles>

Scheme 19. First asymmetric synthesis of hippodamine by Katsumura et al. ${ }^{30}$

In 2014, Snyder and collaborators published an article describing the synthesis of all natural azaphenalene alkaloids except myrrhine, from a common synthetic intermediate. Furthermore, the chiral azaphenalene alkaloids were obtained in enantiopure form. ${ }^{31}$ They also reported the synthesis of some dimeric alkaloids and discovered that the putative natural monomeric precursors afforded only a non-natural analog.

The synthesis started with the commercially available amino-alcohol $\mathbf{1 3 8}$ with a key stereogenic center which would easily encode the remaining sterocenters into the final azaphenalene alkaloids (Scheme 20). After the protection of the alcohol 138, an allylation step was performed followed by an oxidative cleavage obtaining 139. A second allylation and subsequent oxidative cleavage yielded ketone 140 . The corresponding $\alpha, \beta$-enone was formed by treating the derivative with $\mathrm{DBU}$, and a 1,4-reduction and desilylation furnished the key common intermediate $\mathbf{1 4 1}$ in eight steps and $55 \%$ overall yield.

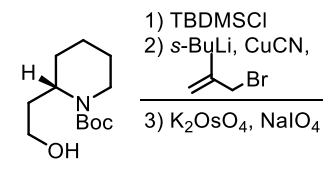

138

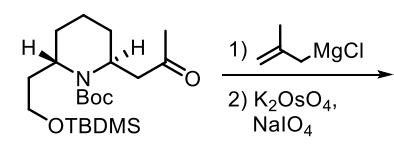

139

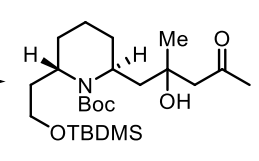

140

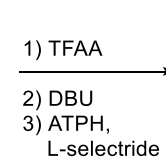

L-selectride

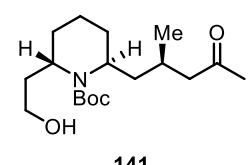

141

Scheme 20. Synthesis of the key common intermediate $141 .^{31}$

Treatment of alcohol 141 with TFA and $\mathrm{PBr}_{3}$ led to the enaminobromide 142, which in the presence of $\mathrm{Et}_{3} \mathrm{~N}$ isomerized to the unstable enamine 143 that rapidly evolved to the equilibrium 
mixture of isopropyleine and propyleine (1:3) in $43 \%$ overall yield (Scheme 21 ). This mixture was converted into precoccinelline through the iminium salt 144.

Alternatively, $\alpha$-carbonyl oxidation of $\mathbf{1 4 1}$ followed by analogous steps furnished ketone 62, an intermediate in the previous synthesis of hippodamine and hippocasine of Mueller. ${ }^{27,39}$

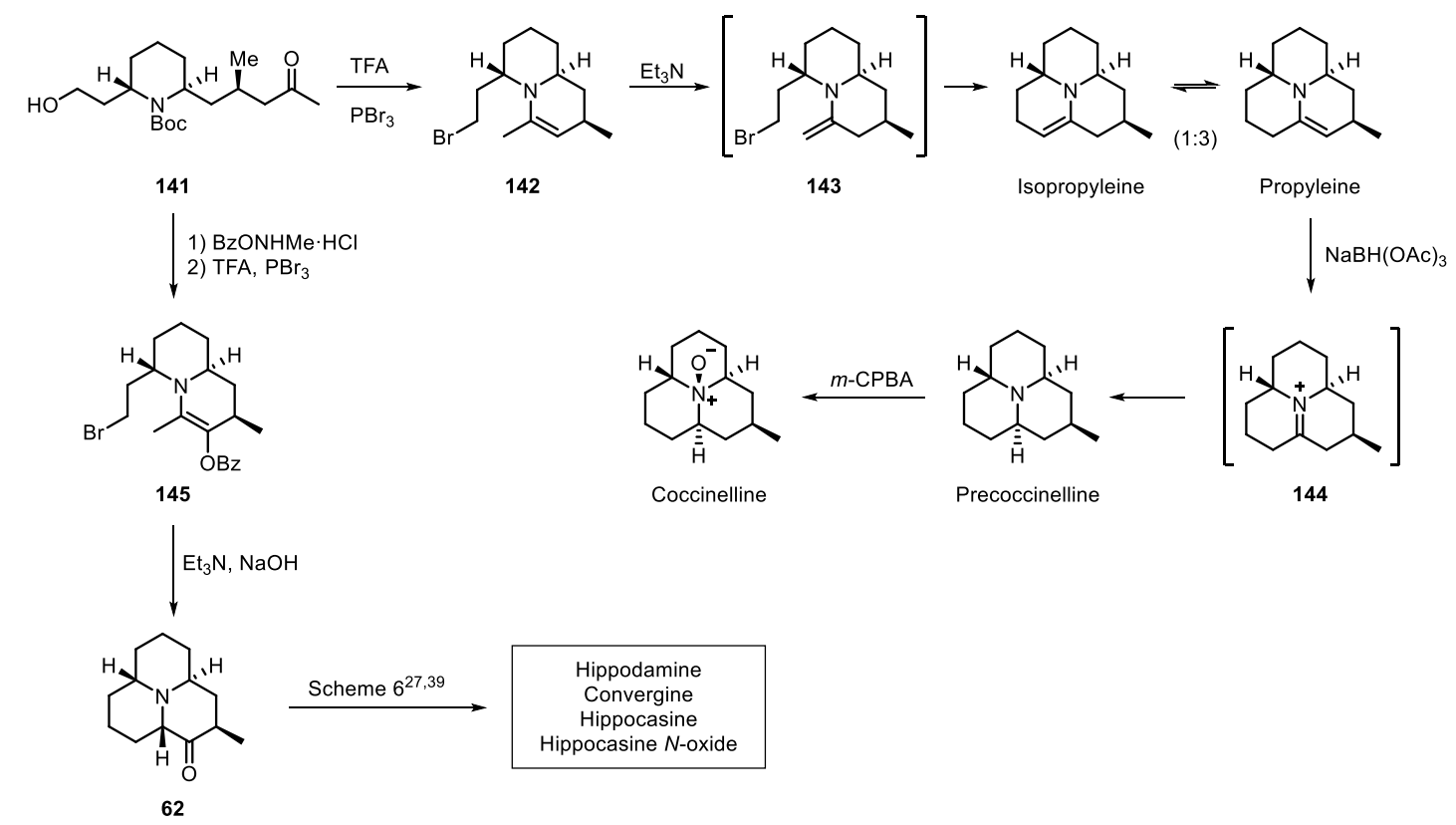

Scheme 21. Synthesis of all natural azaphenalene alkaloids (except myrrhine) through an asymmetric synthesis. ${ }^{31}$

In 2015, Fustero and co-workers developed the first asymmetric synthesis of (+)-epihippodamine and the third of (-)-hippodamine. They utilized a chiral $\mathrm{N}$-sulfinyl amine both as a chiral inducer and nucleophilic nitrogen source (Scheme 22). ${ }^{32}$

The starting material was the known symmetric ketone $146 .{ }^{53}$ Its condensation with $(R)$ $\mathrm{N}$-tert-butanesulfinamide followed by reduction with sodium borohydride led to the reductive amination product containing the chiral auxiliary. This compound was treated with an acrylate in the presence of Hoveyda-Grubbs second generation catalyst to perform a double crossmetathesis yielding the symmetric diester 147. An intramolecular aza-Michael reaction formed the first cycle of the alkaloid, being the isomer 148, with cis configuration, the major. After removing the sulfoxide auxiliary, $\mathbf{1 4 8}$ was submitted to a second intramolecular aza-Michael reaction yielding bicycle 149 in excellent enantiomeric excess. Then, a Dieckmann condensation followed by a decarboxylation afforded ketone $\mathbf{9 8}$ in which a Wittig methylenation produced 99.

\footnotetext{
53 Karatholuvhu, M. S.; Sinclair, A.; Newton, A. F.; Alcaraz, M. L.; Stockman, R. A.; Fuchs, P. L. J. Am. Chem. Soc. 2006, 128, 12656-12657.
} 
Finally, the alkene was hydrogenated furnishing (-)-hippodamine and (+)-epihippodamine in different ratio depending on the catalyst used.

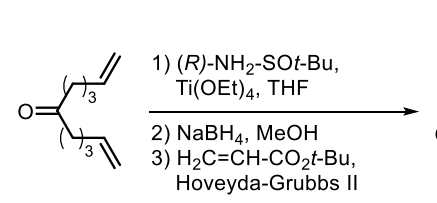

146

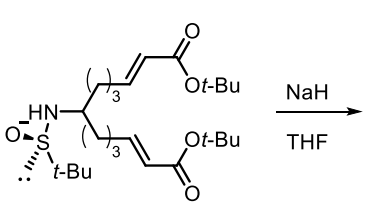

147

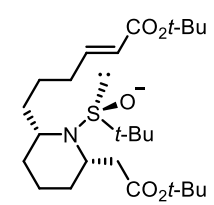

major isomer

148

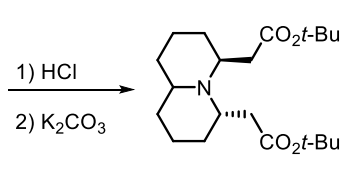

149

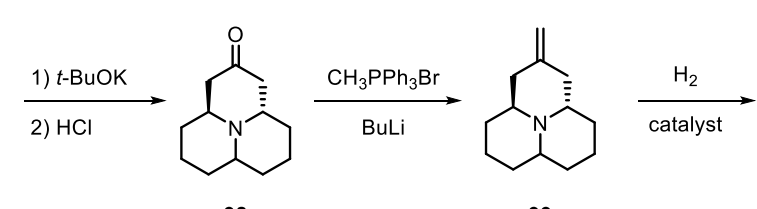

98

99

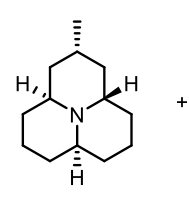

(-)-Hippodamine

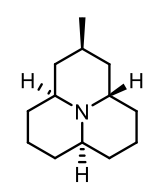

(+)-epi-hippodamine

Scheme 22. Asymmetric synthesis of (-)-hippodamine and (+)-epi-hippodamine by Fustero et al. . $^{32}$

\section{Synthetic background in the research group}

In connection with a project devoted to the synthesis of alkaloids of the Securinega family, our research group adapted the palladium-catalyzed asymmetric allylic alkylation (AAA) of phtalimide developed by Trost $^{54}$ to the preparation of the $N$-substituted glutarimide $(+)-(R)-\mathbf{1 5 3}$ (Scheme 23). ${ }^{55}$ Along these investigations, the tert-butyldiphenylsilyl ether derived from $(+)-(R)$ 153 was reduced to the corresponding acylaminal $\left(1^{\prime} R\right)-154$, as precursor of acyliminium 156 that was then submitted to a vinilogous Mannich reaction. In these studies, we found that it was necessary to acetylate the hydroxyl group before generating the corresponding $\mathrm{N}$-acyliminium ion, in order to circumvent the competitive elimination reaction leading to the enamide 157.

It was envisaged that the $N$-acyliminium ion $\mathbf{1 5 6}$ could act as a template for the construction of the other azabicyclic system, including quinolizidine units, as those present in the azatricyclic skeleton that characterizes the azaphenalene alkaloids.

It is worth to remark that, in the AAA, the enantioselectivity is dictated by the sense of chirality of the palladium ligand, which is equally available in any antipodal form. Hence, both enantiomers of the acyliminium intermediate $\mathbf{1 5 6}$ (and of the products evolved from it) can be likewise prepared.

\footnotetext{
${ }^{54}$ a) Trost, B. M.; Bunt, R. C; Lemoine, R. C.; Calkins, T. L. J. Am. Chem. Soc. 2000, 122, 5968-5976. b) Trost, B. M.; Horne, D. B.; Woltering, M. J. Chem. Eur. J. 2006, 12, 6607-6620.

${ }^{55}$ González-Gálvez, D.; García-García, E.; Alibés, R.; Bayón, P.; de March, P.; Figueredo M.; Font, J. J. Org. Chem. 2009, 74, 6199-6211.
} 

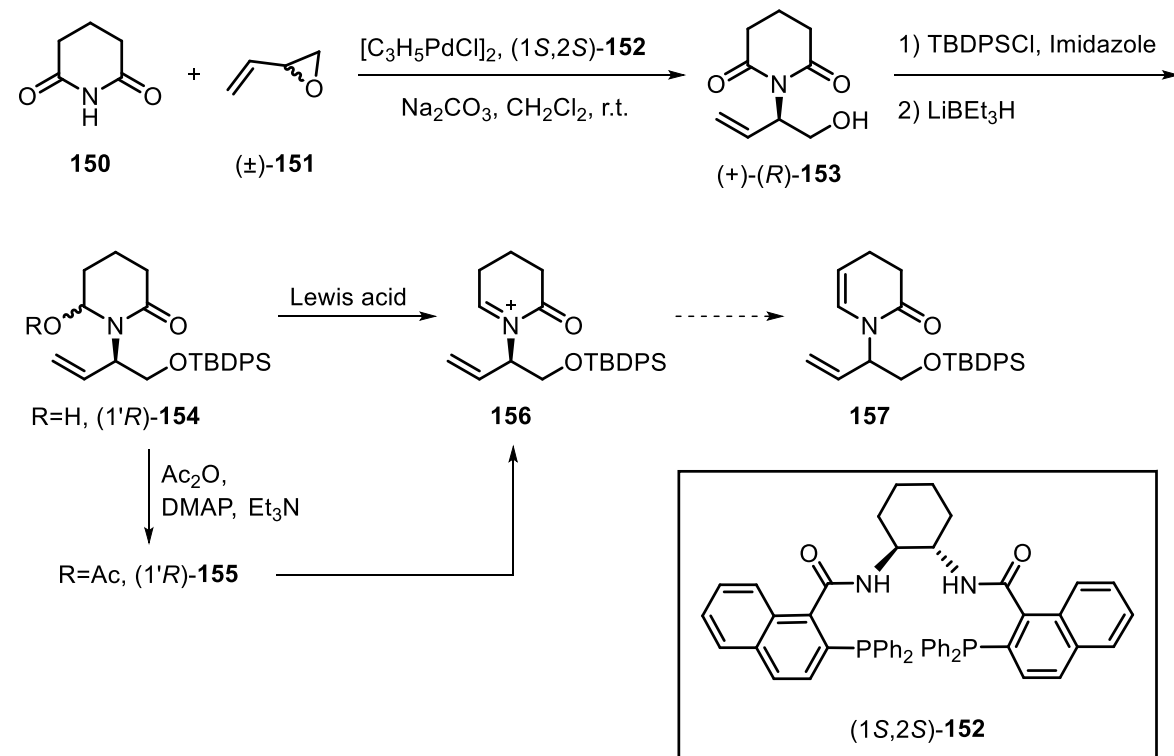

Scheme 23. AAA of glutarimide and preparation of acylaminals $\left(1^{\prime} R\right)-154$ and $\left(1^{\prime} R\right)-155.55$ 


\section{Objectives and synthetic plan}



The initial purpose of this thesis was to design and develop a stereodivergent synthesis of alkaloids with perhydro-9b-azaphenalene structure (Figure 11).

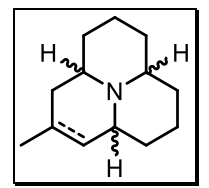

Figure 11. Target compounds.

The synthetic plan is outlined in Scheme 24. The strategy consisted on generating the $\mathrm{N}$ acyliminium ion 156, with a specific configuration of its stereogenic center, in the presence of an allylating reagent. This operation should furnish a diene containing a second stereogenic center. Then, a ring-closing metathesis (RCM) reaction would provide the second ring. Next, the masked alcohol would be used to install an alkene and a second reduction-allylation process to introduce the other alkene moiety and the third stereogenic center. Finally, a second RCM should deliver the tricyclic skeleton. Depending on the stereoselectivity observed and the targeted alkaloid, the methyl group could be introduced in the first nucleophilic allylation or in the second one. Moreover, a hydrogenation could be performed after the first RCM or, alternatively, the two carbon-carbon double bonds could be simultaneously or sequentially hydrogenated at the end of the sequence.<smiles>O=C1CCCC(=O)N1</smiles>

150

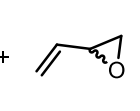

(士)-151

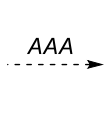

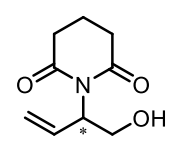

153

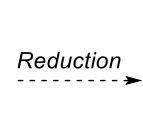

156

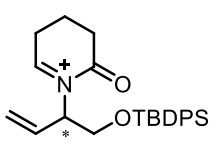

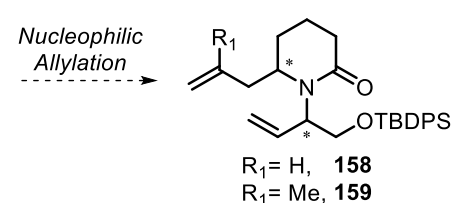

$R_{1}=M e, 159$
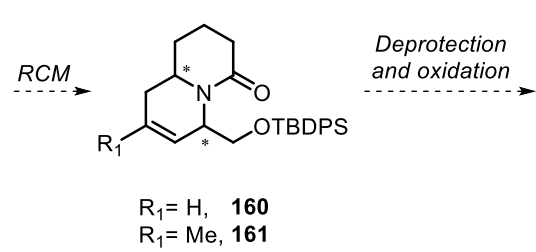

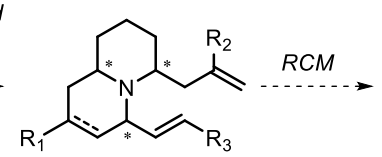

$\mathrm{R}_{1}=\mathrm{H}, \mathrm{R}_{2}=\mathrm{Me}, 164$ $R_{1}=M e, R_{2}=H, 165$

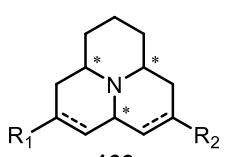

166

$\mathrm{R}_{1}=\mathrm{H}, \mathrm{R}_{2}=\mathrm{Me}$ $\mathrm{R}_{1}=\mathrm{Me}, \mathrm{R}_{2}=\mathrm{H}$

Scheme 24. Synthetic plan designed for alkaloids with perhydro-9b-azaphenalene structure. 

III. Results and discussion. Chapter 1: Synthesis of (-)-9a-epi-hippocasine 



\section{Introduction}

As mentioned in the previous section, the strategy designed to obtain the azaphenalene alkaloids envisages some alternative pathways. Hence, the methyl group could be introduced either in the first or in the second nucleophilic allylation step and an early hydrogenation step could be done after the first RCM or both originated alkenes may be hydrogenated at the end of the synthesis.

In this section, we are going to discuss the synthesis developed to afford the alkaloid $\mathbf{1 6 6}$ starting from glutarimide and butadiene monoepoxide. The methyl group will be introduced in the first nucleophilic allylation step and a chemoselective hydrogenation will be done as the last step of the sequence (Scheme 25).

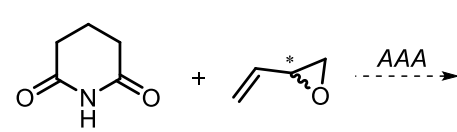

150<smiles>C=C[C@H](CO)N1C(=O)CCCC1=O</smiles>

153<smiles>C=C[C@H](CO[PbH2])CN1C(=O)CCCC1=O</smiles>

167
Reduction<smiles>C=C[C@H](CO[18OH])N1C(=O)CCCC1O</smiles>

154
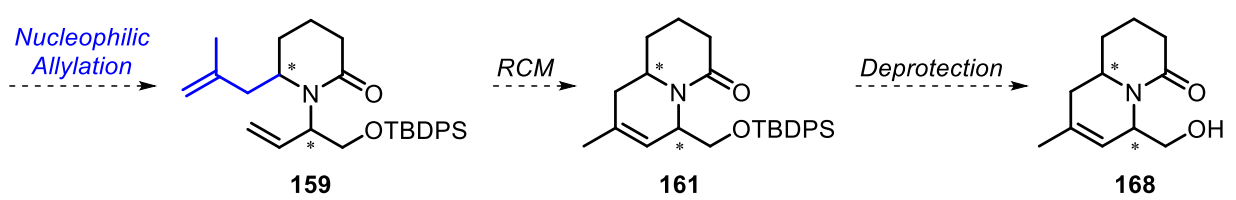

Oxidation and alkenylation

159

168<smiles>C/C=C/C1C=C(C)CC2CCCC(=O)N12</smiles>

169<smiles>[R2]C(C)=C(C)C</smiles>

170<smiles>CC1=CC2C=CCC3CCCC(C1)N23</smiles>

171

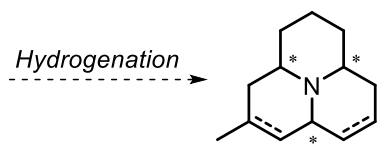

166

Scheme 25. Synthetic plan for the synthesis of $\mathbf{1 6 6 .}$

This sequence has as key steps the initial asymmetric allylic alkylation (AAA) and the two nucleophilic allylations, where the three stereogenic centers of the alkaloid will be generated, together with the two ring-closing metathesis reactions, which would allow to construct two of the three six-membered rings present in the target compounds. 


\section{Preparation of $\mathbf{1 6 9}$}

\subsection{Asymmetric Allylic Alkylation (AAA). Synthesis of compound 167}

As mentioned in the Introduction, the palladium-catalyzed asymmetric $\mathrm{N}$-alkylation of glutarimide has been previously studied and optimized in our research group ${ }^{55}$ by extension of the AAA methodology developed by Trost and collaborators for phtalimide. ${ }^{54}$ According to the mechanism described by these authors, this allylation proceeds through a Pd displacement of an allylic leaving group, followed by the allylic complexation of the metal and, finally, its nucleophilic substitution by the imide. ${ }^{54}$ Figure 12 shows the nature of the reactive complex when the allylating reagent is butadiene monoepoxide. In this process, the ligand is essential to control both the regio- and stereoselectivity by favoring one of the competitive reaction paths. Furthermore, reequilibration of the diastereomeric reactive palladium complexes $\mathbf{I}$ and II is essential to accomplish a good control. ${ }^{54}$

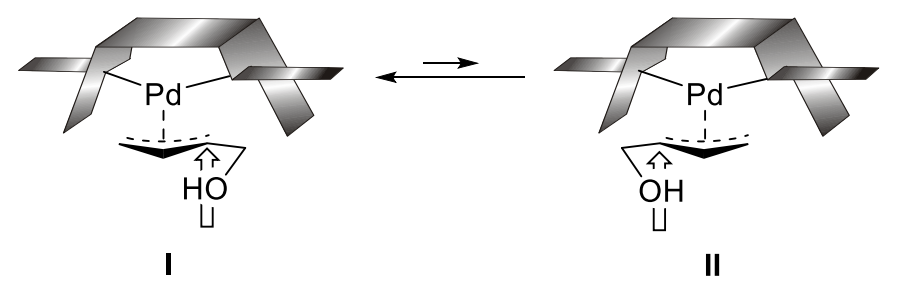

Figure 12. Representation of postulated complexes formed in the AAA.

In the present work, we used the ligand $(1 R, 2 R)-152$, which was synthesized through a reaction between 2-diphenylphosphino-1-naphtoic acid, 172, and $(1 R, 2 R)$-cyclohexane-1,2diamine, $\mathbf{1 7 3}$ (Scheme 26). ${ }^{54}$ In the process of purification by column chromatography we used neutral alumina instead of silica gel as described, due to the instability of the ligand in the acidic media. Thereby, the yield was increased from $51 \%$ to $74 \%$.

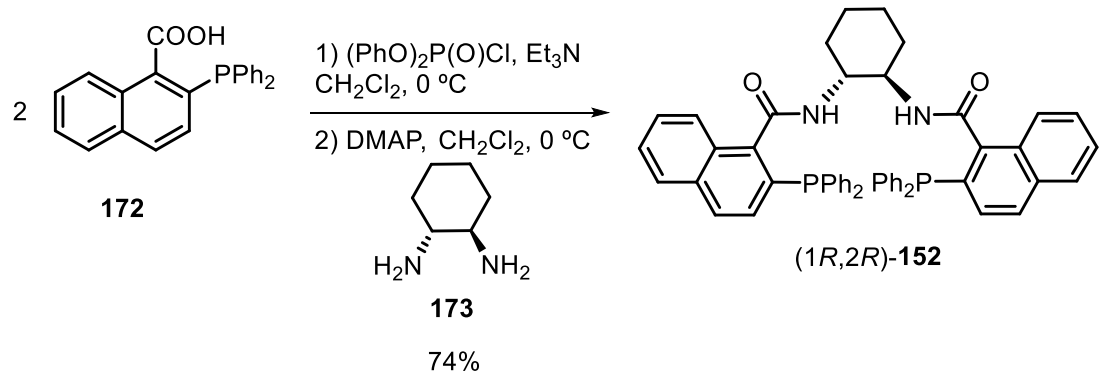

Scheme 26. Synthesis of ligand $(1 R, 2 R)-152$. 
Once Trost ligand $(1 R, 2 R)-\mathbf{1 5 2}$ was obtained, the stereocontrolled AAA between glutarimide and butadiene monoepoxide was performed following the optimized conditions developed in our laboratories. The imide 153 was obtained in $99 \%$ yield by using $0.8 \mathrm{~mol} \%$ of Pd (II), $1.2 \mathrm{~mol} \%$ of $(1 R, 2 R)-152$ and 5 mol\% of $\mathrm{Na}_{2} \mathrm{CO}_{3}$ (Scheme 27). ${ }^{55}$

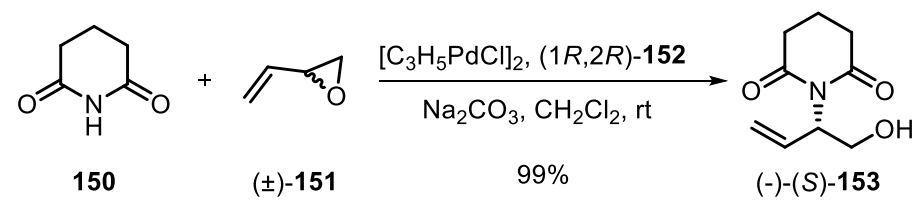

Scheme 27. Preparation of imide (-)-(S)-153..$^{55}$

The enantiomeric excess of the alcohol (-)-153 was 95\%, which was considered good enough to continue with the synthesis. It was determined using CHPLC (Figure 13) by comparing the chromatograms of (-)-153 and that of its racemic mixture, which was obtained through the same allylation reaction, using the racemic ligand ( \pm )-152.

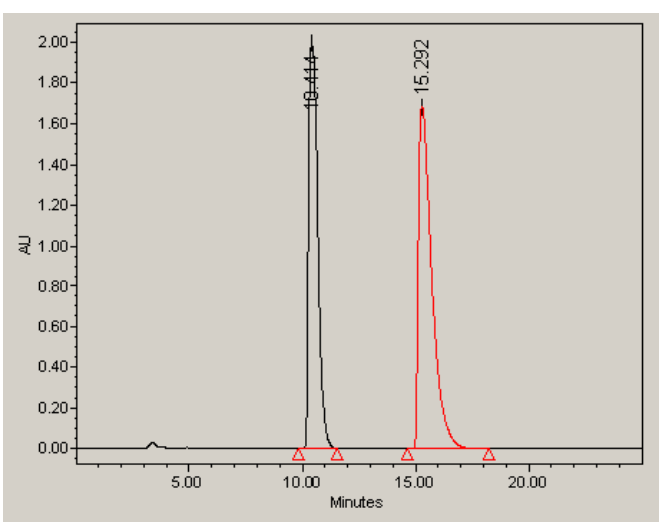

( \pm -153

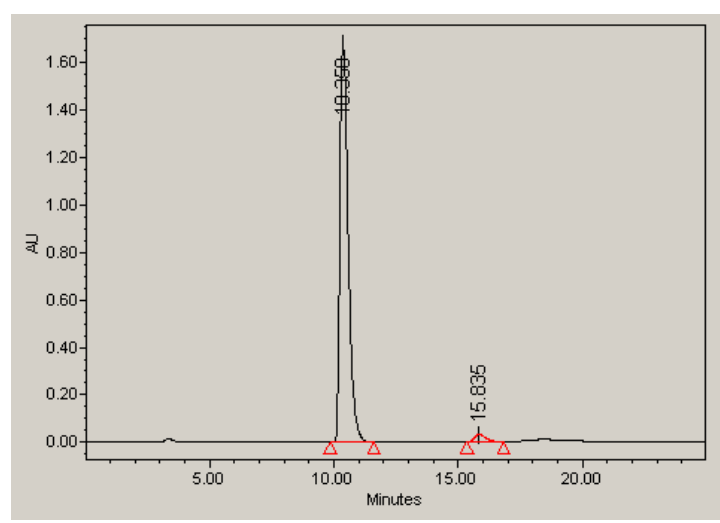

$(-)-153$

Figure 13. CHPLC chromatograms of ( \pm )-153 and (-)-153.

Then, for synthetic aims, we decided to protect the alcohol as a silyl ether. For that, the alcohol (S)-153 was treated with an excess of tert-butyldiphenylsilyl chloride in the presence of imidazole using $\mathrm{CH}_{2} \mathrm{Cl}_{2}$ as solvent. After chromatographic purification with silica gel, the protected imide (S)-167 was obtained in 91\% yield as a white solid (Scheme 28 ).

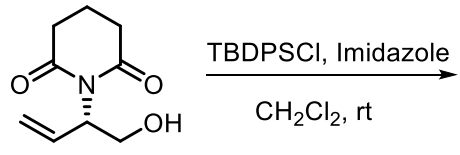

$(S)-153$

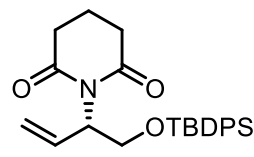

(S)-167

Scheme 28. Synthesis of silyl derivative (S)-167. 


\subsection{Reduction and first nucleophilic allylation. Synthesis of $\mathbf{1 5 9}$}

In the literature are described some examples of acylaminal allylations using allyltrimethylsilane as nucleophile. ${ }^{56}$ In every case, an acyliminium ion is generated, which acts as an electrophile in the following allylation. In our case, the chemoselective reduction of imine (S)-167 was performed using $\mathrm{LiBEt}_{3} \mathrm{H}$ in THF at $-78^{\circ} \mathrm{C}$ for 45 minutes (Scheme 29). The expected acylaminal (1'S)-154 was obtained in 85\% yield after a silica gel column chromatography.<smiles>C=C[C@H](CO[Pb])C(=O)N1C(=O)CCCC1=O</smiles>

$(S)-167$

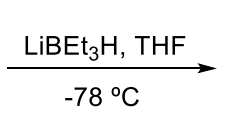

$85 \%$<smiles>C=C[C@H](CO[PbH])[C@H]1CCCCC1=O</smiles>

(1'S)-154

$(1: 12)$

Scheme 29. Synthesis of acylaminal (1'S)-154.

The aminal (1'S)-154 was isolated as a mixture of diastereomers which could not be separated, with a high predominance of one of them, as shown in its ${ }^{1} \mathrm{H}$ NMR spectrum (Figure 14). The ratio between them was $1: 12$, deduced by the relative area of the signals at 6.17 and $5.79 \mathrm{ppm}$, which correspond to the internal alkene protons $\mathrm{H}-\mathrm{2}^{\prime}$.

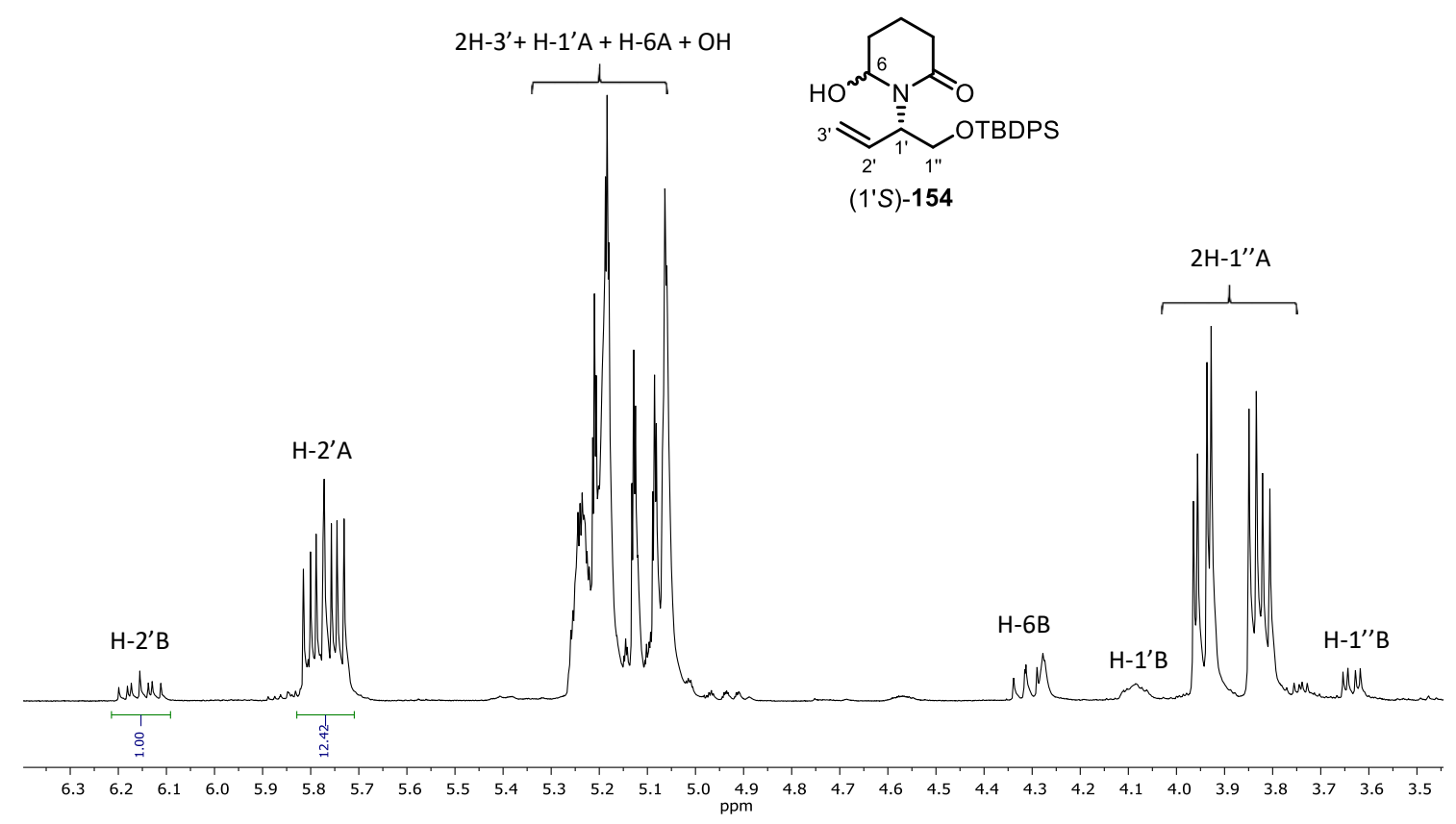

Figure 14. Fragment of the ${ }^{1} \mathrm{H}$ NMR spectrum ( $400 \mathrm{MHz}, \mathrm{CDCl}_{3}$ ) of compound (1'S)-154. Mixture of diastereomers: $A=$ major; $B=$ minor.

\footnotetext{
56 a) Klitzke, C. F.; Pilli, R.A. Tetrahedron Lett. 2001, 42, 5605-5608. b) Girandinà, A.; Mecozzi, T.; Petrini, M. J. Org. Chem. 2000, 65, 8577-8282. c) Pin, F.; Comesse, S.; Garrigues, B.; Marchalín, S.; Daïch, A. J. Org. Chem. 2007, 72, 1181-1191.
} 
Provided that the high diastereoselectivity observed in the reduction is kinetically controlled, one of the two faces of the imine must be more accessible to the approach of the reducing agent. If this is the case, this system could perform a good control in the stereoselectivity of the next steps. The relative configuration of the new stereogenic center was not studied because in principle it is synthetically inconsequent. In the allylation step, an iminium cation with $\mathrm{sp}^{2}$ hybridization would be formed and hence, this stereogenic center would be lost.

As specified in the Introduction, for the formation of the acyliminium ion 156, a previous acetylation step was needed to avoid the formation of enamide 157 . Thus, the acylaminal (1'S)154 was treated with acetic anhydride, DMAP and $\mathrm{Et}_{3} \mathrm{~N}$ in $\mathrm{CH}_{2} \mathrm{Cl}_{2}$ yielding the acetylated intermediate 155, which was used in the next step without further purification (Scheme 30).

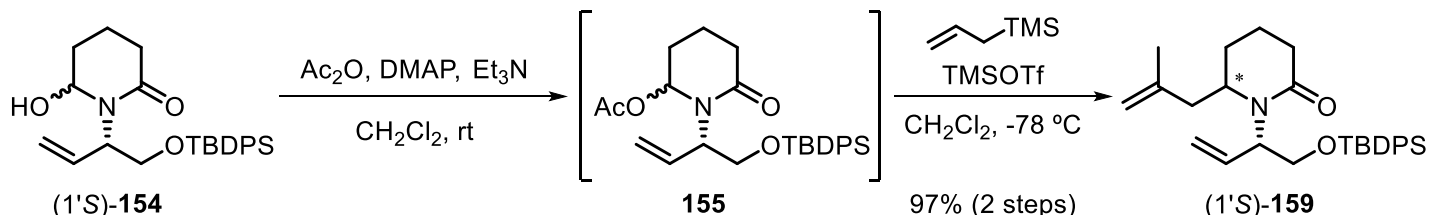

$(1 ' S)-154$
155
$97 \%$ (2 steps)
(1'S)-159

$(1: 10)$

Scheme 30. First nucleophilic allylation. Synthesis of lactam (1'S)-159.

Although intermediate $\mathbf{1 5 5}$ could not be fully characterized due to its instability, a ${ }^{1} \mathrm{H}$ NMR spectrum was registered (Figure 15). The characteristic signals of this lactam are the multiplets at 6.12 and $4.53 \mathrm{ppm}$ corresponding to the $\alpha$-nitrogen protons $\mathrm{H}-6$ and $\mathrm{H}-1^{\prime}$, respectively, the signals of alkene protons at 5.99 and $5.17 \mathrm{ppm}$, two double of doublets at 4.04 and $3.61 \mathrm{ppm}$ of protons $\mathrm{H}-1^{\prime \prime}$ and a singlet at 1.87 ppm corresponding to the methyl group of the acetate.

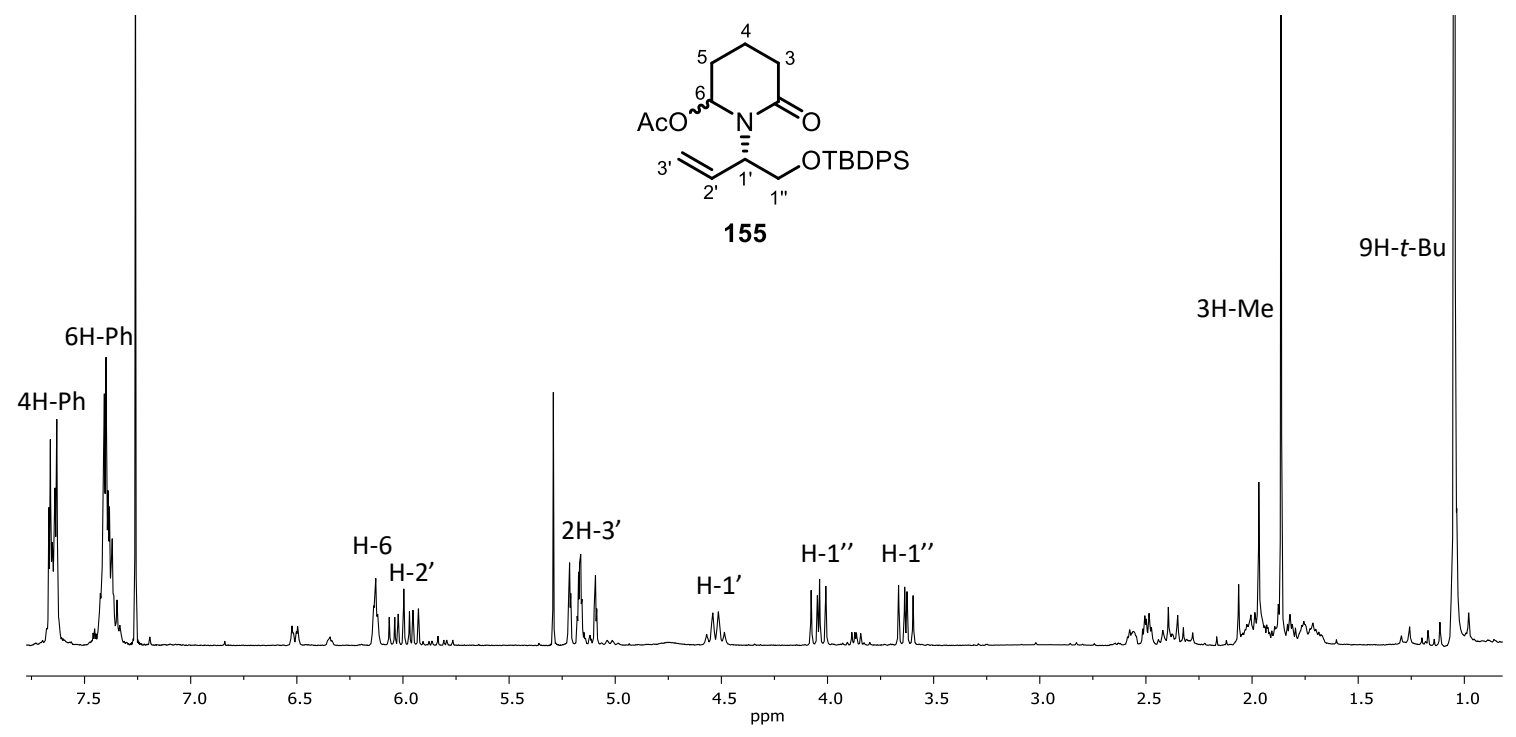

Figure 15. ${ }^{1} \mathrm{H}$ NMR spectrum $\left(250 \mathrm{MHz}, \mathrm{CDCl}_{3}\right)$ of acetylated intermediate 155. 
Immediately after its preparation, $\mathbf{1 5 5}$ was treated with methylallyltrimethylsilane and TMSOTf as Lewis acid in $\mathrm{CH}_{2} \mathrm{Cl}_{2}$, at $-78{ }^{\circ} \mathrm{C}$ for $4 \mathrm{~h}$, furnishing lactam (1'S)-159 in $97 \%$ yield after purification by column chromatography on silica gel.

This diene was isolated as a 1:10 mixture of diastereomers. This ratio was known from the relative area of the signals at 4.04 and 3.85 ppm in its ${ }^{1} \mathrm{H}$ NMR spectrum (Figure 16).

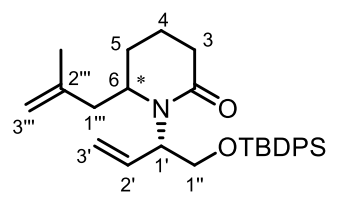

$(1 ' S)-159$

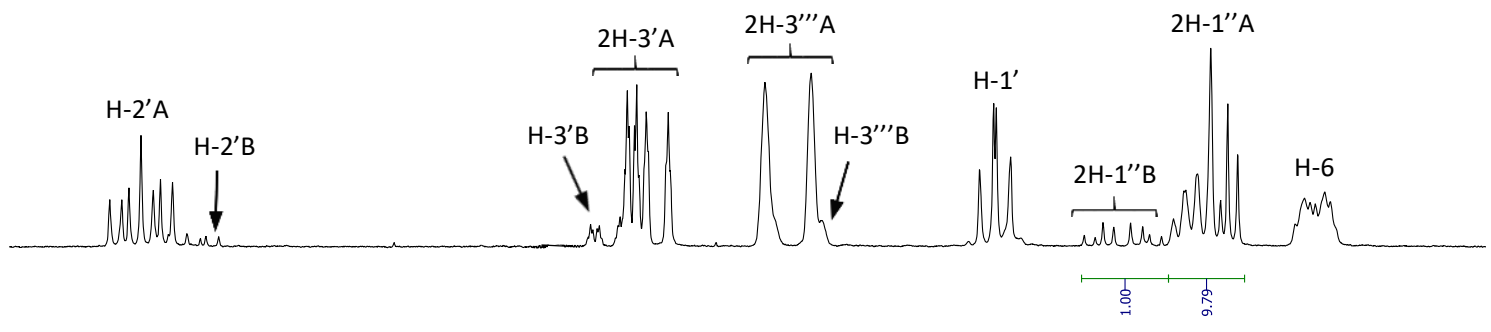

$\begin{array}{llllllllllllllllllllllllllllllllllllllllll}6.4 & 6.3 & 6.2 & 6.1 & 6.0 & 5.9 & 5.8 & 5.7 & 5.6 & 5.5 & 5.4 & 5.3 & 5.2 & 5.1 & 5.0 & 4.9 & 4.8 & 4.7 & 4.6 & 4.5 & 4.4 & 4.3 & 4.2 & 4.1 & 4.0 & 3.9 & 3.8 & 3.7 & 3.6 & 3.5 & 3.4 & 3.3\end{array}$

Figure 16. Fragment of the ${ }^{1} \mathrm{H}$ NMR spectrum (250 MHz, $\mathrm{CDCl}_{3}$ ) of diene (1'S)-159. Mixture of diastereomers: $A=$ major; $B=$ minor.

\subsection{First Ring-closing metathesis. Synthesis of bicycle 168}

The ring-closing metathesis of (1'S)-159 was performed heating the above mixture of diastereomers in $\mathrm{CH}_{2} \mathrm{Cl}_{2}$ at reflux, in the presence of 3 mol\% second generation Grubbs catalyst, added portionwise (Scheme 31). After $48 \mathrm{~h}$, the total consumption of the starting material was observed. Then, the bicycle (6S)-161 was obtained in 91\% yield after a purification by column chromatography on silica gel.<smiles>C=C[C@H](CO[PbH])CN1C(=O)CCCC1CC(=C)C</smiles>

(1'S)-159

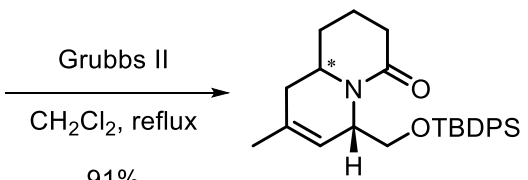

(6S)-161

Scheme 31. Ring-closing metathesis. Preparation of bicycle (6S)-161.

The bicycle (6S)-161 was isolated apparently as a single diastereomer since NMR analysis did not show evidences of a minor component (Figure 17). 


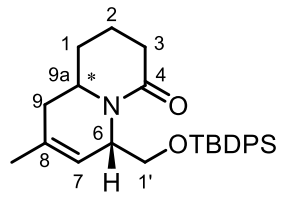

$(6 S)-161$

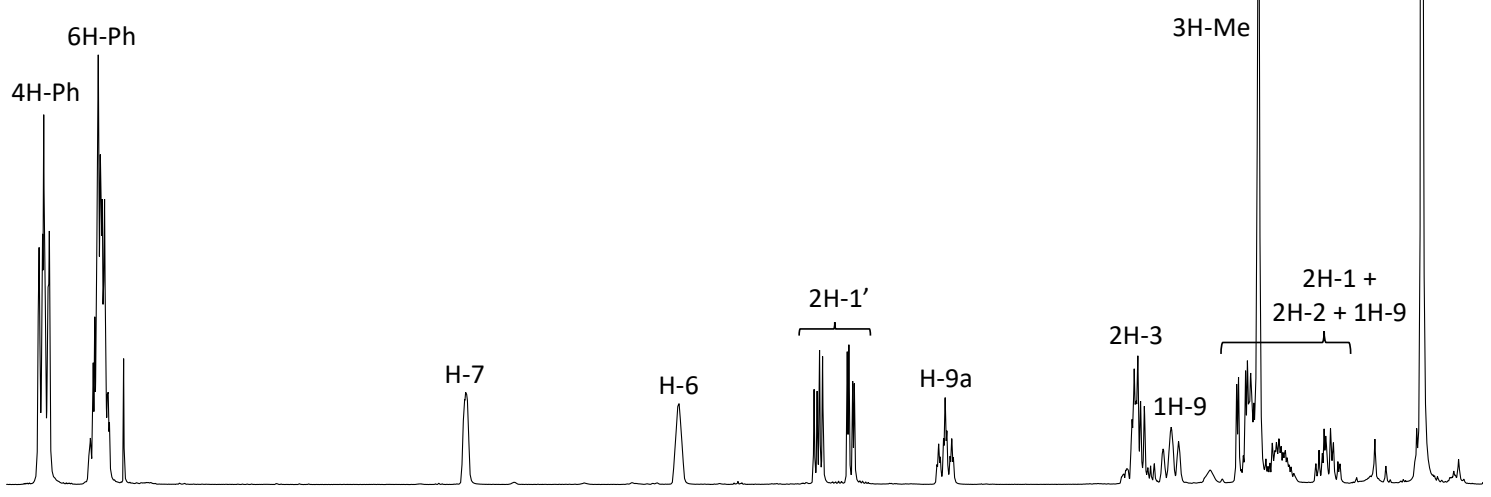

$\begin{array}{lllllllllllllllllllllllllllllllllllllllllllllllllll}7.8 & 7.6 & 7.4 & 7.2 & 7.0 & 6.8 & 6.6 & 6.4 & 6.2 & 6.0 & 5.8 & 5.6 & 5.4 & 5.2 & 5.0 & 4.8 & 4.6 & 4.4 & 4.2 & 4.0 & 3.8 & 3.6 & 3.4 & 3.2 & 3.0 & 2.8 & 2.6 & 2.4 & 2.2 & 2.0 & 1.8 & 1.6 & 1.4 & 1.2 & 1.0 & 0.8\end{array}$

Figure 17. ${ }^{1} \mathrm{H} \mathrm{NMR}$ spectrum $\left(360 \mathrm{MHz}, \mathrm{CDCl}_{3}\right)$ of bicyclic compound $(6 \mathrm{~S})-161$.

For synthetic purposes, the alcohol of $\mathbf{1 6 1}$ was deprotected by treatment with $\mathrm{Et}_{3} \mathrm{~N} \cdot 3 \mathrm{HF}$ in THF at reflux during $14 \mathrm{~h}$. The alcohol 168 was obtained as a single isomer in $94 \%$ yield after purification by column chromatography on silica gel (Scheme 32).

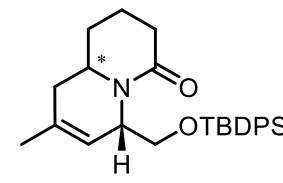

$(6 S)-161$

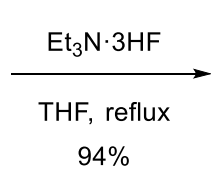

$94 \%$

Scheme 32. Deprotection of the alcohol. Synthesis of $(6 S, 9 a S)-168$.

This alcohol could be crystallized using a mixture of hexane and ethyl acetate. Its X-ray diffraction analysis (Figure 18) revealed that the relative configuration between the protons attached to C-6 and C-9a was cis. Since the configuration of C- 6 was known to be $S$, the absolute configuration of 168 is $(65,9 a S)$.

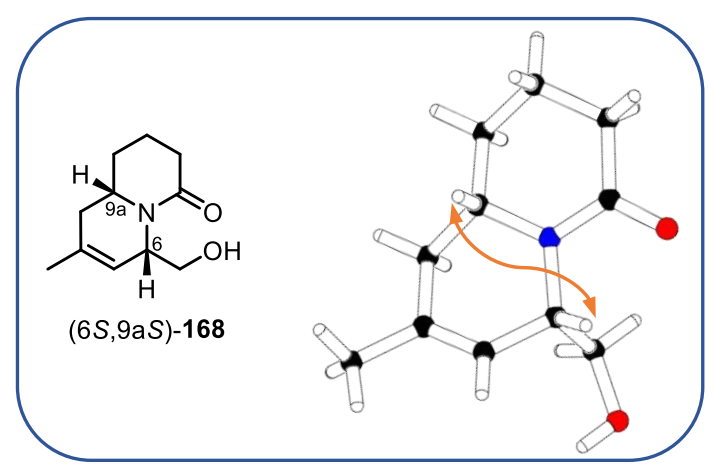

Figure 18. Representation of the structure determined by X-Ray diffraction analysis of alcohol $(6 S, 9 a S)-168$. 


\subsection{Oxidation of alcohol 168 and Wittig alkenylation. Synthesis of intermediate 169}

As a means to perform the next alkenylation, the alcohol obtained in the previous step had to be oxidized to aldehyde. One of the most frequently used methodologies employs the Dess-Martin reagent. ${ }^{57}$ Hence, the alcohol 168 was treated with 1.2 equivalents of Dess-Martin periodinane (DMPI) in dry $\mathrm{CH}_{2} \mathrm{Cl}_{2}$ and the reaction evolution was followed by TLC (Scheme 33). After $3 \mathrm{~h}$, the reaction had finished and aldehyde $\mathbf{1 7 4}$ was obtained as yellow oil. Due to its instability, it was used in the next step without further purification. However, a ${ }^{1} \mathrm{H}$ NMR spectrum could be registered (Figure 19). As shown, the characteristic signal of the aldehyde was present at $8.92 \mathrm{ppm}$ as a doublet. In addition, the signals corresponding to the $\alpha$-nitrogen protons $\mathrm{H}-6$ and $\mathrm{H}-9$ a were observed at 4.47 and $3.40 \mathrm{ppm}$, respectively, together with the signal at $5.18 \mathrm{ppm}$, which was assigned to the alkene proton $\mathrm{H}-7$.<smiles></smiles>

168

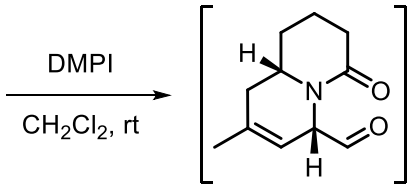

174

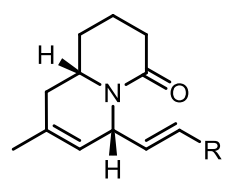

$169,175,176$

Scheme 33. Dess-Martin oxidation and Wittig alkenylation.

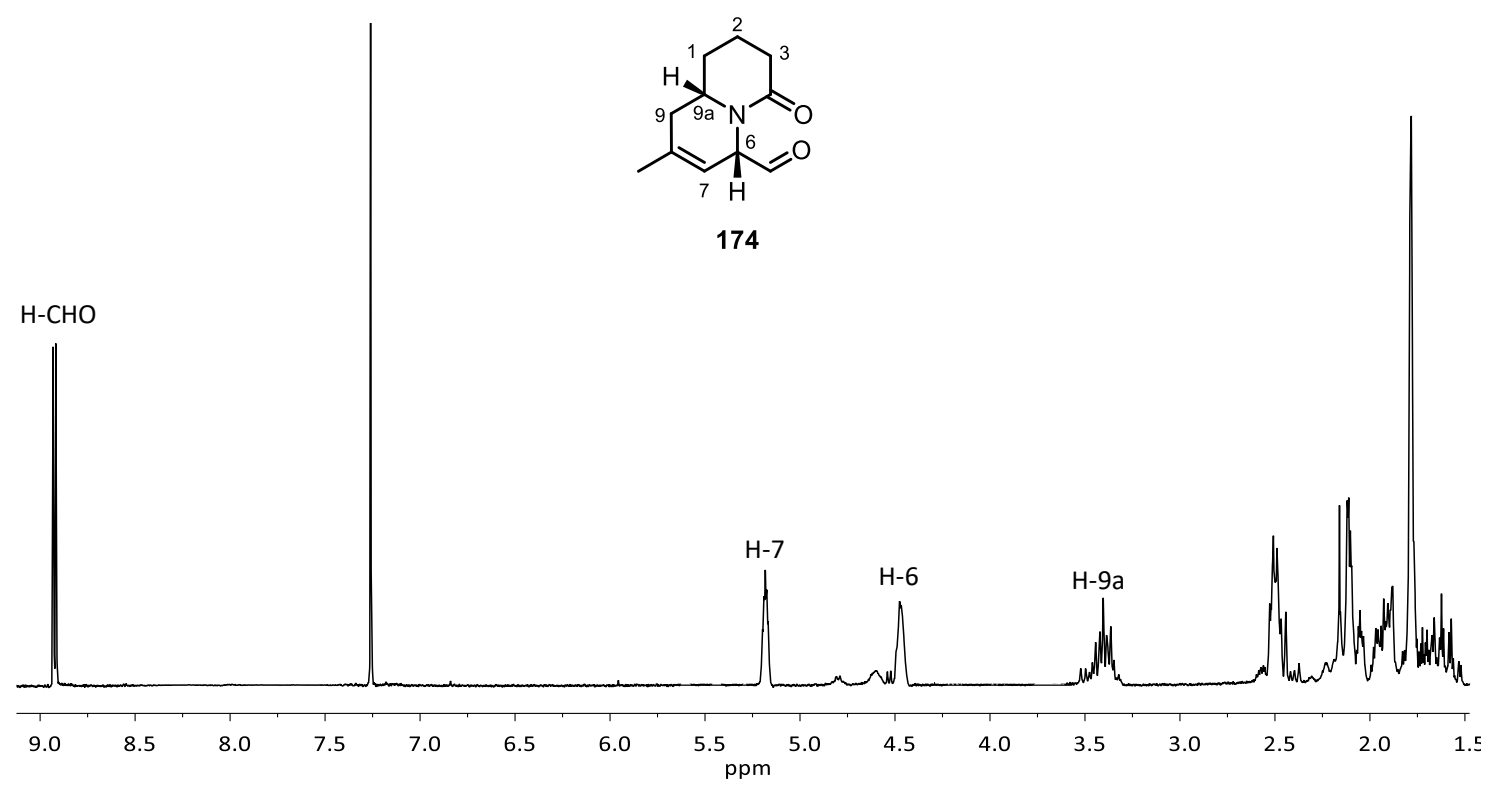

Figure 19. Fragment of the ${ }^{1} \mathrm{H}$ NMR spectrum $\left(250 \mathrm{MHz}, \mathrm{CDCl}_{3}\right)$ of aldehyde 174.

\footnotetext{
${ }^{57}$ Dess, D. B.; Martin, J. C. J. Org. Chem. 1983, 48, 4155-4156.
} 
The next step in the sequence required the alkenylation of the previous aldehyde. From the synthetic point of view, the substituent $R$ of the new alkene moiety is not relevant because in the planed second ring-closing metathesis reaction only one carbon atom of the generated carbon-carbon double bond would remain. Considering that, three different phosphonium salts were tested at the same time, using identical reaction conditions (Table 1).

Table 1. Attempts and results of alkenylation of aldehyde $174 .^{\mathrm{a}}$

\begin{tabular}{ccccc}
\hline Entry & Phosphonium salt & $\mathbf{R}$ & Product & Yield (\%) \\
\hline 1 & $\mathrm{Ph}_{3} \mathrm{PCH}_{3} \mathrm{Br}$ & $\mathrm{H}$ & $\mathbf{1 7 5}$ & 25 \\
2 & $\mathrm{Ph}_{3} \mathrm{PCH}_{2} \mathrm{PhCl}$ & $\mathrm{Ph}$ & $\mathbf{1 7 6}$ & - \\
3 & $\mathrm{Ph}_{3} \mathrm{PCH}_{2} \mathrm{CH}_{3} \mathrm{Br}$ & $\mathrm{CH}_{3}$ & $\mathbf{1 6 9}$ & 77 \\
\hline
\end{tabular}

a In all cases, BuLi was used as base and THF as solvent. Reaction mixtures were stirred at room temperature during $14 \mathrm{~h}$.

The alkenylation performed using methyltriphenylphosphonium bromide led to the olefin 175 in only $25 \%$ yield from alcohol 168 after a column chromatography on silica gel, although the conversion was complete (entry 1 ). In this case, no other compounds could be identified in the ${ }^{1} \mathrm{H}$ NMR spectrum of the crude product. Thus, probably either the starting material or the product were decomposed in the reaction media. The formation of alkene $\mathbf{1 7 5}$ could be confirmed by its ${ }^{1} \mathrm{H}$ NMR spectrum (Figure 20a), where the characteristic signal pattern of a terminal alkene appears at 5.71 and $5.02 \mathrm{ppm}$. In addition, we could distinguish the signal of the other alkene proton $\mathrm{H}-7$ at $5.46 \mathrm{ppm}$ and those of the $\alpha$-nitrogen protons $\mathrm{H}-6$ and $\mathrm{H}-9 \mathrm{a}$ at 4.93 and $3.36 \mathrm{ppm}$, respectively.

The next attempt was done using benzyltriphenylphosphonium chloride (entry 2). The total consumption of the aldehyde $\mathbf{1 7 4}$ was observed by TLC and ${ }^{1} \mathrm{H}$ NMR, but no expected alkene was detected in the crude product. Surely, a decomposition of the starting material or the final product took place again.

A third attempt with ethyltriphenylphosphonium bromide led to the desired alkene $\mathbf{1 6 9}$ in $77 \%$ yield for the two steps, with a Z/E ratio $6: 1$ (entry 3 ) after purification by column chromatography on silica gel, as expected, because non-stabilized phosphonium ylides usually give $Z$-alkenes. This $Z / E$ ratio could be determined from the ${ }^{1} \mathrm{H}$ NMR spectrum (Figure 20b), by analyzing the signals between 5.50 and $4.70 \mathrm{ppm}$ corresponding to the alkene protons. The assignment of the signals was done with the help of 2D NMR spectra. From the major isomer we could calculate $J_{1^{\prime}, 2^{\prime} \text { (major) }}=9.5 \mathrm{~Hz}$, which would indicate that is $Z$ isomer. Moreover, $J_{1^{\prime}, 2^{\prime}(\text { minor })}=13$ 
$\mathrm{Hz}$, which confirmed that the double bond of the major isomer presented $Z$ configuration while the minor had $E$ configuration. This fact is not synthetically relevant since in the next RCM step this configuration would be lost.
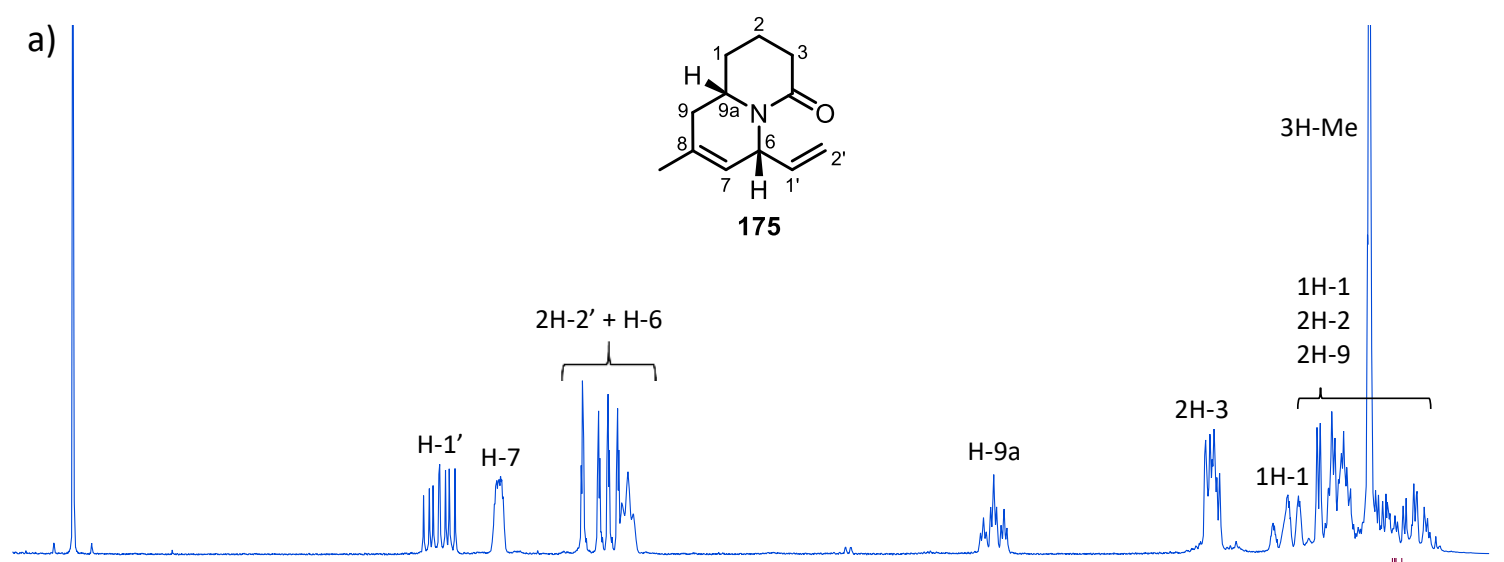

b)
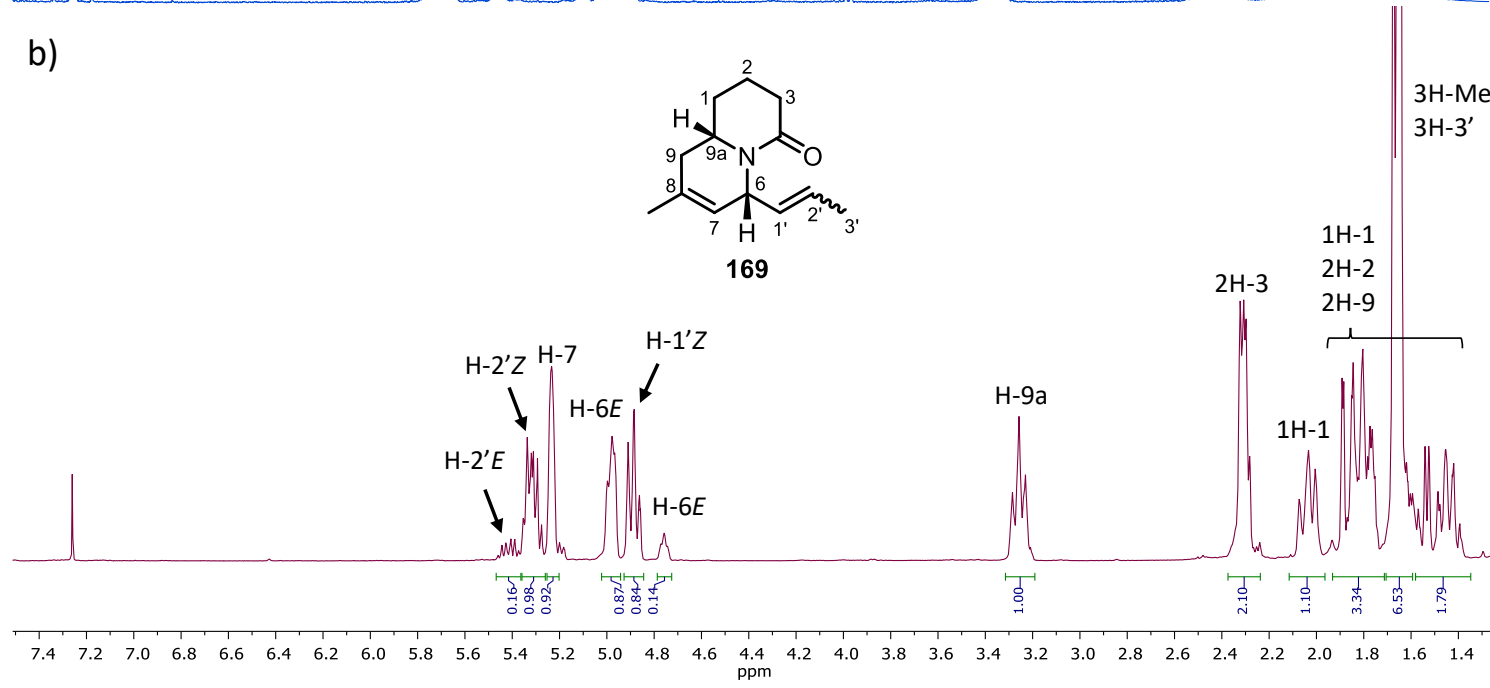

Figure 20. a) ${ }^{1} \mathrm{H}$ RMN spectrum $\left(250 \mathrm{MHz}^{\left.\mathrm{C} C \mathrm{CDl}_{3}\right)}\right.$ of 175 . b) ${ }^{1} \mathrm{H}$ RMN spectrum $\left(400 \mathrm{MHz}, \mathrm{CDCl}_{3}\right)$ of 169.

With these results, the reaction conditions of entry 3 were considered good enough to proceed with the synthesis (Scheme 34).<smiles>CC1=CC2CCCC(=O)N2CCO1</smiles>

$(6 S, 9 a S)-168$

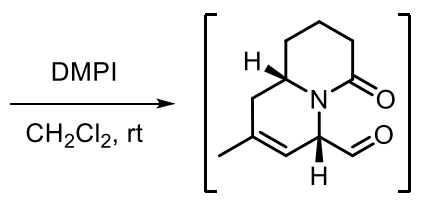

174

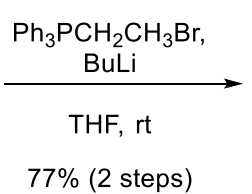

$77 \%$ (2 steps)

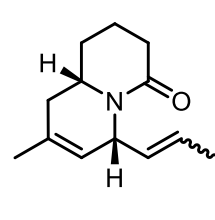

$(6 R, 9 a S)-169$

$(6: 1)$ ZIE

Scheme 34. Synthesis of alkene 169.

It is noticeable that all three reactions were done under the same conditions. Since alkene 169 was obtained in good yield, the decomposition found in entries 1 and 2 surely came from the product and not from the starting material. 


\section{Preparation of tricyclic amine $\mathbf{1 7 1}$}

\subsection{Reduction and second nucleophilic allylation. Synthesis of $\mathbf{1 7 0}$}

In the literature there are some examples for the reduction of lactams, followed by the introduction of an allyl group through a nucleophilic substitution, without the isolation of the intermediate aminal. ${ }^{58}$ For that reason, we first tried to perform the reduction and allylation in one step starting from lactam 169 (Scheme 35).

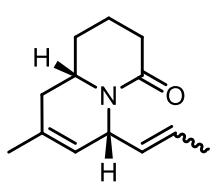

169

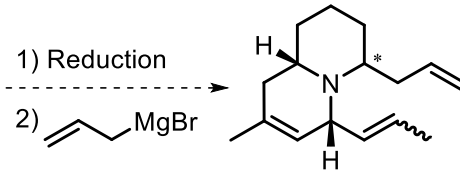

170

Scheme 35. Reduction and allylation of lactam 169.

Considering preliminary studies performed in our research group for the reduction of lactam 175, ${ }^{59}$ we first tried the best conditions found. Hence, the reduction was attempted treating 169 with 2 equivalents of sodium bis(2-methoxyethoxy)aluminum hydride (Red-Al) in THF for $1 \mathrm{~h}$ at $0{ }^{\circ} \mathrm{C}$. After that time, 2 equivalents of allylmagnesium bromide were added and the reaction mixture was stirred for $2 \mathrm{~h}$ at ${ }^{\circ}{ }^{\circ} \mathrm{C}$. Analyses by TLC and ${ }^{1} \mathrm{H} N \mathrm{NMR}$ of the crude reaction product showed evidences of the desired triene $\mathbf{1 7 0}$ accompanied by other products, probably derived from over reduction of the lactam to amine and/or double allylation, all in very low yields. For this reason, we decided to study every reaction separately.

\subsubsection{Study on the reduction of lactam 169}

In order to found the best conditions for the synthesis of aminal 177 (Scheme 36), several experiments were performed (Table 2).

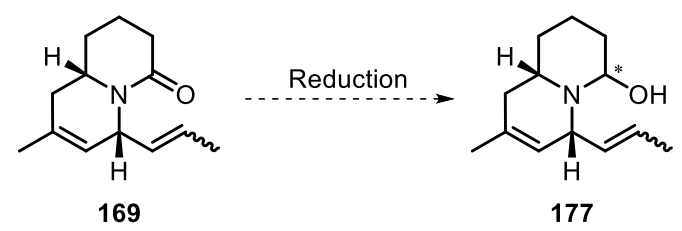

Scheme 36. Reduction to aminal 177.

\footnotetext{
${ }^{58}$ Xiao, K. J.; Wang, Y.; Huang, Y. H.; Wang, X. G.; Huang, P. Q. J. Org. Chem. 2013, 78, 8305-8311.

59 Oliveras-González, C. Màster en Experimentació Química, UAB, 2010.
} 
Table 2. Attempts and results for the reduction of lactam 169.

\begin{tabular}{|c|c|c|c|c|c|c|}
\hline Entry & $\begin{array}{c}\text { Reducing } \\
\text { agent }\end{array}$ & Molar ratio ${ }^{a}$ & Solvent & Temperature & Time & Results \\
\hline 1 & $\mathrm{LiBEt}_{3} \mathrm{H}$ & 1 & THF & $-78^{\circ} \mathrm{C}$ & $1 \mathrm{~h}$ & $\mathrm{sm}$ \\
\hline 2 & Red-Al & 1 & THF & $-55^{\circ} \mathrm{C}$ & $4 \mathrm{~h}$ & 178 \\
\hline 3 & Red-Al & 0.5 & THF & $-55^{\circ} \mathrm{C}$ & $4 \mathrm{~h}$ & $s m+179(1: 1.5)$ \\
\hline 4 & Red-Al & 0.5 & THF & $-55^{\circ} \mathrm{C}$ & $14 \mathrm{~h}$ & decomposed \\
\hline 5 & DIBAL-H & 1.2 & THF & $-78^{\circ} \mathrm{C}$ & $24 \mathrm{~h}$ & $179+178(1: 1)$ \\
\hline 6 & DIBAL-H & 1 & THF & $-78^{\circ} \mathrm{C}$ & $4 \mathrm{~h}$ & $s m+179+178(8: 3: 1)$ \\
\hline 7 & DIBAL-H & 1 & $\mathrm{CH}_{2} \mathrm{Cl}_{2}$ & $-78^{\circ} \mathrm{C}$ & $14 \mathrm{~h}$ & $\mathrm{sm}+178(1: 1)$ \\
\hline 8 & DIBAL-H & 1 & Toluene & $-78^{\circ} \mathrm{C}$ & $14 \mathrm{~h}$ & $\mathrm{sm}+178(1: 2)$ \\
\hline 9 & Red-Al & 1 & THF & $-55^{\circ} \mathrm{C}$ & $3 \mathrm{~h}$ & 179 \\
\hline
\end{tabular}

a Molar ratio between 169 and the reducing agent.

The first reaction conditions tested were the same used for the reduction of the imide $\mathbf{1 6 7}$ (entry 1). After $1 \mathrm{~h}$, no evolution of the reaction was observed, and only the starting material was recovered.

We decided to try other reducing agents stronger than Super-hydride ${ }^{\circledast}$, as Red-Al. In the first attempt using this reducing agent (entry 2), 169 was treated with 1 molar equivalent of it (containing 2 hydrides) and the reaction was followed by TLC. After $4 \mathrm{~h}$ of reaction we observed the total consumption of the starting material, then the reaction mixture was treated with saturated solution of $\mathrm{NaHCO}_{3}$ and after extractions with $\mathrm{CH}_{2} \mathrm{Cl}_{2}$ a crude product was so obtained which was analyzed by ${ }^{1} \mathrm{H}$ NMR (Figure 21). The spectrum was consistent with the total reduction of the lactam 169, yielding the amine 178 as the only product. The isolation of 178 confirmed that in the previous experiment (one-pot reduction-allylation) the yield of the allylation product was too low because the amine was the major product.

Since one molar equivalent ( 2 hydrides) of reducing agent afforded the complete reduction of the lactam, the next experiment was performed using only 0.5 molar equivalents of Red-Al (entry 3). The reaction was difficult to follow by TLC and we decided to stop the reaction after $4 \mathrm{~h}$, which is the same time of the previous experiment and would allow to compare the effect of the equivalents of the reducing agent. After treatment with saturated solution of $\mathrm{NaHCO}_{3}$ and extractions with $\mathrm{CH}_{2} \mathrm{Cl}_{2}$ the crude residue was obtained. Its ${ }^{1} \mathrm{H}$ NMR analysis showed a mixture formed by the starting material 169 and a new compound which was 
identified as enamine 179, in approximately 1:1.5 ratio. The ${ }^{1} \mathrm{H}$ NMR spectrum of enamine 179 is shown in Figure 22, where its characteristic signals could be distinguished. The signals of the alkene protons $\mathrm{H}-3$ and $\mathrm{H}-4$ appear at 5.97 and $4.60 \mathrm{ppm}$, respectively, together with that of the other alkene protons $\mathrm{H}-7, \mathrm{H}-1^{\prime}$ and $\mathrm{H}-2^{\prime}$, which appear between 5.75 and $4.95 \mathrm{ppm}$. Also we could observe the signals corresponding to the $\alpha$-nitrogen protons $\mathrm{H}-6$ and $\mathrm{H}-9$ a at 3.95 and 2.83 ppm, respectively.

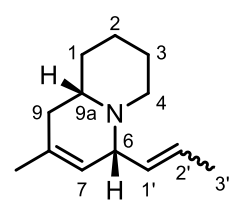

178

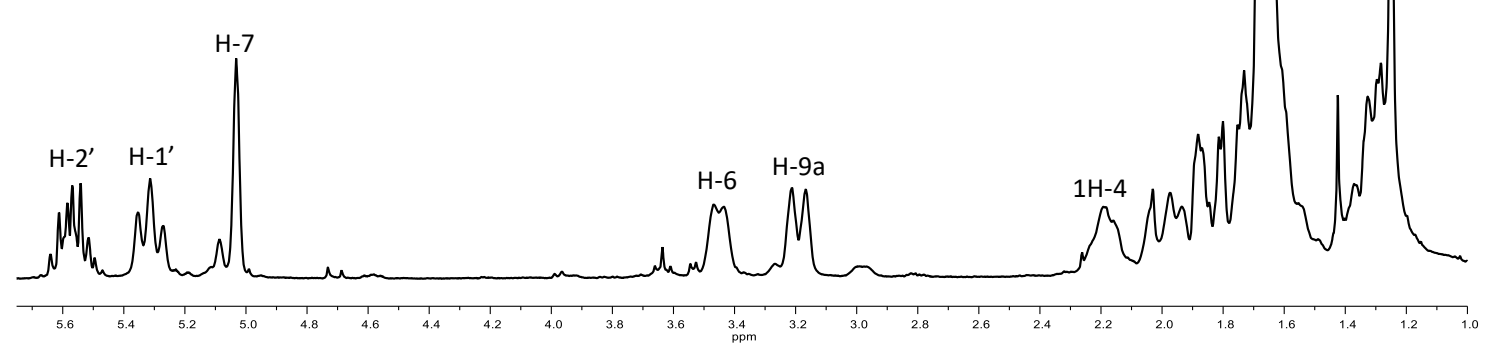

Figure 21. Fragment of the ${ }^{1} \mathrm{H}$ NMR spectrum (250 MHz, CDCl 3 ) of amine 178.

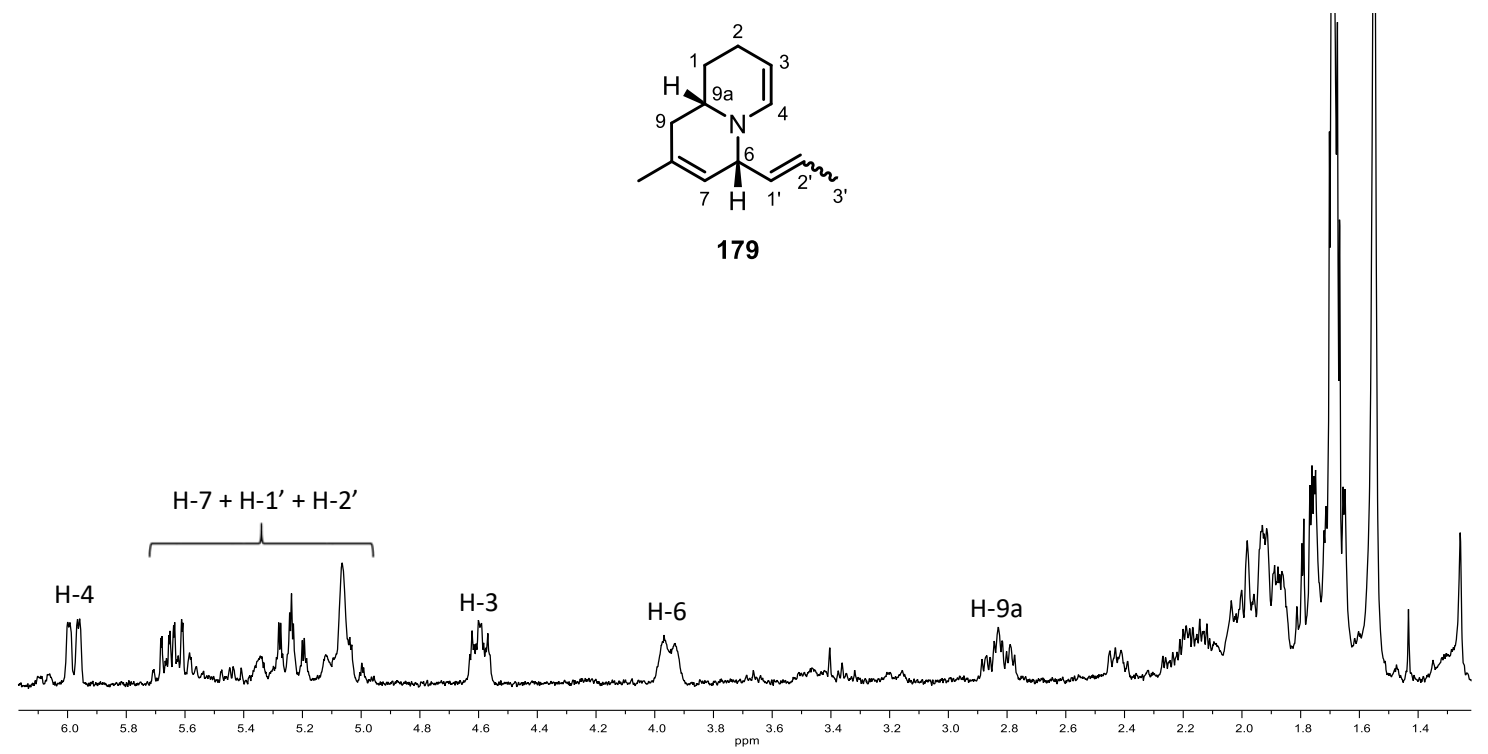

Figure 22. Fragment of the ${ }^{1} \mathrm{H}$ NMR spectrum (250 MHz, CDCl 3 ) of enamine 179.

The formation of the enamine $\mathbf{1 7 9}$ means that the aminal $\mathbf{1 7 7}$ was formed at some point during the reduction of $\mathbf{1 6 9}$ and then it was converted to this enamine, probably in the work-up of the reaction (Scheme 37). In any case, we had to optimize the reduction conditions to isolate 179 as major product. 


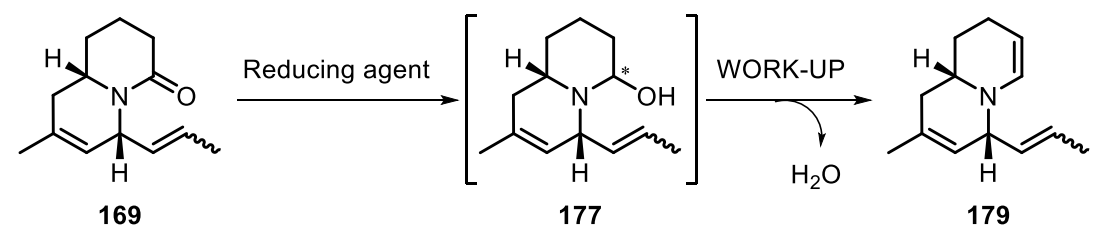

Scheme 37. Formation of enamine 179.

The next attempt was carried out under the same reaction conditions but for $14 \mathrm{~h}$ (entry 4), thinking that more time of reaction would allow to obtain only enamine 179. Unfortunately, we only observed decomposition products.

In view of these results, we decided to change to a reducing agent which could only transfer one hydride, namely DIBAL-H. The first experiment was performed using 1.2 equivalents of it (entry 5 ) and after $4 \mathrm{~h}$ no starting material was observed by TLC. The reaction mixture was then treated with saturated solution of $\mathrm{NaHCO}_{3}$ and the organic phase was extracted with $\mathrm{CH}_{2} \mathrm{Cl}_{2}$ and concentrated under vacuum. According to ${ }^{1} \mathrm{H}$ NMR analysis of the crude product, we observed a mixture of amine 178 and the enamine 179 in an approximately 1:1 ratio. In the next experiment, the amount of DIBAL-H, as well as the reaction time, were reduced in order to minimize the quantity of amine $\mathbf{1 7 8}$ formed (entry 6). However, a mixture of starting material 169, the enamine 179 and the amine 178 was obtained in a ratio of 8:3:1 after the same workup performed in the previous experiment. With these results, we could conclude that DIBAL-H is not selective enough because it has preference to reduce the aminal $\mathbf{1 7 7}$ to the amine $\mathbf{1 7 8}$ than to reduce the lactam 169 to the aminal 177. Nevertheless, we tested the reduction with two more solvents (entries 7 and 8) to see if there was any change, but, in both cases, after the treatment of the reaction mixture with saturated solution of $\mathrm{NaHCO}_{3}$ and extractions with $\mathrm{CH}_{2} \mathrm{Cl}_{2}$, a mixture of $\mathbf{1 6 9}$ and $\mathbf{1 7 8}$ were obtained. Due to these results, this reducing agent was discarded.

Finally, an experiment using again 1 equivalent of Red-Al in THF at $-55^{\circ} \mathrm{C}$ was performed (entry 9). In this experiment, an aliquot of the reaction mixture was withdrawn every $60 \mathrm{~min}$, then submitted to the same work-up as previously and, finally, analyzed by ${ }^{1} \mathrm{H} N M R$. Figure 23 displays some ${ }^{1} \mathrm{H}$ NMR spectra registered over $4 \mathrm{~h}$. In order to follow the reduction, we focused on the signals corresponding to the $\alpha$-nitrogen protons of every possible product, which could be well identified and do not overlap with other signals. In the spectra (b) and (c) we could observe the consumption of the starting material while the signals of the enamine $\mathbf{1 7 9}$ are increasing. 169 almost disappears after $3 \mathrm{~h}$ of reaction, as we could see in spectrum (d). In the next spectrum (e), registered after $4 \mathrm{~h}$ of reaction, we could observe the formation of the amine 178, which indicated that the residual hydrides of Red-Al could led to the total reduction of 
lactam 169. Taking into account all these results we concluded that $3 \mathrm{~h}$ was the best reaction time.

a) before addition of Red-Al (169)
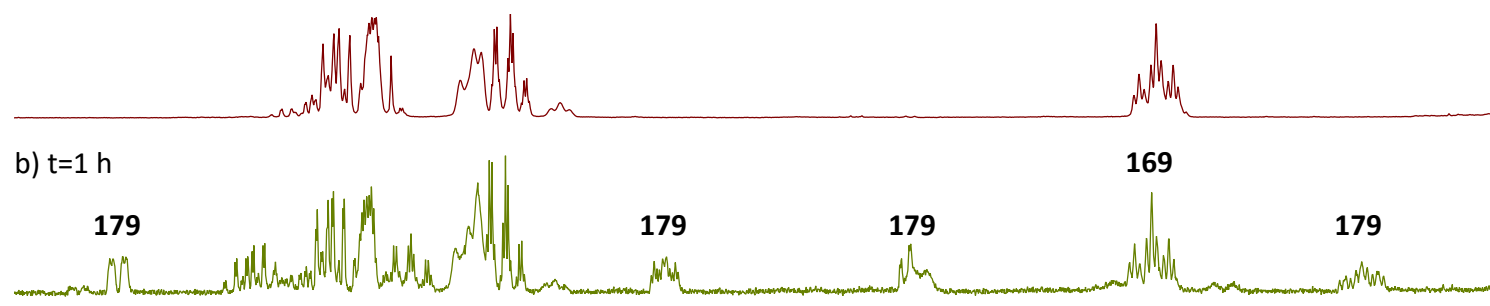

c) $t=2 h$

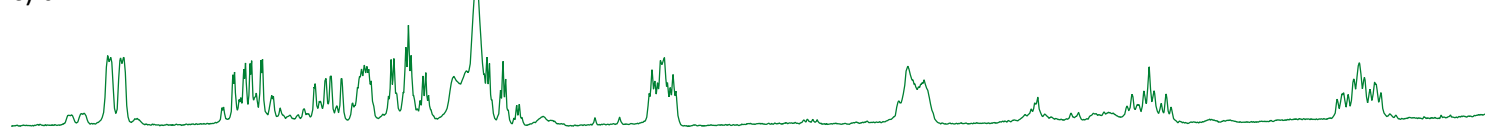

d) $t=3 h$

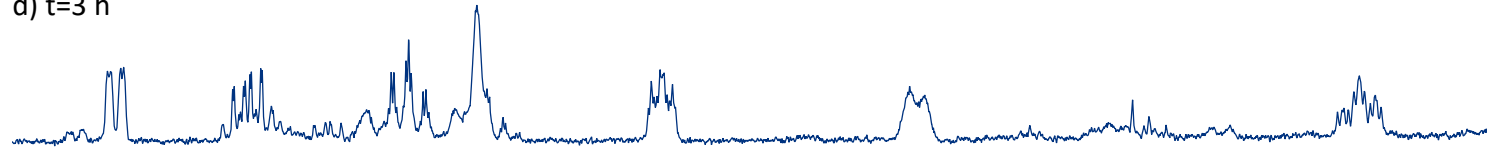

e) $t=4 h$

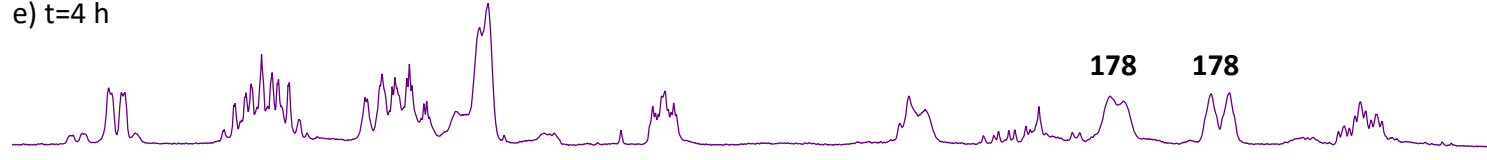

$\begin{array}{llllllllllllllllllllllllllllllllllllllllllllllll}6.2 & 6.1 & 6.0 & 5.9 & 5.8 & 5.7 & 5.6 & 5.5 & 5.4 & 5.3 & 5.2 & 5.1 & 5.0 & 4.9 & 4.8 & 4.7 & 4.6 & 4.5 & 4.4 & 4.3 & 4.2 & 4.1 & 4.0 & 3.9 & 3.8 & 3.7 & 3.6 & 3.5 & 3.4 & 3.3 & 3.2 & 3.1 & 3.0 & 2.9 & 2.8 & 2.7 & 2.6\end{array}$

Figure 23. ${ }^{1} \mathrm{H} \mathrm{NMR}\left(250 \mathrm{MHz}, \mathrm{CDCl}_{3}\right)$ study of the reduction of 169 , using Red-Al as reducing agent, over $4 \mathrm{~h}$.

Consequently, the reaction conditions in entry 9 of Table 2 were stablished to obtain the enamine 179 (Scheme 38), which hopefully was formed in the work-up of the reduction and, thus, aminal 177 existed as major product in the reaction media, probably coordinated with the aluminum atom of Red-Al.

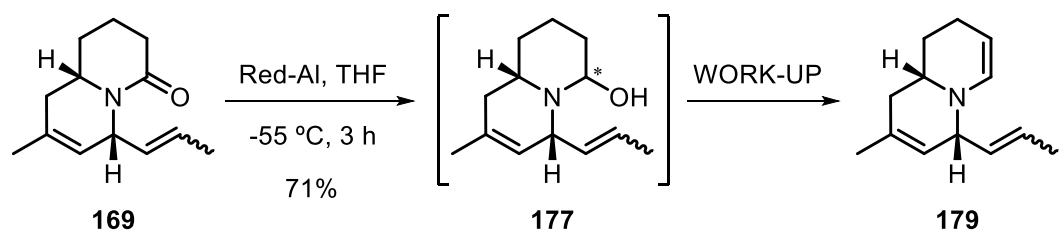

Scheme 38. Optimized conditions for the synthesis of enamine 179.

\subsubsection{Second nucleophilic allylation}

Once the reduction conditions were optimized to obtain 179 as major isolated product, we studied the allylation step by adding the Grignard reagent to the reaction mixture of the reduction of lactam 169 (Table 3). 
Table 3. Attempts and results of the second nucleophilic allylation.

\begin{tabular}{|c|c|c|c|c|}
\hline Entry & Equivalents of $ح \mathrm{MgBr}$ & Temperature & Time & Results \\
\hline 1 & 2 & $-55^{\circ} \mathrm{C}$ & $14 \mathrm{~h}$ & $170+179$ \\
\hline 2 & 4 & $0^{\circ} \mathrm{C}$ & $3 \mathrm{~h}$ & $170+178$ \\
\hline 3 & 10 & $0^{\circ} \mathrm{C} C$ & $3 \mathrm{~h}$ & 170 \\
\hline
\end{tabular}

The first experiment was performed adding 2 equivalents of the selected Grignard reagent at $-55^{\circ} \mathrm{C}$ for $14 \mathrm{~h}$ (entry 1 ). After that time, the formation of the desired product $\mathbf{1 7 0}$ was observed, but it was mixed with enamine $\mathbf{1 7 9}$ as the major. The ratio between them was 1:6, respectively. Having in mind that the enamine $\mathbf{1 7 9}$ was afforded during the work-up from the non-converted aminal 177, we decided to repeat the experiment increasing the temperature of the allylation (entry 2). In this case, we also increased the amount of Grignard reagent from 2 to 4 equivalents, because the reduction could be competitive to the allylation, at higher temperature. After $3 \mathrm{~h}$ of reaction the desired allylation product $\mathbf{1 7 0}$ was obtained, but mixed again with the enamine $\mathbf{1 7 9}$ and also with amine $\mathbf{1 7 8}$ in almost the same ratio. This result evidenced that, at $0{ }^{\circ} \mathrm{C}$, the reaction of the residual hydrides of Red-Al with the aminal to form amine $\mathbf{1 7 8}$ was faster than its allylation.

At the end, we performed an experiment increasing up to 10 the equivalents of the Grignard reagent in order to increase the rate of the allylation step (entry 3 ) and monitoring the reaction evolution to optimize the formation of the desired product. After $3 \mathrm{~h}$, no more evolution of the reaction was detected, so the reaction mixture was treated with saturated solution of $\mathrm{NaHCO}_{3}$ and then extracted with $\mathrm{CH}_{2} \mathrm{Cl}_{2}$. After purification by column chromatography on silica gel, triene $\mathbf{1 7 0}$ was obtained in 83\% yield from lactam 169 (Scheme 39), with a diastereomeric ratio of 5:1, known from the relative area of the signals corresponding to protons $\mathrm{H}-6$, of both isomers, in its ${ }^{1} \mathrm{H}$ NMR spectrum (Figure 24). The diastereomers could not be separated during the purification procedure and we decided to continue the synthesis with the mixture. At this point, it is unknown if the mixture of isomers corresponds to the $Z / E$ or $4 R / 4 S$ mixture. It would be known after the next RCM, where the $Z / E$ isomerism would be lost. The signals of the corresponding protons were assigned by the help of bidimensional NMR experiments. The presence of an allyl group was observed by its characteristic signals at 5.67 and $5.02 \mathrm{ppm}$. In addition, the signals corresponding to the other alkene protons appear at 5.54, 5.25 and $5.04 \mathrm{ppm}$. Also, the signals of the $\alpha$-nitrogen protons of the two isomers could be observed between 4.15 and $2.60 \mathrm{ppm}$. 


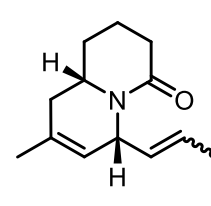

$(6 R, 9 a S)-169$

(6:1) ZIE

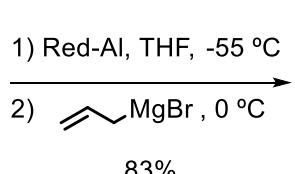

$83 \%$

Scheme 39. Optimized conditions for the synthesis of amine $\mathbf{1 7 0 .}$

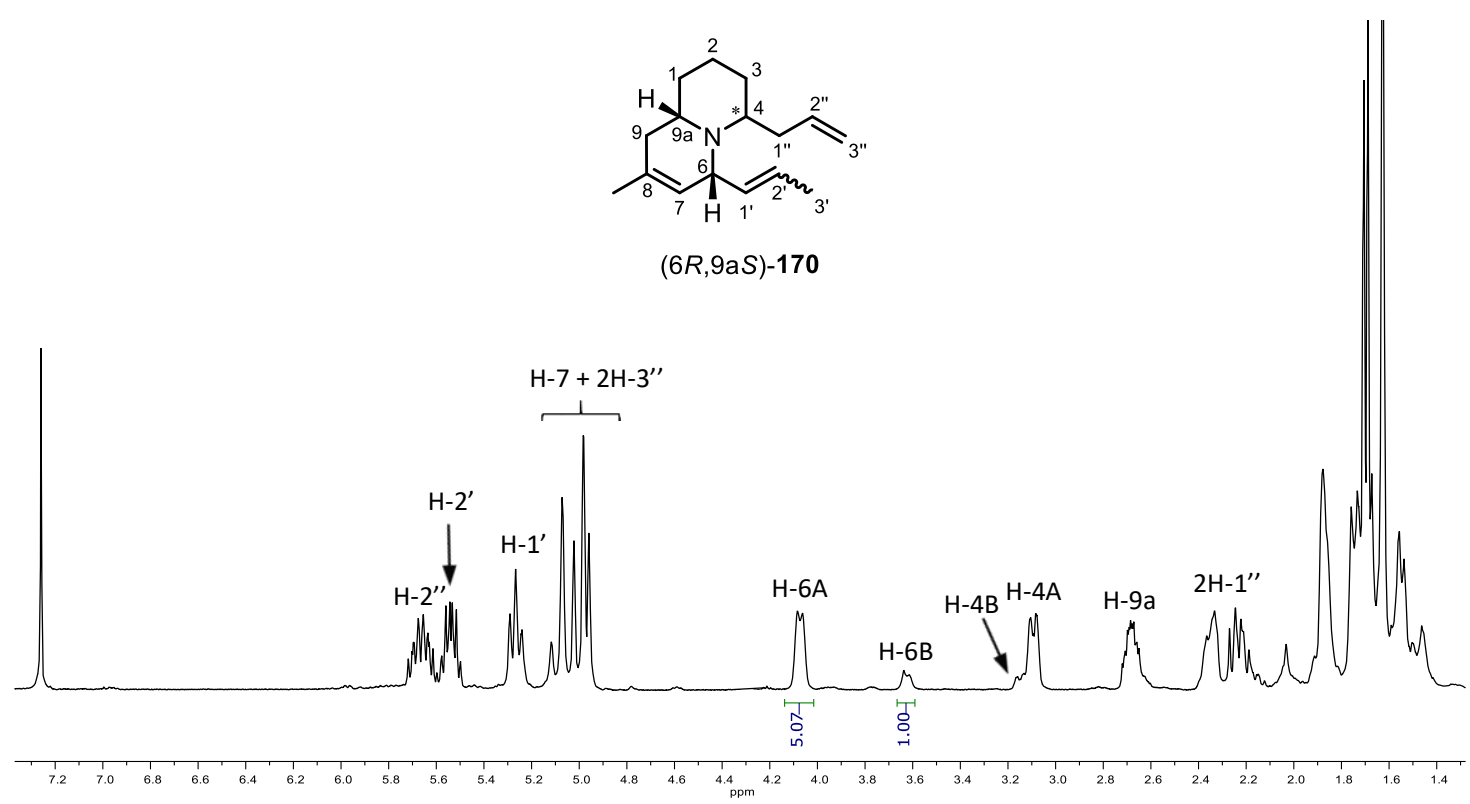

$(6 R, 9 \mathrm{aS})-\mathbf{1 7 0}$

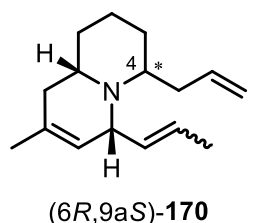

$(5: 1)$

Scheme 39. Optimized conditions for the synthesis of amine 170.

Figure 24. ${ }^{1} \mathrm{H}$ NMR spectrum $\left(400 \mathrm{MHz}, \mathrm{CDCl}_{3}\right)$ of triene 170. Mixture of diastereomers: $A=$ major; $B=$ minor.

It should be noted that tetraene 180, resulting from the diallylation of the lactam 169, was eventually observed as a byproduct of this reaction. Its structure was stablished thanks to the signals in its ${ }^{1} \mathrm{H}$ NMR spectrum (Figure 25), where two typical allyl patterns between 5.90 and 5.05 ppm can be observed. Moreover, there are only two signals of $\alpha$-nitrogen protons at 4.24 and 2.79 ppm.

In order to determine the relative configuration of the new stereogenic center of the major diastereoisomer of triene 170, different selective nOe experiments were performed irradiating the three $\alpha$-nitrogen protons $\mathrm{H}-4, \mathrm{H}-6$ and $\mathrm{H}-9 \mathrm{a}$. The most relevant information was inferred from the selective nOe spectrum obtained after irradiation of H-6 (Figure 26). This spectrum showed a strong enhancement of the signal corresponding to H-9a and one of the protons $\mathrm{H}-\mathrm{1}^{\prime \prime}$ and smaller effects on $\mathrm{H}-4$ and the other $\mathrm{H}-\mathrm{I}^{\prime \prime}$. These nOe's were consistent with the MM2 optimized geometry of $(4 S, 6 R, 9 a S)-170$ (Figure 27), which presents trans- $\mathrm{H}-6 / \mathrm{H}-4$ relationship, thus, the allylic chain is attached to C-4 in axial orientation. 


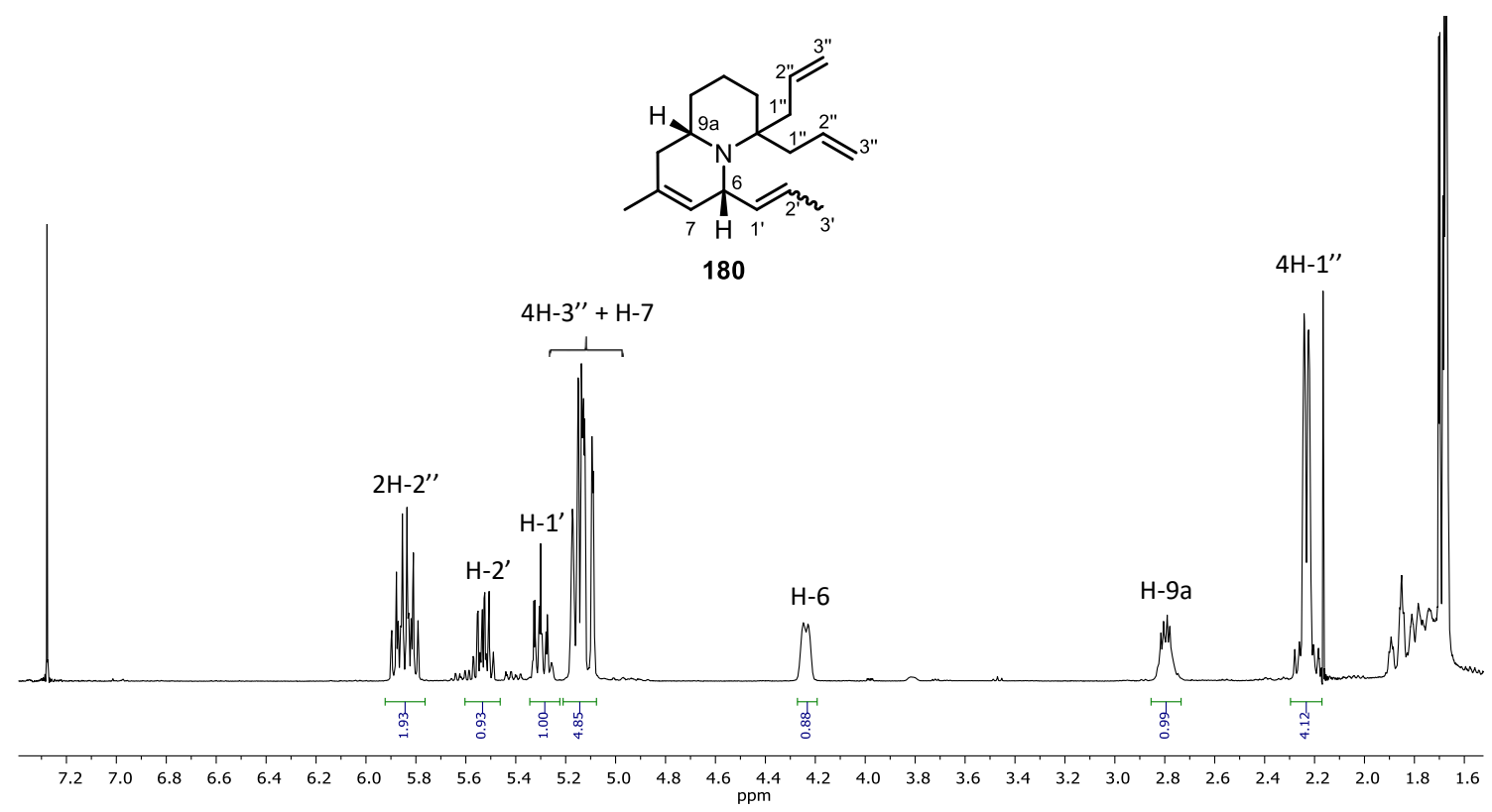

Figure 25. Fragment of the ${ }^{1} \mathrm{H}$ NMR spectrum $\left(400 \mathrm{MHz}, \mathrm{CDCl}_{3}\right)$ of diallylation product 180.
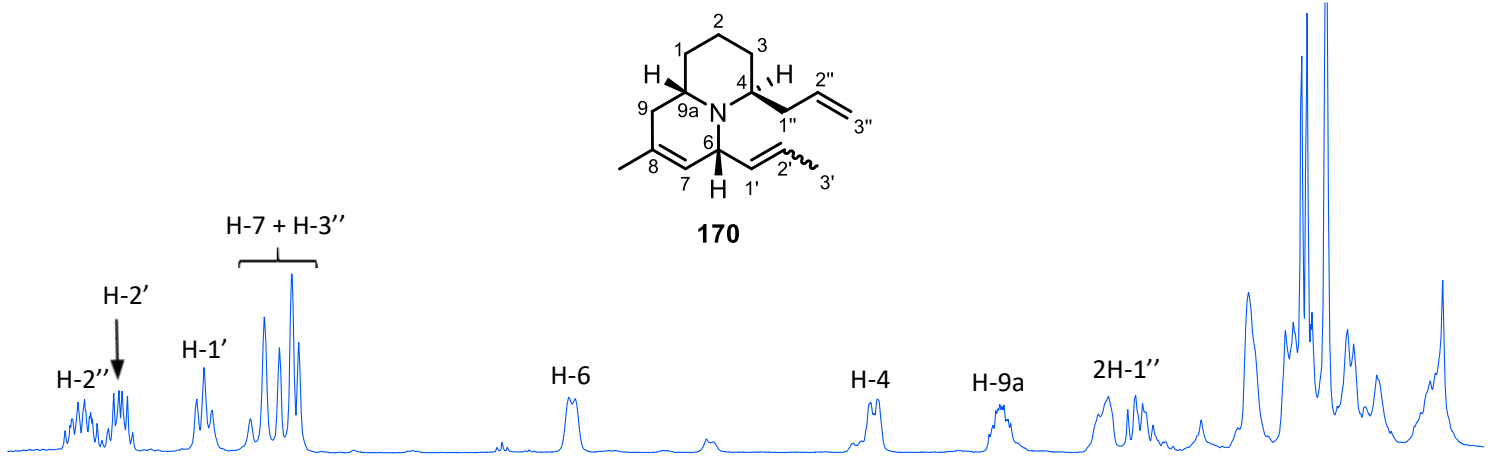


\subsection{Second Ring-Closing Metathesis. Formation of the tricyclic skeleton}

The preferential conformation of triene $\mathbf{1 7 0}$ led us to foresee that the following RCM reaction to form the tricycle was more kinetically demanding than the previous one, since the two alkene residues were pointing in opposite directions.

Hence, the previously obtained diasteromeric mixture (5:1) of amine 170, was refluxed in $\mathrm{CH}_{2} \mathrm{Cl}_{2}$ in the presence of 10 mol\% of second generation Grubbs catalyst (Scheme 40 ). After 14 $\mathrm{h}$, the total consumption of the starting material was observed. Purification of the crude product by column chromatography on neutral alumina delivered the tricyclic amine $\mathbf{1 7 1}$ in $83 \%$ yield as a single isomer, as it could be observed in its ${ }^{1} \mathrm{H}$ NMR spectrum (Figure 28).

With these results, it was confirmed that the diastereomeric ratio of $\mathbf{1 7 0}$ (5:1) was related to $Z / E$ isomerism, thus, the second nucleophilic allylation worked selectively.

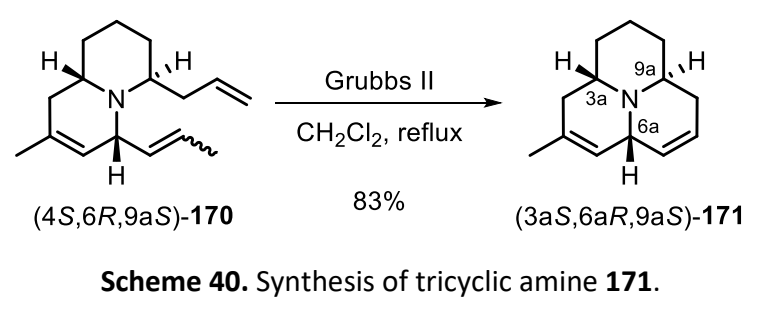

In the ${ }^{1} \mathrm{H}$ NMR spectrum (Figure 28), the signals of the alkene protons appear at 5.66 and 5.22 ppm ( $\mathrm{H}-6, \mathrm{H}-7$ and $\mathrm{H}-8$ ), while those of the $\alpha$-nitrogen protons $\mathrm{H}-6 \mathrm{a}, \mathrm{H}-3 \mathrm{a}$ and $\mathrm{H}-9 \mathrm{a}$, can be observed at 4.02, 3.28 and $2.67 \mathrm{ppm}$, respectively. The assignment of the different protons in this spectrum relayed on the analysis of bidimensional NMR experiments.

To determine the relative configuration of the stereogenic center $\mathrm{C}-9 \mathrm{a}$, another series of selective nOe experiments were registered (Figure 29). As can be observed, when proton H-6a was irradiated, the signal of the proton $\mathrm{H}-3 \mathrm{a}$ and the alkene protons $\mathrm{H}-6$ and $\mathrm{H}-7$ were enhanced. In the same way, irradiation of $\mathrm{H}-3$ a produce nOe in $\mathrm{H}-6$ a while irradiation of $\mathrm{H}-9 \mathrm{a}$ had no effect on the other $\alpha$-nitrogen protons. These observations are in agreement with a cis- $\mathrm{H}-3 \mathrm{a} / \mathrm{H}-6 \mathrm{a}$ and trans-H-3a/H-9a relationship. Hence, the configuration of C-9a was stablished as S (Figure 30), according to the tentative configuration assignment of the bicyclic precursor $\mathbf{1 7 0 .}$ 


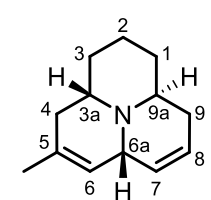

$(3 \mathrm{a} S, 6 \mathrm{a} R, 9 \mathrm{a} S)-171$

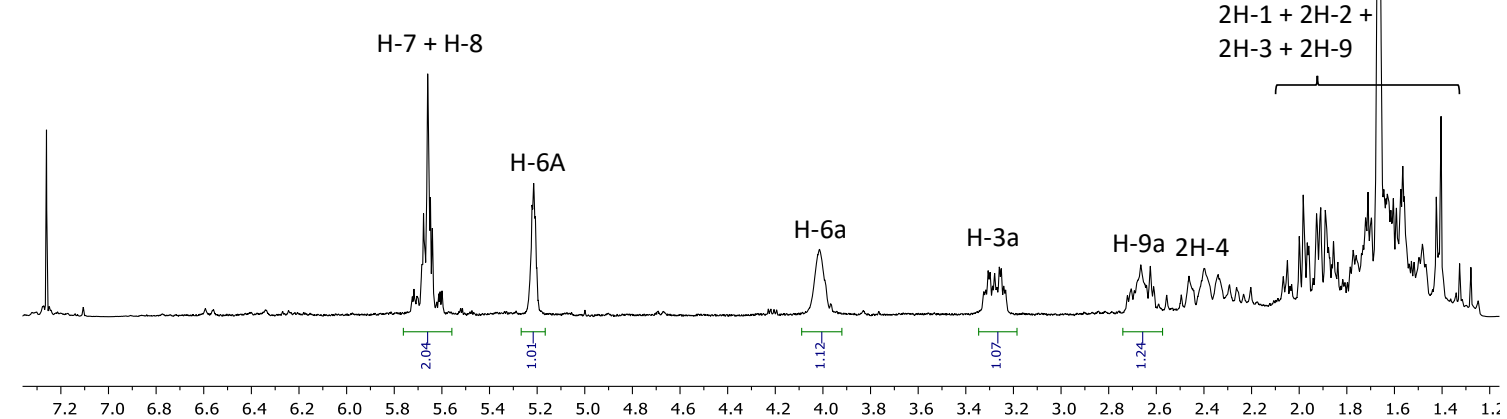

Figure 28. ${ }^{1} \mathrm{H}$ NMR spectrum $\left(250 \mathrm{MHz}, \mathrm{CDCl}_{3}\right)$ of tricyclic compound 171.
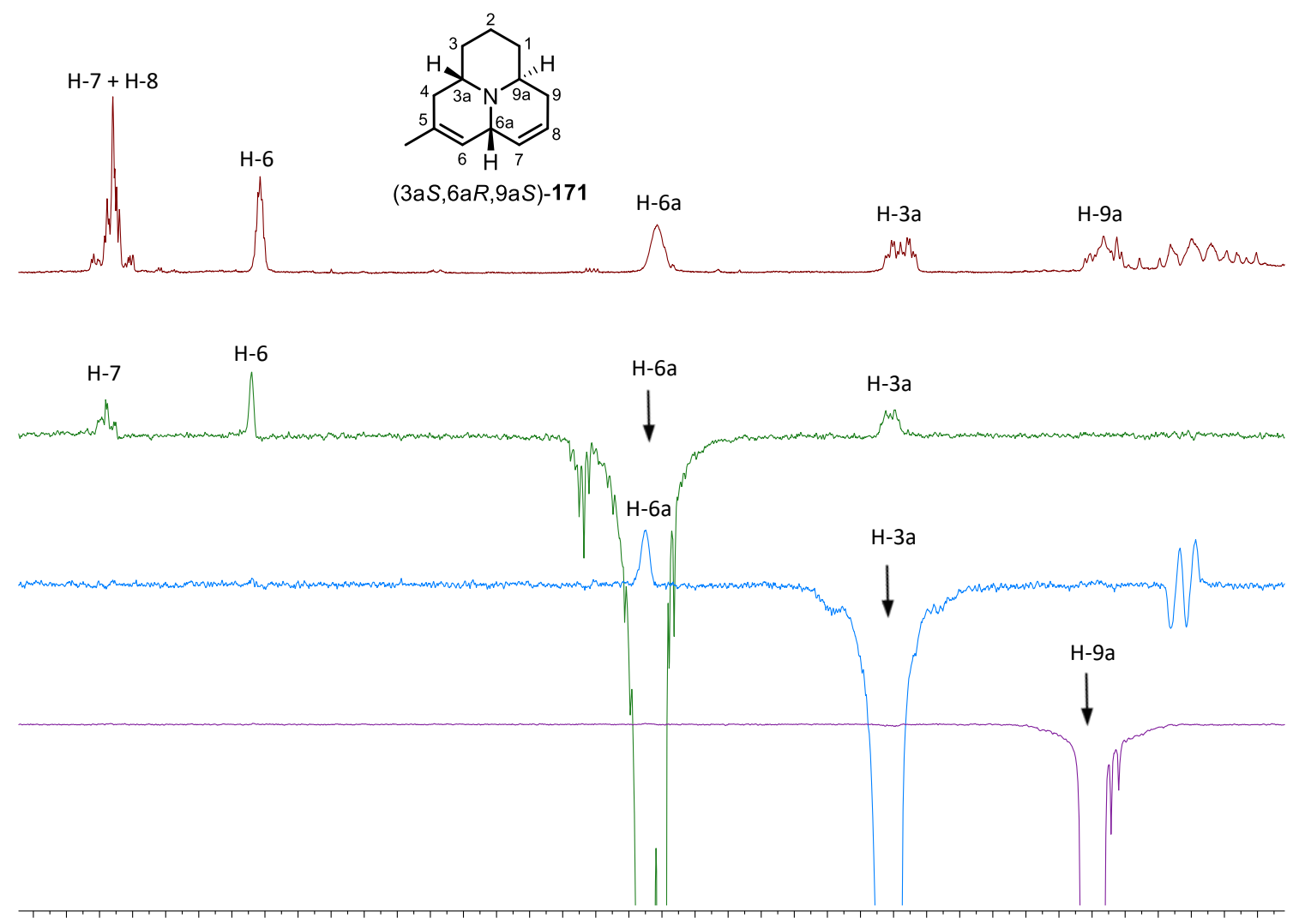

$\begin{array}{lllllllllllllllllllllllllllllllllllllllllllll}5.9 & 5.8 & 5.7 & 5.6 & 5.5 & 5.4 & 5.3 & 5.2 & 5.1 & 5.0 & 4.9 & 4.8 & 4.7 & 4.6 & 4.5 & 4.4 & 4.3 & 4.2 & 4.1 & 4.0 & 3.9 & 3.8 & 3.7 & 3.6 & 3.5 & 3.4 & 3.3 & 3.2 & 3.1 & 3.0 & 2.9 & 2.8 & 2.7 & 2.6 & 2.5 & 2.4 & 2.3 & 2.2\end{array}$ Figure 29. Selective nOe spectra $\left(400 \mathrm{MHz}, \mathrm{CDCl}_{3}\right)$ of tricycle 171 at $4.01,3.29$ and $2.67 \mathrm{ppm}$. 


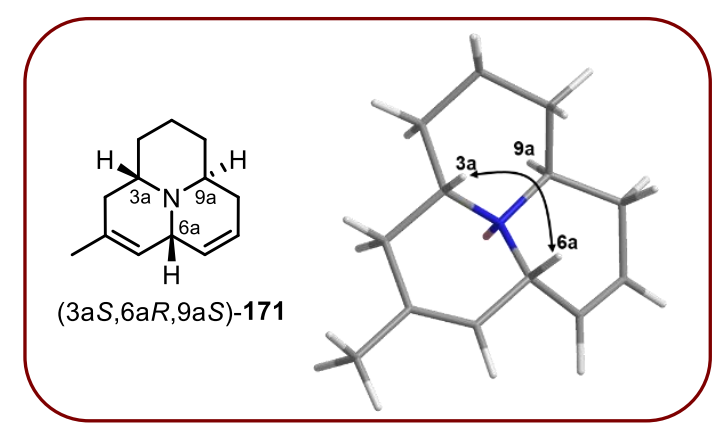

Figure 30. Representation of (3aS,6aR,9aS)-171.

\section{Hydrogenation. Synthesis of the final azaphenalene alkaloid}

The last step in the synthesis would be the hydrogenation of the double bonds present in the tricyclic compound $\mathbf{1 7 1}$. Since the protons $\mathrm{H}-3 \mathrm{a}$ and $\mathrm{H}-6 \mathrm{a}$ was in cis configuration in 171, full hydrogenation would lead to precoccinelline and/or 2-epi-precoccinelline, which have a symmetry plane passing through the methyl group, the carbon atoms C-2 and C-6a and the nitrogen. Thus, the alkaloids would be meso compounds (Scheme 41).

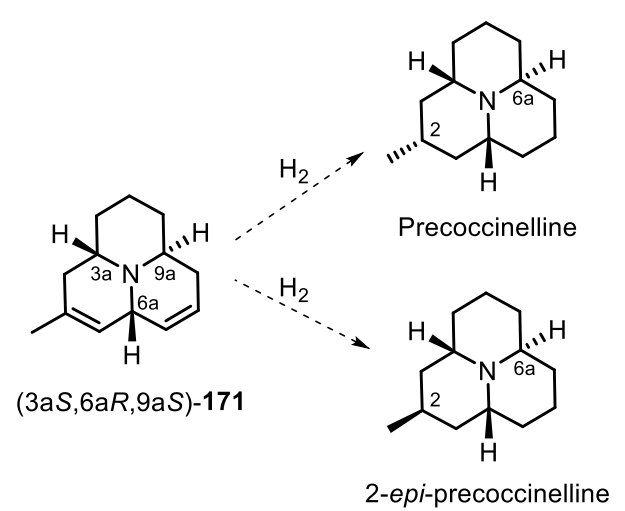

Scheme 41. Possible double hydrogenation products.

Therefore, our efforts were devoted to partial hydrogenation of the diene (Scheme 42), to afford a chiral alkaloid with one endocyclic double bond (Table 4).

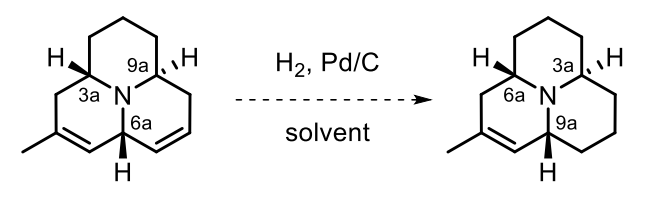

$(3 a S, 6 a R, 9 a S)-171$

$(3 \mathrm{aS}, 6 \mathrm{aS}, 9 \mathrm{a} R)-56$

Scheme 42. Hydrogenation of one double bond. ${ }^{60}$

${ }^{60}$ Atom numbering following the IUPAC rules. 
Table 4. Attempts and results of the selective hydrogenation.

\begin{tabular}{ccccc}
\hline Entry $^{\mathrm{a}}$ & Solvent & Pressure (atm) & Time (h) & Results \\
\hline $\mathbf{1}$ & $\mathrm{MeOH}$ & 1 & 14 & $\mathrm{sm}$ \\
$\mathbf{2}$ & $\mathrm{MeOH}$ & 2 & 14 & $\mathrm{sm}+\mathbf{5 6}(9 \%)+$ byproducts \\
$\mathbf{3}$ & $\mathrm{MeOH}$ & 2 & 48 & $\mathbf{5 6}(\mathbf{1 9 \% )}+$ byproducts \\
$\mathbf{4}$ & $i-\mathrm{PrOH}$ & 2 & 14 & $\mathrm{sm}+\mathbf{5 6}(\mathbf{4 6 \% )}+$ byproducts \\
$\mathbf{5}$ & $\mathrm{MeOH}+\mathrm{AcOH}$ & 2 & 48 & $\mathbf{5 6}(65 \%)$ \\
\hline
\end{tabular}

${ }^{a}$ All the reaction mixtures were filtered through Celite ${ }^{\circledR}$ and washed with $\mathrm{CH}_{2} \mathrm{Cl}_{2}$ before analyzed by ${ }^{1} \mathrm{H}$ NMR.

The first hydrogenation conditions tested were the most standard (entry 1), using methanol as solvent at atmospheric pressure and stirring the reaction mixture overnight but the starting material was fully recovered.

The next experiment, performed increasing the pressure from 1 to 2 atm (entry 2), led to a mixture of the starting material $\mathbf{1 7 1}$ and the desired alkaloid 56, accompanied by some unidentified byproducts. Alkaloid $\mathbf{5 6}$ was isolated in only $9 \%$ yield after purification through column chromatography on neutral alumina, so we needed to increase the reaction conversion.

To this aim, and once $\mathbf{5 6}$ was identified, we decided to increase the reaction time monitoring the reaction evolution by TLC. The disappearance of the starting material was observed after $48 \mathrm{~h}$ of reaction, but only $19 \%$ yield of 56 was obtained after column chromatography over neutral alumina (entry 3 ).

In an attempt to avoid the formation of byproducts, we decided to change the solvent to isopropanol (entry 4) and, after purification through column chromatography over neutral alumina, $\mathbf{5 6}$ was isolated in $\mathbf{4 6 \%}$ yield, accompanied by the starting material $\mathbf{1 7 1}$ and some unidentified byproducts.

Considering that the huge quantity of byproducts was perhaps coming from decomposition of $\mathbf{1 7 1}$ or $\mathbf{5 6}$, we decided to block the nitrogen atom by adding some drops of acetic acid to the reaction medium (entry 5). We changed again to methanol as solvent, at 2 atm, following the reaction evolution by TLC. We observed the total consumption of the starting material after $48 \mathrm{~h}$ of reaction and were able to isolate the final alkaloid $\mathbf{5 6}$ in $65 \%$ yield, as a single isomer, after column chromatography on neutral alumina (Scheme 43). The loss of material was probably due to the high volatility of these compounds. ${ }^{1 a, 31,45}$ 


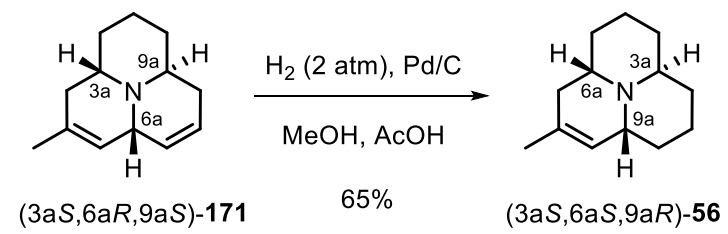

Scheme 43. Optimized conditions for the chemoselective hydrogenation of 171.

The NMR spectra of the alkaloid $\mathbf{5 6}$ were registered as its TFA salt. All the signals could be identified by the help of bidimensional NMR experiments. The ${ }^{1} \mathrm{H}$ NMR spectrum (Figure 31) shows a broad singlet at $5.23 \mathrm{ppm}$ corresponding to the alkene proton $\mathrm{H}-9$, while the signals of the $\alpha$-nitrogen protons $\mathrm{H}-9 \mathrm{a}, \mathrm{H}-6 \mathrm{a}$ and $\mathrm{H}-3 \mathrm{a}$ appear at $4.26,3.84$ and $3.15 \mathrm{ppm}$, respectively.

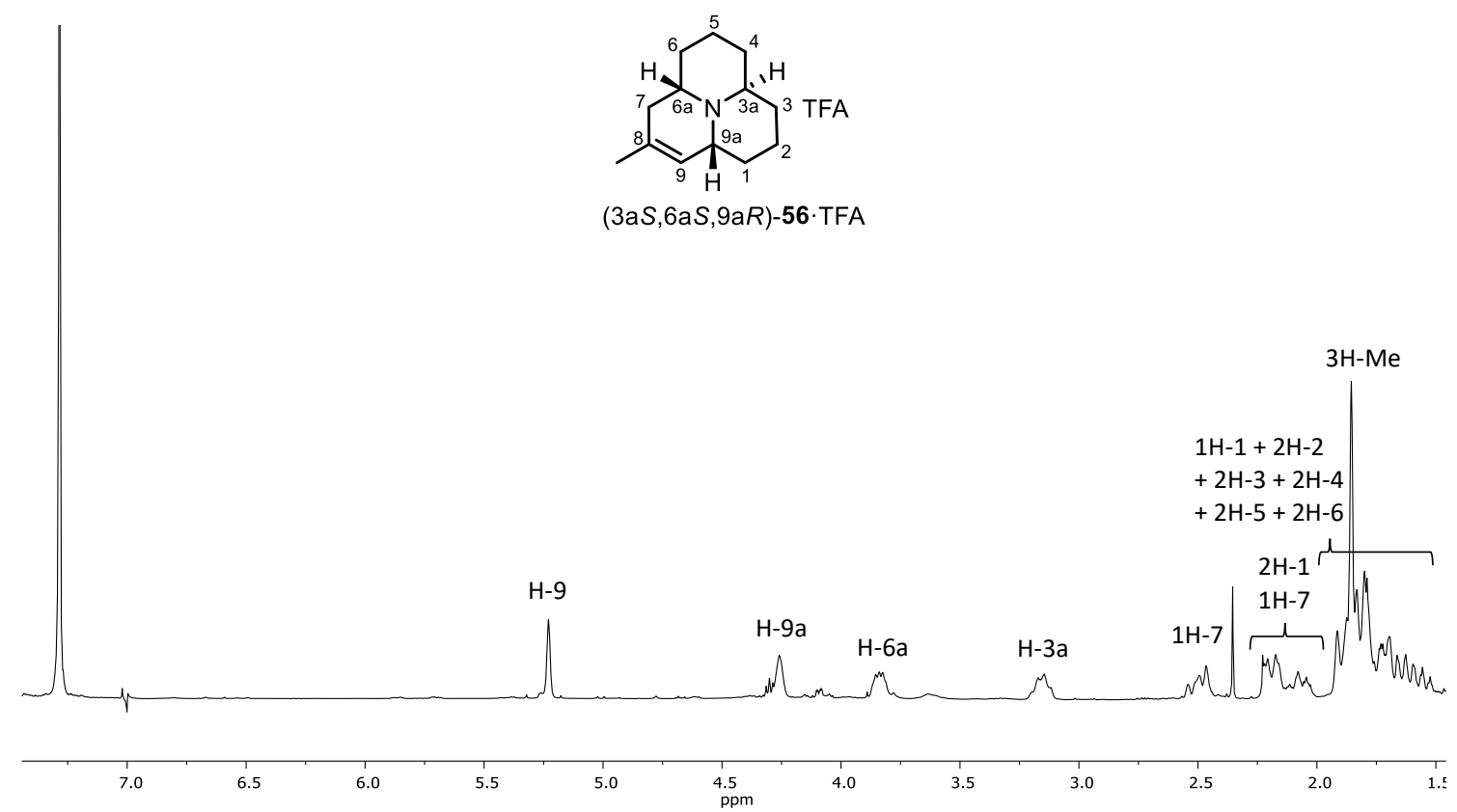

Figure 31. ${ }^{1} \mathrm{H} \mathrm{NMR}$ spectrum $\left(400 \mathrm{MHz}, \mathrm{CDCl}_{3}\right)$ of the final alkaloid $(3 \mathrm{a} S, 6 \mathrm{aS}, 9 \mathrm{a} R)-56 \cdot \mathrm{TFA}$.

In the ${ }^{13} \mathrm{C}$ NMR spectrum (Figure 32) we can observe the signal corresponding to the quaternary carbon C-8 at $134.4 \mathrm{ppm}$. Also, we can distinguish the signal of C-9 at $118.5 \mathrm{ppm}$. The signals of the carbon in the three junction rings (C-9a, C-6a and C-3a) appear at 56.9, 56.0 and $52.7 \mathrm{ppm}$, respectively. All the signals corresponding to the other carbons are presented between 31.1 and $17.2 \mathrm{ppm}$. It should be noticed that in the ${ }^{13} \mathrm{C}$ NMR spectrum no other isomers could be detected evidencing that the alkaloid was obtained as a single isomer. 


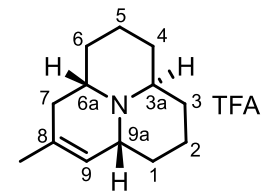

(3aS,6aS,9aR)-56 ·TFA
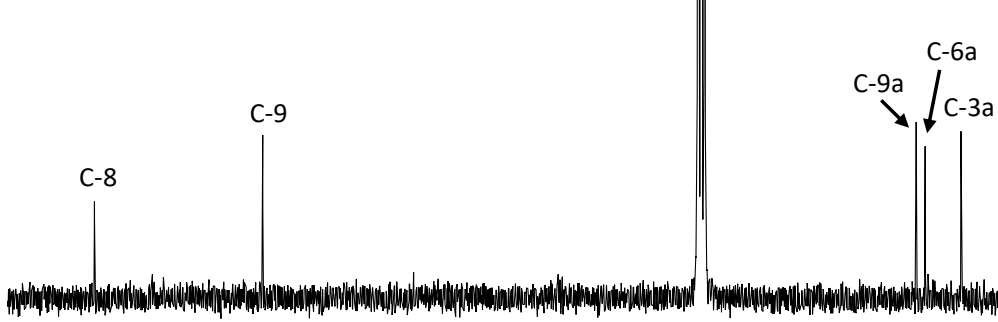

$\mathrm{C}-1+\mathrm{C}-2+\mathrm{C}-3+\mathrm{C}-4+$

$\mathrm{C}-5+\mathrm{C}-6+\mathrm{C}-7+\mathrm{C}-\mathrm{Me}$

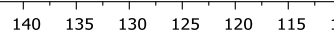

Figure 32. ${ }^{13} \mathrm{C}$ NMR spectrum $\left(101 \mathrm{MHz}, \mathrm{CDCl}_{3}\right)$ of 56-TFA.

To confirm the stereochemistry of $\mathbf{5 6}$, a series of selective nOe experiments were done (Figure 33). As the previous experiments, we focused our attention on the $\alpha$-nitrogen protons of the molecule, which were successively irradiated. From these experiments it was confirmed the trans-H-3a/H-6a and cis-H-6a/H-9a relationship, thus, $\mathbf{5 6}$ was identified as (3aS,6aS,9aR)-8methyl-1,2,3,3a,4,5,6,6a,7,9a-decahydropyrido[2,1,6-de]quinolizine. ${ }^{60}$

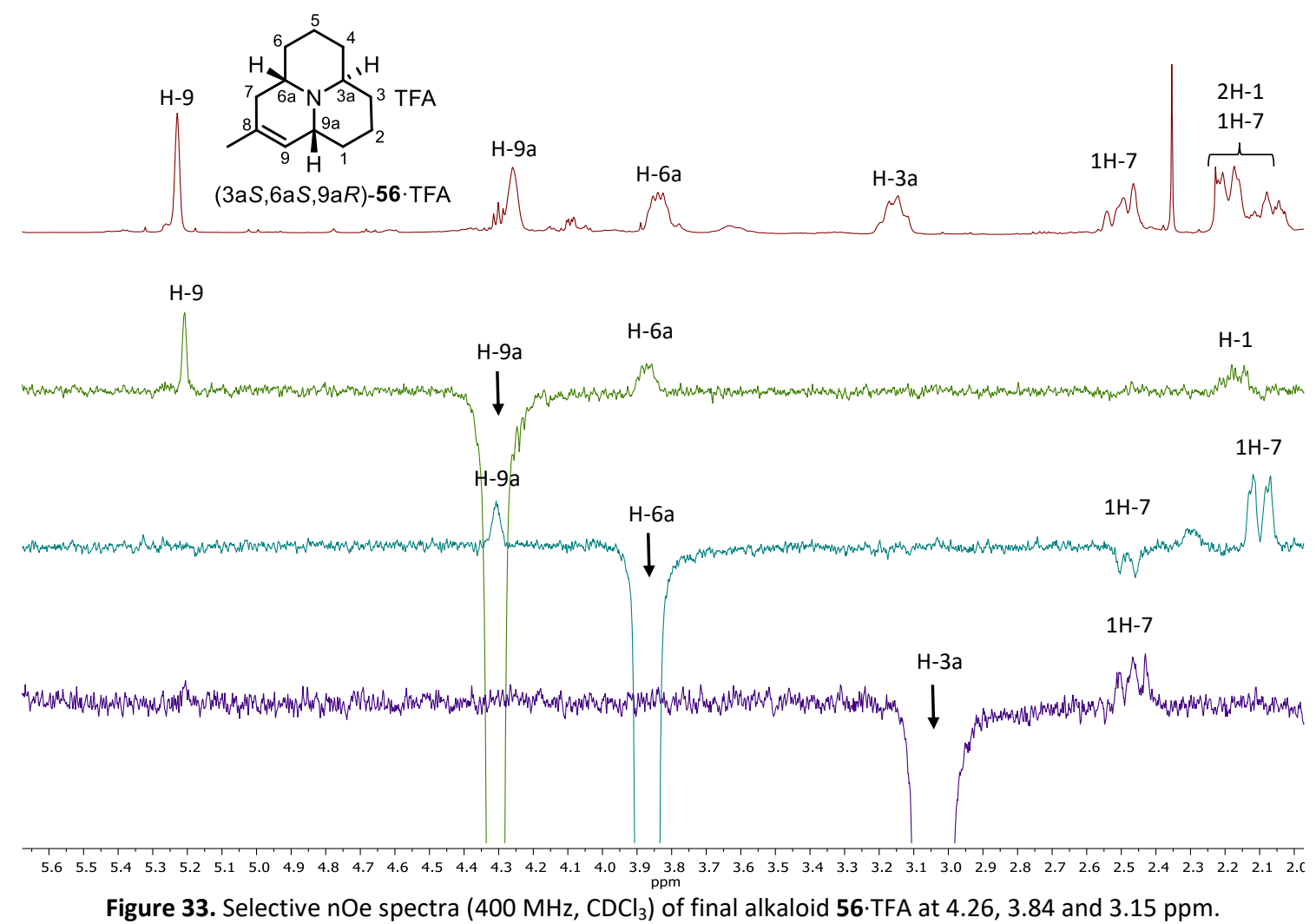




\section{Conclusions}

Comparing the structure of the alkaloid here synthesized with those of the nine monomeric azaphenalene alkaloids isolated from ladybugs, the only one with the same constitution is Hippocasine and we had obtained one of its epimers (Figure 34), previously prepared as a racemate, as precursor of the natural alkaloids precoccinelline and coccinelline. ${ }^{38}$

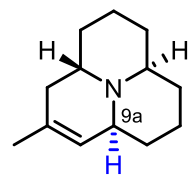

Hippocasine

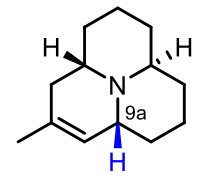

(-)-9a-epi-hippocasine, 56

Figure 34. Comparison of the structures of hippocasine and (-)-9a-epi-hippocasine, 56.

The optical rotation of (-)-9a-epi-hippocasine, 56, was $[\alpha]_{D}{ }^{20}=-0.71\left(c 0.27, \mathrm{CHCl}_{3}\right)$. This very low value correlates with the optical rotations determined for some of the natural alkaloids isolated until now, ${ }^{24}$ which are not racemates.

To sum up, (-)-9a-epi-hippocasine, 56, was synthesized in 13 steps and $22 \%$ overall yield. Its total synthesis had as first key step the asymmetric alkylation of glutarimide. Then, an iterative strategy was applied to generate the two other six-membered rings, encompassing two nucleophilic allylations and two ring-closing metathesis.

Despite the loss of material in the final step of the sequence, this synthesis presents the highest overall yield among all the enantioselective approaches so far described for any azaphenalene alkaloid.

The sense of chirality was determined by the absolute configuration of the palladium ligand used in the first step. Since the ligand is available in both antipodal forms, the same approach could be used to synthesize the opposite enantiomer of the alkaloid. 



\section{Results and discussion. Chapter 2: Towards other azaphenalene alkaloids}





\section{Introduction}

Since the objective was to synthesize chiral azaphenalene alkaloids, the previous sequence leading to (-)-9a-epi-hippocasine, 56, was not appropriate for alkaloids lacking the double bond. It was necessary to modify the synthetic tactics to avoid the formation of meso intermediates or products. Any modification should necessarily involve changing the configuration of one stereocenter. Hence, we decided to change the order in which the reagents of the nucleophilic allylation steps were introduced (Scheme 44). In this way, the methyl group would be incorporated in the second allylation step, in contrast to the previous synthesis of (-)9a-epi-hippocasine, $\mathbf{5 6}$.

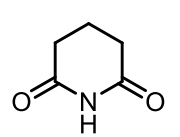

150<smiles>C=C[C@H]1CO1</smiles>

151

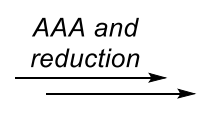

$\mathrm{HO}^{\prime}$<smiles>C=CC(C)C</smiles>

154

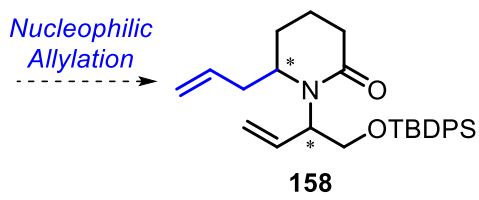

158

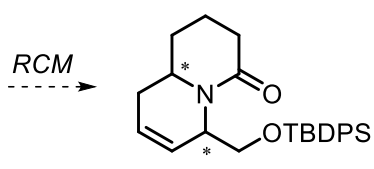

160

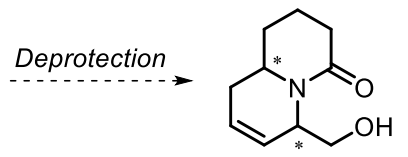

181

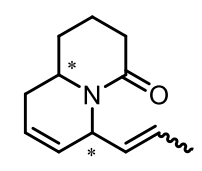

182

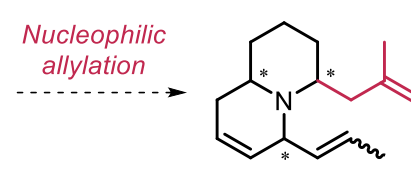

183

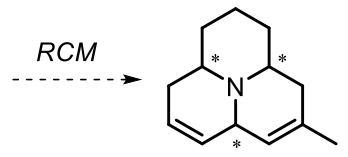

171
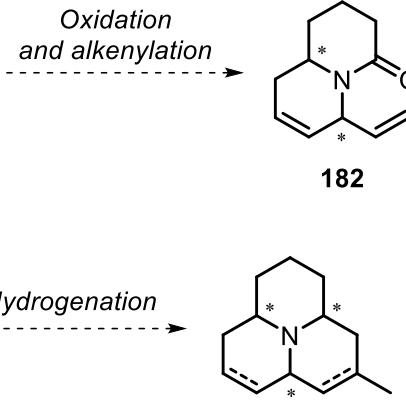

166

Scheme 44. Tactical change for the synthesis of alkaloids lacking the double bond.

The introduction of the methyl group in the second nucleophilic allylation causes that the chirality of the final alkaloid will be determined by the configuration of the stereogenic center generated in this allylation step, as it can be observed in Scheme 45 . The configuration of the stereogenic center generated in the first nucleophilic allylation (blue) is not relevant because both possible diastereomers could be converted into a chiral alkaloid. In contrast, the relative configuration of the stereogenic center last generated (orange) should be trans to the original stereocenter in 154, formed in the AAA. 


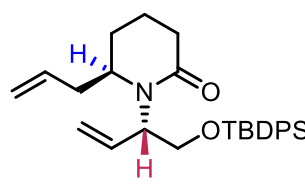

trans-158
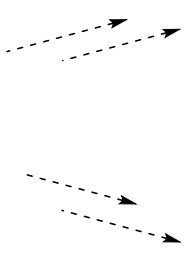

H<smiles>C=C(C)C[C@@H]1CCCC2CC=C[C@H](/C=C/C)N21</smiles>

$(4 S, 6 R, 9 a R)-183$

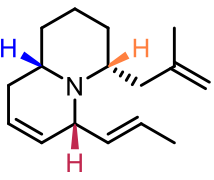

$(4 R, 6 R, 9 \mathrm{aS})-183$

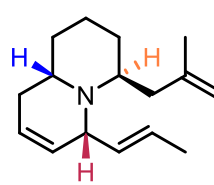

$(4 S, 6 R, 9 a S)-183$
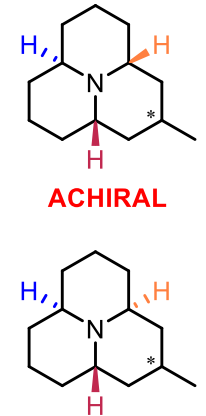

CHIRAL
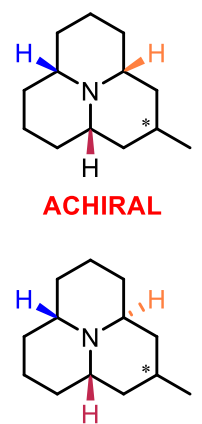

CHIRAL

Scheme 45. Stereodiverse pathways from dienes 158.

\section{Preparation of 181}

\subsection{First nucleophilic allylation}

According to the previous considerations, the first nucleophilic allylation was assayed using allyltrimethylsilane as the allylating agent.

Despite the allylating agent was changed, this reaction was performed under the same conditions optimized to obtain lactam 159. Thus, the acetyl derivative 155 was treated with allyltrimethylsilane and TMSOTf as Lewis acid, in dry $\mathrm{CH}_{2} \mathrm{Cl}_{2}$, at $-78{ }^{\circ} \mathrm{C}$ during $4 \mathrm{~h}$, yielding lactam (1'S)-158 in 77\% yield for the two steps, after chromatographic purification, in a diastereomeric ratio of approximately 1:20 (Scheme 46).

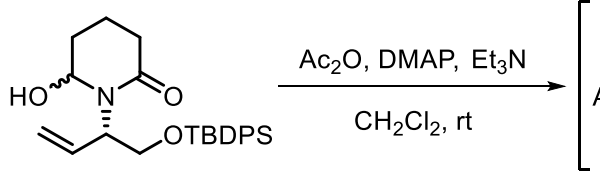

(1'S)-154<smiles>C=C[C@H](CO[Pb])N1C(=O)CCC[C@H]1OC(C)C</smiles>

155

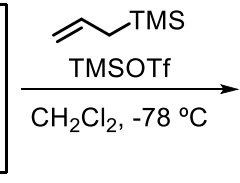

$77 \%$ (2 steps)

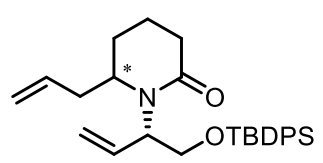

(1'S)-158

(1:20)

Scheme 46. First nucleophilic allylation. Synthesis of (1'S)-158. 
It should be noticed that, compared to the analogous reaction performed with the methylated allyl silane, in this case, more quantity of enamine 157 was isolated and, accordingly, the yield of this step was lower than in the synthesis of 159. We speculated that allyltrimethylsilane is less reactive than methylallyltrimethylsilane and the dehydration reaction competes more advantadgeously. In any case, these results were considered good enough to proceed with the synthesis.

The high predominance of one isomer could be observed in the ${ }^{1} \mathrm{H}$ NMR spectrum of $\mathbf{1 5 8}$ (Figure 35 ) by the relative area of the signals at 6.20 and $6.06 \mathrm{ppm}$, which correspond to the proton $\mathrm{H}-2^{\prime}$ of each isomer. Moreover, we can observe the signal of the other internal alkene protons $\mathrm{H}-2^{\prime \prime \prime}$ at $5.65 \mathrm{ppm}$ together with that of the terminal alkene protons $\mathrm{H}-3^{\prime}$ and $\mathrm{H}-3^{\prime \prime \prime}$ at $5.08 \mathrm{ppm}$. The signals of the $\alpha$-nitrogen protons $\mathrm{H}-1^{\prime}$ and $\mathrm{H}-6$ appear at 4.27 and $3.40 \mathrm{ppm}$, respectively.

The configuration of the new stereogenic center was not determined in this step because the molecule was too flexible for inferring definitive conclusions from selective nOe experiments.

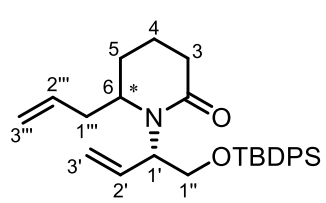

(1'S)-158
$2 \mathrm{H}-3^{\prime} \mathrm{A}+2 \mathrm{H}-3^{\prime \prime \prime} \mathrm{A}+$ $2 \mathrm{H}-3^{\prime} \mathrm{B}$ or $2 \mathrm{H}-3^{\prime \prime \prime} \mathrm{B}$
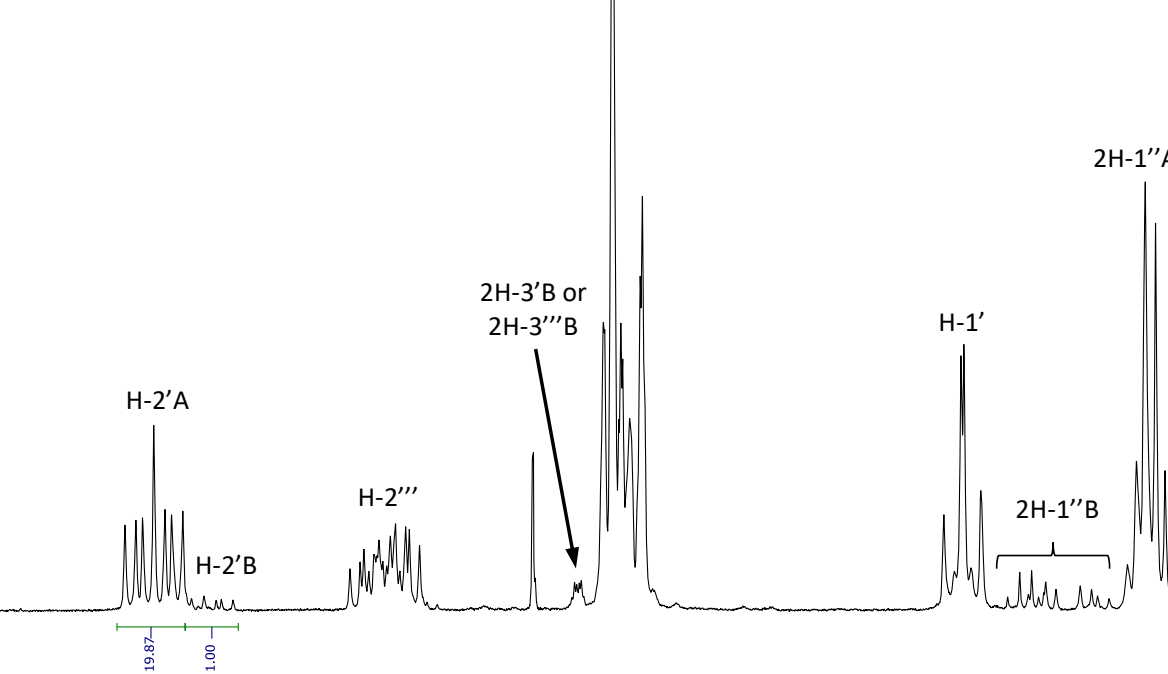

$\mathrm{H}-1^{\prime \prime} \mathrm{A}$

$\begin{array}{llllllllllllllllllllllllllllllllllllllllll}6.5 & 6.4 & 6.3 & 6.2 & 6.1 & 6.0 & 5.9 & 5.8 & 5.7 & 5.6 & 5.5 & 5.4 & 5.3 & 5.2 & 5.1 & 5.0 & 4.9 & 4.8 & 4.7 & 4.6 & 4.5 & 4.4 & 4.3 & 4.2 & 4.1 & 4.0 & 3.9 & 3.8 & 3.7 & 3.6 & 3.5 & 3.4 & 3.3 & 3.2 & 3.1\end{array}$

Figure 35. Fragment of the ${ }^{1} \mathrm{H}$ NMR spectrum $\left(250 \mathrm{MHz}, \mathrm{CDCl}_{3}\right)$ of diene $\left(1^{\prime} S\right)-158$. Mixture of diastereomers: $A=$ major; $B=$ minor. 


\subsection{First ring-closing metathesis and synthesis of alcohol 181}

As in the previous RCM leading to 161 , the second generation Grubbs catalyst was used. In this case, only 1 mol\% of Grubbs II was needed to obtain the expected bicyclic product $\mathbf{1 6 0}$ (Scheme 47). Hence, the 1:20 mixture of diene (1'S)-158 was dissolved in dry and degassed $\mathrm{CH}_{2} \mathrm{Cl}_{2}$ and heated under reflux. The second generation Grubbs catalyst was then added and the reaction was followed by TLC. After $14 \mathrm{~h}$, no starting material was observed. The bicycle (6S)160 was isolated in $96 \%$ yield as a single isomer after a silica gel column chromatography.

Surely, the other isomer was lost during the purification step, because the ${ }^{1} \mathrm{H}$ NMR spectrum of the crude material (Figure 36) showed signals corresponding to the minor isomer, which could not be isolated due to the low quantity obtained. Hence, in the crude product, the bicycle (6S)-160 was present in a diastereomeric ratio of 1:21, determined by the relative area of the signals corresponding to the alkene protons $\mathrm{H}-7$ and $\mathrm{H}-8$ of the two isomers. As expected, the diastereomeric ratio obtained from the first nucleophilic allylation remained constant after the first ring-closing metathesis. In the ${ }^{1} \mathrm{H}$ NMR spectrum, we can also observe the signals of the $\alpha$-nitrogen protons $\mathrm{H}-6$ and $\mathrm{H}-9 \mathrm{a}$ of the major isomer at 4.65 and $3.30 \mathrm{ppm}$, respectively, together with that of protons $\mathrm{H}-1^{\prime}$ at $3.87 \mathrm{ppm}$.

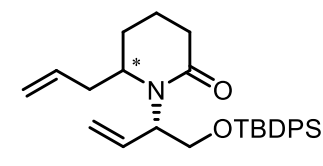

(1'S)-158

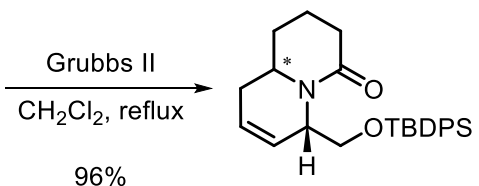

$(6 S)-160$

Scheme 47. First ring-closing metathesis. Synthesis of (6S)-160.

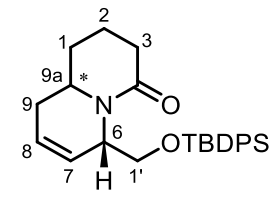

$(6 S)-160$

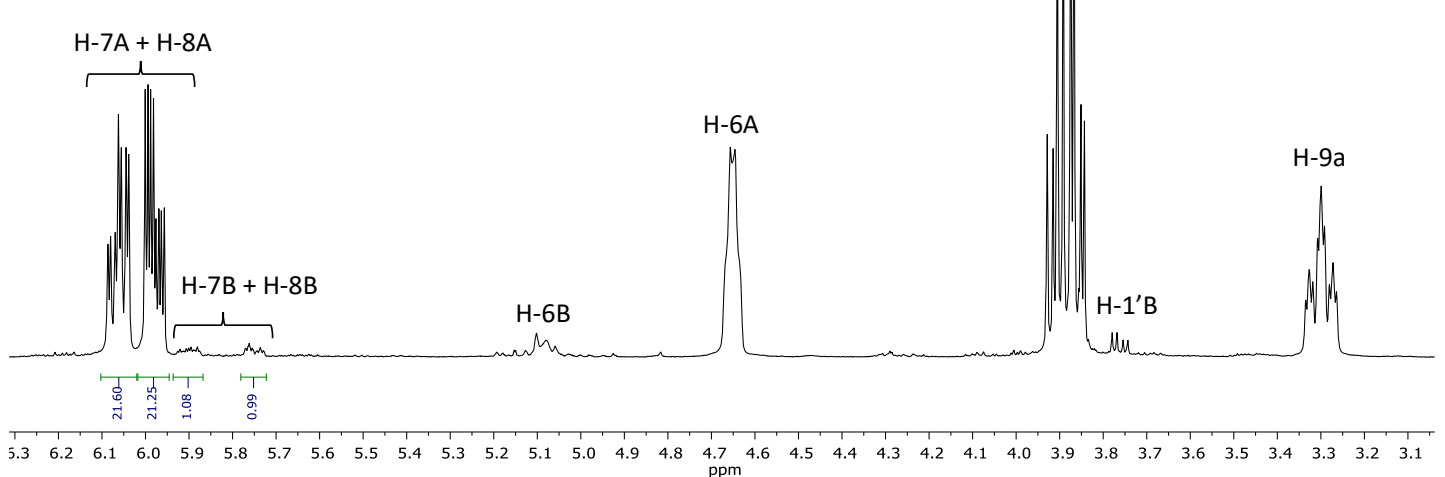

Figure 36. Fragment of ${ }^{1} \mathrm{H}$ NMR spectrum $\left(400 \mathrm{MHz}, \mathrm{CDCl}_{3}\right)$ of the crude product of 160 . Mixture of diastereomers: $A=$ major; $B=$ minor. 
As in the synthesis of (-)-9a-epi-hippocasine, 56, described in Chapter 1, we need to deprotect the alcohol to continue with the planed reactions. Hence, the isolated diastereomer of the bicyclic compound (6S)-160 was treated with Et ${ }_{3} \mathrm{~N} \cdot 3 \mathrm{HF}$ in THF under reflux for 14 hours, affording the corresponding alcohol $\mathbf{1 8 1}$ in $94 \%$ yield, as a single isomer, after chromatographic purification (Scheme 48).

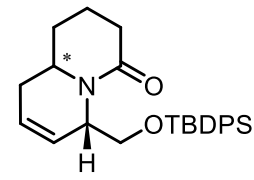

$(6 S)-160$

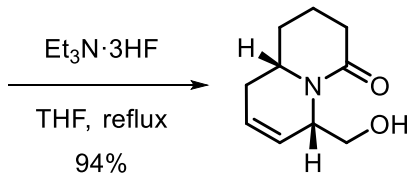

$(6 S, 9 a S)-181$

Scheme 48. Deprotection of the alcohol. Synthesis of 181.

This alcohol could be crystallized using a mixture of hexane and ethyl acetate and the crystals obtained were submitted to X-ray diffraction analysis. As in alcohol $\mathbf{1 6 8}$, the protons attached to the stereogenic centers, $\mathrm{H}-6$ and $\mathrm{H}-9 \mathrm{a}$, of $\mathbf{1 8 1}$ present a cis relative configuration (Figure 37). So, we can conclude that the diastereoselectivity of the allylation is independent of the reagent used (methylallyltrimethylsilane or allyltrimethylsilane). Nevertheless, according to the synthetic strategy planed, the configuration of C-9a is not relevant because it will not determine the chirality of the final alkaloid (see Scheme 45).

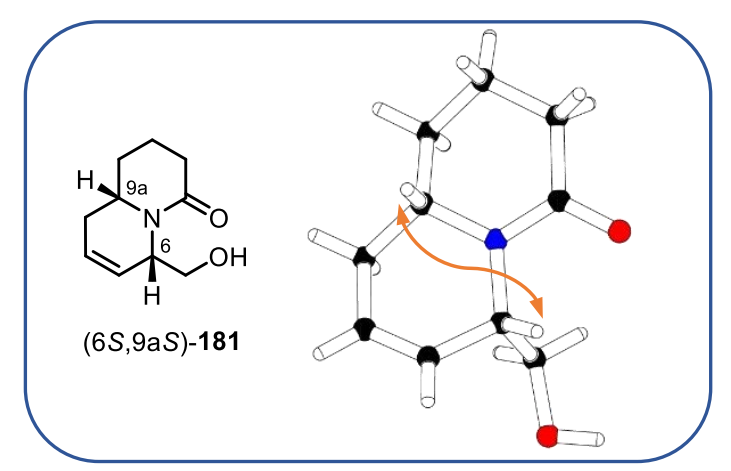

Figure 37. Representation of the structure determined by X-Ray diffraction analysis of alcohol (6S,9aS)-181.

\section{Synthesis of 183}

\subsection{Oxidation of alcohol 181 and Wittig alkenylation. Synthesis of intermediate 182}

Considering the good results obtained in the previous Dess-Martin oxidation, together with the optimized Wittig alkenylation described for the synthesis of 169, we started intending the synthesis of (6R,9aS)-182 by using the same reagents and reaction conditions (Scheme 49). 
<smiles>O=C1CCC[C@H]2CC=C[C@H](CO)N12</smiles>

$(6 S, 9 a S)-181$

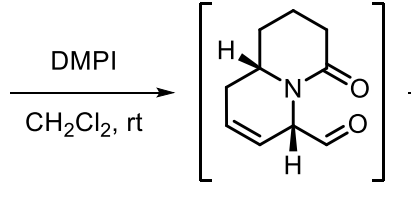

$(6 S, 9 a S)-184$

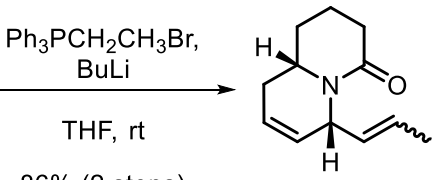

$(6 R, 9 a S)-182$

$(6: 1)$ ZIE

Scheme 49. Synthesis of $(6 R, 9 a S)-182$.

In a first attempt, the alcohol (6S,9aS)-181 was treated with 1.2 equivalents of DessMartin periodinane. Although the reaction was not completed after $5 \mathrm{~h}$, no further evolution was observed by TLC analysis. Therefore, we increased the quantity of the oxidizing agent to 1.5 equivalents and, then, the starting material was consumed after $3 \mathrm{~h}$. The aldehyde (6S,9aS)-184 was isolated as yellow oil and it was used in the next step without further purification due to its instability. Consequently, it could not be fully characterized, but an ${ }^{1} \mathrm{H}$ NMR spectrum was registered (Figure 38), where it can be seen the characteristic proton of the aldehyde at 8.91 ppm. We can also observe the signals of the alkene protons $\mathrm{H}-7$ and $\mathrm{H}-8$ at 6.08 and 5.50 ppm, together with that of the $\alpha$-nitrogen protons $\mathrm{H}-6$ and $\mathrm{H}-9 \mathrm{a}$, at 4.52 and $3.40 \mathrm{ppm}$, respectively.

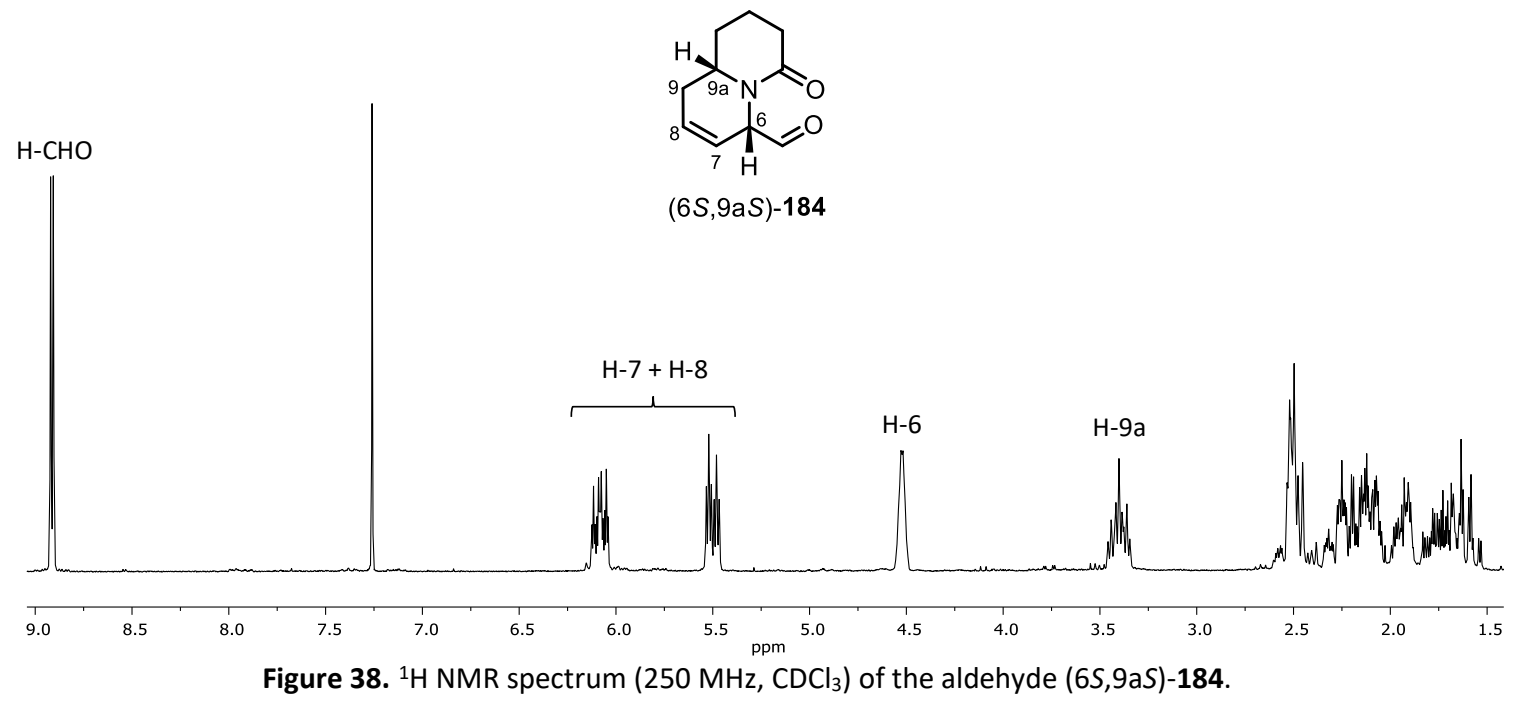

The isolated aldehyde $(6 S, 9 a S)-\mathbf{1 8 4}$ was treated with 1.2 equivalents of the phosphonium ylide, formed in situ by treatment of 1.2 equivalents of ethyltriphenylphosphonium bromide with an equimolar amount of BuLi. As a result, the desired olefin (6R,9aS)-182 was obtained in $48 \%$ yield from alcohol $(6 S, 9 a S)-181$. Since this yield was considered too low to follow with the synthesis, we needed to find better reaction conditions of this alkenylation. It was reasonable to think that the moderate yield was due to a bad performance of the Wittig reaction, because the weight of the crude aldehyde $(6 S, 9 a S)-184$ was reasonable and its ${ }^{1} \mathrm{H}$ NMR spectrum showed that it was pure enough. 
After a bibliographic research, ${ }^{61}$ we tested this Wittig reaction with the same phosphonium salt, but increasing the equivalents up to 6.3 and those of BuLi from 1.2 to 5.2.

In this way, we ensured the formation of enough phosphonium ylide and no residual base was able to react with the substrate. Under these new conditions, the desired diene (6R,9aS)182 was obtained in $86 \%$ yield, for the two steps, in a Z/E ratio of $6: 1$ determined by the relative areas as well as the coupling constant values of the signals corresponding to $\mathrm{H}-\mathrm{1}^{\prime}$ in its ${ }^{1} \mathrm{H}$ NMR spectrum (Figure 39). From the major isomer, $J_{1^{\prime}, 2^{\prime}(\text { major })}=10.3 \mathrm{~Hz}$, which surely corresponds to a $Z$ coupling constant. As expected, $J_{1^{\prime}, 2^{\prime}(\text { minor })}=15.2 \mathrm{~Hz}$, thus the configuration of the major isomer was established as $Z$ and that of minor isomer as $E$. These isomers present similar polarity and could not be chromatographically separated, but, considering that the stereogenic double bond will participate in the RCM process, this diastereomerism is synthetically inconsequent.

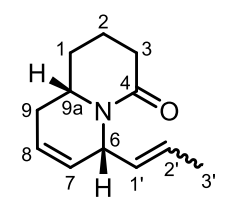

$(6 R, 9 \mathrm{aS})-182$

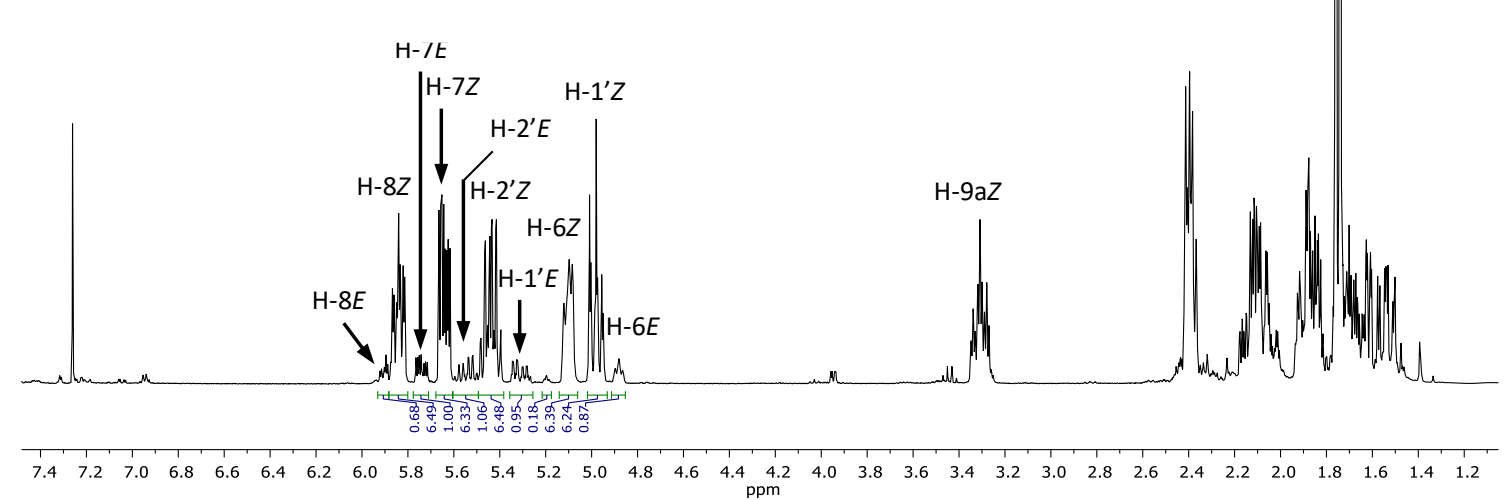

Figure 39. ${ }^{1} \mathrm{H}$ NMR spectrum $\left(360 \mathrm{MHz}, \mathrm{CDCl}_{3}\right)$ of the lactam $(6 R, 9 \mathrm{aS})-\mathbf{1 8 2}$.

\subsection{Second nucleophilic allylation}

As shown in the synthetic plan (Scheme 44), the methyl substituent of the azaphenalene system would be introduced in this second nucleophilic allylation step. The third stereogenic center would be formed and its relative configuration will determine the chirality of the final product, as mentioned in the Introduction of this chapter.

\footnotetext{
${ }^{61}$ Hog, D. T.; Huber, F. M. E.; Jiménez-Osés, G.; Mayer, P.; Houk, K. N.; Trauner, D. Chem. Eur. J. 2015, 21, 13646-13665.
} 
For the reduction-allylation step, taking into account the results obtained in Chapter 1, the objective was to found the best conditions to observe the maximum proportion of enamine 186 (analogous to enamine 179), which would be the dehydration product of the desired intermediate aminal 185 (Scheme 50). Due to the good results obtained in the optimized reduction of lactam 169, we decided to study the next combined reduction-allylation steps in the same way for 182 .

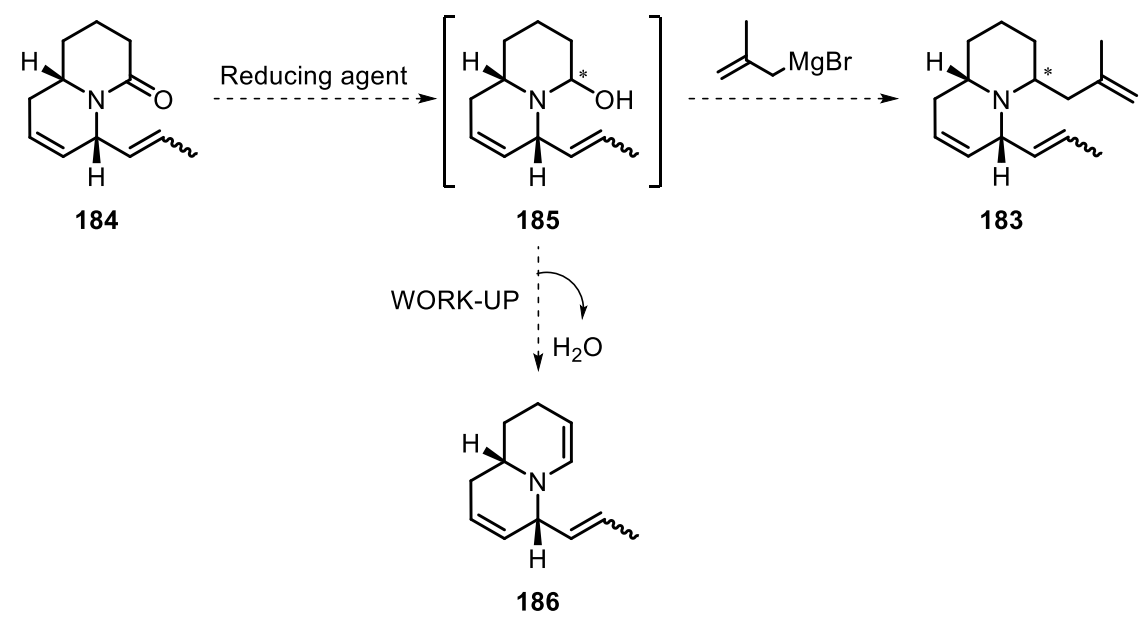

Scheme 50. Formation of enamine 186 after aqueous work-up of intermediate $\mathbf{1 8 5}$ as indirect prove of its generation.

Hence, to optimize the reaction conditions for the reduction of lactam 182, it was treated with 1 equivalent of Red-Al in THF at $-55^{\circ} \mathrm{C}$. During the reaction, some aliquot samples were withdrawn from the reaction media, then treated with $\mathrm{NaHCO}_{3}$ saturated solution and extracted with $\mathrm{CH}_{2} \mathrm{Cl}_{2}$ and, finally, analyzed by ${ }^{1} \mathrm{H} \mathrm{NMR}$ (Figure 40 ).

In Figure 40b we can observe that another product was generated after $1 \mathrm{~h}$ of reaction. By analogy to the ${ }^{1} \mathrm{H}$ NMR spectrum of enamine 179 (Figure 22, Chapter 1 ), the new signals were assigned to the enamine 186. After $1.30 \mathrm{~h}$ of the addition of the reducing agent, a roughly $1: 1$ ratio between the starting material 182 and the enamine 186 could be observed (Figure 40c). After $3 \mathrm{~h}$ of reaction, the starting lactam was totally consumed and only enamine $\mathbf{1 8 6}$ was observed in the spectrum (Figure 40d). Hence, the conditions for the reduction of lactam $\mathbf{1 8 2}$ were established as: 1 equivalent of Red-Al as reducing agent, in THF, at $-55^{\circ} \mathrm{C}$ during $3 \mathrm{~h}$. 
a) before addition of Red-Al (182)

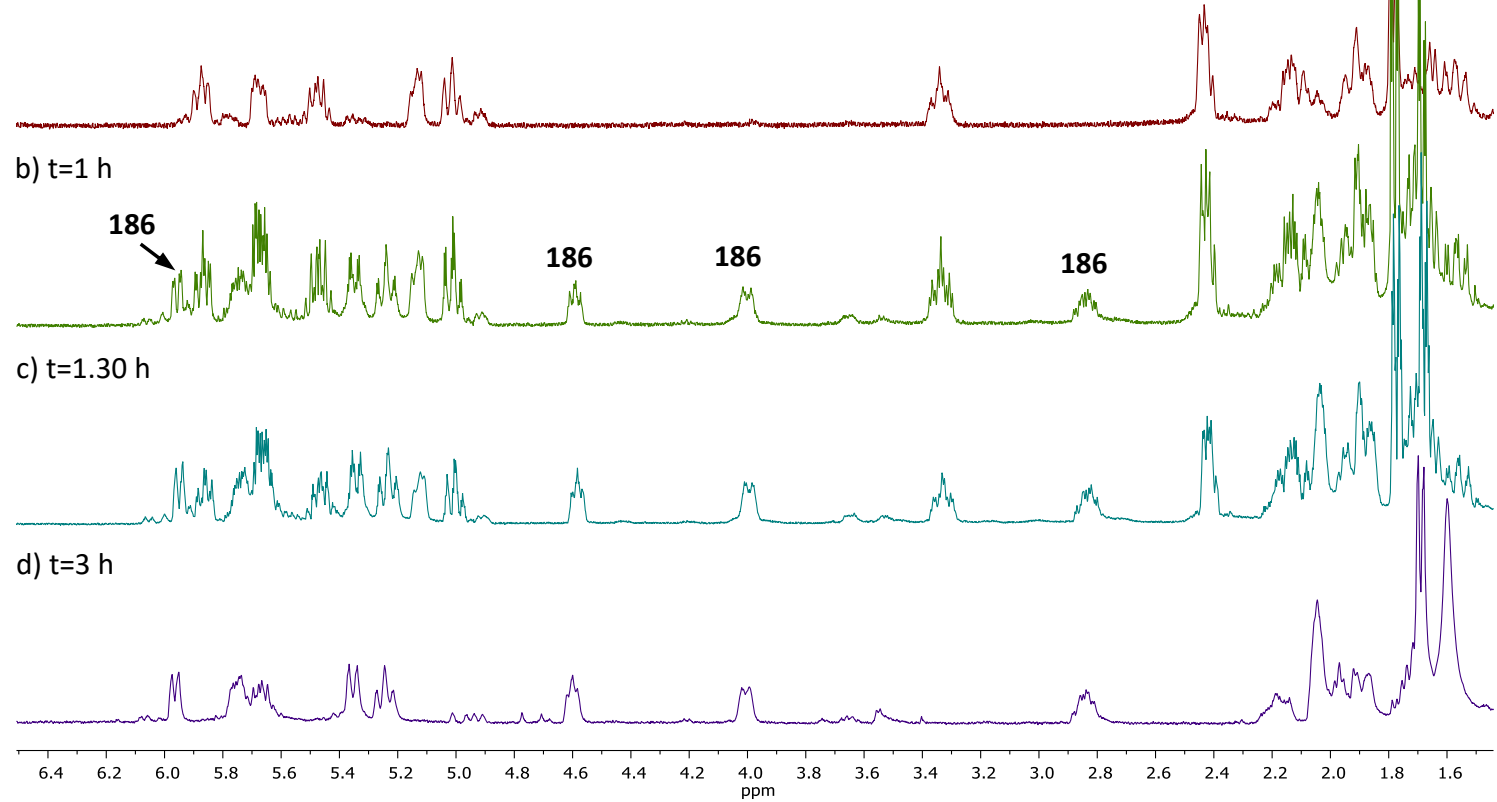

Figure $40 .{ }^{1} \mathrm{H} \mathrm{NMR}\left(250 \mathrm{MHz}, \mathrm{CDCl}_{3}\right)$ study of the reduction of 182, using Red-Al as reducing agent, over $3 \mathrm{~h}$.

The ${ }^{1} \mathrm{H}$ NMR spectrum of enamine 186 is displayed in Figure 41, where the most significant signals were assigned. The characteristic alkene protons $\mathrm{H}-4$ and $\mathrm{H}-3$ of the enamine appear at 5.97 and $4.60 \mathrm{ppm}$, respectively. The other alkene protons could be observed between 5.80 and $5.19 \mathrm{ppm}$ and the $\alpha$-nitrogen protons $\mathrm{H}-6$ and $\mathrm{H}-9 \mathrm{a}$ at 4.00 and $2.85 \mathrm{ppm}$, respectively.

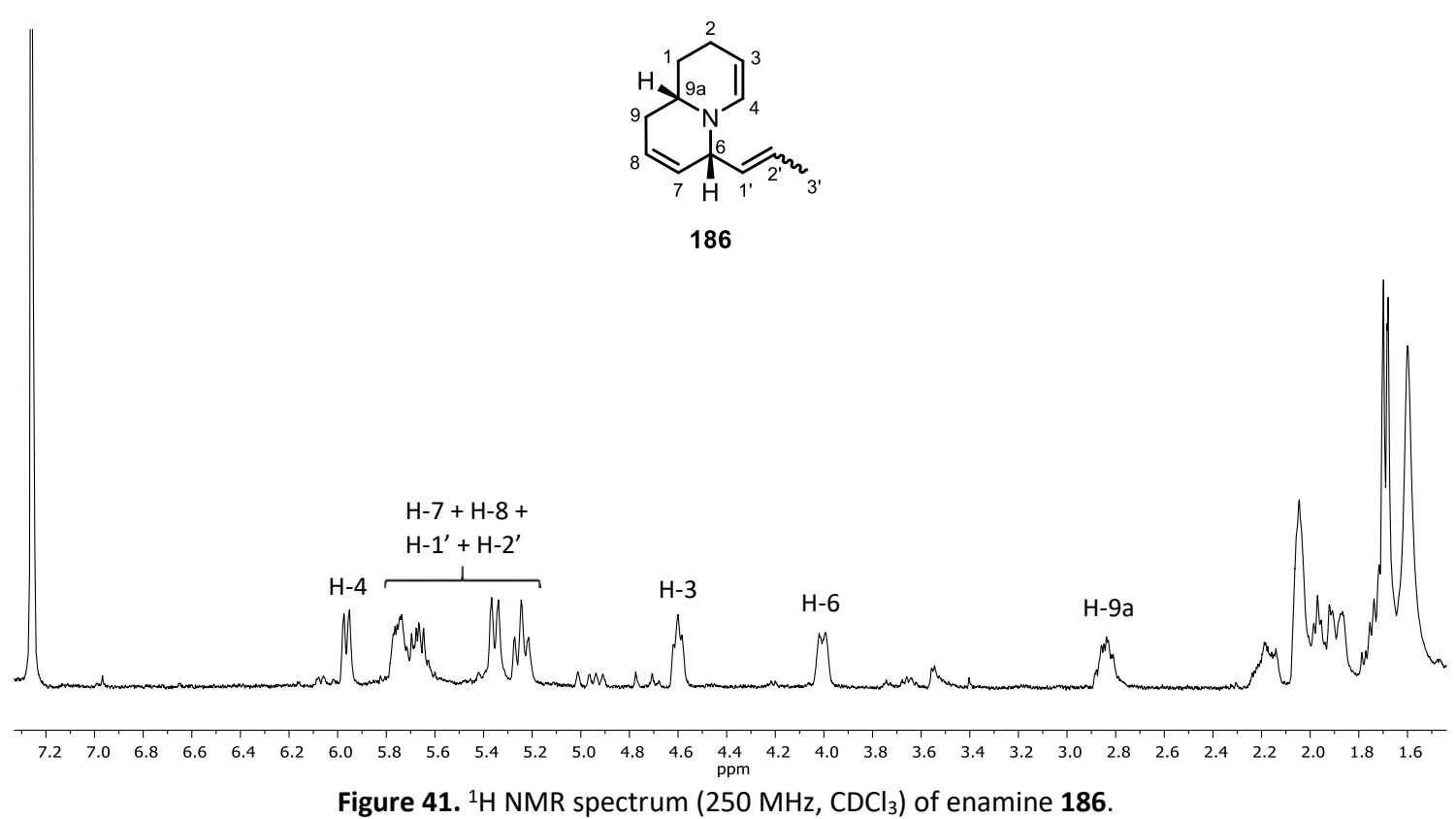

Figure 41. ${ }^{1} \mathrm{H}$ NMR spectrum $\left(250 \mathrm{MHz}, \mathrm{CDCl}_{3}\right)$ of enamine 186. 
Once the reduction was optimized, the second nucleophilic allylation was performed in the same way than the previous synthesis. Therefore, 10 equivalents of the Grignard reagent (in this case 2-methylallylmagnesium bromide, which was generated in situ) were added directly to the reduction medium and the temperature was increased from $-55^{\circ} \mathrm{C}$ to $0{ }^{\circ} \mathrm{C}$ (Scheme 51 ). The reaction was followed by TLC and, after 4 hours at the same temperature, it was completed. Then the reaction mixture was treated with saturated aqueous $\mathrm{NaHCO}_{3}$ and the organic phase was extracted with $\mathrm{CH}_{2} \mathrm{Cl}_{2}$.

Chromatographic purification of the crude product allowed the isolation of two fractions (74\% and $9 \%$ ). The relative configuration of the new stereogenic center for the major component of each fraction was investigated with the help of selective nOe experiments (Figures 42 and 43).<smiles>C/C=C/[C@H]1C=CC[C@H]2CCCC(=O)N12</smiles>

182
1) Red-Al, THF, $-55^{\circ} \mathrm{C}$

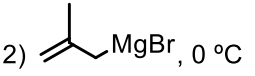

$83 \%$

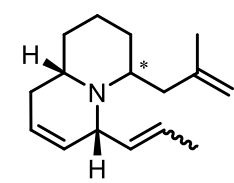

183

Scheme 51. Synthesis of amine 183

Figure 42 displays a series of selective nOe experiments of the major fraction of amine 183. The protons irradiated were the $\alpha$-nitrogen protons ( $\mathrm{H}-4, \mathrm{H}-6$ and $\mathrm{H}-9 \mathrm{a})$. Irradiation of $\mathrm{H}-6$ caused a strong nOe effect on protons $\mathrm{H}-\mathrm{1}^{\prime \prime}$. Also, caused an effect on protons $\mathrm{H}-4$ and $\mathrm{H}-9$ although the enhancement of the signal corresponding to $\mathrm{H}-4$ was substantially smaller. When proton $\mathrm{H}-4$ was irradiated, a considerable nOe effect was observed on the alkene proton $\mathrm{H}-1$ ' of the ethylene chain, a quite strong evidence that $\mathrm{H}-4$ and this chain are in the same face of the bicyclic system. If this was the case, the small nOe observed between $\mathrm{H}-6$ and $\mathrm{H}-4$ could perhaps be attributed to a minor component of this fraction (an $E$ isomer). The irradiation of $\mathrm{H}-9$ a did not give additional information.

Figure 43 shows selective nOe experiments of the minor fraction of amine 183. As before, the $\alpha$-nitrogen protons were irradiated. The most significant observation was the absence of nOe between $\mathrm{H}-4$ and any proton of the ethylene chain.

In Figure 45 are displayed the ${ }^{1} \mathrm{H}$ NMR spectra of both fractions. Based on the above nOe experiments, their major components were temptatively assigned as $(Z, 4 S, 6 R, 9 a S)-\mathbf{1 8 3}$ and $(Z, 4 R, 6 R, 9 \mathrm{a} S)-183$, represented in Figure 44 . We expected to confirm this sterochemical assignment after the RCM, since the rigidity of the tricyclic systems and the absence of $Z / E$ isomerism should facilitate it. 


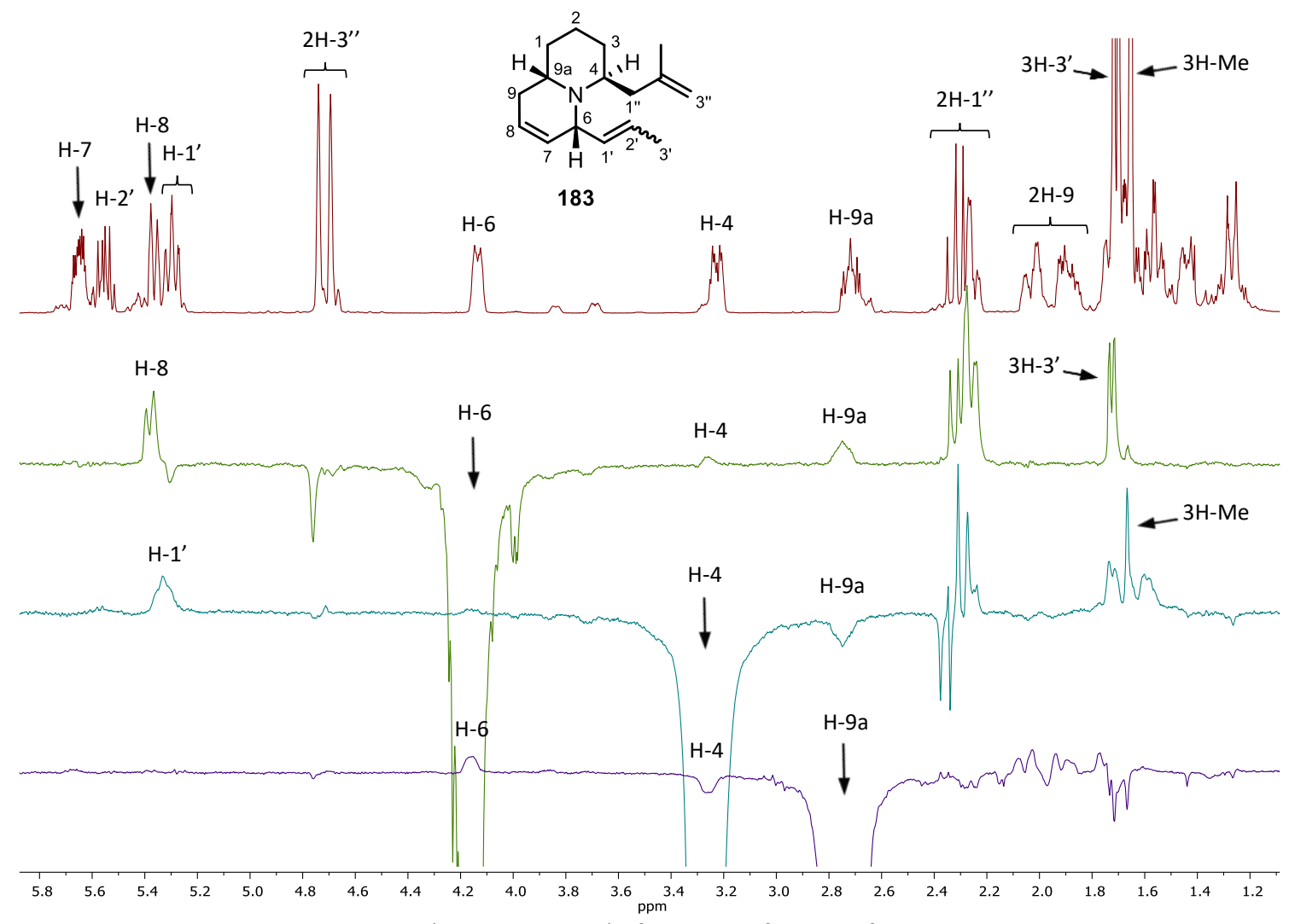

Figure 42. Selective nOe spectra $\left(400 \mathrm{MHz}, \mathrm{CDCl}_{3}\right)$ of the major fraction of 183 at $4.12,3.21$ and $2.70 \mathrm{ppm}$.

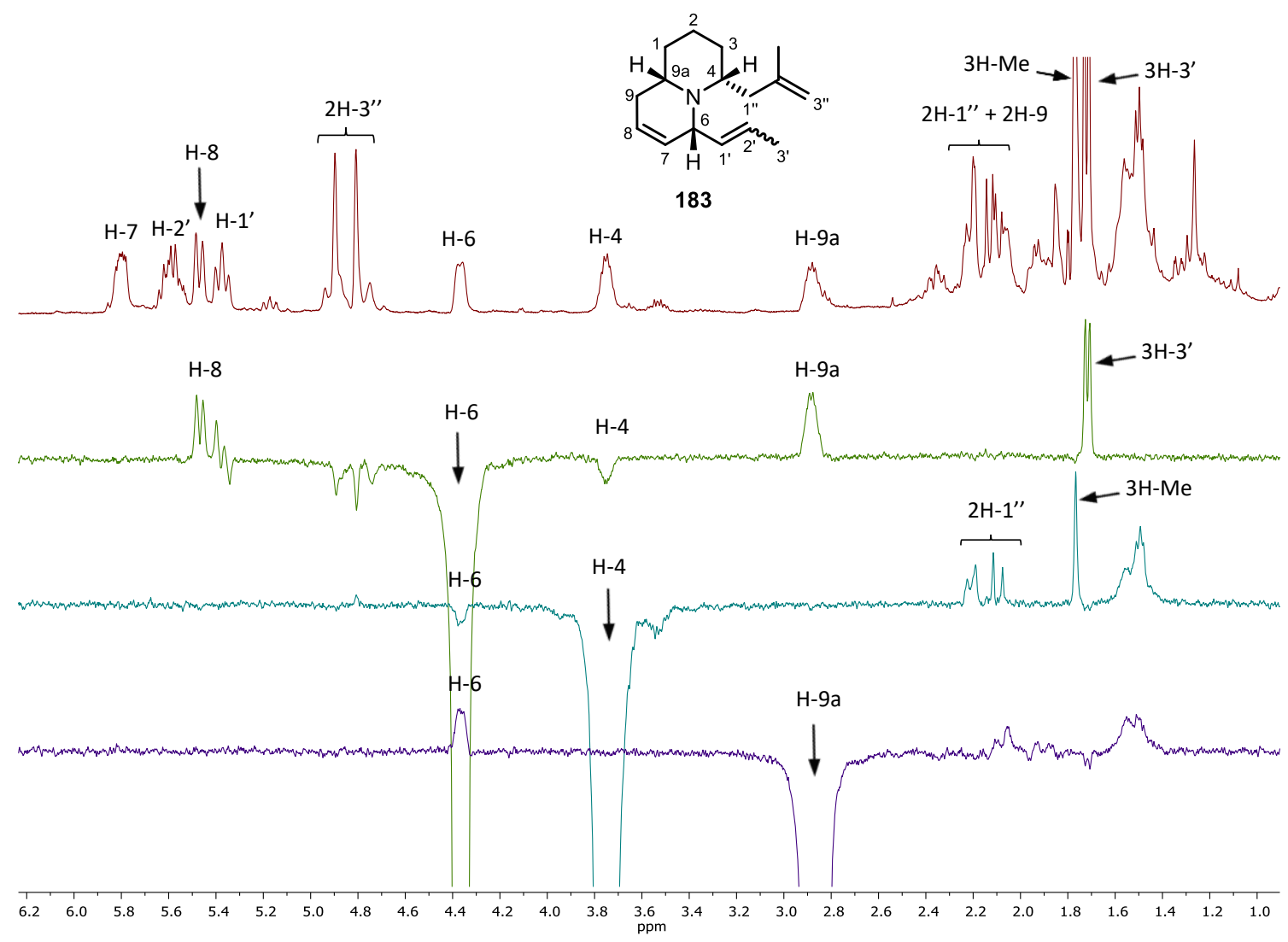

Figure 43. Selective nOe spectra $\left(360 \mathrm{MHz}, \mathrm{CDCl}_{3}\right)$ of the minor fraction of $\mathbf{1 8 3}$ at $4.32,3.73$ and $2.83 \mathrm{ppm}$. 


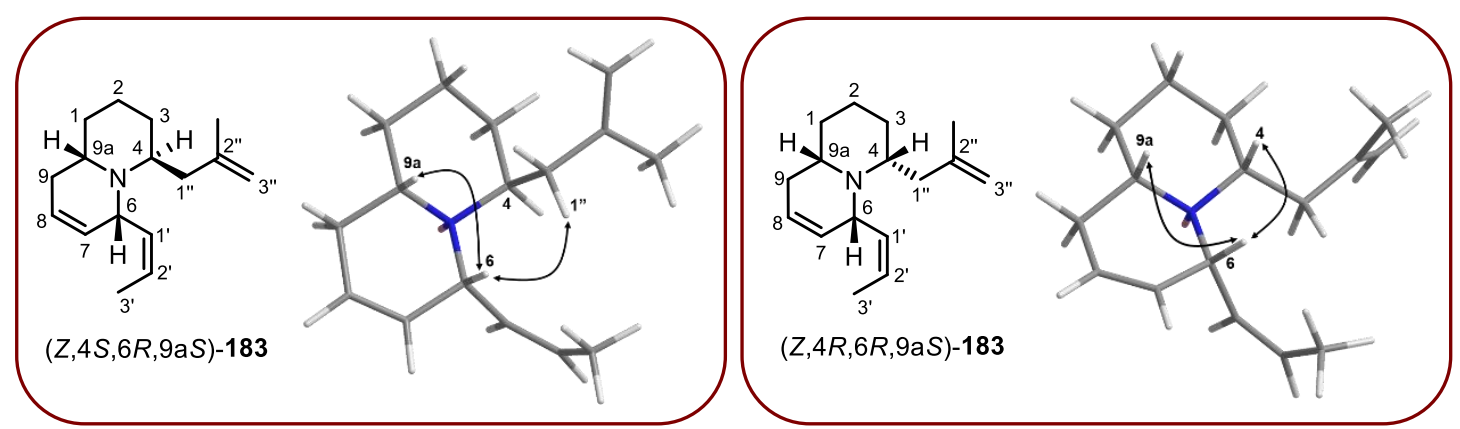

Figure 44. Representation of the structure stablished for the major and minor isomers of 183.
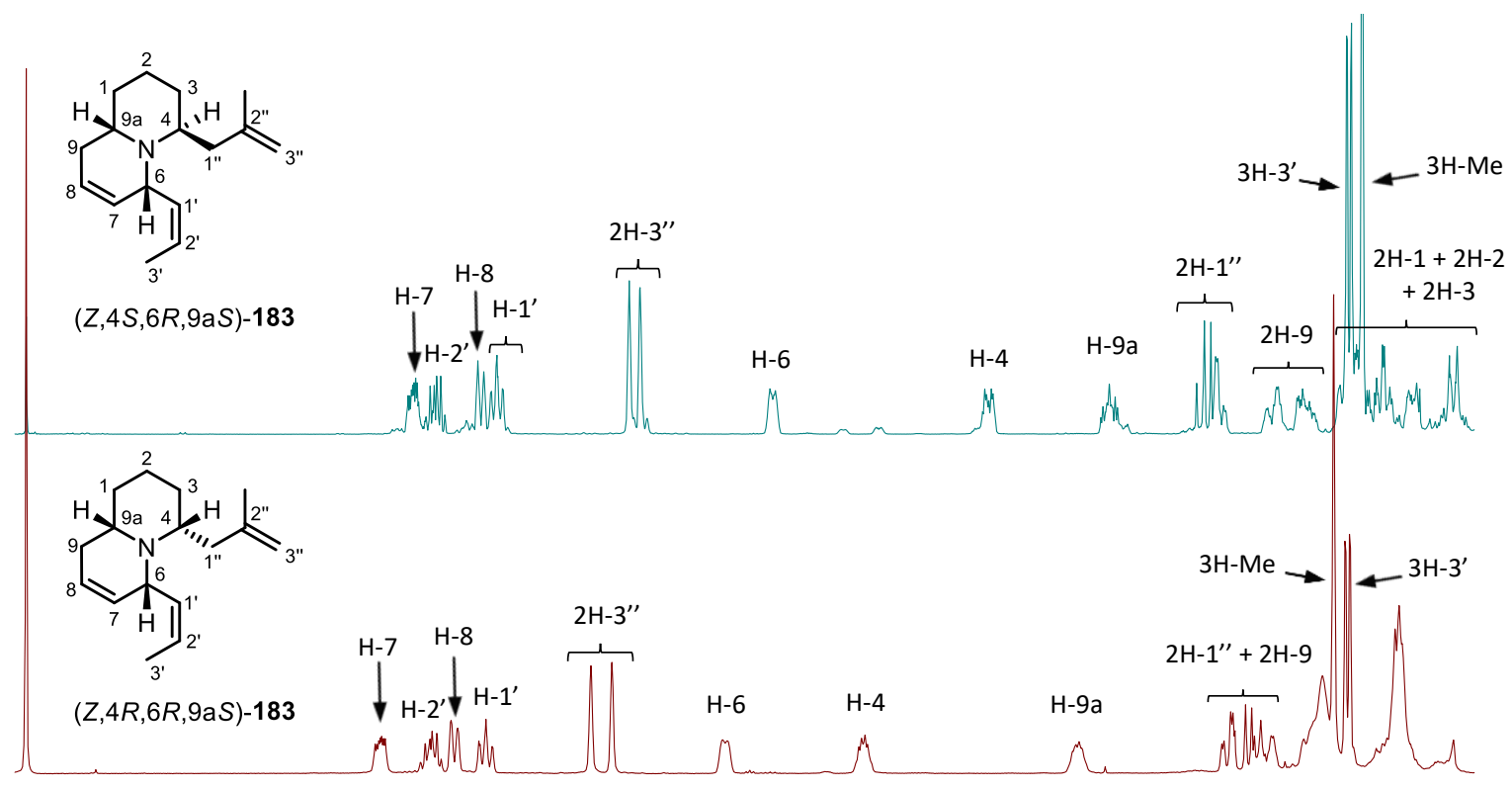

$\begin{array}{lllllllllllllllllllllllllllllllllllllllll}7.2 & 7.0 & 6.8 & 6.6 & 6.4 & 6.2 & 6.0 & 5.8 & 5.6 & 5.4 & 5.2 & 5.0 & 4.8 & 4.6 & 4.4 & 4.2 & 4.0 & 3.8 & 3.6 & 3.4 & 3.2 & 3.0 & 2.8 & 2.6 & 2.4 & 2.2 & 2.0 & 1.8 & 1.6 & 1.4 & 1.2\end{array}$

Figure 45. ${ }^{1} \mathrm{H}$ NMR spectra (400 MHz and $360 \mathrm{MHz}^{\mathrm{CDCl}} 3$ ) of both isomers of 183.

It is important to remark that the configuration of the stereogenic center generated in the second nucleophilic allylation en route to (-)-9a-epi-hippocasine, 56, had also the $S$ configuration, an additional fact to support this provisional assignment.

Fortunately, the configuration of the new stereogenic center generated in the major isomer was the desired one, since it would lead to a chiral alkaloid (see Scheme 45). 


\section{Second ring-closing metathesis}

The ring closing metathesis was assayed with each one of the fractions separated in the previous step (Scheme 52).<smiles>C=C(C)CC1CCC[C@H]2CC=CC(C=CC)(C=CC)N12</smiles>

183

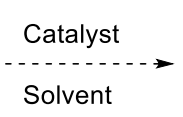

Solvent<smiles>CC1=C[C@H]2C=CC[C@H]3CCCC[C@H]3CC2C1</smiles>

171

Scheme 52. Ring-closing metathesis of 183

The major isomer of the previous allylation step seemed to be quite stable and hence the fraction containing it was used in the first RCM experiments (Table 5, entries 1-7).

Table 5. Attempts and results for the second ring-closing metathesis of $\mathbf{1 8 3 .}$

\begin{tabular}{|c|c|c|c|c|}
\hline Entry & Fraction & Catalyst $^{a}$ & Solvent $\mathrm{t}^{\mathrm{b}}$ & Results \\
\hline 1 & Major & Grubbs II & $\mathrm{CH}_{2} \mathrm{Cl}_{2}$ & $\mathrm{sm}$ \\
\hline 2 & Major & Grubbs II & 1,2-Dichloroethane & sm \\
\hline 3 & Major & Grubbs II & Toluene & $171+$ sm + decomposed \\
\hline 4 & Major & Hoveyda-Grubbs II & $\mathrm{CH}_{2} \mathrm{Cl}_{2}$ & sm \\
\hline 5 & Major & Grubbs II + TFA & $\mathrm{CH}_{2} \mathrm{Cl}_{2}$ & $\mathrm{sm} \cdot \mathrm{TFA}$ \\
\hline 6 & Major & Grubbs II + TFA & Toluene & $\mathrm{sm} \cdot \mathrm{TFA}+$ decomposed \\
\hline 7 & Major & Schrock & $\mathrm{CH}_{2} \mathrm{Cl}_{2}$ & sm \\
\hline 8 & Minor & Grubbs II & 1,2-Dichloroethane ${ }^{c}$ & $\mathrm{sm}$ \\
\hline 9 & Minor & Grubbs II & 1,2-Dichloroethane & Decomposed \\
\hline 10 & Minor & Grubbs II & $\mathrm{CH}_{2} \mathrm{Cl}_{2}$ & Decomposed \\
\hline
\end{tabular}

a In all the attempts a 10 mol\% of the catalyst was used. ${ }^{b}$ All the experiments were performed under reflux. ${ }^{c}$ This experiment was performed at room temperature.

As all the previous ring-closing metathesis performed in this thesis worked well by using the second generation Grubbs catalyst, the first experiment was performed using $10 \mathrm{~mol} \%$ of it, under reflux of dry $\mathrm{CH}_{2} \mathrm{Cl}_{2}$ (entry 1). Unfortunately, after $14 \mathrm{~h}$, only starting material was present in the reaction media, which was identified by TLC. After filtration through neutral alumina, only starting material was recovered, in a reasonable weight, and no decomposition products were 
observed by ${ }^{1} \mathrm{H}$ NMR. Since the amount of catalyst used was high and no reaction conversion was observed, we decided to study this RCM using other reaction conditions.

Considering that the RCM of sterically demanding alkenes is known to be difficult to achieve, we decided to increase the temperature in order to favor the formation of the tricyclic compound 171 . Firstly, we used 1,2 -dichloroethane (boiling point $83^{\circ} \mathrm{C}$, entry 2 ) and the amine 183 was treated again with 10 mol\% of Grubbs II but, after 14 h, only starting material was observed by TLC. Luckily, no decomposition products were observed by ${ }^{1} \mathrm{H}$ NMR in the crude product, meaning that we could further increase the reaction temperature.

The next solvent tested was toluene (boiling point $111^{\circ} \mathrm{C}$, entry 3 ). After $24 \mathrm{~h}$, there were significant changes in the TLC analysis. We decided to stop the reaction by filtering the mixture through a short pad of neutral alumina and the crude residue was analyzed by ${ }^{1} \mathrm{H} N M R$. The spectrum was not really clear and the crude product was purified by column chromatography on neutral alumina. After the purification, we observed a huge quantity of decomposition products (almost $89 \%$ in weight), $9 \%$ of starting material and $2 \%$ of a fraction which could contain the tricycle 171 (which was not pure). Even though the quantity of the tricyclic compound 171 was low, we could register an ${ }^{1} \mathrm{H}$ NMR spectrum (Figure 46), where we could distinguish some characteristic signals to identify the tricyclic amine 171.

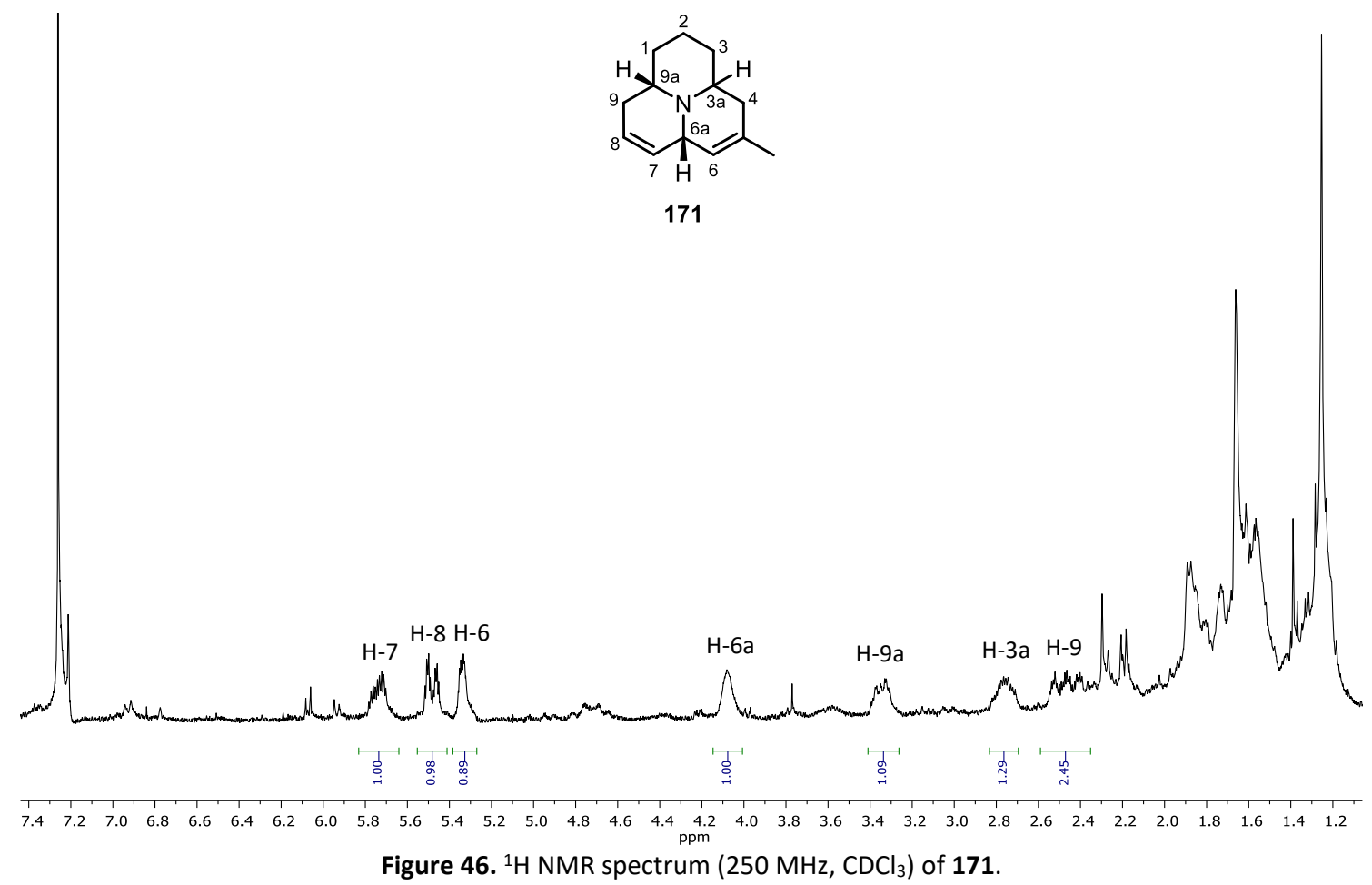


The signals were assigned with the help of a 2D-COSY experiment (Figure 47). The signals of alkene protons $\mathrm{H}-7, \mathrm{H}-8$ and $\mathrm{H}-6$ are observed at $5.75,5.48$ and $5.35 \mathrm{ppm}$, respectively. Also, we could establish the signals of the $\alpha$-nitrogen protons $\mathrm{H}-6 \mathrm{a}, \mathrm{H}-9 \mathrm{a}$ and $\mathrm{H}-3 \mathrm{a}$, which are present at $4.10,3.35$ and $2.75 \mathrm{ppm}$, respectively, and recognize the signals of the protons $\mathrm{H}-9$, which are at $2.45 \mathrm{ppm}$.

While registering the ${ }^{1} \mathrm{H}$ NMR spectra, it was observed that the tricyclic compound slowly decomposed. Consequently, it was not advisable to run the reaction at higher temperatures. For this reason, we decided to assay other catalysts, that could hopefully perform better under milder conditions.

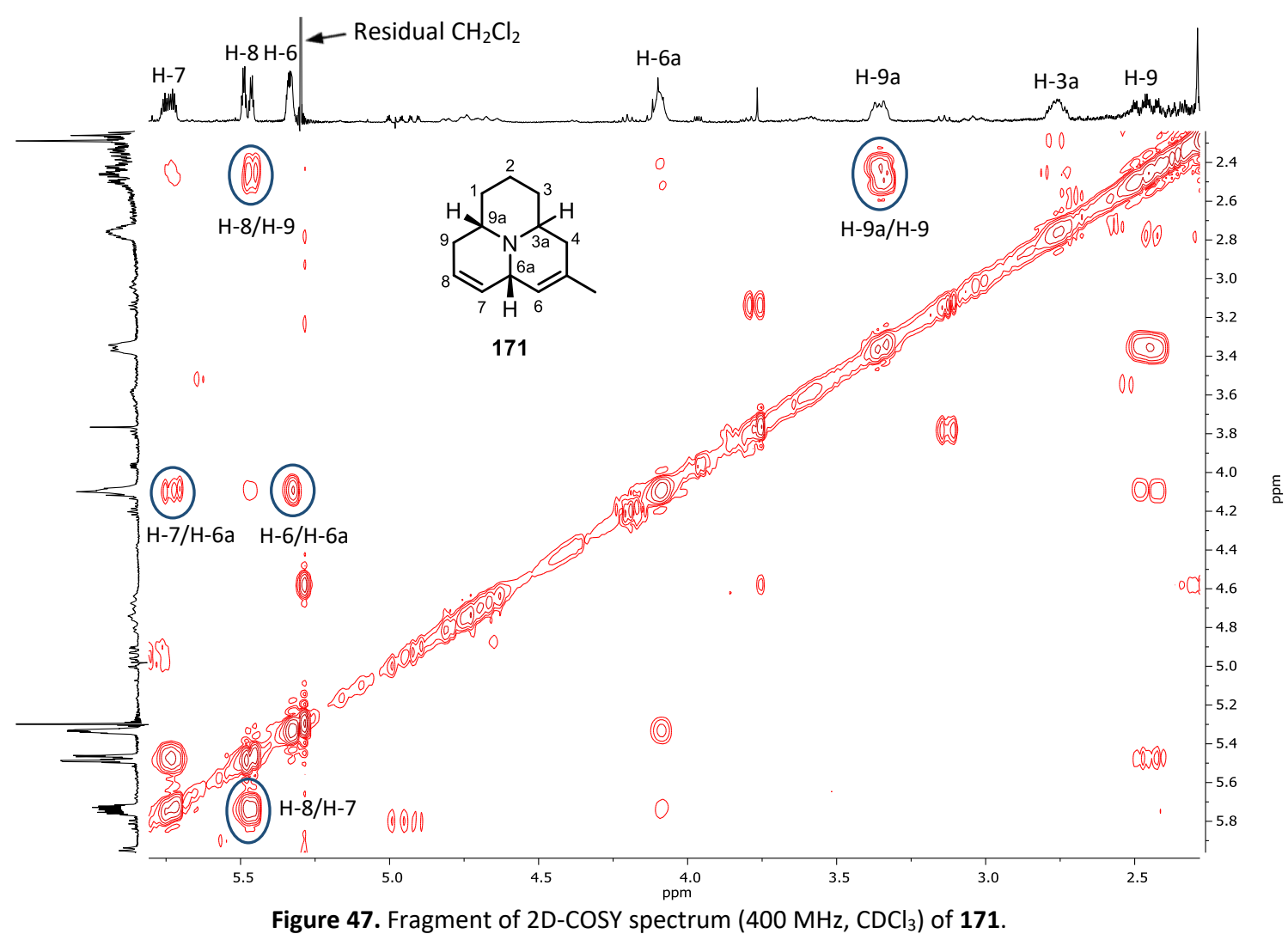

Therefore, we changed to the Hoveyda-Grubbs second generation catalyst, by using a 10 mol\% loading, under reflux of dry $\mathrm{CH}_{2} \mathrm{Cl}_{2}$ (entry 4). After $16 \mathrm{~h}$, no changes were observed by TLC. As expected, no degradation products were observed by ${ }^{1} \mathrm{H}$ NMR of the reaction crude residue and the starting material was recovered in the same amount. 
It is known that the RCM of tertiary amines are difficult and sometimes requires the use of acid derivatives in order to avoid a possible catalyst deactivation by the basic nitrogen. ${ }^{62}$ Because of that, we used TFA in the next experiment to protonate the amine. Hence, the fifth experiment was performed using $10 \mathrm{~mol} \%$ of second generation Grubbs catalyst and 1 equivalent of TFA under reflux of $\mathrm{CH}_{2} \mathrm{Cl}_{2}$ (entry 5). After 16 hours, the reaction mixture was filtered through a short pad of neutral alumina, and only starting material was spoted in the ${ }^{1} \mathrm{H}$ NMR spectrum of the reaction crude residue. Nevertheless, no degradation products were observed and the starting material was recovered in a reasonable weight. For this reason, the temperature could be increased.

In the next experiment we changed the solvent to toluene (entry 6). After 16 hours the aspect of the TLC changed and we decided to stop the reaction by filtering the mixture through a short pad of neutral alumina. The crude residue was analyzed by ${ }^{1} \mathrm{H} N M R$, where it could be observed the signals corresponding to the protonated starting material as well as a lot of decomposition products.

Considering these results, we decided to change to the more reactive Schrock catalyst. Hence, amine 183 was treated with 10 mol\% of it and heated to reflux temperature in $\mathrm{CH}_{2} \mathrm{Cl}_{2}$ (entry 7). After $4 \mathrm{~h}$, no change in the TLC could be observed, but the reaction mixture changed its color from yellow to dark green, maybe coming from the decomposition of the Schrock catalyst. It is well known that this catalyst exhibits high sensitivity to air and moisture and also presents thermal instability. ${ }^{63}$ The reaction mixture was filtered through a short pad of neutral alumina and the crude residue was analyzed by ${ }^{1} \mathrm{H}$ NMR. The ${ }^{1} \mathrm{H}$ NMR spectrum confirmed that the reaction did not work. Only starting material was recovered and no decomposition products were perceived.

Some RCM were intended also starting from the minor fraction isolated in the previous allylation step (Table 5, entries 8-10). Due to the limited stability of the major component of this fraction, the first attempt was performed at room temperature in 1,2-dichloroethane as solvent by using 10 mol\% of second generation Grubbs catalyst (entry 8 ). After $14 \mathrm{~h}$, only starting material was observed by TLC of the reaction mixture. This was also confirmed by ${ }^{1} \mathrm{H}$ NMR analysis. No decomposition products were present in it.

\footnotetext{
62 a) Wright, D. L.; Schulte II, J. P.; Page, M, A. Org. Lett. 2000, 2, 1847-1850. b) Woodward, C. P.; Spiccia, N. D.; Jackson, W. R.; Robinson, A. J. Chem. Commun. 2011, 47, 779-781. c) Senter, T. J.; Schulte, M. L.; Konkol, L. C.; Wadzinski, T. E.; Lindsley, C. W. Tetrahedron Lett. 2013, 54, 1645-1648.

${ }^{63}$ Scholl, M.; Ding, S.; Lee. C. W.; Grubbs, R. H. Org. Lett. 1999, 1, 953-956.
} 
A second experiment (entry 9) was performed also in 1,2-dichloroethane, at reflux temperature. After $5 \mathrm{~h}$, no starting material was observed but no defined spots were present in the TLC. The ${ }^{1} \mathrm{H}$ NMR of the crude product did not show neither the presence of the tricycle nor starting material but only the presence of decomposition products, probably derived from the starting material.

The next attempt was made in $\mathrm{CH}_{2} \mathrm{Cl}_{2}$ as solvent and the reaction was performed at reflux in the presence of $10 \mathrm{~mol} \%$ of Grubbs II (entry 10). After $5 \mathrm{~h}$ no starting material was observed by TLC. The reaction mixture was filtered through a short pad of neutral alumina and the ${ }^{1} \mathrm{H}$ NMR spectrum of the crude residue showed again only the presence of decomposition products.

These negative results may be a consequence of different issues involving high steric hindrance, limited stability of the starting materials and/or products, among others. For these reasons, we decided to explore alternative pathways, which could overcome the difficulties found.

\section{Alternative approaches}

\subsection{Second synthetic plan}

According to the above considerations, we planned to substitute the ethylene chain by a terminal alkene (Scheme 53). This fact could increase the accessibility of the RCM catalyst to form the carbene. Furthermore, the presence of a terminal alkene would eliminate the formation of $Z / E$ diastereomers.<smiles>O=C1CCC[C@H]2CC=C[C@H](CO)N12</smiles>

181
1) Oxidation

2) Tebbe alkenylation

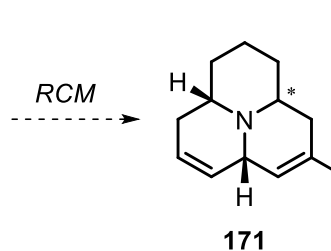

171

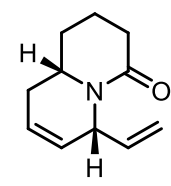

187

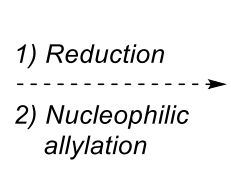

allylation

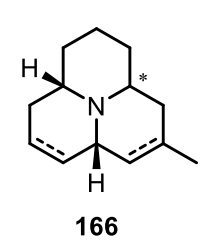

Scheme 53. Second synthetic plan. 


\subsubsection{Dess-Martin oxidation and Tebbe alkenylation}

For the methylenation, we decided to assay, as the first choice, a Tebbe alkenylation instead of a Wittig reaction because, a priori, it seems easy to perform and it does not produce triphenylphosphine oxide, which is hard to separate by column chromatography.

After the alkenylation, the reduction and second nucleophilic allylation steps would be intended, followed by the second ring-closing metathesis. Once the tricyclic compound $\mathbf{1 6 6}$ would be obtained, depending on the stereoselectivity observed, we would decide if the final hydrogenation step should be chemoselective or not.

To proceed with the Tebbe alkenylation, the previous oxidation of the alcohol $(6 S, 9 a S)$ 181 was performed as before and, without previous purification, the aldehyde (6S,9aS)-184 was treated with 1 equivalent of Tebbe reagent using THF as solvent at $0{ }^{\circ} \mathrm{C}$ (Scheme 54). ${ }^{64}$ The reaction was monitored by TLC and after $50 \mathrm{~min}$, when no starting material was observed, the reaction mixture was worked-up and the crude residue was analyzed by ${ }^{1} \mathrm{H}$ NMR. It showed the formation of the desired diene $(6 R, 9 a S)-\mathbf{1 8 7}$. Then, after purification by column chromatography on silica gel, the terminal alkene $(6 R, 9 a S)-187$ was obtained in $58 \%$ yield from alcohol $(6 S, 9 a S)$ 181.

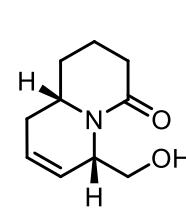

$(6 S, 9 a S)-181$

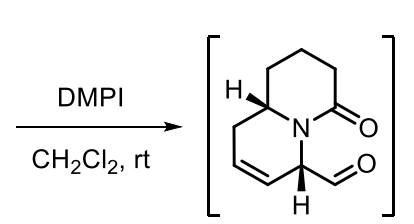

$(6 S, 9 a S)-184$

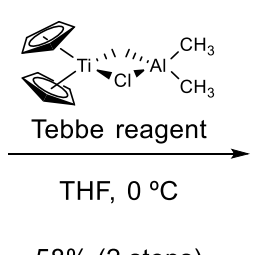

$58 \%$ (2 steps)

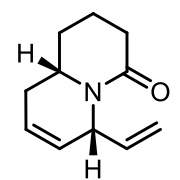

$(6 R, 9 a S)-187$

Scheme 54. Synthesis of terminal alkene $(6 R, 9 a S)-187$

In the ${ }^{1} \mathrm{H}$ NMR spectrum of the crude residue, the presence of decomposition products was not detected but, unfortunately, after the purification step, a huge quantity of them were isolated (around 40\%). Because of that, the yield of the reaction was moderate. Nevertheless, (6R,9aS)-187 became stable once isolated. To reduce the product degradation, a column chromatography on neutral alumina was also tried, but the result was the same.

The ${ }^{1} \mathrm{H}$ NMR spectrum of diene $(6 R, 9 a S)-187$ is shown in Figure 48 , where there can be seen the signals of the alkene protons between 6.00 and $4.97 \mathrm{ppm}$. The typical pattern of the

\footnotetext{
${ }^{64}$ Nicolaou, K. C.; Snyder, S. A.; Huang, X.; Simonsen, K. B.; Koumbis, A. E.; Bigot, A. J. Am. Chem. Soc. 2004, 126, 10162-10173.
} 
terminal alkene was perfectly identified. Also the signals of the $\alpha$-nitrogen protons $\mathrm{H}-6$ and $\mathrm{H}-$ 9a were present at 4.95 and 3.35 ppm respectively together with that of $\mathrm{H}-3$ at 2.43 ppm.

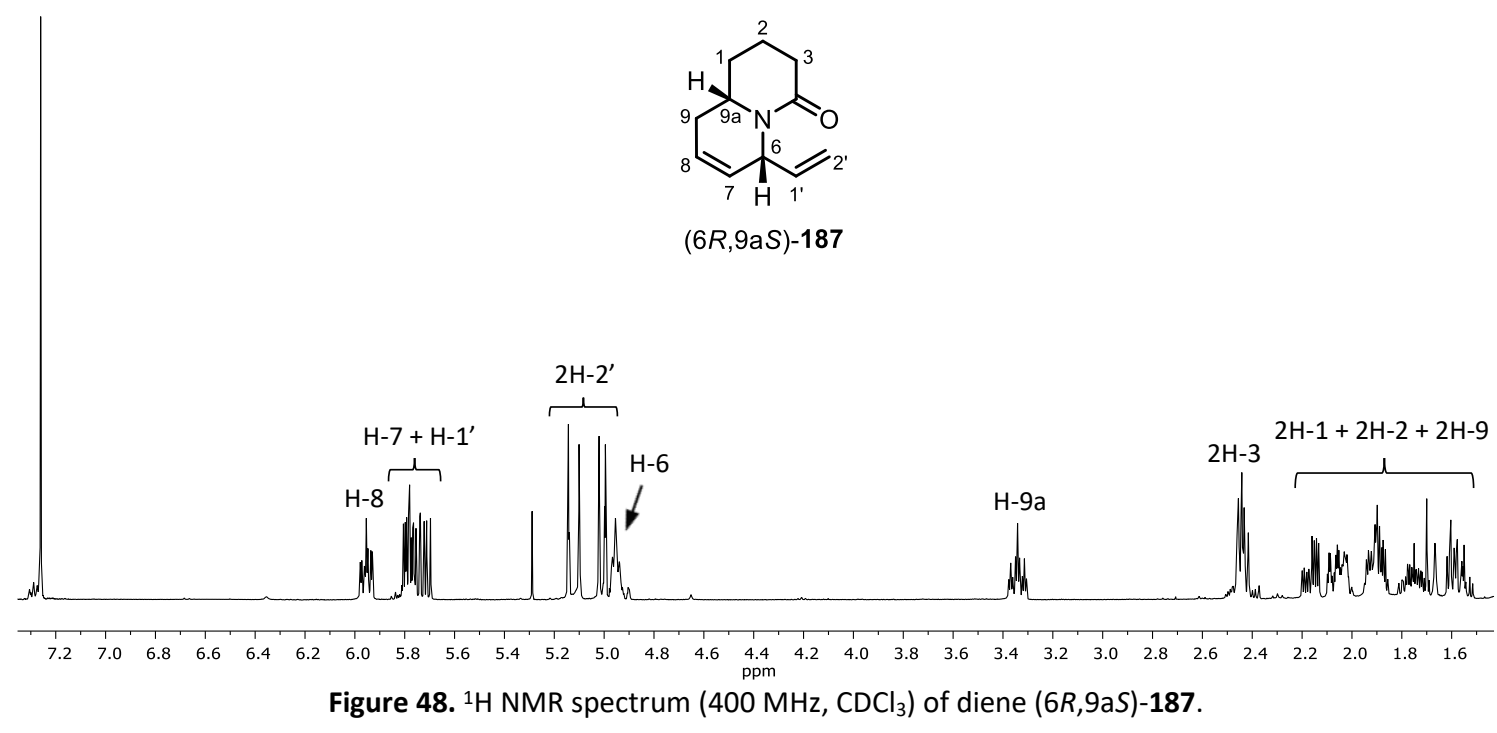

\subsubsection{Reduction and second nucleophilic allylation}

To overcome the problem of the degradation of $(6 R, 9 a S)-187$ and increase the overall yield of the sequence, we tried to perform Dess-Martin oxidation, Tebbe alkenylation, lactam reduction and nucleophilic allylation in one step (Scheme 55), namely isolating the intermediates but without purifying them.

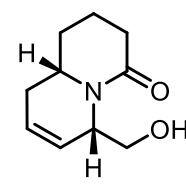

$(6 S, 9 a S)-181$
1) $\mathrm{DMPI}, \mathrm{CH}_{2} \mathrm{Cl}_{2}$, $\mathrm{rt}$

2) Tebbe reagent, THF, $0^{\circ} \mathrm{C}$

3) Red-Al, THF, $-55^{\circ} \mathrm{C}$

4)

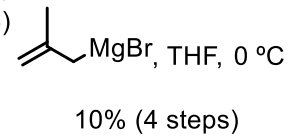

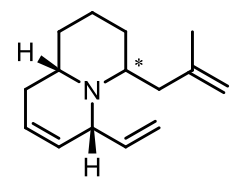

(6R,9aS)-188

Scheme 55. Synthesis of (6R,9aS)-188 from alcohol (6S,9aS)-181.

To study the reduction of $(6 R, 9 a S)-\mathbf{1 8 7}$ we used the same method than for the reduction of $(6 R, 9 a S)-182$. Hence, the crude lactam (6R,9aS)-187 was treated with 1 equivalent of Red-Al, in THF at $-55^{\circ} \mathrm{C}$ and some aliquot samples were withdrawn from the reaction media every hour, treated with saturated aqueous $\mathrm{NaHCO}_{3}$ and analyzed by ${ }^{1} \mathrm{H}$ NMR (Figure 49). As before, the objective was to observe the formation of the enamine 189.

As it can be seen in Figure 49, $1 \mathrm{~h}$ after the addition of the reducing agent, a little quantity of the enamine 189 was present. The signals of the enamine 189 were stablished by analogy to that of enamine 186. Thus, we focused in the signal at $6.05 \mathrm{ppm}$ and also in the signals of the 
$\alpha$-nitrogen protons. After $2 \mathrm{~h}$, the consumption of the starting material was almost finished but, after $3 \mathrm{~h}$, some signals of decomposition products appeared in the ${ }^{1} \mathrm{H}$ NMR spectrum. Therefore, the best compromise between starting material consumption and appearance of degradation products seems to be after $2 \mathrm{~h}$ of reduction.

a) before addition of Red-Al (187)
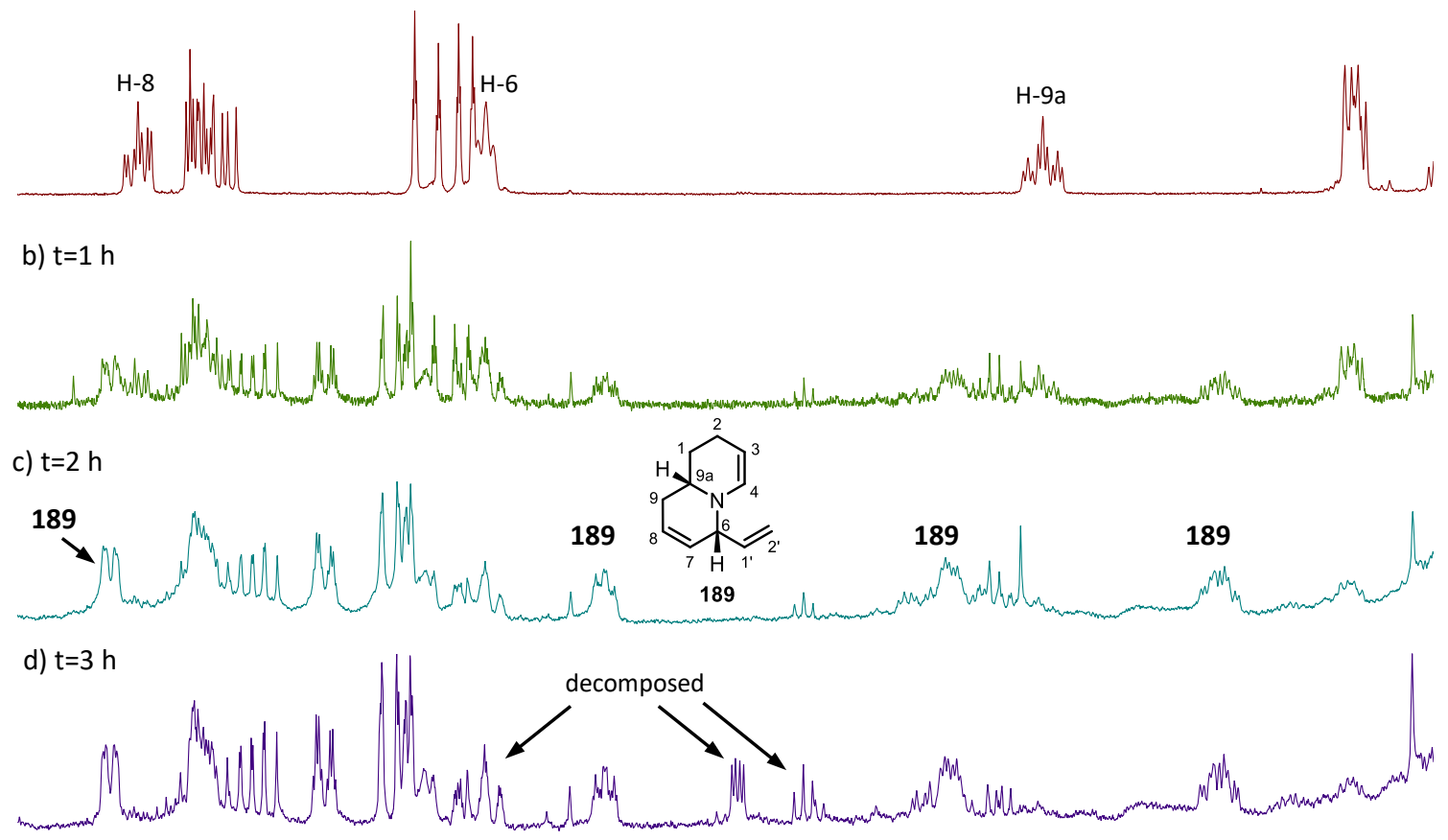

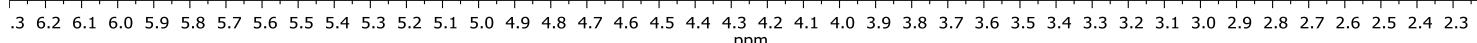

Figure 49. ${ }^{1} \mathrm{H} \mathrm{NMR}\left(250 \mathrm{MHz}, \mathrm{CDCl}_{3}\right)$ study of the reduction of 187 , using Red-Al as reducing agent, over $3 \mathrm{~h}$.

Taking this information into account, we proceeded to perform the second nucleophilic allylation. To this end, 10 equivalents of the Grignard reagent (generated in situ) were added directly to the reduction medium, in the same way of the reduction-allylation of lactam $\mathbf{1 8 2}$. After $3 \mathrm{~h}$, no starting material was detected by TLC and the reaction was quenched by treatment with saturated aqueous $\mathrm{NaHCO}_{3}$ and, after extractions with $\mathrm{CH}_{2} \mathrm{Cl}_{2}$, the crude residue was analyzed by ${ }^{1} \mathrm{H}$ NMR. The ${ }^{1} \mathrm{H}$ NMR spectrum of the crude residue of the reduction-allylation step (Figure 50b) does not display the enamine signals and shows that probably two isomers are present, according to the two signals between 4.05 and $3.75 \mathrm{ppm}$, which could be attributed to protons $\mathrm{H}-6$ of 188 , by analogy to that of amine 183 , where the signals corresponding to the protons $\mathrm{H}-6$ of both isomers appear between 4.38 and 4.05 ppm (see Figure 45 ).

Unfortunately, after purification by column chromatography on silica gel, triene $\mathbf{1 8 8}$ was isolated in only $10 \%$ yield from alcohol 181 and yet not totally pure (Figure 50c). The other 
fractions collected from the chromatography were decomposition products (almost $90 \%$ of the weight).

In the ${ }^{1} \mathrm{H}$ NMR spectrum of the isolated fraction (Figure 50c), some characteristic signals of the triene 188, can be distinguished. Hence, protons of the terminal alkene, $\mathrm{H}-\mathrm{1}^{\prime}$ and $\mathrm{H}-\mathrm{2}^{\prime}$, were present at 5.68 and $5.13 \mathrm{ppm}$, respectively, with their typical pattern. The signal of the other terminal alkene, $\mathrm{H}-3^{\prime \prime}$, appears at $4.73 \mathrm{ppm}$ and the signals of the other alkene protons $\mathrm{H}$ 7 and H-8 were at 5.68 and $5.42 \mathrm{ppm}$. We can also identify the signals corresponding to the $\alpha-$ nitrogen protons $\mathrm{H}-6, \mathrm{H}-4$ and $\mathrm{H}-9 \mathrm{a}$ at $3.75,3.25$ and $2.68 \mathrm{ppm}$, respectively.

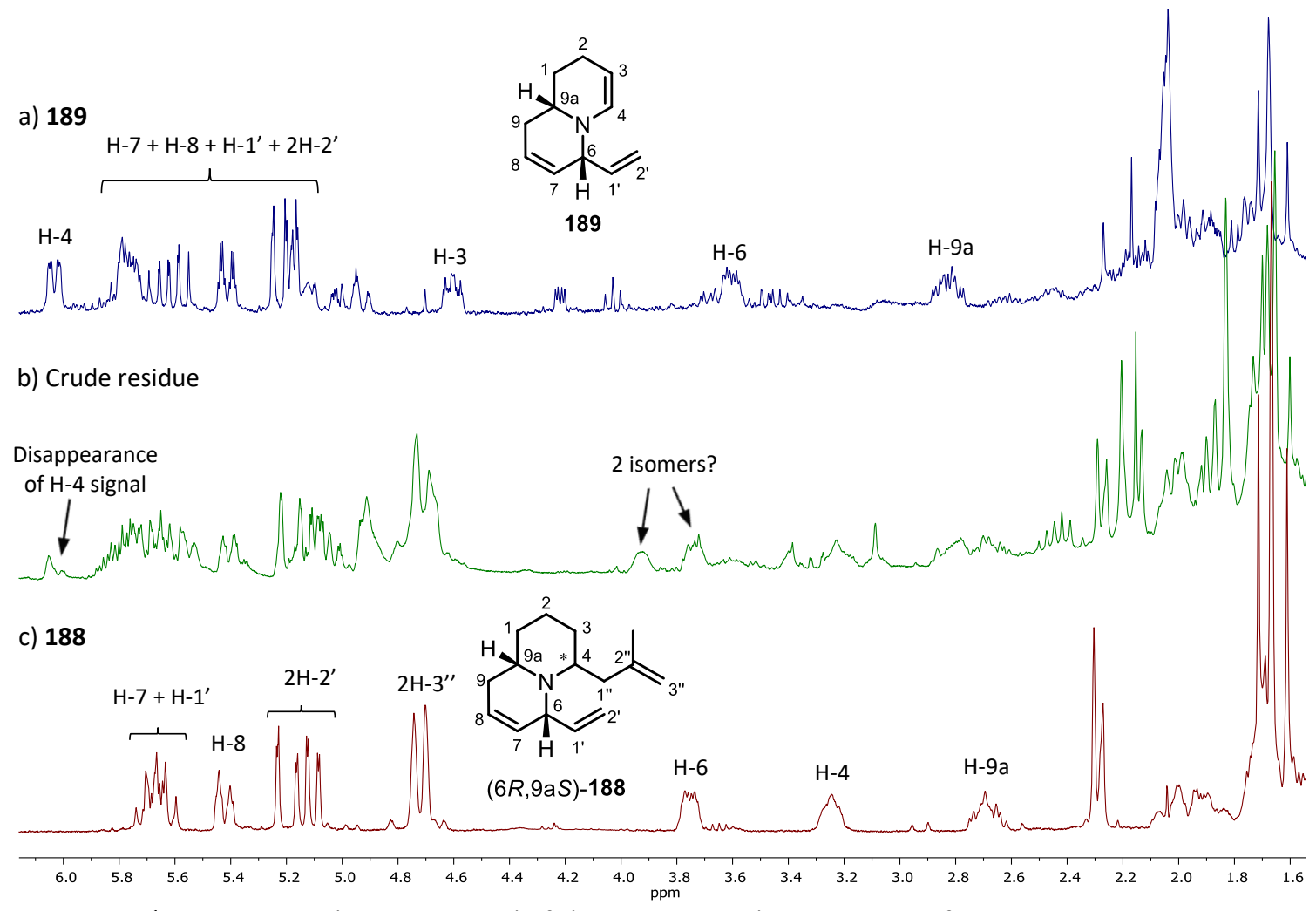

Figure 50. ${ }^{1} \mathrm{H}$ NMR spectra $\left(250 \mathrm{MHz}, \mathrm{CDCl}_{3}\right)$ of a) enamine 189 , b) crude residue of oxidation-Tebbe-reductionallylation step, c) isolated amine $\mathbf{1 8 8 .}$

Although the ${ }^{1} \mathrm{H}$ NMR spectrum of the crude product of the 4-step sequence was not totally clear, it was evident that it contained more amine 188 than the amount isolated, thus, a huge quantity of it was decomposed during the column chromatography. Moreover, only one isomer was detected after the purification trial, surely because the other one was completely degraded.

The amine 188 could not fully characterized due to its instability, therefore, this synthetic pathway had to be discarded. 


\subsection{Third synthetic plan}

In the previous synthetic route, we obtained unstable intermediates yielding mainly decomposition products. As a way to overcome this difficulty, we decide to assay the hydrogenation of the firstly generated $\mathrm{C}-\mathrm{C}$ double bond and then continue with the synthetic route to see if the new compounds present more stability (Scheme 56).<smiles>O=C1CCC[C@H]2CC=C[C@H](CO)N12</smiles>

181<smiles>O=C1CCC[C@H]2CCC[C@@H](CO)N12</smiles>

190
1) Oxidation

2) Alkenylation

$\mathrm{R}=\mathrm{H}, 191$
$\mathrm{R}=\mathrm{Me}, 192$

$\mathrm{R}=\mathrm{H}, \quad 191$

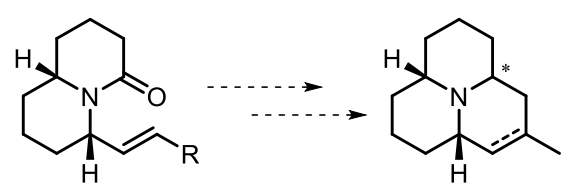

Scheme 56. Third synthetic plan.

Therefore, the new route would consist on hydrogenation of the alkene in alcohol 181, followed by Dess-Martin oxidation and then alkenylation. This alkenylation could be done via Wittig reaction to deliver alkene $\mathbf{1 9 2}$ or using the Tebbe reagent to afford the terminal alkene 191. The synthesis would follow with the reduction-allylation step and the second ring-closing metathesis to obtain the azabicycle, which could be hydrogenated or not, depending on the relative configuration of the stereogenic centers.

\subsubsection{Hydrogenation of the C-7, C-8 double bond}

Following the methodology employed for the hydrogenation of 171 in Chapter 1, the alcohol $(65,9 \mathrm{aS})-\mathbf{1 8 1}$ was treated with $\mathrm{H}_{2}$ (2 atm) using a 10\% (w/w) of $\mathrm{Pd} / \mathrm{C}$ catalyst and some drops of acetic acid in $\mathrm{MeOH}$ for $14 \mathrm{~h}$ (Scheme 57). After that time, no starting material was spotted in the TLC and the reaction mixture was filtered through Celite ${ }^{\circledR}$. After treatment with saturated aqueous $\mathrm{NaHCO}_{3}$ and extractions with $\mathrm{CH}_{2} \mathrm{Cl}_{2}$, the purification was done by filtration through a short pad of silica gel. Alcohol $(6 S, 9 a R)-190$ was obtained in $78 \%$ yield.

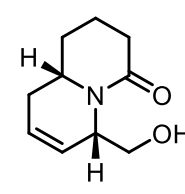

(6S,9aS)-181

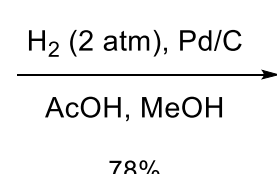

$78 \%$

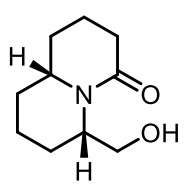

$(6 S, 9 a R)-190$

Scheme 57. Hydrogenation of the first double bond. Synthesis of $(6 S, 9 a R)-190$. 
It was easy to know that the hydrogenation worked well by ${ }^{1} \mathrm{H}$ NMR because the signals at 5.97 and $5.76 \mathrm{ppm}$ corresponding to the alkene protons of 181 disappeared in the ${ }^{1} \mathrm{H}$ NMR spectrum of 190, as it can be seen in Figure 51.

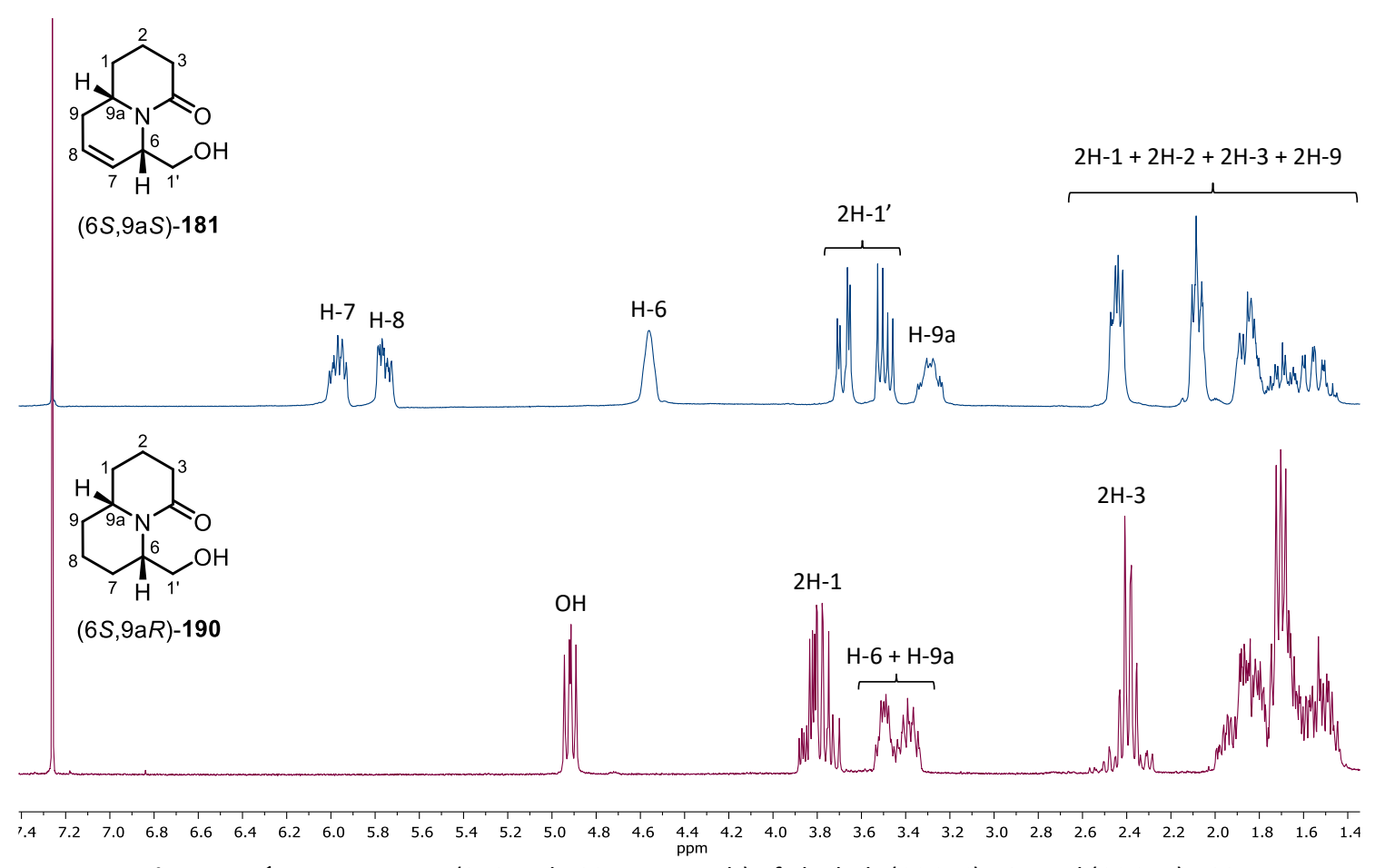

Figure 51. ${ }^{1} \mathrm{H}$ NMR spectra ( 250 and $400 \mathrm{MHz}, \mathrm{CDCl}_{3}$ ) of alcohols $(6 \mathrm{~S}, 9 \mathrm{aS})-181$ and $(6 \mathrm{~S}, 9 \mathrm{a} R)-\mathbf{1 9 0}$.

\subsubsection{Dess-Martin oxidation and alkenylation}

Alcohol (6S,9aR)-190 was treated with 1.2 equivalents of Dess-Martin periodinane in $\mathrm{CH}_{2} \mathrm{Cl}_{2}$ at room temperature (Scheme 58 ). After $3 \mathrm{~h}$, when no starting material was present in the reaction medium, the reaction was quenched by the treatment with an aqueous solution of $\mathrm{NaHCO}_{3}$ and $\mathrm{NaS}_{2} \mathrm{O}_{3}$ and the organics extracted with $\mathrm{CH}_{2} \mathrm{Cl}_{2}$. The crude residue, analyzed by ${ }^{1} \mathrm{H}$ NMR, showed the presence of the desired aldehyde $(4 S, 9 a R)-193$, which was not further purified to prevent its decomposition. However, an ${ }^{1} \mathrm{H}$ NMR spectrum was registered (Figure 52), where the signal of the aldehyde appears at $9.35 \mathrm{ppm}$. Also the signals corresponding to the $\alpha$-nitrogen protons $\mathrm{H}-4$ and $\mathrm{H}-9 \mathrm{a}$ can be distinguished at 3.52 and 3.21 ppm, respectively.

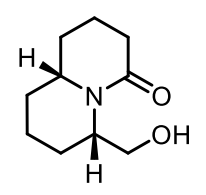

$(6 S, 9 a R)-190$

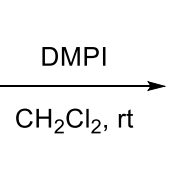

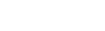

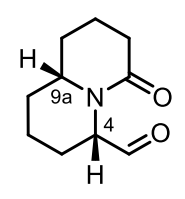

$(4 S, 9 a R)-193$

Scheme 58. Oxidation of alcohol $(6 S, 9 a R)-190$ 


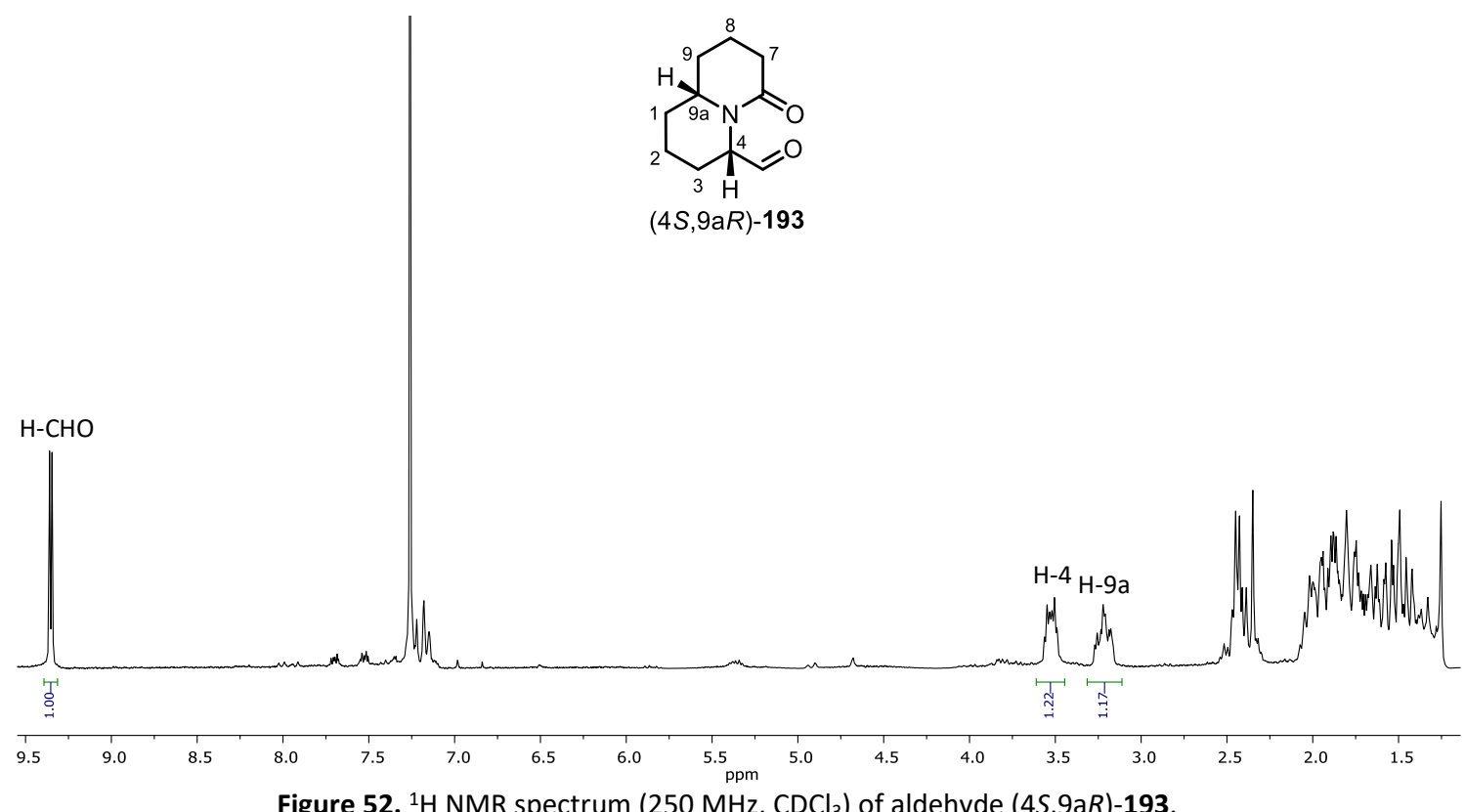

Figure 52. ${ }^{1} \mathrm{H}$ NMR spectrum $\left(250 \mathrm{MHz}, \mathrm{CDCl}_{3}\right)$ of aldehyde $(4 S, 9 \mathrm{a} R)-193$

Next, we proceeded with the study of the alkenylation of aldehyde $(4 S, 9 a R)-193$. Firstly, we focused on the Tebbe reaction, because it would yield a terminal alkene, 191, more accessible to form the carbene in the second RCM (Scheme 59).

Hence, aldehyde $(4 S, 9 a R)-\mathbf{1 9 3}$ was treated with 1 equivalent of Tebbe reagent in THF at 0 ${ }^{\circ} \mathrm{C}$, monitoring the reaction by TLC. After $50 \mathrm{~min}$, the starting material was totally consumed but no defined spots were present on the TLC. The reaction was quenched by treatment with $5 \%$ aqueous $\mathrm{NaOH}$ and the organic phase filtered through Celite ${ }^{\circledR}$, washing with $\mathrm{Et}_{2} \mathrm{O}$. The ${ }^{1} \mathrm{H}$ NMR of the crude residue showed only decomposition products.

In view of that, we decided to study the Wittig alkenylation with ethyltriphenylphosphonium bromide (Scheme 59), which worked well in the previous sequences. Hence, aldehyde (4S,9aR)-193 was treated with 1.2 equivalents of the phosphonium ylide (generated in situ) in THF, at room temperature during $14 \mathrm{~h}$. After that time, no starting material was observed by TLC. The crude residue, analyzed by ${ }^{1} \mathrm{H} N \mathrm{NR}$, showed the formation of a new product, probably the expected alkene $(6 S, 9 a R)-192$. After purification by column chromatography on silica gel, the alkene $(6 S, 9 a R)-192$ was isolated in only $28 \%$ yield from alcohol $(65,9 a R)-190$. 


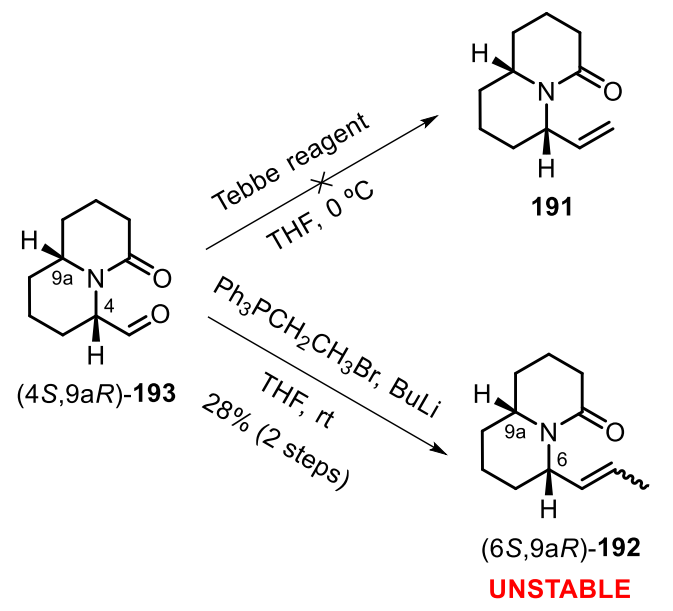

Scheme 59. Assayed alkenylation of aldehyde $(4 S, 9 a R)-193$.

Figure 53 shows the ${ }^{1} \mathrm{H}$ NMR spectrum of $(65,9 \mathrm{a} R)-192$, where the signals of the alkene protons of the new chain can be observed between 5.58 and $5.35 \mathrm{ppm}$, together with the signals corresponding to the $\alpha$-nitrogen protons $\mathrm{H}-6$ and $\mathrm{H}-9 \mathrm{a}$, which appear at 4.90 and $3.50 \mathrm{ppm}$, respectively. From this spectrum, we could stablish the configuration of the new double bond as $Z$ because $J_{1^{\prime} 2^{\prime}}=10 \mathrm{~Hz}$, which are the typical value of $Z$ coupling constant.

Considering that the conversion was total, the weight of the crude reaction product was reasonable and its ${ }^{1} \mathrm{H}$ NMR spectrum showed mainly the alkene $(6 S, 9 \mathrm{a} R)-192$, we concluded that this alkene was not stable enough to proceed with the synthetic sequence and this route was also abandoned.

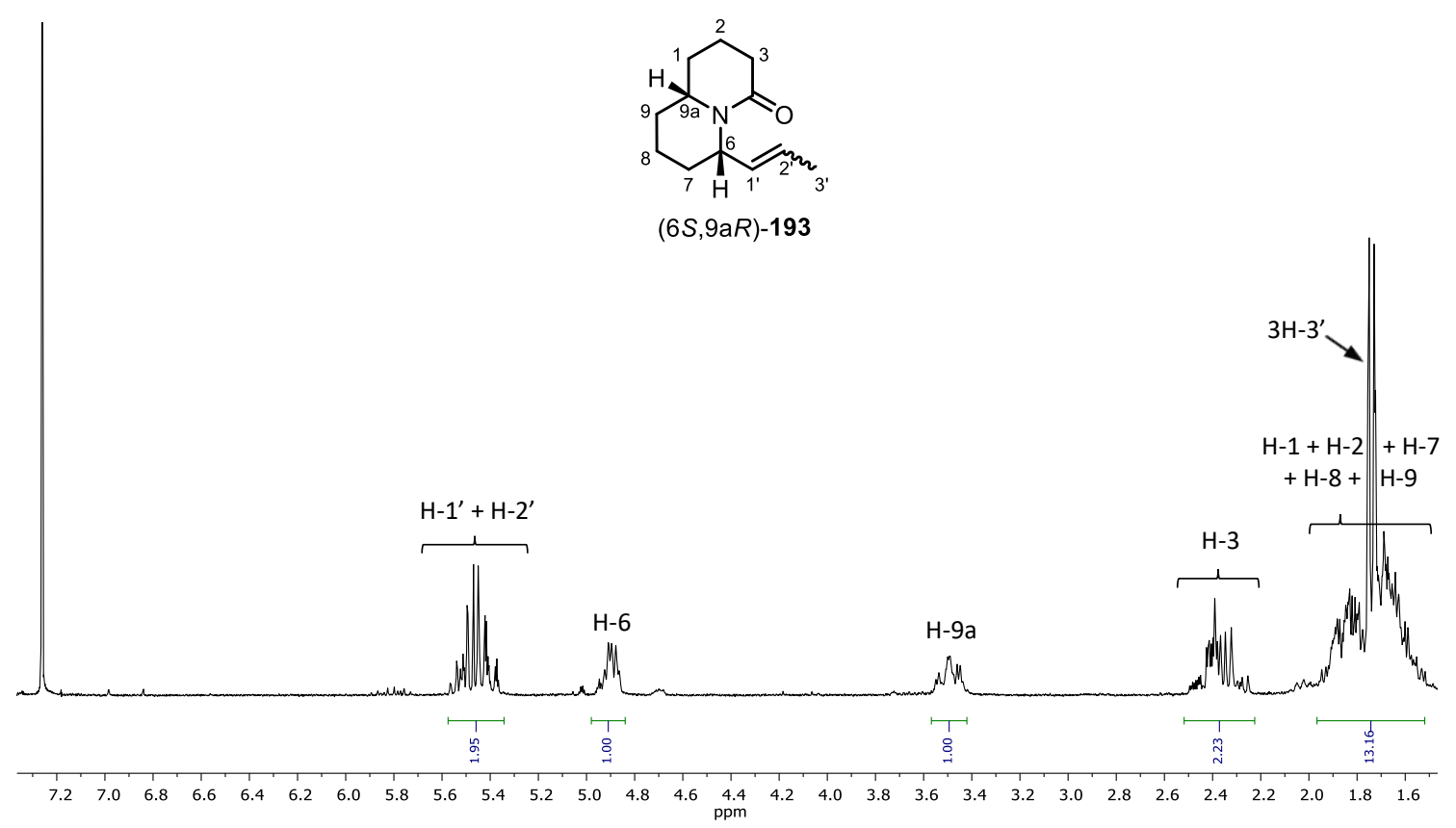

Figure 53. ${ }^{1} \mathrm{H}$ NMR spectrum $\left(250 \mathrm{MHz}, \mathrm{CDCl}_{3}\right)$ of alkene $(65,9 \mathrm{a} R)-192$. 


\subsection{Forth synthetic plan. The Relay Ring-Closing Metathesis approach. Preliminary studies}

Since the previous alternative synthetic ways gave unstable products, our objective was to change the strategy again. After exhaustive bibliographic research, we found a new alternative to ring-closing metathesis, namely relay ring-closing metathesis (RRCM). ${ }^{65}$

\subsubsection{Definition of Relay Ring-Closing Metathesis (RRCM)}

Relay ring-closing metathesis is a strategy first introduced in 2004 that is useful when classic ring-closing metathesis fail, because the substrate alkenes are either sterically hindered or electronically deactivated. ${ }^{65}$

As depicted in Scheme 60, compound $\mathrm{I}$ is a RCM unreactive diene due to steric hindrance. This fact implies that the formation of the reactive carbene II is not favored neither from $\mathbf{A}$ nor from B double bonds, what means that no RCM product III would be obtained. The RRCM strategy consist in carrying out the reaction from triene IV, which is analog to diene I, but providing an arm fitted with a non-hindered terminal olefin $\mathbf{C}$. This olefin is reactive enough to form carbene $\mathbf{V}$ by reacting with the catalyst. Carbene $\mathbf{V}$, easily generates carbene II as a product of the thermodynamically favored RCM involving olefin A (producing, in this example, cyclopentene). Finally, once carbene II is formed, the RCM to produce III is achieved straightforwardly.

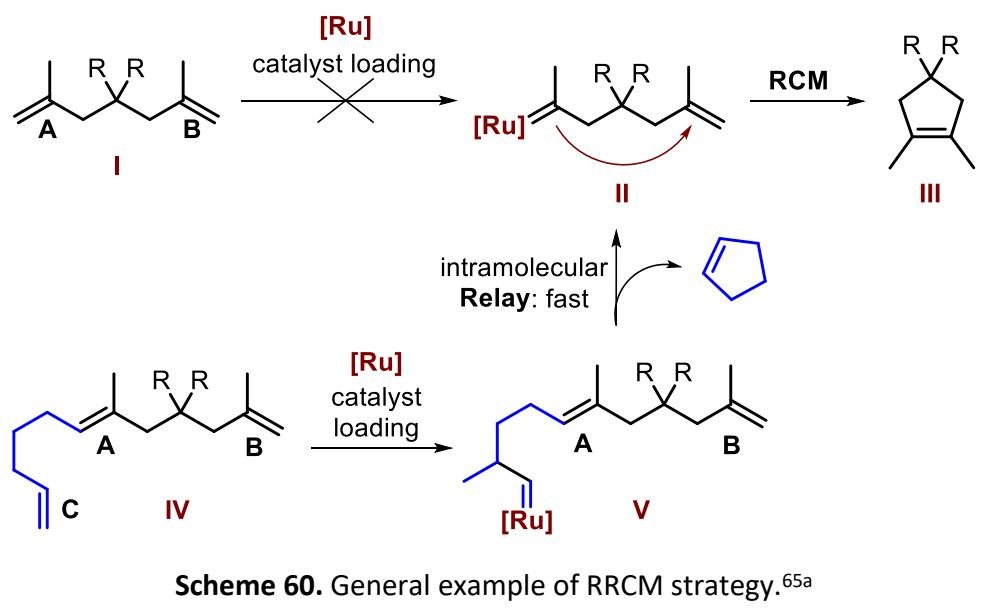

\footnotetext{
${ }^{65}$ a) Hoye, T. R.; Jeffrey, C. S.; Tennakoon, M. A. Wang, J.; Zhao, H. J. Am. Chem. Soc. 2004, 126, $10210-$ 10211. b) Wang, X.; Bowman, E. J.; Bowman, B. J.; Porco, J. A. Angew. Chem. Int. Ed. 2004, 43, $3601-$ 3605.
} 
This methodology could be useful in our synthetic approach because the second RCM over amine 183 did not work easily (Scheme 52, page 89). Then, our objective would be to introduce a relay-arm that may allow us to perform the relay ring-closing metathesis affording the desired tricyclic compound 166.

\subsubsection{Possible relay-arms and aldehydes to be tested}

According to the literature, different relay-arms providing a reactive terminal olefin could be useful to achieve de RRCM. Having in mind different described RRCM examples in the literature, ${ }^{65,66}$ among these possibilities we chose three (marked in blue) in the corresponding compounds shown in Figure 54.
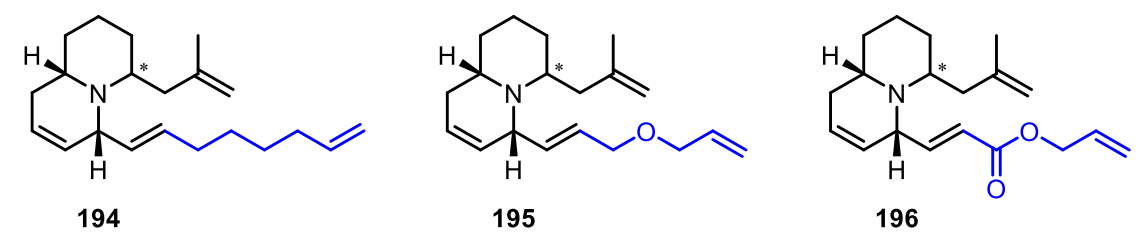

Figure 54. Possible precursors of the RRCM.

Scheme 61 shows the planed assays to evaluate the RRCM strategy from the three different candidates 194, 195 and 196 . The unavoidable thermodynamically favored by-products are also represented in each case. One feasible manner to introduce the relay arm seemed to be an alkenylation reaction of an aldehyde. For this reason, aldehyde 197 was proposed as the common precursor for the RRCM substrates. In this way, the methyl allyl fragment (red color) would be provided before introduction of the relay arm because this functionalization implies a reduction step.

\footnotetext{
66 a) Druais, V.; Hall, M. J.; Corsi, C.; Wendeborn, S. V.; Meyer, C.; Cossy, J. Tetrahedron, 2010, 66, 63586375. b) Fujioka, K.; Yokoe, H.; Yoshida, M.; Shishido, K. Org. Lett. 2012, 14, 244-247.
} 


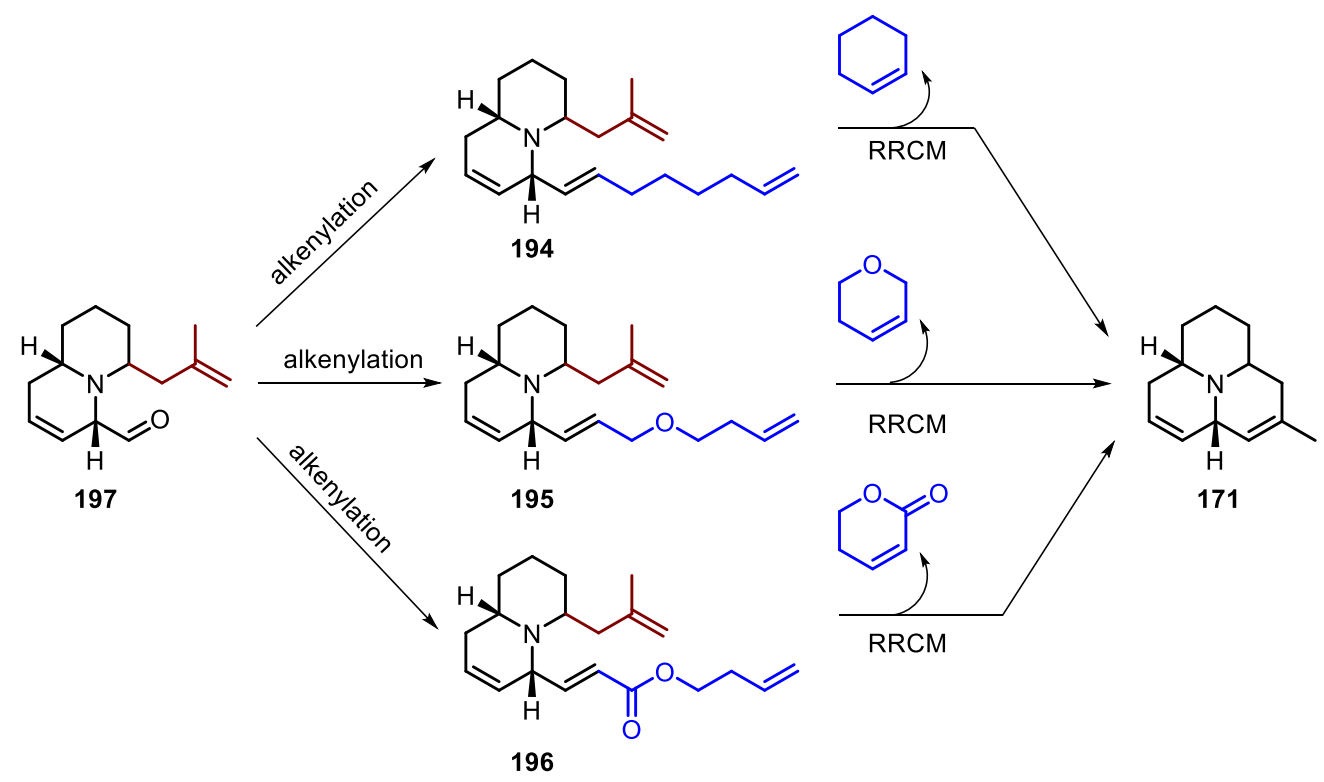

Scheme 61. Proposed candidates to assess the RRCM strategy in our synthesis.

\subsubsection{Synthesis of aldehyde 197}

Based on some precedents ${ }^{67}$ as well as the previous work in our group ${ }^{59}$ we planned the synthesis of aldehyde 197 starting from alcohol 181 (Scheme 62). Thus, aminal 198 would be obtained after a reduction of lactam 181 . Then, 198 would be submitted to a second nucleophilic allylation to afford alcohol 199, which would produce the aldehyde 197 after an oxidation step.<smiles>O=C1CCC[C@H]2CC=C[C@H](CO)N12</smiles>

$(6 S, 9 a S)-181$

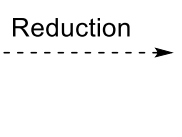

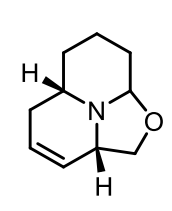

198

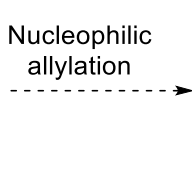

199<smiles>C=C(C)CC1CCCC2CC=CC(O)N21</smiles><smiles>C=C(C)CC1CCCC2(CC=C[C@H]1C=O)CCO2</smiles>

197

Scheme 62. Synthetic plan to obtain the aldehyde 197.

\subsubsection{Reduction of lactam 181 and allylation}

The reduction of the lactam (6S,9aS)-181 was performed using 3 molar equivalents of the reducing agent Red-Al in THF at $-55^{\circ} \mathrm{C}$ and the reaction was followed by TLC (Scheme 63). After $14 \mathrm{~h}$, no spot corresponding to the starting material was observed. Then, the reaction was quenched by treatment with a $5 \%$ of aqueous solution of $\mathrm{NaOH}$. Extractions with $\mathrm{CH}_{2} \mathrm{Cl}_{2}$ allowed to isolate tricyclic aminal (2aS,5aS)-198, which was used in the next step without purification due to its possible instability. Nevertheless, an ${ }^{1} \mathrm{H}$ NMR spectrum of this compound was

\footnotetext{
${ }^{67}$ Amat, M.; Llor, N.; Hidalgo, J.; Escolano, C.; Bosch, J. J. Org. Chem. 2003, 68, 1919-1928.
} 
registered (Figure 55), where it can be distinguished the signal of alkene protons $\mathrm{H}-3$ and $\mathrm{H}-4$ at $5.75 \mathrm{ppm}$, the signals corresponding to the $\alpha$-nitrogen protons $\mathrm{H}-8 \mathrm{a}, \mathrm{H}-2 \mathrm{a}$ and $\mathrm{H}-5 \mathrm{a}$ at 3.97, 3.00 and 2.58 ppm, respectively, and also the signals of protons $\mathrm{H}-2$ between 3.69 and $3.32 \mathrm{ppm}$.

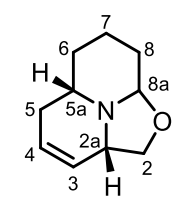

198

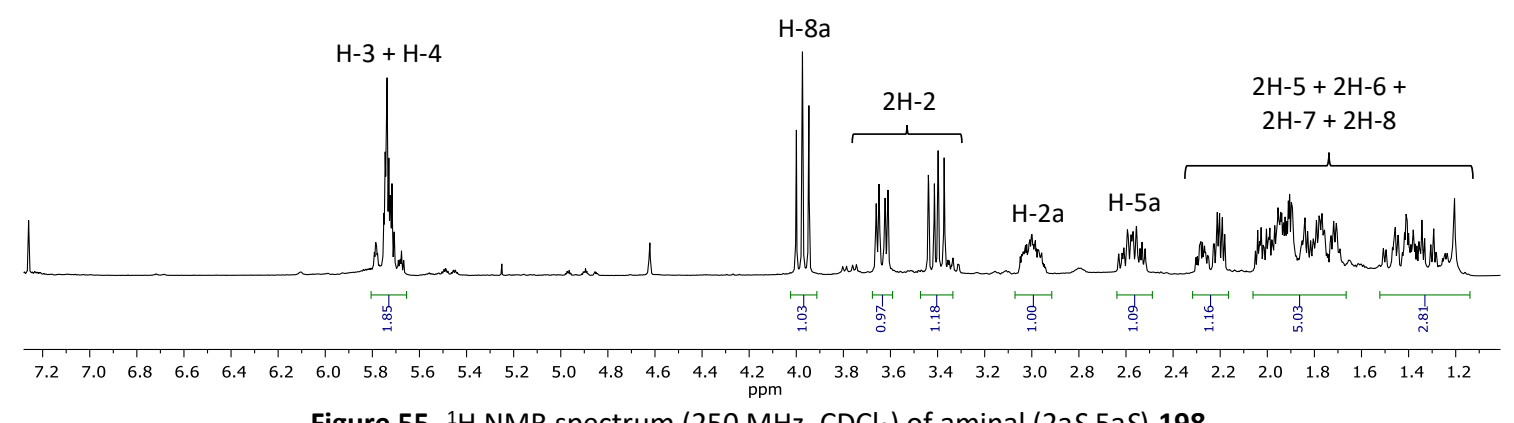

Figure 55. ${ }^{1} \mathrm{H}$ NMR spectrum $\left(250 \mathrm{MHz}, \mathrm{CDCl}_{3}\right)$ of aminal (2aS,5aS)-198.

Then, the isolated aminal 198 was dissolved in THF and the corresponding Grignard reagent, which was synthesized in situ, was added at $0{ }^{\circ} \mathrm{C}$. In this way, after $4 \mathrm{~h}$, alcohol $(6 S, 9 a S)$ 199 was obtained in $60 \%$ yield from alcohol $(6 S, 9 a S)-181$ with a diastereomeric ratio of 1:5, inferred from the relative area of the signals between 6.02 and $5.78 \mathrm{ppm}$ in its ${ }^{1} \mathrm{H}$ NMR spectrum (Figure 56) corresponding to proton $\mathrm{H}-8$ of both isomers.

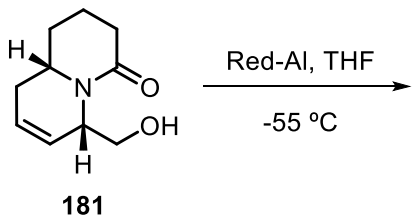

81<smiles>C1=CC2CCCC3OCCCC3N2C1</smiles>

198

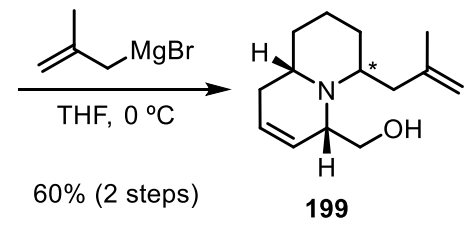

(1:5)

Scheme 63. Second nucleophilic allylation. Synthesis of alcohol (6S,9aS)-199. 


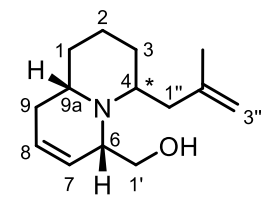

199

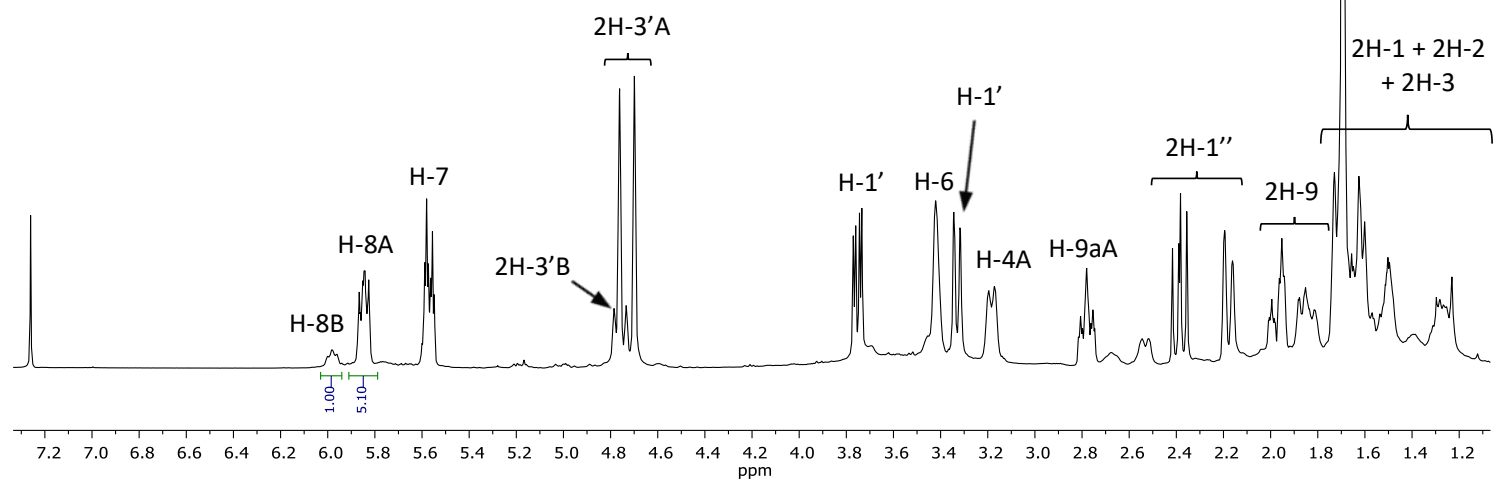

Figure 56. ${ }^{1} \mathrm{H}$ NMR spectrum $\left(400 \mathrm{MHz}, \mathrm{CDCl}_{3}\right)$ of the alcohol $(6 \mathrm{~S}, 9 \mathrm{aS})$-199. Mixture of diastereomers: $\mathrm{A}=$ major; $\mathrm{B}=$ minor.

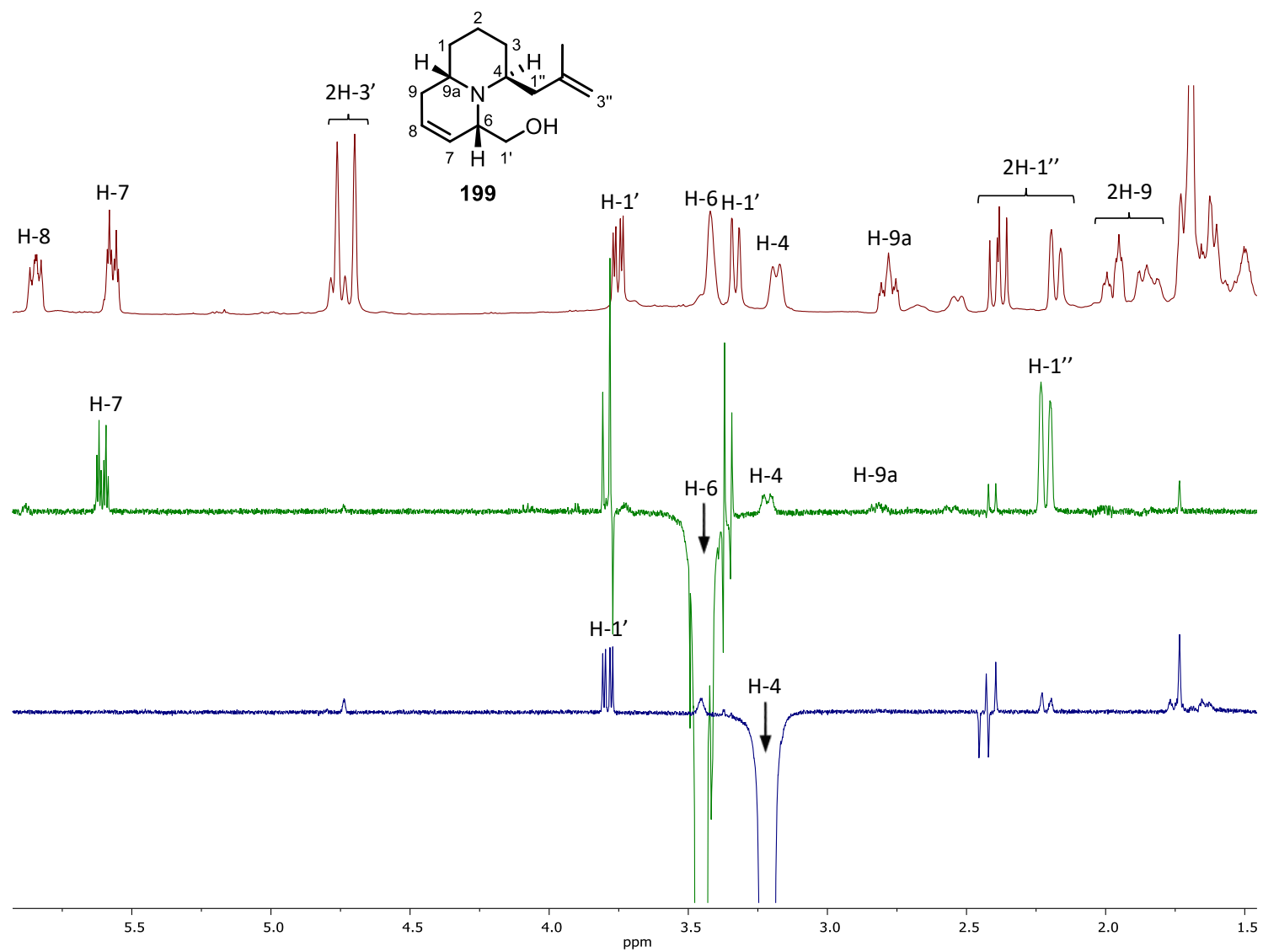

Figure 57. Selective nOe spectra (400 MHz, $\left.\mathrm{CDCl}_{3}\right)$ of alcohol (6S,9aS)-199 at 3.48 and $3.22 \mathrm{ppm}$. 
Although both diastereomers could not be separated, a series of selective nOe spectra were registered with the mixture (Figure 57), in order to determine the configuration of the new stereogenic center in the major isomer. The irradiation was done over the $\alpha$-nitrogen protons $\mathrm{H}-6$ and $\mathrm{H}-4$.

When irradiating $\mathrm{H}-6$, it is noticeable the strong nOe effect with one $\mathrm{H}-\mathrm{1}^{\prime \prime}$, so this indicates that $\mathrm{H}-6$ is in the same side of the bicyclic system than the methylallyl chain. This was also confirmed when $\mathrm{H}-4$ was irradiated as signals corresponding to $\alpha-\mathrm{OH}, \mathrm{H}-1^{\prime}$, were affected. With these results, we could establish the configuration of the new stereogenic center generated as $S$, for the major isomer present in the diastereomeric mixture (Figure 58).

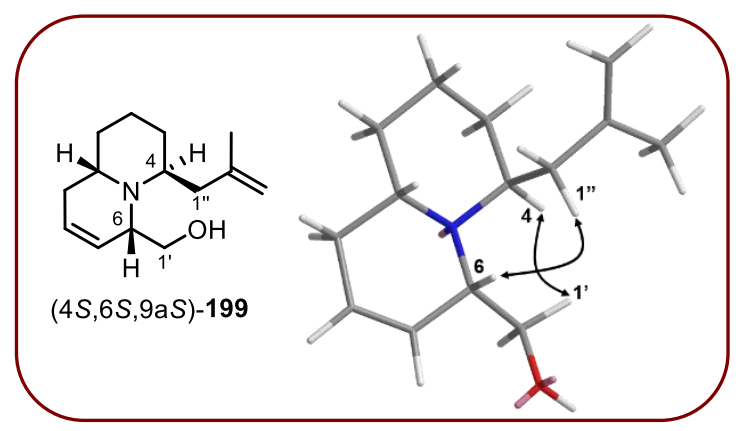

Figure 58. Representation of (4S,6S,9aS)-199.

\subsubsection{Oxidation}

To study the oxidation of the alcohol $(4 S, 65,9 a S)-199$ (Scheme 64) we tested several oxidizing agents (Table 6).

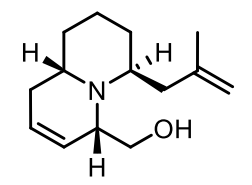

(4S,6S,9aS)-199

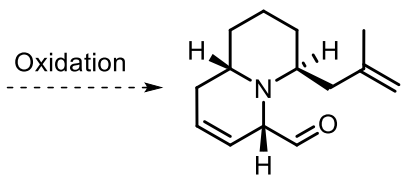

(4S,6S,9aS)-197

Scheme 64. Oxidation of $(4 S, 65,9 a S)-199$.

First, we assayed Dess-Martin periodinane that furnished very good results in the previous related oxidations (entry 1). Unexpectedly, after $4 \mathrm{~h}$ at room temperature, only starting material was recovered. Then, we increased the temperature by refluxing in $\mathrm{CH}_{2} \mathrm{Cl}_{2}$ and the reaction time up to 16 hours (entry 2), but still the alcohol (4S,6S,9aS)-199 did not react with DMPI. The reason of this lack of reactivity could be attributed to the steric hindrance caused by the methylallyl chain. 
Table 6. Attempts and results for the oxidation of $(4 S, 6 S, 9 a S)-199$.

\begin{tabular}{|c|c|c|c|c|}
\hline Entry & Oxidizing agent & Temperature & Time & Results \\
\hline 1 & Dess-Martin Periodinane & $\mathrm{rt}$ & $4 \mathrm{~h}$ & sm \\
\hline 2 & Dess-Martin Periodinane & $40^{\circ} \mathrm{C}$ & $16 \mathrm{~h}$ & sm \\
\hline 3 & $\begin{array}{c}\text { NCS, DMS } \\
\text { (Corey-Kim oxidation) }\end{array}$ & $-40^{\circ} \mathrm{C}$ & $2 \mathrm{~h}$ & $\mathrm{sm}$ \\
\hline 4 & $\begin{array}{c}\text { NCS, DMS } \\
\text { (Corey-Kim oxidation) }\end{array}$ & $\mathrm{rt}$ & $16 \mathrm{~h}$ & sm \\
\hline 5 & PCC & $0^{\circ} \mathrm{C}$ & $20 \mathrm{~h}$ & sm \\
\hline 6 & PCC & $\mathrm{rt}$ & $24 \mathrm{~h}$ & $\mathrm{sm}$ \\
\hline 7 & PCC (more equivalents) & $\mathrm{rt}$ & $16 \mathrm{~h}$ & decomposed \\
\hline 8 & $\begin{array}{c}(\mathrm{COCl})_{2}, \text { DMSO } \\
\text { (Swern oxidation) }\end{array}$ & $-78^{\circ} \mathrm{C}$ to $0{ }^{\circ} \mathrm{C}$ & $1 \mathrm{~h}$ & $\begin{array}{c}197+ \\
\text { decomposed }\end{array}$ \\
\hline 9 & $\begin{array}{c}(\mathrm{COCl})_{2}, \mathrm{DMSO} \\
\text { (Swern oxidation) }\end{array}$ & $-78{ }^{\circ} \mathrm{C}$ to $0{ }^{\circ} \mathrm{C}$ & $30 \mathrm{~min}$ & $\begin{array}{c}197+ \\
\text { decomposed }\end{array}$ \\
\hline
\end{tabular}

Then, we decided to intend the Corey-Kim oxidation, ${ }^{68}$ which uses $\mathrm{N}$-chlorosuccinimide and dimethylsulfoxide to generate the dimethylchlorosulphonium ion, which is the active oxidizing agent. The first experiment performed using these reagents at $-40{ }^{\circ} \mathrm{C}$, for $2 \mathrm{~h}$ (entry $3)^{69}$ gave only starting material. Then, we decided to try the reaction at room temperature (entry 4). This reaction was difficult to follow by TLC and after $16 \mathrm{~h}$, we decided to stop it. The ${ }^{1} \mathrm{H}$ NMR of the crude residue showed again only the presence of starting material.

In view of these results, we changed to another oxidizing agent, in this case, PCC. The first trial was using 1.5 molar equivalents of it, at $0{ }^{\circ} \mathrm{C}$ (entry 5$) .{ }^{70}$ The reaction was followed by TLC and, after $20 \mathrm{~h}$, no changes could be detected. In any case, the reaction mixture was filtered over silica gel and the crude residue was analyzed by ${ }^{1} \mathrm{H} N M R$, showing the presence of only the starting material. This oxidant was also assayed at room temperature for $24 \mathrm{~h}$ with the same

\footnotetext{
${ }^{68}$ Corey, E. J.; Kim, C. U. J. Am. Chem. Soc. 1972, 94, 7586-7587.

69 Maheng, J-H.; Funk, R. L. Org. Lett. 2002, 4, 331-333.

${ }^{70}$ Rosillo, M.; Arnáiz, E.; Abdi, D.; Blanco-Urgoiti, J.; Domínguez, G.; Pérez-Castells, J. Eur. J. Org. Chem. 2008, 3917-3927.
} 
result (entry 6) and using up to 3 molar equivalents of PCC at room temperature (entry 7). In this last case, after $16 \mathrm{~h}$, only decomposition products were obtained.

Finally, we assayed the Swern oxidation, ${ }^{71}$ where oxalyl chloride and dimethylsulfoxide are used to generate chloro(dimethyl)sulphonium chloride, which acts as the active oxidizing agent. Following the example of Trauner and collaborators, ${ }^{61}$ the oxidizing ion was generated mixing 8 equivalents of DMSO and 7 equivalents of oxalyl chloride in $\mathrm{CH}_{2} \mathrm{Cl}_{2}$ at $-78{ }^{\circ} \mathrm{C}$ (entry 8). After $15 \mathrm{~min}$, this mixture was added to a solution of the alcohol 199 in $\mathrm{CH}_{2} \mathrm{Cl}_{2}$ and stirred at -78 ${ }^{\circ} \mathrm{C}$. After $1 \mathrm{~h}$, no starting material was detected by TLC and the reaction was quenched by adding 14 molar equivalents of $\mathrm{Et}_{3} \mathrm{~N}$ and the temperature was slowly changed to $0{ }^{\circ} \mathrm{C}$. After extractions with $\mathrm{NaCl}$ saturated aqueous solution and $\mathrm{CH}_{2} \mathrm{Cl}_{2}$, a crude residue was obtained that was analyzed by ${ }^{1} \mathrm{H}$ NMR. Apparently, some signals corresponding to an aldehyde were observed, but it is not clear because of the presence of a huge quantity of decomposition products.

Therefore, we decided to decrease the time of the reaction to $30 \mathrm{~min}$ (entry 9) following the same procedure. In this case, the ${ }^{1} \mathrm{H}$ NMR spectrum of the crude residue was slightly cleaner and a signal of aldehyde as well as the signal of the alkene protons could be distinguished and maybe even some signals of the $\alpha$-nitrogen protons (Figure 59). Nevertheless, from 2.50 to 0.75 ppm no characteristic signals could be assigned.

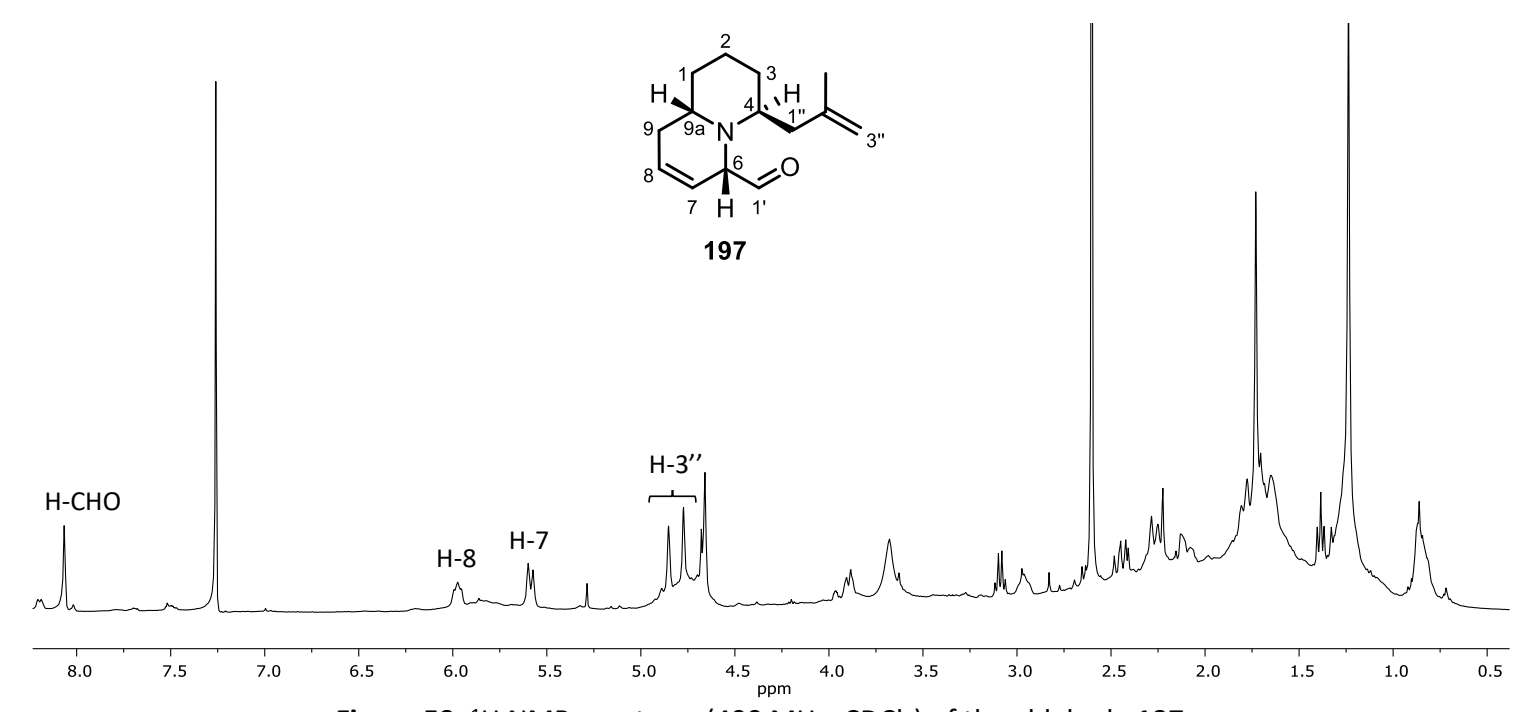

Figure 59. ${ }^{1} \mathrm{H}$ NMR spectrum $\left(400 \mathrm{MHz}, \mathrm{CDCl}_{3}\right)$ of the aldehyde 197.

71 a) Omura, K.; Swern, D. Tetrahedron, 1978, 34, 1651-1660. b) Mancuso, A. J.; Brownfain, D. S.; Swern, D. J. Org. Chem. 1979, 44, 4148-4150. 
Due to the lack of time, the reaction conditions of entry 9 could not be further improved and attemps to purify aldehyde 197 were not made. In any case, we concluded that the reaction in Scheme 65 should be the starting point for future studies related to the RRCM approach.

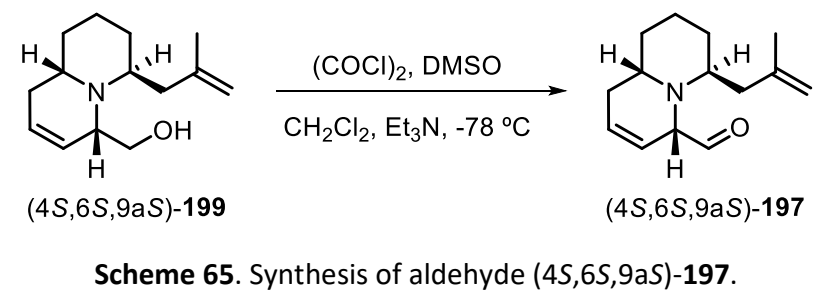

\section{Conclusions}

By introducing the methyl group in the second nucleophilic allylation, the configuration of the third stereogenic center generated was the desired one, which would lead us to chiral alkaloids. Unfortunately, the second ring-closing metathesis gave us many problems and the desired azatricycle 166 could not be obtained.

To overcome this problem, three alternative routes were tried but none of them was successful.

To assay the RRCM approach, we should work on the oxidation of alcohol 199 to obtain aldehyde 197 , because the reaction was not totally optimized. 